\title{
NUTRITIONAL IMPACT ON MOLECULAR AND PHYSIOLOGICAL ADAPTATIONS TO EXERCISE
}

nutrition matters

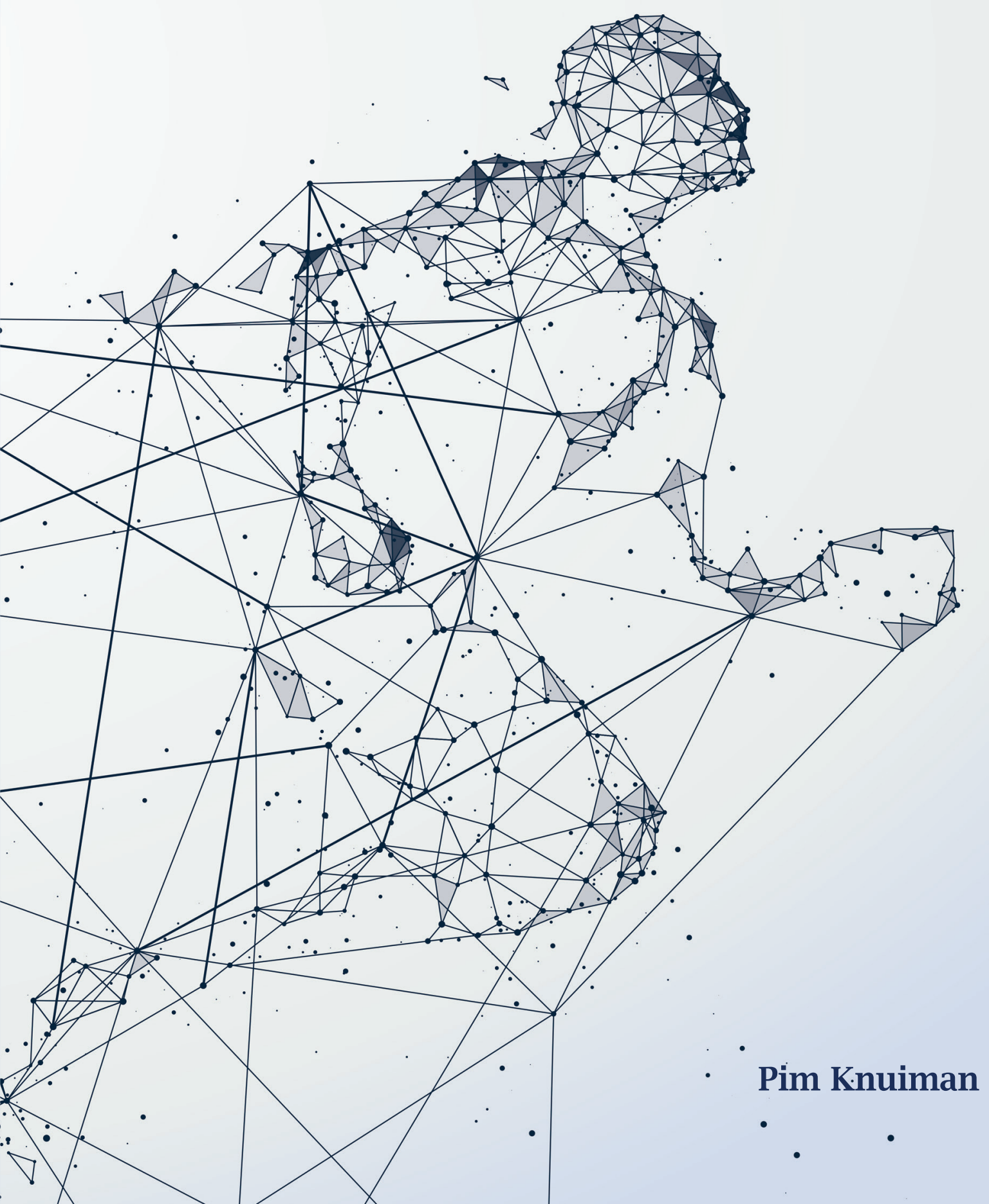





\section{PROPOSITIONS}

1. Carbohydrate availability is immaterial in the acute adaptive response to resistance.

(this thesis)

2. Protein supplementation enhances molecular and physiological adaptation to endurance training.

(this thesis)

3. Variability of endurance trainability weakens science-based endurance training recommendations.

4. The extrapolation of experimental findings from studies on acute effects of exercise to potential mechanisms of chronic adaptation requires caution.

5. Chronic testosterone administration should be advised by general practitioners for hypogonadal older male adults.

6. Scientific reviewers providing comments like "this finding is not interesting or surprising" should read crime novels instead of scientific papers.

7. Perseverance and risk taking are key to achieving success in science.

Propositions belonging to the thesis, entitled:

Nutritional Impact on Molecular and Physiological Adaptations to Exercise

Pim Knuiman

Wageningen, $11^{\text {th }}$ October 2019 



\section{NUTRITIONAL IMPACT ON MOLECULAR AND PHYSIOLOGICAL ADAPTATIONS TO EXERCISE}

nutrition matters

Pim Knuiman 


\section{Thesis committee}

\section{Promotors}

Prof. Dr R.F. Witkamp

Professor of Nutritional Biology

Division of Human Nutrition and Health

Wageningen University \& Research

Prof. Dr M.T.E. Hopman

Professor of Integrative Physiology

Radboud University Medical Centre, Nijmegen

\section{Co-promotors}

Dr M.R. Mensink

Assistant professor, Division of Human Nutrition and Health

Wageningen University \& Research

Dr J.A. Wouters

Program Expert Nutrition Innovation, Sportcenter Papendal, Arnhem

\section{Other members}

Prof. Dr S. Kersten, Wageningen University

Prof. Dr M. Hesselink, Maastricht University

Dr J. Gonzalez, University of Bath, UK

Dr S. Timmers, Wageningen University

This research was conducted under the auspices of the Graduate School VLAG (Advanced Studies in Food Technology, Agrobiotechnology, Nutrition and Health Sciences). 


\title{
NUTRITIONAL IMPACT ON MOLECULAR AND PHYSIOLOGICAL ADAPTATIONS TO EXERCISE
}

\author{
nutrition matters
}

\section{Pim Knuiman}

\section{Thesis}

submitted in fulfilment of the requirements for the degree of doctor at Wageningen University

by the authority of Rector Magnificus,

Prof. dr. A.P.J. Mol,

in the presence of the

Thesis Committee appointed by the Academic Board

to be defended in public

on Friday 11 October 2019

at 1.30 p.m. in the Aula. 


\section{Pim Knuiman}

Nutritional Impact on Molecular and Physiological Adaptations to Exercise nutrition matters

PhD thesis, Wageningen University, Wageningen, the Netherlands (2019) With references, with summary in English

ISBN: 978-94-6395-006-0

DOI: $10.18174 / 479016$ 


\section{Table of contents}

Chapter 1 General introduction

Chapter 2 Glycogen availability and skeletal muscle adaptations with endurance and resistance exercise

Chapter 3 Select skeletal muscle mRNAs related to exercise adaptation are minimally affected by different pre-exercise meals that differ in macronutrient profile

Chapter 4 Plasma cytokine response to resistance exercise with different nutrient availability on a concurrent exercise day in trained healthy males

Chapter 5 Protein and the adaptive response with endurance training: wishful thinking or a competitive edge?

Chapter 6 Protein supplementation elicits greater gains in maximal oxygen uptake capacity and stimulates lean mass accretion during prolonged endurance training: a double-blind randomised controlled trial

Chapter 7 Regulation of skeletal muscle transcriptome is increased by protein supplementation and reflects the extent of physiological adaptation to endurance training

Chapter 8 General discussion

Chapter 9 Summary

Acknowledgements

List of publications

About the author

Training activities 


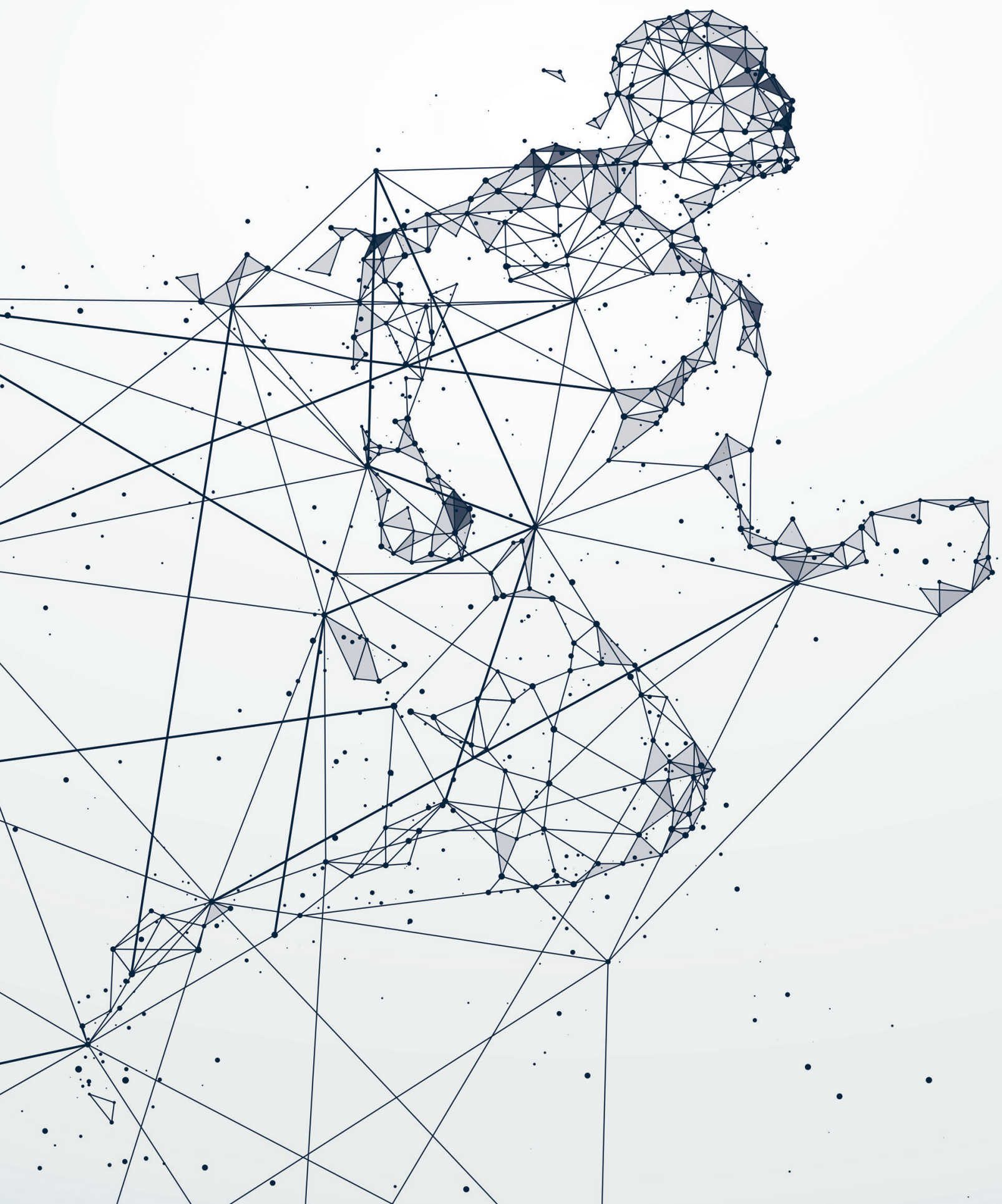


Chapter 1

General introduction 


\section{Exercise training and skeletal muscle adaptation}

Multiple exercise bouts within a certain period of time are generally referred to as exercise training. Exercise training can be simply divided into enduranceand resistance exercise. At the musculoskeletal level, endurance exercise training increases mitochondrial and capillary density together contributing to enhanced oxidative capacity (1). In contrast, general adaptations observed with resistance exercise training and anaerobic type of exercise such as high intensity power training are an increase in muscle fibre size, strength and power (2). In humans, approximately $40-50 \%$ of body mass consist of skeletal muscle tissue (3). Skeletal muscle is therefore the largest tissue in humans and likely the tissue that is most affected by contractile-activity stimuli such as exercise (4). The plasticity of skeletal muscle tissue in response to exercise training and altered nutrient availability is remarkable and demonstrated by its phenotypic adaptation over time $(5,6)$. Phenotypic adaptation can be defined as the changes in the body as a result of environmental changes such as exercise training. From a mechanistic perspective, the exercise-induced change in metabolic and mechanical factors, the so-called "acute exercise response" that disturb cellular homeostasis is likely explanatory for the phenotypic alteration. Cellular homeostatic disturbances begin with the onset of exercise and persist until the end of the post-exercise recovery phase (5). Furthermore, it is the current thought among molecular exercise physiologists that repeated exercise bouts causes a variety of biological events thereby affecting gene expression profiles and subsequently specific proteins required for phenotypic adaptation. This thought is substantiated by previous work demonstrating that structural and metabolic adaptations during exercise training is the outcome of the sum of the biological effects of each exercise bout (7-9).

\section{Skeletal muscle adaptation and nutrition}

The acute molecular responses during and after cessation of an exercise bout, such as changes in gene expression and protein levels and enzyme activity appears to be a fundamental process in the phenotypic adaptation to exercise training (1). At the molecular level, exercise affects gene expression profiles, augments signalling pathways thereby enhancing mRNA translation and the synthesis of particular proteins. The timespan of adaptive response ranges from acute (e.g. immediately during/after exercise) to more prolonged (e.g. weeks/months) (8), and can be influenced by nutrition (e.g. carbohydrates or proteins) (Figure 1). 

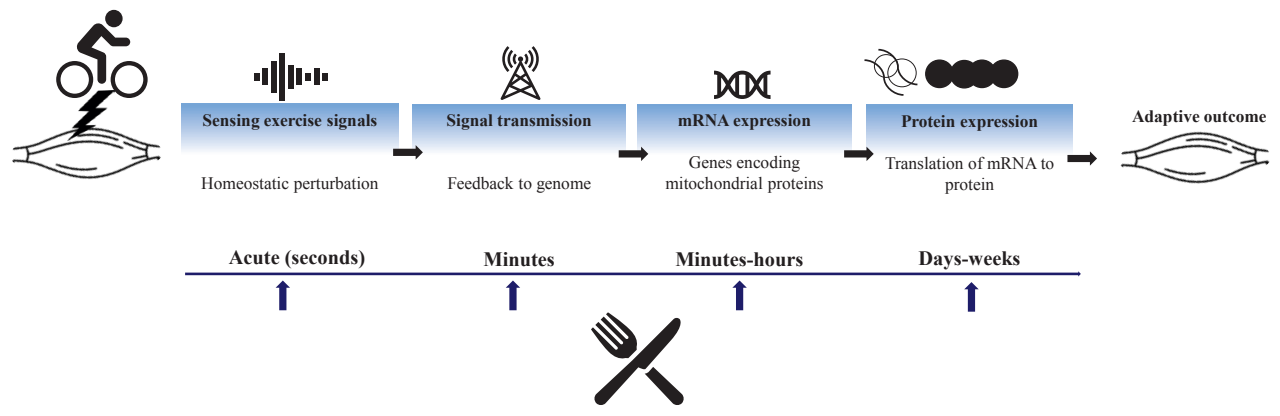

Figure 1. General model based on the signal transduction hypothesis for adaptation to endurance exercise training $(1,5,10)$, highlighting the importance nutrition. Homeostatic perturbation: $\mathrm{Ca} 2+, \mathrm{pO}_{2}$, AMP, glycogen; Signal transmission: $\uparrow \mathrm{AMPf} \rightarrow \mathrm{AMPK}, \mathrm{Ca}^{2+} \rightarrow \mathrm{CaMK}$, $\mathrm{Ca}^{2+} \rightarrow$ p38/MAPK; mRNA expression: transcription factors and coactivators, genes encoding specific protein; Protein expression: translation of mRNA to protein, import and assembly and expansion of reticulum (enhanced capacity); Skeletal muscle adaptation: increase in mitochondrial density/function.

\section{Carbohydrates and fat}

It is widely accepted that nutrition plays a central role in mediating skeletal muscle adaptations with exercise training $(11,12)$. Carbohydrates and fat are recognized as the main substrates for facilitating energy requirements during endurance exercise (13). Carbohydrates are stored as glycogen in muscle and liver cells. The relative use of energy sources during exercise is mainly determined by the intensity and the duration of the exercise bout, as well as the athlete's training status (13). Fat as source of energy is relatively most dominant during low- to moderate intensity exercise (30-65\% of $\mathrm{VO}_{2 \max }$ ), whereas the relative contribution of carbohydrate oxidation to total energy expenditure becomes greater when exercise intensity increases, with muscle glycogen becoming the most important substrate source (14). Although the amount of liver and skeletal muscle glycogen is relatively small compared to stored fat, glycogen is recognized as the major source for fuel during prolonged moderate- to high intensity endurance exercise (15).

\section{Protein}

Skeletal muscle mass is maintained by the balance between muscle protein synthesis and muscle protein breakdown rates such that overall net muscle protein balance remains essentially unchanged over the course of the day. A prolonged imbalance between muscle protein synthesis and muscle protein breakdown results in a positive (hypertrophy: muscle protein synthesis > muscle protein breakdown) or negative net protein balance (atrophy: muscle protein synthesis $<$ muscle protein breakdown). The two main potent stimuli 
for muscle protein synthesis are food ingestion and exercise (16). Food ingestion (e.g. dietary protein) causes a transient stimulation of muscle protein synthesis, but cannot account for muscle protein accretion alone. Likewise, endurance and/or resistance exercise improves net protein balance, however, the ingestion of protein during the post-exercise recovery period is required to induce a positive net protein balance (17). Thus, both exercise and protein ingestion must be deployed in combination in order to create a positive net protein balance (16).

\section{Empirical shortcomings: carbohydrate availability and adaptation to resistance exercise}

It is well known that carbohydrate intake, and hence glucose availability, after exercise is of great importance for replenishing liver and muscle stores and subsequent exercise performance (18). Similarly, the ability of protein or amino acid intake to stimulate muscle protein synthesis, and to reduce, to a lesser extent, protein breakdown promotes net muscle growth $(19,20)$. The molecular events activated by exercise show some similarity with the molecular events that can be activated by altered nutrient availability. For instance, the phosphatidylinositol 3-kinase/Akt/mechanistic target of rapamycin signalling pathway (PI3k-Akt-mTOR) and 5'adenosine monophosphate-activated protein kinase (AMPK) are targets for both exercise and nutrient availability $(5,21)$. Yet, most studies in the field of exercise training and nutrient availability have largely focused on either carbohydrates with endurance exercise training or proteins with resistance exercise training. This scientific paradigm has resulted in empirical shortcomings in the field of nutrient availability and exercise training. Indeed, literature on the role of carbohydrates with resistance exercise training and protein with endurance exercise training is scarce (22-26).

\section{Carbohydrate availability and resistance exercise}

During the past decades, the role of carbohydrate availability with endurance training and performance has been intensively studied. Scientific consensus has been achieved on the facilitating role of carbohydrates as a key substrate during endurance exercise as well as a mediator for numerous molecular responses to a single bout of endurance exercise $(12,23)$. In addition, it is generally well accepted that high habitual carbohydrate intake is beneficial for endurance training performance, in particular that of prolonged and highintensity $(27,28)$. In contrast, the role of carbohydrate availability with resistance exercise on cellular responses, phenotypic adaptation and performance has yet to be fully characterised. Theoretically, based on molecular events underpinning resistance exercise adaptation, it could be argued that carbohydrate intake may not be of great importance to maximise adaptation, as well as the importance of reduced muscle glycogen levels. 
Indeed, current evidence indicates that the key kinase PI3k-Akt-mTOR signalling pathway is unaffected by limited carbohydrate availability or low skeletal muscle glycogen concentrations. A reasonable approach to tackle this empirical shortcoming is a shift in the scientific focus; more research focusing on carbohydrate availability with resistance exercise training.

\section{Protein intake and endurance training}

It is a widely held view that general recommendations for protein intake in individuals commencing endurance exercise training is sufficient to maximise adaptation to endurance training $(29,30)$. However, there is some evidence to suggest that additional dietary protein has the potential to further enhance endurance exercise training adaptations such as whole-body aerobic capacity in humans $(31,32)$, changes in body composition (32), muscle fibre type I hypertrophy $(33,34)$, upregulated expression profiles associated with skeletal muscle growth, oxidative muscle fibre remodelling, immunity and defence, energy metabolism (35) and, performance (36-38). Limited scientific insight on this topic might be the result of reasoning that carbohydrates and fat are the most important nutrients to facilitate energy requirements during endurance exercise (13). Furthermore, it is generally thought that endurance athletes already consume sufficient protein and that adding dietary protein therefore will not further enhance endurance training adaptations. The latter may have prevented scientists to fully scrutinise the topic. Future evidence must be derived from long-term endurance training studies that combine performance outcomes and biochemical/physiological endpoints.

\section{Outline of this thesis}

Studying exercise-nutrient interactions on skeletal muscle level is complex. A better understanding of the physiological and molecular responses can provide new insights into potential nutritional strategies to maximise skeletal muscle adaptation and ultimately performance. The aim of the research presented in this thesis is to study the role of nutrient availability with divergent types of exercise on molecular responses and physiological adaptations. Specifically, carbohydrate availability with resistance exercise and protein intake with endurance exercise. This thesis will shine new light on the empirical shortcomings pointed out in the introduction by conducting I) an acute exercise study on carbohydrate availability and the adaptive response with resistance exercise; II) a chronic training study on the effect of protein intake and endurance training adaptations.

In chapter 2 an overview of the role of skeletal muscle glycogen with endurance and resistance exercise is given. In chapter 3, skeletal muscle glycogen levels and acute selective mRNA responses are used to study the effects of carbohydrate availability on the physiological and molecular 
responses in the post-resistance exercise period. With this study, we aimed to explore the effects of differences in carbohydrates and fat availability on postresistance exercise gene expression. After a glycogen depleting endurance exercise session in the morning subjects received an isocaloric mixed meal containing different amounts of carbohydrates and fat 2 hours before a resistance exercise session in the afternoon, while ample protein was provided throughout the day. We hypothesize that some of the post-resistance exercise selected mRNAs associated with substrate metabolism and mitochondrial biogenesis will differ between the nutritional conditions, without any changes in proteolytic genes. In chapter 4, from the same study, we analysed plasma cytokines to see whether these cytokines are affected by carbohydrate availability. In this study we aimed to determine the effects of a pre-resistance exercise carbohydrate meal versus fat meal on post-resistance exercise circulating plasma cytokine concentrations. We hypothesized that some of the selected cytokines will differ between nutritional conditions, but that the majority of the circulating cytokines with a possible role in skeletal muscle growth do not respond differently. Findings of chapter 3 and 4 may call into question the prominence of carbohydrate intake with regard to resistance exercise training adaptations. In chapter 5 , a perspective on the field of protein and the adaptive response with endurance training is given. In this perspective, the theoretical rationale why protein may be beneficial for individuals participating in endurance training programs is proposed. Chapter 6 investigates the effects of protein supplementation on endurance training adaptations in healthy young males. The aim of the study was to determine the impact of protein supplementation on $\mathrm{VO}_{2 \max }$, body composition and skeletal muscle adaptations with 10-weeks of vigorous endurance exercise training. In addition, to gain insight into temporary adaptations we measured adaptations after 5 and 10 weeks of endurance training. We hypothesized that protein supplementation further enhances gains in $\mathrm{VO}_{2 \max }$, lean mass and skeletal muscle adaptations during 10-weeks of endurance training. Chapter 7 reveals how the enhanced endurance training adaptations by protein supplementation could be explained by steady-state skeletal muscle transcriptional changes. These findings contribute to the view that protein supplementation with endurance exercise plays a major role in the process of adaptation with prolonged endurance training. Finally, chapter 8 provides an overall discussion of the results presented in this thesis, as well as future perspectives. 


\section{References}

1. Egan B, Zierath JR. Exercise metabolism and the molecular regulation of skeletal muscle adaptation. Cell metabolism 2013;17(2):162-84. doi: 10.1016/j.cmet.2012.12.012.

2. Folland JP, Williams AG. The adaptations to strength training : morphological and neurological contributions to increased strength. Sports medicine 2007;37(2):145-68.

3. Hoppeler H, Baum O, Lurman G, Mueller M. Molecular mechanisms of muscle plasticity with exercise. Comprehensive Physiology 2011;1(3):1383-412. doi: 10.1002/cphy.c100042.

4. Gunn HM. Heart weight and running ability. Journal of anatomy 1989;167:225-33.

5. Hawley JA, Lundby C, Cotter JD, Burke LM. Maximizing Cellular Adaptation to Endurance Exercise in Skeletal Muscle. Cell metabolism 2018;27(5):962-76. doi: 10.1016/j.cmet.2018.04.014.

6. Hawley JA, Hargreaves M, Joyner MJ, Zierath JR. Integrative biology of exercise. Cell 2014;159(4):738-49. doi: 10.1016/j.cell.2014.10.029.

7. Wilkinson SB, Phillips SM, Atherton PJ, Patel R, Yarasheski KE, Tarnopolsky MA, Rennie MJ. Differential effects of resistance and endurance exercise in the fed state on signalling molecule phosphorylation and protein synthesis in human muscle. The Journal of physiology 2008;586(Pt 15):3701-17. doi: 10.1113/jphysiol.2008.153916.

8. Perry CG, Lally J, Holloway GP, Heigenhauser GJ, Bonen A, Spriet LL. Repeated transient mRNA bursts precede increases in transcriptional and mitochondrial proteins during training in human skeletal muscle. The Journal of physiology 2010;588(Pt 23):4795810. doi: 10.1113/jphysiol.2010.199448.

9. Widegren U, Ryder JW, Zierath JR. Mitogen-activated protein kinase signal transduction in skeletal muscle: effects of exercise and muscle contraction. Acta physiologica Scandinavica 2001;172(3):227-38. doi: 10.1046/j.1365-201x.2001.00855.x.

10. Wackerhage H, Smith J, Wisneiwski DJOtocs, medicine e. Molecular exercise physiology. 2017:430-40.

11. Coffey VG, Moore DR, Burd NA, Rerecich T, Stellingwerff T, Garnham AP, Phillips SM, Hawley JA. Nutrient provision increases signalling and protein synthesis in human skeletal muscle after repeated sprints. European journal of applied physiology 2011;111(7):1473-83. doi: 10.1007/s00421-010-1768-0.

12. Hawley JA, Burke LM, Phillips SM, Spriet LL. Nutritional modulation of training-induced skeletal muscle adaptations. Journal of applied physiology 2011;110(3):834-45. doi: 10.1152/japplphysiol.00949.2010.

13. Cermak NM, van Loon LJ. The use of carbohydrates during exercise as an ergogenic aid. Sports medicine 2013;43(11):1139-55. doi: 10.1007/s40279-013-0079-0.

14. van Loon LJ, Greenhaff PL, Constantin-Teodosiu D, Saris WH, Wagenmakers AJ. The effects of increasing exercise intensity on muscle fuel utilisation in humans. The Journal of physiology 2001;536(Pt 1):295-304.

15. Tsintzas K, Williams C. Human muscle glycogen metabolism during exercise. Effect of carbohydrate supplementation. Sports medicine 1998;25(1):7-23.

16. Burd NA, Tang JE, Moore DR, Phillips SM. Exercise training and protein metabolism: influences of contraction, protein intake, and sex-based differences. Journal of applied physiology 2009;106(5):1692-701. doi: 10.1152/japplphysiol.91351.2008.

17. Rennie MJ, Wackerhage H, Spangenburg EE, Booth FW. Control of the size of the human muscle mass. Annual review of physiology 2004;66:799-828. doi: 10.1146/annurev.physiol.66.052102.134444.

18. Burke LM, van Loon LJC, Hawley JA. Postexercise muscle glycogen resynthesis in humans. Journal of applied physiology 2017;122(5):1055-67. doi: 10.1152/japplphysiol.00860.2016. 
19. Phillips SM. Dietary protein requirements and adaptive advantages in athletes. The British journal of nutrition 2012;108 Suppl 2:S158-67. doi: $10.1017 / \mathrm{s} 0007114512002516$.

20. Cermak NM, Res PT, de Groot LC, Saris WH, van Loon LJ. Protein supplementation augments the adaptive response of skeletal muscle to resistance-type exercise training: a meta-analysis. The American journal of clinical nutrition 2012;96(6):1454-64. doi: 10.3945/ajcn.112.037556.

21. Hardie DG, Ross FA, Hawley SA. AMPK: a nutrient and energy sensor that maintains energy homeostasis. Nature reviews Molecular cell biology 2012;13(4):251-62. doi: $10.1038 / \mathrm{nrm} 3311$.

22. Escobar KA, VanDusseldorp TA, Kerksick CM. Carbohydrate intake and resistancebased exercise: are current recommendations reflective of actual need? The British journal of nutrition 2016:1-13. doi: 10.1017/s0007114516003949.

23. Knuiman P, Hopman MT, Mensink M. Glycogen availability and skeletal muscle adaptations with endurance and resistance exercise. Nutrition \& metabolism 2015;12:59. doi: 10.1186/s12986-015-0055-9.

24. Knuiman P, Hopman MTE, Verbruggen C, Mensink M. Protein and the Adaptive Response With Endurance Training: Wishful Thinking or a Competitive Edge? Frontiers in physiology 2018;9:598. doi: 10.3389/fphys.2018.00598.

25. Moore DR, Camera DM, Areta JL, Hawley JA. Beyond muscle hypertrophy: why dietary protein is important for endurance athletes. Applied physiology, nutrition, and metabolism = Physiologie appliquee, nutrition et metabolisme 2014;39(9):987-97. doi: 10.1139/apnm-2013-0591.

26. Tarnopolsky M. Protein requirements for endurance athletes. Nutrition 2004;20(78):662-8. doi: 10.1016/j.nut.2004.04.008.

27. Achten J, Halson SL, Moseley L, Rayson MP, Casey A, Jeukendrup AE. Higher dietary carbohydrate content during intensified running training results in better maintenance of performance and mood state. Journal of applied physiology 2004;96(4):1331-40. doi: 10.1152/japplphysiol.00973.2003.

28. Bergstrom J, Hermansen L, Hultman E, Saltin B. Diet, muscle glycogen and physical performance. Acta physiologica Scandinavica 1967;71(2):140-50. doi: 10.1111/j.17481716.1967.tb03720.x.

29. Kato H, Nakano S, Inoue Y, Takeda T, Miura K, Nakamura T, Suzuki K, Bannai M. Greater Amino Acid Intake Is Required to Maximize Whole-Body Protein Synthesis Immediately after Endurance Exercise Than at Rest in Endurance-Trained Rats, as Determined by an Indicator Amino Acid Oxidation Method. The Journal of nutrition 2016;146(8):1546-51. doi: 10.3945/jn.115.226373.

30. Kato H, Suzuki K, Bannai M, Moore DR. Protein Requirements Are Elevated in Endurance Athletes after Exercise as Determined by the Indicator Amino Acid Oxidation Method. PloS one 2016;11(6):e0157406. doi: 10.1371/journal.pone.0157406.

31. Robinson MM, Turner SM, Hellerstein MK, Hamilton KL, Miller BF. Long-term synthesis rates of skeletal muscle DNA and protein are higher during aerobic training in older humans than in sedentary young subjects but are not altered by protein supplementation. FASEB journal : official publication of the Federation of American Societies for Experimental Biology 2011;25(9):3240-9. doi: 10.1096/fj.11-186437.

32. Ferguson-Stegall L, McCleave E, Ding Z, Doerner Iii PG, Liu Y, Wang B, Healy M, Kleinert M, Dessard B, Lassiter DG, et al. Aerobic exercise training adaptations are increased by postexercise carbohydrate-protein supplementation. Journal of nutrition and metabolism 2011;2011:623182. doi: 10.1155/2011/623182.

33. Harber MP, Konopka AR, Undem MK, Hinkley JM, Minchev K, Kaminsky LA, Trappe TA, Trappe S. Aerobic exercise training induces skeletal muscle hypertrophy and age- 
dependent adaptations in myofiber function in young and older men. Journal of applied physiology 2012;113(9):1495-504. doi: 10.1152/japplphysiol.00786.2012.

34. Konopka AR, Harber MP. Skeletal muscle hypertrophy after aerobic exercise training. Exercise and sport sciences reviews 2014;42(2):53-61. doi: 10.1249/jes.0000000000000007.

35. Rowlands DS, Thomson JS, Timmons BW, Raymond F, Fuerholz A, Mansourian R, Zwahlen MC, Metairon S, Glover E, Stellingwerff T, et al. Transcriptome and translational signaling following endurance exercise in trained skeletal muscle: impact of dietary protein. Physiological genomics 2011;43(17):1004-20. doi: 10.1152/physiolgenomics.00073.2011.

36. Ivy JL, Res PT, Sprague RC, Widzer MO. Effect of a carbohydrate-protein supplement on endurance performance during exercise of varying intensity. International journal of sport nutrition and exercise metabolism 2003;13(3):382-95.

37. Saunders MJ, Kane MD, Todd MK. Effects of a carbohydrate-protein beverage on cycling endurance and muscle damage. Medicine and science in sports and exercise 2004;36(7):1233-8.

38. Saunders MJ, Luden ND, Herrick JE. Consumption of an oral carbohydrate-protein gel improves cycling endurance and prevents postexercise muscle damage. Journal of strength and conditioning research / National Strength \& Conditioning Association 2007;21(3):678-84. doi: 10.1519/r-20506.1. 


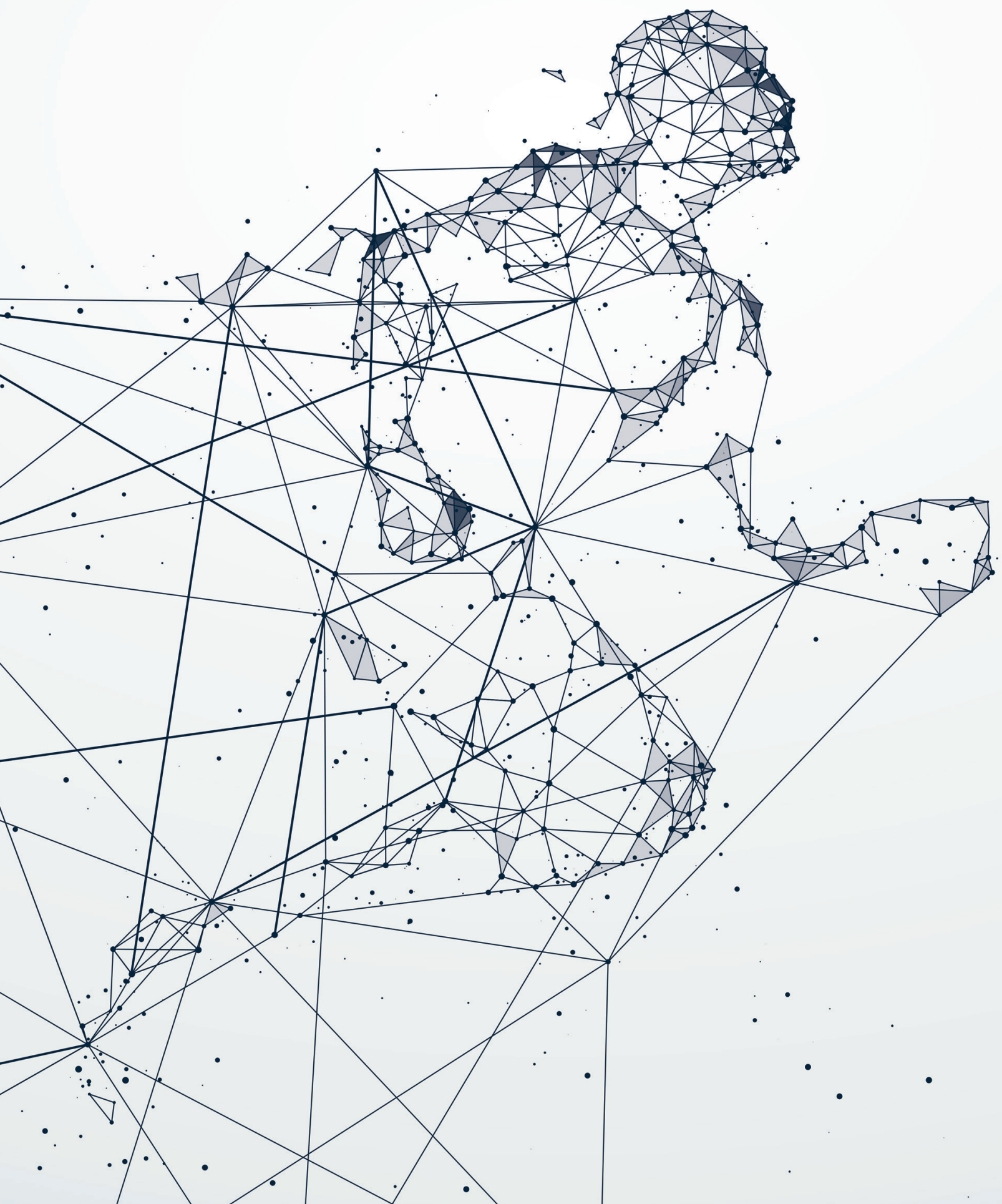




\section{Chapter 2}

Glycogen availability and skeletal muscle adaptations with endurance and resistance exercise

Pim Knuiman

Maria Hopman

Marco Mensink 


\begin{abstract}
It is well established that glycogen depletion affects endurance exercise performance negatively. Moreover, numerous studies have demonstrated that post-exercise carbohydrate ingestion improves exercise recovery by increasing glycogen resynthesis. However, recent research into the effects of glycogen availability sheds new light on the role of the widely accepted energy source for adenosine triphosphate (ATP) resynthesis during endurance exercise. Indeed, several studies showed that endurance training with low glycogen availability leads to similar and sometimes even better adaptations and performance compared to performing endurance training sessions with replenished glycogen stores. In the case of resistance exercise, a few studies have been performed on the role of glycogen availability on the early postexercise anabolic response. However, the effects of low glycogen availability on phenotypic adaptations and performance following prolonged resistance exercise remains unclear to date. This review summarizes the current knowledge about the effects of glycogen availability on skeletal muscle adaptations for both endurance and resistance exercise. Furthermore, it describes the role of glycogen availability when both exercise modes are performed concurrently.
\end{abstract}




\section{Introduction}

Roughly, exercise can be divided in endurance- and resistance exercise. Endurance exercise can be further subdivided in traditional -endurance exercise and high intensity interval training (HIIT). Traditional endurance exercise is characterized by continues submaximal muscular contractions aimed at improving aerobic power production. Whereas high intensity interval training primarily consists of brief, intermittent bursts of vigorous movements, alternated by periods of rest or low-intensity movements with the purpose to improve both aerobic and anaerobic power production (1). Resistance exercise, on the other hand involves short bursts of nearly maximal muscular contractions and primarily focuses on the development of muscle hypertrophy and/or muscular strength. The skeletal muscle adaptations are determined by the type, intensity and duration of the performed exercise. In short, endurance exercise training mainly results in mitochondrial biogenesis, increases capillary density and enzymes leading to enhanced skeletal muscle $\mathrm{O}_{2}$ utilization capacity (2-4). In contrast, resistance exercise promotes skeletal muscle hypertrophy and strength through increases in myofibrillar volume predominantly in type II fibres $(5,6)$.

It is now widely accepted that nutrition plays an important role in mediating skeletal muscle adaptations (7). Carbohydrates and fat are recognized as the main substrates for powering prolonged muscle contractions during endurance exercise (8). Although carbohydrates are widely accepted as fuel for skeletal muscle both during (8) and following endurance exercise (8), recent investigations introduced a novel approach of exercising with reduced glycogen levels aimed to optimize skeletal muscle adaptations $(9,10)$. Indeed, several studies have reported that endurance exercise with low glycogen availability may be a strategy to augment the response in exercise-induced signalling associated with improved oxidative capacity (11-17), and potentially enhance exercise performance $(17,18)$. In contrast, the effects of low glycogen availability on muscular adaptations following resistance exercise remain somewhat unclear. A recent study revealed that performing resistance exercise with low glycogen could improve acute signalling processes that promote mitochondrial biogenesis to a larger extent compared to exercise with normal glycogen levels (19), whereas another study demonstrated that muscle protein synthesis following a single bout of resistance exercise appeared to be unaffected by the level of glycogen (20).

A literature review concerning the role of glycogen availability for both endurance- and resistance exercise on skeletal muscle adaptations is at this time absent. Therefore, the purpose of this review is to identify the effects of glycogen availability on skeletal muscle training adaptations and performance with both endurance- and resistance exercise. Firstly, the role of glycogen in local skeletal muscle fatigue and energy metabolism will be described. 
Thereafter, the effects of glycogen availability on performance and markers of skeletal muscle adaptations are discussed. Finally, this review addresses the role of glycogen availability when both exercise modes are performed concurrently.

\section{Glycogen content, location and skeletal muscle fatigue}

In humans, most glycogen is made and stored in cells of the liver $(\sim 100 \mathrm{~g})$ and muscles ( 350 - $700 \mathrm{~g}$; depending on training status, diet, muscle fibre type composition, sex and bodyweight) and can be reduced by fasting, low intake of dietary carbohydrates and/or by exercise. It seems that the critical level of muscle glycogen is approximately around $250-300 \mathrm{mmol} \cdot \mathrm{kg}^{-1} \mathrm{dry}$ weight (d.w.), levels below this amount have been associated with impaired sarcoplasmic reticulum function by diminishing vesicle $\mathrm{Ca}^{2+}$ release rate and reductions in peak power output (21). Glycogen is differently distributed within the muscle fibres (subsarcolemmal $\sim 5-15 \%$, intermyofibrillar $~ 75 \%$ and intramyofibrillar 5-15\%) (22). Moreover, it appears that subsarcolemmal, intermyofibrillar and intramyofibrillar glycogen powers different mechanisms in muscle contractions. It is thought that intermyofibrillar glycogen powers the release of sarcoplasmic stored $\mathrm{Ca}^{2+}$ and in this way activates the tropomyosin active sites. Intramyofibrillar glycogen is preferably depleted during high-intensity exercise and seems to power cross-bridge cycling (23). Moreover, depletion of this form highly correlates well with skeletal muscle fatigue (24). Reduction of intramyofibrillar glycogen might decrease $\mathrm{Na}$, K-ATPase activity leading to decreased ATP cleavage, and subsequently a lower energy production to power cross-bridge cycling (22).

Moreover, Duhamel et al. (25) found that commencing an endurance type bout of exercise till fatigue with low glycogen availability resulted in earlier deteriorations in $\mathrm{SR} \mathrm{Ca}^{2+}$ release. Specifically, their data indicated that a cycling session of $70 \% \mathrm{VO}_{2 \text { peak }}$ carried out at low glycogen levels causes faster reductions in $\mathrm{SR} \mathrm{Ca}^{2+}$ uptake and $\mathrm{Ca}^{2+}$ release during exercise compared to high glycogen levels. Furthermore, it was found that reductions in SR $\mathrm{Ca}^{2+}$-ATPase activity followed a similar time course as that of $\mathrm{Ca}^{2+}$ uptake suggesting a mediating role for SR $\mathrm{Ca}^{2+}$-ATPase activity. In another study by Ortenblad et al. (21) it was shown that ingestion of carbohydrates during $4 \mathrm{~h}$ recovery following exercise markedly increases glycogen content and normalizes SR $\mathrm{Ca}^{2+}$ compared to the group who were omitted from carbohydrates during the recovery period. Based on SR vesicle experiments Ortenblad et al. (22) proposed that there is mechanistic role of glycogen on $\mathrm{SR} \mathrm{Ca}^{2+}$ release. Moreover, Ortenblad et al. stated that the reduction in SR $\mathrm{Ca}^{2+}$ release by itself induces a diminution in tetanic intracellular free $\left[\mathrm{Ca}^{2+}\right]_{\text {i, }}$, which is in accordance with isolated fibres studies showing a faster decrease of tetanic $\left[\mathrm{Ca}^{2+}\right]_{i}$ when glycogen content is reduced within these fibres. Taken together, the aforementioned findings at both the whole-body and organelle level suggest 
that the location of the glycogen, especially the intramyofibrillar pool, is important to sustain repeated muscle contractions.

\section{Glycogen and energetic demand with exercise}

Glycogen is an essential substrate during high intensity exercise by providing a mechanism by which adenosine tri phosphate (ATP) can be resynthesized from adenosine diphosphate (ADP) and phosphate. The relative use of energy sources during exercise is mainly determined by the intensity and the duration of the exercise bout, as well as the athlete's training status (8). Fat as source of energy is relatively most dominant during low-moderate intensity (30-65\% of $\mathrm{VO}_{\text {2peak }}$ ), whereas the relative contribution of carbohydrate oxidation to total energy expenditure becomes greater when exercise intensity increases, with muscle glycogen becoming the most important substrate source (26). Although the amount of liver and skeletal muscle glycogen is relatively small compared to endogenously stored fat, glycogen is recognized as the major source for fuel during prolonged moderate- to high intensity endurance exercise (27). Therefore, glycogen availability is essential to power ATP resynthesis during high intensity exercise which relies heavily on glycogenolysis. Furthermore, it has been well documented that the capability of skeletal muscle to exercise is impaired when the glycogen store is reduced to a certain level, even when there is sufficient amount of other fuels available (28). Together, prolonged endurance exercise leads to muscle glycogen depletion, which is in turn linked to fatigue and makes it difficult to meet the energetic requirements of training and competition $(22,29)$.

\section{Low glycogen and performance with exercise}

\section{Endurance training performance}

Low-glycogen availability causes a shift in substrate metabolism during and after exercise $(30,31)$. In addition, low-glycogen availability induces an increase in systemic release of amino acids and simultaneously increases fat oxidation, and as a consequence exercise intensity drops (30). However, the low-glycogen approach seems to promote expression of genes that stimulate fat catabolism and mitochondrial biogenesis and as such improves oxidative capacity (10). To date, few studies have found an improved training-induced performance effect of conducting the exercise bouts with low glycogen levels compared with replenished glycogen levels $(17,18)$. Hansen et al. (17) were the first to show that training with reduced glycogen availability results in improved oxidative capacity. In their study seven untrained males completed a 10-week training program. The untrained subjects performed leg-knee extensor exercise for $5 \mathrm{~d} \cdot \mathrm{wk}^{-1}$. Although the total amount of work was the same for each leg, one leg was trained in a glycogen depleted manner, while the contralateral leg was trained with full glycogen stores. The finding of their study was a significant gain in endurance (time till exhaustion) in the low- 
glycogen compared to normal glycogen levels. In addition, they found that lowglycogen improved oxidative capacity (citrate synthase activity) to a larger extent than commencing all exercise sessions with high-glycogen. The findings of Hansen et al. (17) were pioneering and in contrast with the studies reporting that glycogen content is a limiting factor when it comes to exercise adaptation and performance. Subsequently, other research groups tested the same hypothesis by using an alternative model with trained subjects $(12,16)$. Yeo et al. (16) demonstrated that subjects who undertook the exercise sessions in the low-glycogen state ( $\sim 50 \%$ depletion) showed significantly lower performance during the sessions compared to the subjects that undertook the sessions with high-glycogen (16). Interestingly, following the 3-wk intervention period, several markers of training adaption were increased. However, 60-min timetrial performance was similar in both the low-glycogen and high-glycogen group. Although speculative, the similar effect in performance suggests that the low-glycogen group showed a greater training adaptation, relative to their level of training intensity. Hulston et al.(12) reported that lipid oxidation during the steady-state exercise at $70 \% \mathrm{VO}_{2 \max }$ increased more in the lowglycogen group relative to the high-glycogen group, as a result of increased intramuscular triglycerides utilization. Moreover, this was accompanied by increases in oxidation of fatty acids, sparing of muscle glycogen, and greater increases in succinate dehydrogenase and 3-hydroxyacyl-CoA dehydrogenase enzyme activity (12). However, with regard to performance, the training with low muscle glycogen availability was not more effective than training with high muscle glycogen levels (12). Together, low-glycogen availability affects substrate use during exercise by increasing fatty acid oxidation compared to training with normal glycogen levels; this effect is independent of the subject training status.

Recently, Cochran et al. (18) demonstrated that a two week high-intensityinterval-training (HIIT) protocol performed with low muscle glycogen levels, improved cycling time trial performance compared with high glycogen stores. Specifically, training sessions consisted of 5 times 4 -min intervals at $60 \% \mathrm{~W}_{\text {peak }}$ ( 95-100\% of heart rate reserve) interspersed with 2 min of rest. Both groups trained on a total of $6 \mathrm{~d}$ over a 2-wk period, with a minimum of one day of rest between training days. Furthermore, subjects completed two identical HIIT sessions on each training day, separated by $3 \mathrm{~h}$ of recovery. After two weeks of HIIT, mean power output during a $250-\mathrm{kJ}$ time trial increased to a greater extent in the low-glycogen group compared to the high-glycogen group (18). A novel aspect of their study was that the subjects performed whole-body exercise for a relatively short period of time (2 weeks), while the study of Hansen et al. (17) lasted 10 weeks and used an exercise protocol where upper leg muscles performed isolated knee extensions 
Discrepancies between and limitations of the low-glycogen endurance exercise studies

A possible explanation for the different outcomes on performance between low-glycogen studies could be differences in the training status of the subjects. Hansen et al. (17) and Cochran et al. (18) used untrained subjects, whereas others tested well-trained subjects $(12,16)$. Indeed, it has previously been shown that the effectiveness of nutritional interventions is influenced by the subject training status (32), possibly because trained subjects depend less on carbohydrate utilization because they have greater metabolic flexibility. Another methodological issue is the selected test used to determine performance. In some studies, self-selected intensities were used, which could be influenced by carbohydrate manipulation. Cochran et al. (18) therefore prescribed and controlled power output during training to ensure that glycogen manipulation did not affect training intensity.

To summarize, although some studies reported that repetitive low-glycogen training leads to improved performance compared with high glycogen $(17,18)$, extrapolating these findings to sports-specific performance should be done with prudence. First, the study of Hansen et al. (17) used an isolated kneeextensor model $\left(5 \mathrm{~d} \cdot \mathrm{wk}^{-1}\right)$ as training protocol and performance measurement. However, this model does not accurately reflects an athlete's performance in a real life sports event. Second, as suggested by Yeo et al. (16), athletes generally use multiple intensities, as well as progressive overload $(33,34)$, rather than a fixed submaximal exercise intensity as was used during the training sessions in the study of Hansen et al. (17). Lastly, chronic exercise sessions commencing in the low-glycogen state may enhance the risk for overtraining syndrome (35) which in turn may result in reduced training capacity (36).

\section{Resistance exercise performance}

Resistance exercise is typically characterized by short bursts of nearly maximal muscular contractions. When performing resistance exercise, glycogen is crucial to resynthesize the phosphate pool, which provides energy during high intensity muscle contractions (37). According to MacDougall et al. (37), the majority of ATP is derived from glycolysis (38). In line with this, a typical resistance exercise session has been shown to reduces glycogen levels by approximately 24-40\% $(37,39-41)$. This reduction in glycogen content during exercise is determined by the intensity and volume of the performed exercise bout. The largest reductions in glycogen are seen with high repetitions with moderate load training (40), an effect that mainly occurs in type II fibres (39). It has been demonstrated that a reduction of muscle glycogen affects both isokinetic torque (29) and isoinertial resistance exercise capacity negatively (42). However, this effect is not always evident (43) and is likely to be affected by the protocol used to induce glycogen depletion (44). Based on the 
assumption that pre-exercise glycogen content can influence exercise performance, it seems that the pre-exercise carbohydrate ingestion requires particular attention (44).

Although it is widely accepted that carbohydrate ingestion before endurance exercise enhances work capacity $(45,46)$, carbohydrate ingestion before resistance exercise has not been studied to the same extent. The importance of carbohydrates for the resistance exercise-type athlete can be substantiated by the idea that glycogen plays a relatively important role in energy metabolism during resistance exercise. For example, it has been shown that pre-resistance exercise carbohydrate ingestion increases the amount of total work (47-49). In contrast, other reports show no benefit of carbohydrate ingestion on total work capacity $(50,51)$. To precisely determine the role of glycogen availability for the resistance exercise athlete more training studies that feature a defined area of outcome measures specifically for performance and adaptation are needed.

\section{Mitochondrial biogenesis on low-glycogen regimes and molecular pathways involved}

\section{Endurance exercise}

$P G C-1 \alpha$

Activity of the exercise-induced peroxisome proliferator-activated $\gamma$-receptor co-activator $1 \alpha$ (PGC-1 $\alpha$ ) has been proposed to play a key role in the adaptive response with endurance exercise (Figure 1). Endurance exercise leads to more PGC- $1 \alpha$ and more active of PGC- $1 \alpha$ which increases mitochondrial volume. Increased mitochondrial volume improves oxidative capacity through increased fatty acid $\beta$-oxidation and mitigating glycogenolysis (52). As a result, muscle glycogen can be spared which might delay the onset of muscle fatigue and enhances oxidative exercise performance. PGC- $1 \alpha$ is responsible for the activation of mitochondrial transcription factors e.g. the nuclear respiratory factors (NRF-1 and -2) and the mitochondrial transcription factor A (Tfam) (53). 


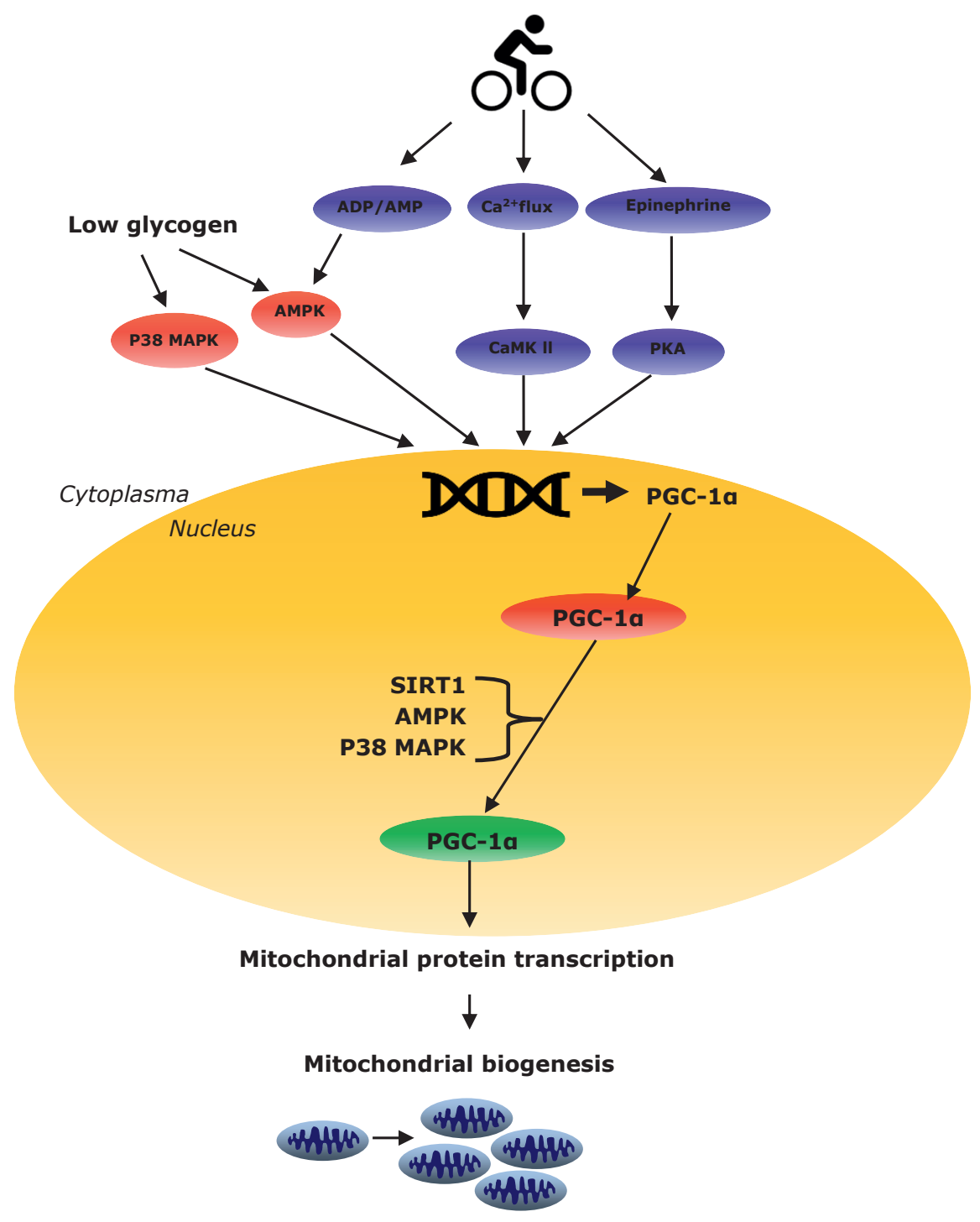

Figure 1. Schematic overview of training-induced mitochondrial adaptation in skeletal muscle. Schematic figure representing the regulation of mitochondrial biogenesis by endurance exercise. Endurance exercise acutely increases $\mathrm{Ca}^{2+}$, ADP, AMP and epinephrine. In addition, exercise reduces skeletal muscle glycogen in the contracting muscles which in turn activates the sensing proteins AMPK and p38 MAPK. Especially elevated AMP and ADP trigger an increased phosphorylation of AMPK at Thr172 and the increased $\mathrm{Ca}^{2+}$ concentration via calmodulin causes CaMK II autophosphorylation. Both AMPK and p38 MAPK activate and translocate the transcriptional co-activator PGC-1 $\alpha$ to the mitochondria and nucleus. The kinases AMPK , p38 MAPK and SIRT 1 then might phosphorylate PGC- $1 \alpha$ and reduce the acetylation of PGC-1 $\alpha$, which increases its activity. Thus, endurance exercise leads to more PGC- $1 \alpha$ which over time results in mitochondrial biogenesis. 


\section{$P G C-1 \alpha$ and $A M P K$}

Activation of PGC- $1 \alpha$ is amongst others regulated by the major upstream proteins 5 ' adenosine monophosphate-activated protein kinase (AMPK) (54). Prolonged endurance type exercise requires a large amount of ATP resulting in accumulation of ADP and AMP in the recruited muscle fibres (55). This activates AMPK with the purpose to restore cellular energy homeostasis $(56,57)$. A relative drop of ATP by less than $1 \%$ translates into a doubling or more of the ADP and AMP concentrations (58). The rise of ADP and AMP during prolonged endurance type exercise results in the phosphorylation of AMPK at Thr172, the active site on the AMPK $\alpha$ subunit (58-60). Canto and colleagues (2009) showed that AMPK action on PGC-1 $\alpha$ transcriptional activity is partly regulated by SIRT1, a sirtuin family protein which deacetylates several proteins that contribute to cellular regulation (57). Furthermore, it was shown that the acute actions of AMPK on lipid oxidation alter the balance between cellular NAD1 and NADH, which acts as a messenger to activate SIRT1 (57).

\section{PGC-1 $\alpha$, AMPK and $p 38$ MAPK in response to glycogen depletion}

During prolonged endurance type exercise skeletal muscle glycogen reduces, this is sensed by the AMPK $\beta$ subunit resulting in an activation of AMPK (Figure 1). The AMPK is then also activated through phosphorylation of Thr172 and this response is likely dependent on the rise of AMP and ADP during exercise. Chan et al (2004) suggested that low muscle glycogen availability associates with the phosphorylation of the nuclear P38 mitogen-activated protein kinases (p38 MAPK), rather than translocation of p38 MAPK to the nucleus per se (61). Accordingly, p38 MAPK particularly phosphorylate the expression of PGC- $1 \alpha$ $(53,62)$, whereas AMPK could both phosphorylate and enhance expression of PGC-1 $\alpha(53,62)$. Restricted CHO availability during or after exercise has also been shown to augment phosphorylation of (i.e. activate) p38 MAPK (63) and AMPK (15). In another study by Mathai and colleagues (2008) it was shown that changes in muscle glycogen correlates with the changes in PGC- $1 \alpha$ protein abundance during exercise and recovery (64). The majority of the studies show that the PGC- $1 \alpha$ mRNA content increased during and directly after exercise and returned to resting levels by $24 \mathrm{~h}$ after exercise. However, the studies that measured both PGC- $1 \alpha$ mRNA and PGC- $1 \alpha$ protein after chronic or acute exercise failed to find increases in both (64). Therefore, changes of PGC- $1 \alpha$ mRNA content are not necessarily compatible with changes in PGC- $1 \alpha$ protein abundance following exercise (64).

Although these studies suggest that the signalling response to exercise is affected by CHO supply, it remains unclear whether exercise in a glycogendepleted state can enhance the adaptive signalling response that is required for mitochondrial biogenesis. Thus, AMPK and MAPK 38 play a key role in the transcriptional regulation of mitochondrial biogenesis trough PGC- $1 \alpha$ in response to stress. However, the precise role of potential regulators which are 
responsive to glycogen availability, in the processes of mitochondrial biogenesis, needs to be further elucidated.

\section{P53}

Another described protein that regulates mitochondrial biogenesis is $\mathrm{p} 53$, which appears to be sensitive to changes in glycogen availability (65). Previous research has shown that p53 is phosphorylated by AMPK and p38 AMPK (66, 67). Furthermore, p53 is implicated in the stimulation of gene expression of mitochondrial function $(66,67)$. It has been demonstrated that commencing endurance exercise in a glycogen depleted state upregulates p53 to a larger extent than during exercise in a replenished glycogen state (68). However, the influence on PGC- $1 \alpha$ mRNA expression is difficult to interpret because the subjects involved were not only on an exercise regime with low glycogen availability, but also on a calorie restricted diet. Accordingly, it remains unknown which potent regulator was responsible for the increase in mitochondrial biogenesis in this study. The precise role of both potential regulators in the processes of mitochondrial biogenesis needs to be further elucidated.

\section{Resistance exercise}

Although resistance exercise is mainly recognized as mechanical stimulus for increases in strength and hypertrophy, the aerobic effects following resistance exercise have also been studied. Early investigations have shown that skeletal mitochondrial volume (69) and oxidative capacity (70) are unaltered following prolonged resistance exercise. However, it has been recently reported that resistance exercise increases the activity of oxidative enzymes in tissue homogenates $(19,71)$ and respiration in skinned muscle fibres $(72)$. Moreover, resistance training augmented oxidative phosphorylation in sedentary older adults (73) and respiratory capacity and intrinsic function of skeletal muscle mitochondria in young healthy men (74). In a recent investigation by Irving and co-workers (75) young and older adults performed 8 weeks of endurance training, resistance training or concurrent/combined training. Interestingly, following all exercise modalities, concurrent training induced the most robust improvements in mitochondrial related outcomes and mRNA expression (75). Notably, the improvements in mitochondria were independent of age. Therefore, exploring molecular processes regulating the metabolic and oxidative responses with resistance training may lead to a better understanding and eventually to optimized adaptations. Studies examining the effect of low glycogen availability on mitochondrial regulators largely centred on endurance training. However, Camera et al. (19) recently showed that both phosphorylation of p53 and mRNA abundance of PGC- $1 \alpha$ increased during the early $(4 \mathrm{~h})$ post-exercise recovery period after resistance exercise undertaken with low glycogen availability. It appears that the level of glycogen acts as a 
modulator of processes regulating mitochondrial biogenesis, independent of the nature of exercise stimuli. The supposed mechanism by which p53 is translocated from the nucleus to the mitochondria and subsequently enhances mitochondrial biogenesis is through its interaction with mitochondrial transcription factor A (Tfam) and also by preventing p53 suppression of PGC$1 \alpha$ activation in the nucleus (67). According to the findings of Camera et al. (19) and others $(20,76,77)$ resistance exercise seems capable of increasing PGC-1 mRNA expressions and p53 phosphorylation that has the potential to stimulate mitochondrial adaptation. Moreover, the acute metabolic response to resistance exercise can be modulated in a glycogen-dependent manner. However, whether these acute alterations in regulators of mitochondrial biogenesis are sufficient to promote mitochondrial volume and function remains to be elucidated in future long-term training studies.

\section{Low glycogen availability and protein metabolism}

Endurance exercise

Skeletal muscle mass is maintained by the balance between muscle protein synthesis (MPS) and muscle protein breakdown (MPB) rates such that overall net muscle protein balance (NPB) remains essentially unchanged over the course of the day. A prolonged imbalance between MPS and MPB results in a positive (hypertrophy: MPS > MPB) or negative NPB (atrophy: MPS < MPB). The two main potent stimuli for MPS are food ingestion and exercise (78). Nutrition, proteins in particular, induces a transient stimulation of MPS and is therefore in itself, i.e. in the absence of exercise, not sufficient to induce a positive NPB. Likewise, resistance exercise improves NPB, however, the ingestion of protein during the post-exercise recovery period is required to induce a positive NPB (79). Thus, both exercise and food ingestion must be deployed in combination in order to create a positive NPB (78).

To date, only a few studies examined the role of glycogen availability on protein metabolism following endurance exercise $(30,80,81)$. It seems that glycogen availability mediates MPB. An early study from Lemon and Mullin showed that when exercise was performed with reduced glycogen availability nitrogen losses more than doubled, suggesting an increase in MPB and amino acid oxidation (80). Subsequently, two other studies $(30,81)$ used the arterialvenous (a-v) difference method to explore whether exercise in the low glycogen state affects amino acid flux and then estimated NPB. In both studies subjects performed an exercise session in the low-glycogen state, the researchers found a net release of amino acids during exercise indicating an increase in MPB. However, these studies may be methodologically flawed because the a-v balance method only allows for the determination of net amino acid balance. Conclusions about changes in MPS and MPB are therefore of a speculative nature (82). A more recent study by Howarth et al. (82) used the stable isotope tracer methodology and therefore enabled to determine the changes in MPS 
and MPB. They found that skeletal muscle NPB was lower when exercise was commenced with low glycogen availability compared to the high glycogen group, indicating an increase in MPB and decrease in MPS during exercise. It appears that endurance exercise with reduced muscle glycogen availability negatively influences muscle protein turnover and impairs skeletal muscle repair and recovery from endurance exercise. As described previously, low glycogen could be used as a strategy to augment mitochondrial adaptations to exercise, however, protein ingestion is required to offset MPB and increase MPS. Indeed, recent evidence reported that protein ingestion during or following endurance exercise increases MPS leading to a positive NPB $(83,84)$.

\section{Resistance exercise}

Resistance exercise type muscular contraction and/or protein ingestion affect the complex of regulatory processes that determines the changes in MPB and MPS. The Akt-mTOR-S6K pathway that controls the process of MPS has been studied extensively $(85,86)$. However, the effects of glycogen availability with resistance exercise and its effects on these regulatory processes remains to be further scrutinized. It has been observed that low-glycogen availability $(\sim 160$ $\mathrm{mmol} \cdot \mathrm{kg}^{-1}$ d.w.) elevates resting and exercise-induced AMPK activity compared to high-glycogen availability $\left(\sim 910 \mathrm{mmol} \cdot \mathrm{kg}^{-1} \mathrm{~d}\right.$.w. $)(87)$. Furthermore, work by Churchly et al. (88) demonstrated that low-glycogen availability $(\sim 193$ mmol $\cdot \mathrm{kg}^{-1}$ d.w.) did not enhance the activity of genes involved in muscle hypertrophy. Creer et al. (89), on the other hand, investigated the role of glycogen availability on two key pathways involved in cellular growth. Subjects performed three sets of 10 repetitions of bilateral knee extension exercise at $70 \%$ of 1-RM separated by a 2-min recovery period. Muscle biopsies were taken to determine the activation of extracellular signal-regulated kinase (ERK1/2) and Akt signalling pathways. They found an increase in both ERK1/2 and p90 ribosomal S6 kinase phosphorylation, but this effect was independent of the level of glycogen. Further, Akt phosphorylation was attenuated in the low glycogen $\left(\sim 175 \mathrm{mmol} \cdot \mathrm{kg}^{-1} \mathrm{~d} . \mathrm{w}.\right)$, whereas it was increased in the high glycogen $\left(\sim 600 \mathrm{mmol} \cdot \mathrm{kg}^{-1} \mathrm{~d} . \mathrm{w}\right.$.) group. mTOR phosphorylation was similar to that of Akt, however, the change was not significant. In a comparable study from Camera et al. (20) young healthy men performed 8 sets of 5 unilateral leg press repetitions at 80\% 1RM. Muscle biopsies were taken at rest and 1 and $4 \mathrm{~h}$ after the single exercise bout. Although mTOR phosphorylation increased to a higher extent in the normal glycogen group, there were no detectable differences found in MPS suggesting that the small differences in signalling are negligible since MPS was unaffected. The result that MPS is not influenced by the level of glycogen was an interesting finding since it has been previously reported that energy deficit attenuates rates of mixed MPS by 19\% (90). However, it should be noted that being in an energy deficit state does not 
necessarily reflects glycogen levels are low. Hence, the total energy available for the cell to undertake its normal homeostatic processes is less.

Summarized, it seems that glycogen availability had no influence on the anabolic effects induced by resistance exercise. However, aforementioned studies on the effects of glycogen availability on resistance exercise-induced anabolic response do not resemble a training volume typically used by resistance-type athletes. Future long-term training studies ( 12 weeks) are needed to find out whether performing resistance exercise with low glycogen availability leads to divergent skeletal muscle adaptations compared to performing the exercise bouts with replenished glycogen levels.

\section{Role of glycogen availability with concurrent training}

To date, many sports such as soccer, volleyball, tennis or swimming require a phenotype which features a high oxidative capacity and a sufficient amount of strength/power in order to achieve maximal performance. To develop both endurance capacity and strength/power simultaneously, a targeted training model must include both endurance and resistance exercise, known as concurrent training. Concurrent training does improve both endurance capacity and muscular strength/power, although numerous studies have revealed that strength development is compromised with concurrent training compared to resistance exercise alone (91-94), a phenomenon known as the "interference" effect. Vice versa, the effect of resistance exercise on endurance performance and $\mathrm{VO}_{2 \max }$ appears to be marginal $(95,96)$. However, some studies reported compromised gains in aerobic capacity with concurrent training compared to endurance exercise alone $(97,98)$. Following the work of Hickson et al. (99), numerous studies have investigated the effect of concurrent training on skeletal muscle adaptations. Although the existing human data on acute molecular events is insufficient to entirely explain the impaired strength/power gains for the concurrent athlete compared with either exercise modality alone, it has been hypothesized that the exercise-induced signalling antagonism may play a role herein. Since a detailed analysis on the interference effect associated with concurrent training is beyond the scope of this review, we refer the reader to expert reviews on the interference effect seen with concurrent training (Baar et al. (2014b); Fyfe, Bishop, \& Stepto (2014); PerezSchindler et al.(2015) (100-102). Briefly, the most hypothesized mechanism blameworthy for the impaired strength/power gains seen with concurrent training is the impaired upregulation of the P13K-AKT $\rightarrow$ mechanistic target of rapamycin complex-1 (mTORC1) signalling pathway $(89,102,103)$. It is thought that endurance exercise results in an activation of AMPK, which inhibits the mTORC1 signalling via tuberous sclerosis protein (TSC), and this will eventually suppress MPS resulting in a negative net protein balance. In addition, a higher contractile activity also results in a higher calcium flux, which decreases peptide-chain elongation via activation of eukaryotic 
elongation factor-2 kinase (eEF2k) leading to a decreased MPS (89, 102, 103). However, whether the exercise-induced acute interference between AMPK and mTORC1 entirely explains the blunted strength gains seen with concurrent training is to date obscure.

To optimize skeletal muscle adaptations and performance, nutritional strategies for both exercise modes should differ. Indeed, it was recently proposed that, when practicing endurance and resistance exercise on the same day, the endurance session should be performed in the morning in the fasted state, with ample protein ingestion (102). While the afternoon resistance exercise session should be conducted only after carbohydrate replenishment with adequate post-exercise protein ingestion (102). Furthermore, whether such a nutritional strategy leads to improved performance compared to general recommendations for carbohydrate and protein intake remains elusive. Interestingly, it has been demonstrated that a resistance exercise session subsequently after low-intensity endurance, non-glycogen depleting session could enhance molecular signalling of mitochondrial biogenesis induced by endurance exercise (104). Furthermore it is currently unclear whether performing resistance exercise with low-glycogen availability affects the acute anabolic molecular events and whether the effects of these responses possibly result in improved or impaired training adaptation.

Furthermore, whether low-glycogen availability during the endurance bout amplifies the oxidative resistance exercise induced response remains to be investigated. It seems that both modes of exercise in a low glycogen state as part of a periodized training regime are interesting in terms of acute expressions of markers involved in substrate utilization and oxidative capacity. However, on the other hand, a sufficient amount of glycogen is essential in order to meet the energetic demands of both endurance and resistance exercise.

Most existing information on nutrition and concurrent training adaptation is derived from studies where subjects performed exercise in the fasted state (104-108). Coffey and colleagues investigated the effects of successive bouts of resistance and endurance exercise performed in different order in close proximity on the early skeletal muscle molecular response (76). Although the second exercise bout was performed with different levels of skeletal muscle glycogen content, the subsequent effects on Akt, mTOR and p70 signalling following the second exercise bout remained the same. Prospective long-term concurrent training studies may help to understand the complexity of the impaired adaptation with concurrent training and further determine to what extend the acute signalling antagonism contributes to this. Moreover, the role of nutritional factors in counteracting the interference effect remains to be further elucidated. 


\section{Concluding remarks and perspectives}

In this review we summarized the role of glycogen availability with regard to performance and skeletal muscle adaptations for both endurance and resistance exercise. Most of the studies with low-glycogen availability focused on endurance type training. The results of these studies are promising if the acute molecular response truly indicates skeletal muscle adaptations over a prolonged period of time. Unfortunately, these results on low-glycogen availability may be biased because many other variables including training parameters (time, intensity, frequency, type, rest between bouts) and nutritional factors (type, amount, timing, isocaloric versus non-isocaloric placebo) varied considerably between the studies and it is therefore difficult to make valid inferences. Furthermore, the majority of the studies with low glycogen availability were of short duration (18) and showed no changes (1117), or showed, in some cases decreases in performance (109). Nevertheless, reductions in glycogen stores by manipulation of carbohydrate ingestion have shown to enhance the formation of training-induced specific proteins and mitochondrial biogenesis following endurance exercise to a greater extent than in the glycogen replenished state $(11-16,18,68)$.

For resistance exercise, glycogen availability seemed to have no significant influence on the anabolic effects induced by resistance exercise when MPS was measured with the stable isotope methodology. However, the exercise protocols used in most studies do not resemble a training volume that is typical for resistance-type athletes. Future long-term training studies $(\sim 12$ weeks) are needed to investigate whether performing resistance exercise with low glycogen availability leads to divergent skeletal muscle adaptations compared to performing the exercise bouts with replenished glycogen levels. The role of glycogen availability on skeletal muscle adaptations and performance needs to be further investigated. In particular researchers need to examine glycogen availability when endurance and resistance exercise are conducted concurrently, for example, on the same day or on alternating days during the week. To date, only a few studies have investigated the interactions between nutrient intake and acute response following a concurrent exercise model. We recommend that future research in this field should focus on the following questions:

- What is the impact of performing one of the exercise bouts (endurance or resistance) with low glycogen availability on response of markers of mitochondrial biogenesis of the subsequent (endurance or resistance) exercise bout?

- Does the resistance exercise bout need to be conducted with replenished glycogen stores in order to optimize the adaptive response when performed after a bout of endurance exercise? 
- Is nutritional timing within a concurrent exercise model crucial to maximize skeletal muscle adaptations following prolonged concurrent training?

To conclude, depletion of muscle glycogen is strongly associated with the degree of fatigue development during endurance exercise. This is mainly caused by reduced glycogen availability which is essential for ATP resynthesis during high-intensity endurance exercise. Furthermore, it is hypothesized that other physiological mechanisms involved in excitation-contraction coupling of skeletal muscle may play a role herein. On the other hand, the low glycogen approach seems promising with regard to the adaptive response following exercise. Therefore, low glycogen training may be useful as part of a wellthought out periodization program. However, further research is needed to further scrutinize the role of low glycogen training in different groups (e.g. highly trained subjects) combined with different exercise protocols (e.g. concurrent modalities), to develop a nutritional strategy that has the potential to improve skeletal muscle adaptations and performance with concurrent training. 


\section{References}

1. Gibala MJ, Little JP, Macdonald MJ, Hawley JA. Physiological adaptations to low-volume, high-intensity interval training in health and disease. The Journal of physiology 2012;590(Pt 5):1077-84. doi: 10.1113/jphysiol.2011.224725.

2. Bebout DE, Hogan MC, Hempleman SC, Wagner PD. Effects of training and immobilization on VO2 and DO2 in dog gastrocnemius muscle in situ. Journal of applied physiology 1993;74(4):1697-703.

3. Burelle Y, Hochachka PW. Endurance training induces muscle-specific changes in mitochondrial function in skinned muscle fibers. Journal of applied physiology 2002;92(6):2429-38. doi: 10.1152/japplphysiol.01024.2001.

4. Charifi N, Kadi F, Feasson L, Costes F, Geyssant A, Denis C. Enhancement of microvessel tortuosity in the vastus lateralis muscle of old men in response to endurance training. The Journal of physiology 2004;554(Pt 2):559-69. doi: 10.1113/jphysiol.2003.046953.

5. Folland JP, Williams AG. The adaptations to strength training : morphological and neurological contributions to increased strength. Sports medicine 2007;37(2):145-68.

6. Cermak NM, Res PT, de Groot LC, Saris WH, van Loon LJ. Protein supplementation augments the adaptive response of skeletal muscle to resistance-type exercise training: a meta-analysis. The American journal of clinical nutrition 2012;96(6):1454-64. doi: 10.3945/ajcn.112.037556.

7. Coffey VG, Moore DR, Burd NA, Rerecich T, Stellingwerff T, Garnham AP, Phillips SM, Hawley JA. Nutrient provision increases signalling and protein synthesis in human skeletal muscle after repeated sprints. European journal of applied physiology 2011;111(7):1473-83. doi: 10.1007/s00421-010-1768-0.

8. Cermak NM, van Loon LJ. The use of carbohydrates during exercise as an ergogenic aid. Sports medicine 2013;43(11):1139-55. doi: 10.1007/s40279-013-0079-0.

9. Hawley JA, Burke LM. Carbohydrate availability and training adaptation: effects on cell metabolism. Exercise and sport sciences reviews 2010;38(4):152-60. doi: 10.1097/JES.0b013e3181f44dd9.

10. Bartlett JD, Hawley JA, Morton JP. Carbohydrate availability and exercise training adaptation: Too much of a good thing? European journal of sport science 2015;15(1):312. doi: 10.1080/17461391.2014.920926.

11. Cox GR, Clark SA, Cox AJ, Halson SL, Hargreaves M, Hawley JA, Jeacocke N, Snow RJ, Yeo WK, Burke LM. Daily training with high carbohydrate availability increases exogenous carbohydrate oxidation during endurance cycling. Journal of applied physiology 2010;109(1):126-34. doi: 10.1152/japplphysiol.00950.2009.

12. Hulston CJ, Venables MC, Mann CH, Martin C, Philp A, Baar K, Jeukendrup AE. Training with low muscle glycogen enhances fat metabolism in well-trained cyclists. Medicine and science in sports and exercise 2010;42(11):2046-55. doi: 10.1249/MSS.0b013e3181dd5070.

13. Morton JP, Croft L, Bartlett JD, Maclaren DP, Reilly T, Evans L, McArdle A, Drust B. Reduced carbohydrate availability does not modulate training-induced heat shock protein adaptations but does upregulate oxidative enzyme activity in human skeletal muscle. Journal of applied physiology 2009;106(5):1513-21. doi: 10.1152/japplphysiol.00003.2009.

14. Van Proeyen K, Szlufcik K, Nielens H, Ramaekers M, Hespel P. Beneficial metabolic adaptations due to endurance exercise training in the fasted state. Journal of applied physiology 2011;110(1):236-45. doi: 10.1152/japplphysiol.00907.2010.

15. Yeo WK, McGee SL, Carey AL, Paton CD, Garnham AP, Hargreaves M, Hawley JA. Acute signalling responses to intense endurance training commenced with low or normal 
muscle glycogen. Experimental physiology 2010;95(2):351-8. doi: 10.1113/expphysiol.2009.049353.

16. Yeo WK, Paton CD, Garnham AP, Burke LM, Carey AL, Hawley JA. Skeletal muscle adaptation and performance responses to once a day versus twice every second day endurance training regimens. Journal of applied physiology 2008;105(5):1462-70. doi: 10.1152/japplphysiol.90882.2008.

17. Hansen AK, Fischer CP, Plomgaard P, Andersen JL, Saltin B, Pedersen BK. Skeletal muscle adaptation: training twice every second day vs. training once daily. Journal of applied physiology 2005;98(1):93-9. doi: 10.1152/japplphysiol.00163.2004.

18. Cochran AJ, Myslik F, MacInnis MJ, Percival ME, Bishop D, Tarnopolsky MA, Gibala MJ. Manipulating Carbohydrate Availability Between Twice-Daily Sessions of High-intensity Interval Training Over Two Weeks Improves Time-trial Performance. International journal of sport nutrition and exercise metabolism 2015. doi: 10.1123/ijsnem.20140263.

19. Camera DM, Hawley JA, Coffey VG. Resistance exercise with low glycogen increases p53 phosphorylation and PGC-1alpha mRNA in skeletal muscle. European journal of applied physiology 2015. doi: 10.1007/s00421-015-3116-x.

20. Camera DM, West DW, Burd NA, Phillips SM, Garnham AP, Hawley JA, Coffey VG. Low muscle glycogen concentration does not suppress the anabolic response to resistance exercise. Journal of applied physiology 2012;113(2):206-14. doi: 10.1152/japplphysiol.00395.2012.

21. Ortenblad N, Nielsen J, Saltin B, Holmberg HC. Role of glycogen availability in sarcoplasmic reticulum $\mathrm{Ca} 2+$ kinetics in human skeletal muscle. The Journal of physiology 2011;589(Pt 3):711-25. doi: 10.1113/jphysiol.2010.195982.

22. Ortenblad N, Westerblad H, Nielsen J. Muscle glycogen stores and fatigue. The Journal of physiology 2013;591(Pt 18):4405-13. doi: 10.1113/jphysiol.2013.251629.

23. Nielsen J, Holmberg HC, Schroder HD, Saltin B, Ortenblad N. Human skeletal muscle glycogen utilization in exhaustive exercise: role of subcellular localization and fibre type. The Journal of physiology 2011;589(Pt 11):2871-85. doi: 10.1113/jphysiol.2010.204487.

24. Nielsen J, Suetta C, Hvid LG, Schroder HD, Aagaard P, Ortenblad N. Subcellular localization-dependent decrements in skeletal muscle glycogen and mitochondria content following short-term disuse in young and old men. American journal of physiology Endocrinology and metabolism 2010;299(6):E1053-60. doi: 10.1152/ajpendo.00324.2010.

25. Duhamel TA, Perco JG, Green HJ. Manipulation of dietary carbohydrates after prolonged effort modifies muscle sarcoplasmic reticulum responses in exercising males. American journal of physiology Regulatory, integrative and comparative physiology 2006;291(4):R1100-10. doi: 10.1152/ajpregu.00858.2005.

26. van Loon LJ, Greenhaff PL, Constantin-Teodosiu D, Saris WH, Wagenmakers AJ. The effects of increasing exercise intensity on muscle fuel utilisation in humans. The Journal of physiology 2001;536(Pt 1):295-304.

27. Tsintzas K, Williams C. Human muscle glycogen metabolism during exercise. Effect of carbohydrate supplementation. Sports medicine 1998;25(1):7-23.

28. Bergstrom J, Hultman E. A study of the glycogen metabolism during exercise in man. Scandinavian journal of clinical and laboratory investigation 1967;19(3):218-28. doi: 10.3109/00365516709090629.

29. Jacobs I, Kaiser P, Tesch P. Muscle strength and fatigue after selective glycogen depletion in human skeletal muscle fibers. European journal of applied physiology and occupational physiology 1981;46(1):47-53. 
30. Blomstrand E, Saltin B. Effect of muscle glycogen on glucose, lactate and amino acid metabolism during exercise and recovery in human subjects. The Journal of physiology 1999;514 ( Pt 1):293-302.

31. Weltan SM, Bosch AN, Dennis SC, Noakes TD. Preexercise muscle glycogen content affects metabolism during exercise despite maintenance of hyperglycemia. The American journal of physiology 1998;274(1 Pt 1):E83-8.

32. Porcelli S, Ramaglia M, Bellistri G, Pavei G, Pugliese L, Montorsi M, Rasica L, Marzorati M. Aerobic Fitness Affects the Exercise Performance Responses to Nitrate Supplementation. Medicine and science in sports and exercise 2014. doi: 10.1249/MSS.0000000000000577.

33. Stellingwerff T, Boit MK, Res PT, International Association of Athletics F. Nutritional strategies to optimize training and racing in middle-distance athletes. Journal of sports sciences 2007;25 Suppl 1:S17-28. doi: 10.1080/02640410701607213.

34. Hawley JA. Adaptations of skeletal muscle to prolonged, intense endurance training. Clinical and experimental pharmacology \& physiology 2002;29(3):218-22.

35. Petibois C, Cazorla G, Poortmans JR, Deleris G. Biochemical aspects of overtraining in endurance sports : the metabolism alteration process syndrome. Sports medicine 2003;33(2):83-94.

36. Achten J, Halson SL, Moseley L, Rayson MP, Casey A, Jeukendrup AE. Higher dietary carbohydrate content during intensified running training results in better maintenance of performance and mood state. Journal of applied physiology 2004;96(4):1331-40. doi: 10.1152/japplphysiol.00973.2003.

37. MacDougall JD, Ray S, Sale DG, McCartney N, Lee P, Garner S. Muscle substrate utilization and lactate production. Canadian journal of applied physiology $=$ Revue canadienne de physiologie appliquee 1999;24(3):209-15.

38. Katz A, Broberg S, Sahlin K, Wahren J. Leg glucose uptake during maximal dynamic exercise in humans. The American journal of physiology 1986;251(1 Pt 1):E65-70.

39. Koopman R, Manders RJ, Jonkers RA, Hul GB, Kuipers H, van Loon LJ. Intramyocellular lipid and glycogen content are reduced following resistance exercise in untrained healthy males. European journal of applied physiology 2006;96(5):525-34. doi: 10.1007/s00421-005-0118-0.

40. Pascoe DD, Costill DL, Fink WJ, Robergs RA, Zachwieja JJ. Glycogen resynthesis in skeletal muscle following resistive exercise. Medicine and science in sports and exercise 1993;25(3):349-54.

41. Tesch PA, Colliander EB, Kaiser P. Muscle metabolism during intense, heavy-resistance exercise. European journal of applied physiology and occupational physiology 1986;55(4):362-6.

42. Leveritt M, Abernethy PJ. Effects of carbohydrate restriction on strength performance. Journal of Strength and Conditioning Research 1999;13(1):52-7.

43. Mitchell JB, DiLauro PC, Pizza FX, Cavender DL. The effect of preexercise carbohydrate status on resistance exercise performance. International journal of sport nutrition 1997;7(3):185-96.

44. Slater G, Phillips SM. Nutrition guidelines for strength sports: sprinting, weightlifting, throwing events, and bodybuilding. Journal of sports sciences 2011;29 Suppl 1:S67-77. doi: 10.1080/02640414.2011.574722.

45. Burke LM, Hawley JA, Wong SH, Jeukendrup AE. Carbohydrates for training and competition. Journal of sports sciences 2011;29 Suppl 1:S17-27. doi: 10.1080/02640414.2011.585473.

46. Jeukendrup A. A step towards personalized sports nutrition: carbohydrate intake during exercise. Sports medicine 2014;44 Suppl 1:S25-33. doi: 10.1007/s40279-0140148-z. 
47. Lambert CP, Flynn MG, Boone Jr JB, Michaud TJ, Rodriguez-Zayas J. Effects of Carbohydrate Feeding on Multiple-bout Resistance Exercise. The Journal of Strength \& Conditioning Research 1991;5(4):192-7.

48. Haff G, Schroeder C, Koch A, Kuphal K, Comeau M, Potteiger J. The effects of supplemental carbohydrate ingestion on intermittent isokinetic leg exercise. Journal of sports medicine and physical fitness 2001;41(2):216-22.

49. Haff GG, Stone MH, Warren BJ, Keith R, Johnson RL, Nieman DC, FRANKLIN WILLIAMS J, KIRKSEY KB. The Effect of Carbohydrate Supplementation on Multiple Sessions and Bouts of Resistance Exercise. The Journal of Strength \& Conditioning Research 1999;13(2):111-7.

50. Kulik JR, Touchberry CD, Kawamori N, Blumert PA, Crum AJ, Haff GG. Supplemental carbohydrate ingestion does not improve performance of high-intensity resistance exercise. The Journal of Strength \& Conditioning Research 2008;22(4):1101-7.

51. Haff GG, Koch AJ, Potteiger JA, Kuphal KE, Magee LM, Green SB, Jakicic JJ. Carbohydrate supplementation attenuates muscle glycogen loss during acute bouts of resistance exercise. International journal of sport nutrition and exercise metabolism 2000;10(3):326-39.

52. Margolis LM, Pasiakos SM. Optimizing intramuscular adaptations to aerobic exercise: effects of carbohydrate restriction and protein supplementation on mitochondrial biogenesis. Advances in nutrition 2013;4(6):657-64. doi: 10.3945/an.113.004572.

53. Jager S, Handschin C, St-Pierre J, Spiegelman BM. AMP-activated protein kinase (AMPK) action in skeletal muscle via direct phosphorylation of PGC-1alpha. Proceedings of the National Academy of Sciences of the United States of America 2007;104(29):12017-22. doi: 10.1073/pnas.0705070104.

54. Psilander N, Frank P, Flockhart M, Sahlin K. Exercise with low glycogen increases PGC1alpha gene expression in human skeletal muscle. European journal of applied physiology 2013;113(4):951-63. doi: 10.1007/s00421-012-2504-8.

55. Drake JC, Wilson RJ, Yan Z. Molecular mechanisms for mitochondrial adaptation to exercise training in skeletal muscle. FASEB journal : official publication of the Federation of American Societies for Experimental Biology 2015. doi: 10.1096/fj.15276337.

56. Mounier R, Theret M, Lantier L, Foretz M, Viollet B. Expanding roles for AMPK in skeletal muscle plasticity. Trends in endocrinology and metabolism: TEM 2015;26(6):275-86. doi: 10.1016/j.tem.2015.02.009.

57. Canto C, Gerhart-Hines Z, Feige JN, Lagouge M, Noriega L, Milne JC, Elliott PJ, Puigserver $\mathrm{P}$, Auwerx J. AMPK regulates energy expenditure by modulating NAD+ metabolism and SIRT1 activity. Nature 2009;458(7241):1056-60. doi: 10.1038/nature07813.

58. Wackerhage H. Molecular Exercise Physiology: An Introduction: Taylor \& Francis, 2014.

59. Xiao B, Sanders MJ, Underwood E, Heath R, Mayer FV, Carmena D, Jing C, Walker PA, Eccleston JF, Haire LF, et al. Structure of mammalian AMPK and its regulation by ADP. Nature 2011;472(7342):230-3. doi: 10.1038/nature09932.

60. Carling D, Thornton C, Woods A, Sanders MJ. AMP-activated protein kinase: new regulation, new roles? The Biochemical journal 2012;445(1):11-27. doi: 10.1042/bj20120546.

61. Chan MH, McGee SL, Watt MJ, Hargreaves M, Febbraio MA. Altering dietary nutrient intake that reduces glycogen content leads to phosphorylation of nuclear p38 MAP kinase in human skeletal muscle: association with IL-6 gene transcription during contraction. FASEB journal : official publication of the Federation of American Societies for Experimental Biology 2004;18(14):1785-7. doi: 10.1096/fj.03-1039fje.

62. Knutti D, Kressler D, Kralli A. Regulation of the transcriptional coactivator PGC-1 via MAPK-sensitive interaction with a repressor. Proceedings of the National Academy of 
Sciences of the United States of America 2001;98(17):9713-8. doi: 10.1073/pnas.171184698.

63. Cochran AJ, Little JP, Tarnopolsky MA, Gibala MJ. Carbohydrate feeding during recovery alters the skeletal muscle metabolic response to repeated sessions of highintensity interval exercise in humans. Journal of applied physiology 2010;108(3):62836. doi: 10.1152/japplphysiol.00659.2009.

64. Mathai AS, Bonen A, Benton CR, Robinson DL, Graham TE. Rapid exercise-induced changes in PGC-1alpha mRNA and protein in human skeletal muscle. Journal of applied physiology 2008;105(4):1098-105. doi: 10.1152/japplphysiol.00847.2007.

65. Saleem A, Carter HN, Iqbal S, Hood DA. Role of p53 within the regulatory network controlling muscle mitochondrial biogenesis. Exercise and sport sciences reviews 2011;39(4):199-205. doi: 10.1097/JES.0b013e31822d71be.

66. Donahue RJ, Razmara M, Hoek JB, Knudsen TB. Direct influence of the p53 tumor suppressor on mitochondrial biogenesis and function. FASEB journal : official publication of the Federation of American Societies for Experimental Biology 2001;15(3):635-44. doi: 10.1096/fj.00-0262com.

67. Saleem A, Adhihetty PJ, Hood DA. Role of p53 in mitochondrial biogenesis and apoptosis in skeletal muscle. Physiological genomics 2009;37(1):58-66. doi: 10.1152/physiolgenomics.90346.2008.

68. Bartlett JD, Louhelainen J, Iqbal Z, Cochran AJ, Gibala MJ, Gregson W, Close GL, Drust B, Morton JP. Reduced carbohydrate availability enhances exercise-induced p53 signaling in human skeletal muscle: implications for mitochondrial biogenesis. American journal of physiology Regulatory, integrative and comparative physiology 2013;304(6):R450-8. doi: 10.1152/ajpregu.00498.2012.

69. MacDougall JD, Sale DG, Moroz JR, Elder GC, Sutton JR, Howald H. Mitochondrial volume density in human skeletal muscle following heavy resistance training. Medicine and science in sports 1979;11(2):164-6.

70. Chilibeck PD, Syrotuik DG, Bell GJ. The effect of strength training on estimates of mitochondrial density and distribution throughout muscle fibres. European journal of applied physiology and occupational physiology 1999;80(6):604-9. doi: $10.1007 / \mathrm{s} 004210050641$.

71. Tang JE, Hartman JW, Phillips SM. Increased muscle oxidative potential following resistance training induced fibre hypertrophy in young men. Applied physiology, nutrition, and metabolism = Physiologie appliquee, nutrition et metabolisme 2006;31(5):495-501. doi: 10.1139/h06-026.

72. Pesta D, Hoppel F, Macek C, Messner H, Faulhaber M, Kobel C, Parson W, Burtscher M, Schocke M, Gnaiger E. Similar qualitative and quantitative changes of mitochondrial respiration following strength and endurance training in normoxia and hypoxia in sedentary humans. American journal of physiology Regulatory, integrative and comparative physiology 2011;301(4):R1078-87. doi: 10.1152/ajpregu.00285.2011.

73. Jubrias SA, Esselman PC, Price LB, Cress ME, Conley KE. Large energetic adaptations of elderly muscle to resistance and endurance training. Journal of applied physiology 2001;90(5):1663-70.

74. Porter C, Reidy PT, Bhattarai N, Sidossis LS, Rasmussen BB. Resistance Exercise Training Alters Mitochondrial Function in Human Skeletal Muscle. Medicine and science in sports and exercise 2014. doi: 10.1249/mss.0000000000000605.

75. Irving BA, Lanza IR, Henderson GC, Rao RR, Spiegelman BM, Nair KS. Combined Training Enhances Skeletal Muscle Mitochondrial Oxidative Capacity Independent of Age. The Journal of clinical endocrinology and metabolism 2015;100(4):1654-63. doi: 10.1210/jc.2014-3081. 
76. Coffey VG, Zhong Z, Shield A, Canny BJ, Chibalin AV, Zierath JR, Hawley JA. Early signaling responses to divergent exercise stimuli in skeletal muscle from well-trained humans. FASEB journal : official publication of the Federation of American Societies for Experimental Biology 2006;20(1):190-2. doi: 10.1096/fj.05-4809fje.

77. Gordon PM, Liu D, Sartor MA, IglayReger HB, Pistilli EE, Gutmann L, Nader GA, Hoffman EP. Resistance exercise training influences skeletal muscle immune activation: a microarray analysis. Journal of applied physiology 2012;112(3):443-53. doi: 10.1152/japplphysiol.00860.2011.

78. Burd NA, Tang JE, Moore DR, Phillips SM. Exercise training and protein metabolism: influences of contraction, protein intake, and sex-based differences. Journal of applied physiology 2009;106(5):1692-701. doi: 10.1152/japplphysiol.91351.2008.

79. Rennie MJ, Wackerhage H, Spangenburg EE, Booth FW. Control of the size of the human muscle mass. Annual review of physiology 2004;66:799-828. doi: 10.1146/annurev.physiol.66.052102.134444.

80. Lemon PW, Mullin JP. Effect of initial muscle glycogen levels on protein catabolism during exercise. Journal of applied physiology: respiratory, environmental and exercise physiology 1980;48(4):624-9.

81. Van Hall G, Saltin B, Wagenmakers AJ. Muscle protein degradation and amino acid metabolism during prolonged knee-extensor exercise in humans. Clinical science 1999;97(5):557-67.

82. Howarth KR, Phillips SM, MacDonald MJ, Richards D, Moreau NA, Gibala MJ. Effect of glycogen availability on human skeletal muscle protein turnover during exercise and recovery. Journal of applied physiology 2010;109(2):431-8. doi: 10.1152/japplphysiol.00108.2009.

83. Howarth KR, Moreau NA, Phillips SM, Gibala MJ. Coingestion of protein with carbohydrate during recovery from endurance exercise stimulates skeletal muscle protein synthesis in humans. Journal of applied physiology 2009;106(4):1394-402. doi: 10.1152/japplphysiol.90333.2008.

84. Pasiakos SM, McClung HL, McClung JP, Margolis LM, Andersen NE, Cloutier GJ, Pikosky MA, Rood JC, Fielding RA, Young AJ. Leucine-enriched essential amino acid supplementation during moderate steady state exercise enhances postexercise muscle protein synthesis. The American journal of clinical nutrition 2011;94(3):809-18. doi: 10.3945/ajcn.111.017061.

85. Glass DJ. Skeletal muscle hypertrophy and atrophy signaling pathways. The international journal of biochemistry \& cell biology 2005;37(10):1974-84. doi: 10.1016/j.biocel.2005.04.018.

86. Philp A, Hamilton DL, Baar K. Signals mediating skeletal muscle remodeling by resistance exercise: PI3-kinase independent activation of mTORC1. Journal of applied physiology 2011;110(2):561-8. doi: 10.1152/japplphysiol.00941.2010.

87. Wojtaszewski JF, MacDonald C, Nielsen JN, Hellsten Y, Hardie DG, Kemp BE, Kiens B, Richter EA. Regulation of 5'AMP-activated protein kinase activity and substrate utilization in exercising human skeletal muscle. American journal of physiology Endocrinology and metabolism 2003;284(4):E813-22. doi: 10.1152/ajpendo.00436.2002.

88. Churchley EG, Coffey VG, Pedersen DJ, Shield A, Carey KA, Cameron-Smith D, Hawley JA. Influence of preexercise muscle glycogen content on transcriptional activity of metabolic and myogenic genes in well-trained humans. Journal of applied physiology 2007;102(4):1604-11. doi: 10.1152/japplphysiol.01260.2006.

89. Creer A, Gallagher P, Slivka D, Jemiolo B, Fink W, Trappe S. Influence of muscle glycogen availability on ERK1/2 and Akt signaling after resistance exercise in human skeletal 
muscle. Journal of applied physiology 2005;99(3):950-6. doi: 10.1152/japplphysiol.00110.2005.

90. Pasiakos SM, Vislocky LM, Carbone JW, Altieri N, Konopelski K, Freake HC, Anderson JM, Ferrando AA, Wolfe RR, Rodriguez NR. Acute energy deprivation affects skeletal muscle protein synthesis and associated intracellular signaling proteins in physically active adults. The Journal of nutrition 2010;140(4):745-51. doi: 10.3945/jn.109.118372.

91. Bell GJ, Syrotuik D, Martin TP, Burnham R, Quinney HA. Effect of concurrent strength and endurance training on skeletal muscle properties and hormone concentrations in humans. European journal of applied physiology 2000;81(5):418-27. doi: $10.1007 / \mathrm{s} 004210050063$.

92. Dolezal BA, Potteiger JA. Concurrent resistance and endurance training influence basal metabolic rate in nondieting individuals. Journal of applied physiology 1998;85(2):695700 .

93. Hakkinen K, Alen M, Kraemer WJ, Gorostiaga E, Izquierdo M, Rusko H, Mikkola J, Hakkinen A, Valkeinen H, Kaarakainen E, et al. Neuromuscular adaptations during concurrent strength and endurance training versus strength training. European journal of applied physiology 2003;89(1):42-52. doi: 10.1007/s00421-002-0751-9.

94. Kraemer WJ, Patton JF, Gordon SE, Harman EA, Deschenes MR, Reynolds K, Newton RU, Triplett NT, Dziados JE. Compatibility of high-intensity strength and endurance training on hormonal and skeletal muscle adaptations. Journal of applied physiology 1995;78(3):976-89.

95. Leveritt M, Abernethy PJ, Barry BK, Logan PA. Concurrent strength and endurance training. A review. Sports medicine 1999;28(6):413-27.

96. Chromiak JA, Mulvaney DR. A Review: The Effects of Combined Strength and Endurance Training on Strength Development. The Journal of Strength \& Conditioning Research 1990;4(2):55-60.

97. Hennessy LC, Watson AW. The Interference Effects of Training for Strength and Endurance Simultaneously. The Journal of Strength \& Conditioning Research 1994;8(1):12-9.

98. Wilson JM, Marin PJ, Rhea MR, Wilson SM, Loenneke JP, Anderson JC. Concurrent training: a meta-analysis examining interference of aerobic and resistance exercises. The Journal of Strength \& Conditioning Research 2012;26(8):2293-307.

99. Hickson RC. Interference of strength development by simultaneously training for strength and endurance. European journal of applied physiology and occupational physiology 1980;45(2-3):255-63.

100. Baar K. Using molecular biology to maximize concurrent training. Sports medicine 2014;44 Suppl 2:S117-25. doi: 10.1007/s40279-014-0252-0.

101. Fyfe JJ, Bishop DJ, Stepto NK. Interference between concurrent resistance and endurance exercise: molecular bases and the role of individual training variables. Sports medicine 2014;44(6):743-62. doi: 10.1007/s40279-014-0162-1.

102. Perez-Schindler J, Hamilton DL, Moore DR, Baar K, Philp A. Nutritional strategies to support concurrent training. European journal of sport science 2015;15(1):41-52. doi: 10.1080/17461391.2014.950345.

103. Bolster DR, Crozier SJ, Kimball SR, Jefferson LS. AMP-activated protein kinase suppresses protein synthesis in rat skeletal muscle through down-regulated mammalian target of rapamycin (mTOR) signaling. The Journal of biological chemistry 2002;277(27):23977-80. doi: 10.1074/jbc.C200171200.

104. Wang L, Mascher H, Psilander N, Blomstrand E, Sahlin K. Resistance exercise enhances the molecular signaling of mitochondrial biogenesis induced by endurance exercise in 
human skeletal muscle. Journal of applied physiology 2011;111(5):1335-44. doi: 10.1152/japplphysiol.00086.2011.

105. Apro W, Wang L, Ponten M, Blomstrand E, Sahlin K. Resistance exercise induced mTORC1 signaling is not impaired by subsequent endurance exercise in human skeletal muscle. American journal of physiology Endocrinology and metabolism 2013;305(1):E22-32. doi: 10.1152/ajpendo.00091.2013.

106. Carrithers JA, Carroll CC, Coker RH, Sullivan DH, Trappe TA. Concurrent exercise and muscle protein synthesis: implications for exercise countermeasures in space. Aviation, space, and environmental medicine 2007;78(5):457-62.

107. Coffey VG, Pilegaard H, Garnham AP, O'Brien BJ, Hawley JA. Consecutive bouts of diverse contractile activity alter acute responses in human skeletal muscle. Journal of applied physiology 2009;106(4):1187-97. doi: 10.1152/japplphysiol.91221.2008.

108. Coffey VG, Jemiolo B, Edge J, Garnham AP, Trappe SW, Hawley JA. Effect of consecutive repeated sprint and resistance exercise bouts on acute adaptive responses in human skeletal muscle. American journal of physiology Regulatory, integrative and comparative physiology 2009;297(5):R1441-51. doi: 10.1152/ajpregu.00351.2009.

109. Havemann L, West SJ, Goedecke JH, Macdonald IA, St Clair Gibson A, Noakes TD, Lambert EV. Fat adaptation followed by carbohydrate loading compromises highintensity sprint performance. Journal of applied physiology 2006;100(1):194-202. doi: 10.1152/japplphysiol.00813.2005. 


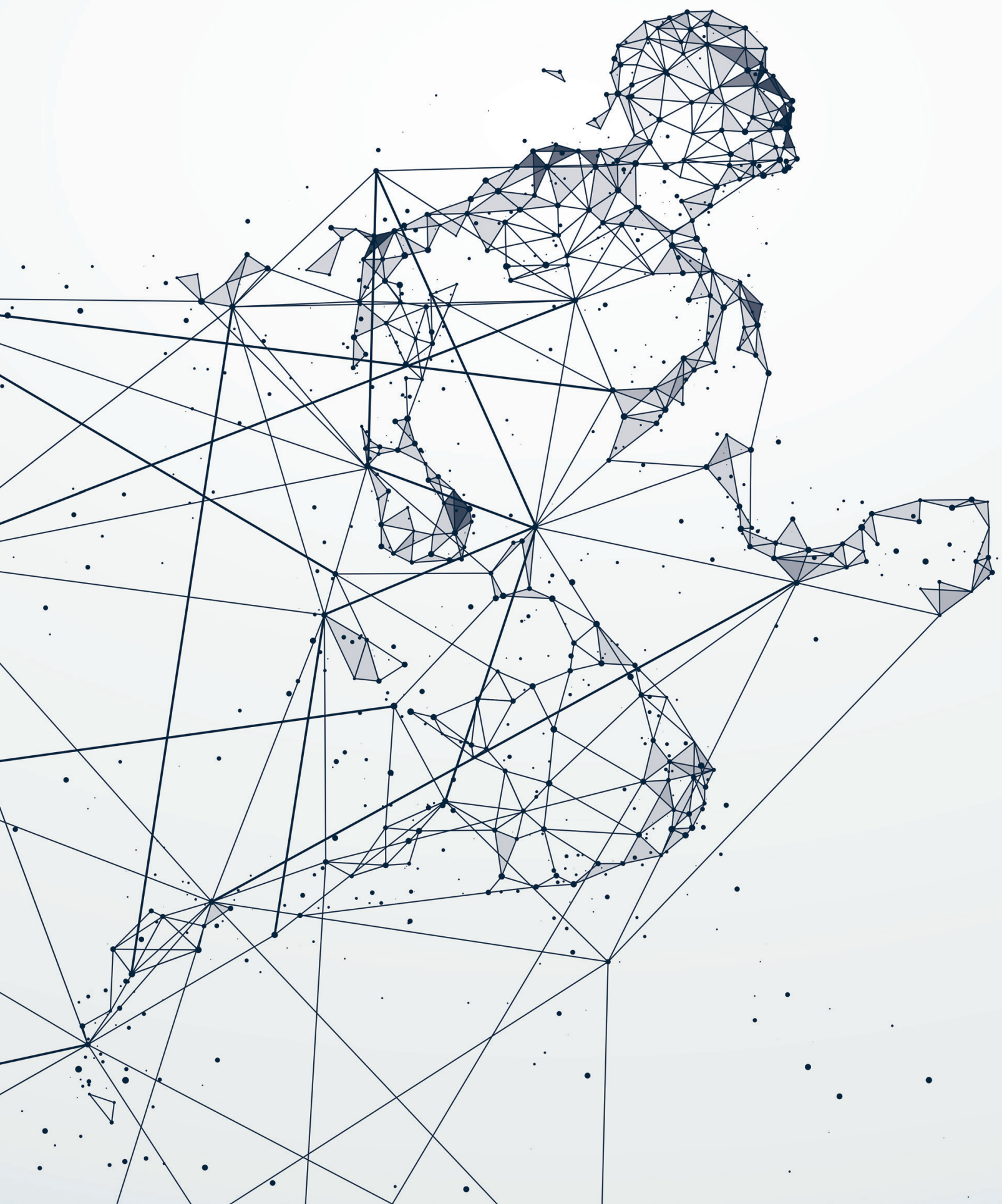




\title{
Chapter 3
}

Select skeletal muscle mRNAs related to exercise adaptation are minimally affected by different pre-exercise meals that differ in macronutrient profile

\author{
Pim Knuiman \\ Maria Hopman \\ Jeroen Wouters \\ Marco Mensink
}




\section{Abstract}

Background Substantial research has been done on the impact of carbohydrate and fat availability on endurance exercise adaptation, though its role in the acute adaptive response to resistance exercise has yet to be fully characterised. Purpose We aimed to assess the effects of a pre-resistance exercise isocaloric mixed meal containing different amounts of carbohydrates and fat, on postresistance exercise gene expression associated with muscle adaptation.

Methods Thirteen young (age $21.2 \pm 1.6$ year), recreationally trained $\left(\mathrm{VO}_{2 \max }\right.$ $51.3 \pm 4.8 \mathrm{ml} / \mathrm{kg} / \mathrm{min}$ ) men undertook an aerobic exercise session of 90-min continuous cycling $\left(70 \% \mathrm{VO}_{2 \max }\right)$ in the morning with pre- and post-exercise protein ingestion ( $10 \mathrm{~g}$ and $15 \mathrm{~g}$ casein in a $500 \mathrm{ml}$ beverage pre- and postexercise, respectively). Subjects then rested for two hours and were provided with a meal consisting of either $3207 \mathrm{~kJ}$; 52g protein; $51 \mathrm{~g}$ fat and $23 \mathrm{~g}$ carbohydrate (FAT) or $3124 \mathrm{~kJ}$; 53g protein; 9g fat; and 109g carbohydrate (CHO). Two hours after the meal, subjects completed $5 \times 8$ repetitions (80\% 1RM) for both bilateral leg press and leg extension directly followed by $25 \mathrm{~g}$ of whey protein ( $500 \mathrm{ml}$ beverage). Muscle biopsies were obtained from the vastus lateralis at baseline (morning) and $1 \mathrm{~h}$ and $3 \mathrm{~h}$ post-resistance exercise (afternoon) to determine intramuscular mRNA response.

Results Muscle glycogen levels were significantly decreased post-resistance exercise, without any differences between conditions. Plasma free fatty acids increased significantly after the mixed meal in the FAT condition, while glucose and insulin were higher in the CHO condition. However, PDK4 mRNA quantity was significantly higher in the FAT condition at $3 \mathrm{~h}$ post-resistance exercise compared to CHO. HBEGF, INSIG1, MAFbx, MURF1, SIRT1 and myostatin responded solely as a result of exercise without any differences between the CHO and FAT group. FOXO3A, IGF-1, PGC- $1 \alpha$, and VCP expression levels remained unchanged over the course of the day.

Conclusion We conclude that mRNA quantity associated with muscle adaptation after resistance exercise is not affected by a difference in preexercise nutrient availability. PDK4 was differentially expressed between CHO and FAT groups, suggesting a potential shift towards fat oxidation and reduced glucose oxidation in the FAT group. 


\section{Introduction}

The fundamental phenotypic adaptation to repeated bouts of resistance exercise is an increase in muscle mass and strength. It is assumed that the cumulative effect of frequent resistance exercise sessions within a certain period of time modifies specific proteins, thereby enabling or enhancing the crucial biological processes required for adaptation [1-3]. Considerable attention has been paid to the time course of mRNA response in relation to exercise, and we now know that the exercise-induced changes in mRNA quantity peak immediately post exercise up to 12 hours and return to basal levels within 24 hours [4-7].

It is well known that manipulating nutrition affects the acute intramuscular response with exercise. For instance, post resistance exercise protein provision augments the AKT-mTOR-S6K signalling pathway to initiate translation $[8,9]$. On the other hand, carbohydrate restriction with endurance exercise reduces muscle glycogen levels, which in turn affect mRNA levels of genes involved in mitochondrial biogenesis $[10,11]$. In addition, undertaking resistance exercise with low skeletal muscle glycogen levels enhances PGC- $1 \alpha$ mRNA quantity [12]. The mRNA response to resistance exercise has been examined under a variety of nutritional states (fasted vs fed; protein vs placebo) [1, 13], however, the role of pre-exercise fat and carbohydrate availability on the acute adaptive response remains to be examined. Additionally, most literature assessing low-carbohydrate diets [14-18] or lowcarbohydrate availability with exercise [19-22] has focused on endurance exercise. Consequently, specific guidelines for daily carbohydrate intake and timing regarding resistance exercise training are primarily derived from endurance models and the available data on the acute resistance exercise response with different carbohydrate availability. However, to our knowledge, it remains unclear whether pre-resistance exercise carbohydrate or fat availability affects the post-resistance exercise mRNA response when matched for protein intake. Therefore, we aimed to explore the effects of differences in carbohydrates and fat availability on post-resistance exercise gene expression. After a glycogen depleting endurance exercise session in the morning subjects received an isocaloric mixed meal containing different amounts of carbohydrates and fat 2 hours before a resistance exercise session in the afternoon, while ample protein was provided throughout the day. We hypothesize that some of the post-resistance exercise selected mRNAs e.g. PDK4, PGC-1 $\alpha$ and SIRT1 will respond differently to the nutritional conditions, without any changes in proteolytic genes. 


\section{Methods}

\section{Subject characteristics}

All subjects were non-smokers, free of injury and not using any medication or nutritional supplements. All subjects provided a full-written informed consent. This study was carried out in accordance with the guidelines for human research of The Medical Ethical Committee of Wageningen University. The Medical Ethical Committee of Wageningen University approved all study procedures. Fourteen healthy physically-active males volunteered to participate in this study: age $21.2 \pm 1.6$ years, height $1.87 \pm 0.05 \mathrm{~cm}$, weight $76.7 \pm 4.7) \mathrm{kg}$, leg extension $1-\mathrm{RM} 111 \pm 11 \mathrm{~kg}$, leg press $1-\mathrm{RM} 266 \pm 30 \mathrm{~kg}$ and $\mathrm{VO}_{2 \max } 51.3 \pm 4.8 \mathrm{ml} / \mathrm{kg} / \mathrm{min}^{-1}$ (Table 1). One subject dropped out after test day 1 because of discomfort of the muscle biopsies. Physical characteristics of 13 volunteers are shown in table 1 .

Table 1. Physical characteristics of subjects.

\begin{tabular}{|c|c|}
\hline & $\operatorname{Mean} \pm \mathrm{SE}$ \\
\hline Age (years) & $21.2 \pm 0.5$ \\
\hline Height (m) & $1.87 \pm 0.0$ \\
\hline Weight (kg) & $76.7 \pm 1.3$ \\
\hline BMI ( $\left.\mathrm{kg} / \mathrm{m}^{2}\right)$ & $22.0 \pm 0.2$ \\
\hline $\mathrm{W}_{\max }(\mathrm{W})$ & $346 \pm 7.6$ \\
\hline $\mathrm{VO}_{2 \max }\left(\mathrm{mL} / \mathrm{kg} / \mathrm{min}^{-1}\right)$ & $51.3 \pm 1.3$ \\
\hline Leg press 1-RM (kg) & $266 \pm 8.2$ \\
\hline Leg extension 1-RM (kg) & $111 \pm 3.0$ \\
\hline
\end{tabular}

\section{Study Design}

This study used a crossover design with two experimental days. On both experimental days subjects completed the same protocol: an endurance exercise session in the morning $(08.30-10.00 \mathrm{am})$ and a resistance exercise session in the afternoon $(02.00-02.30 \mathrm{pm})$ with a resting period of 4 hours between sessions (Figure 1). The subjects received a mixed meal in between the exercise sessions (12.00 pm), which was either a high carbohydrate - low fat meal (CHO) or a low carbohydrate- high fat meal (FAT). Each trial was 
separated by a minimum of 12 days (range: 12-30 days), during which time the subjects were instructed to maintain their habitual lifestyle.

\section{Figure 1.}

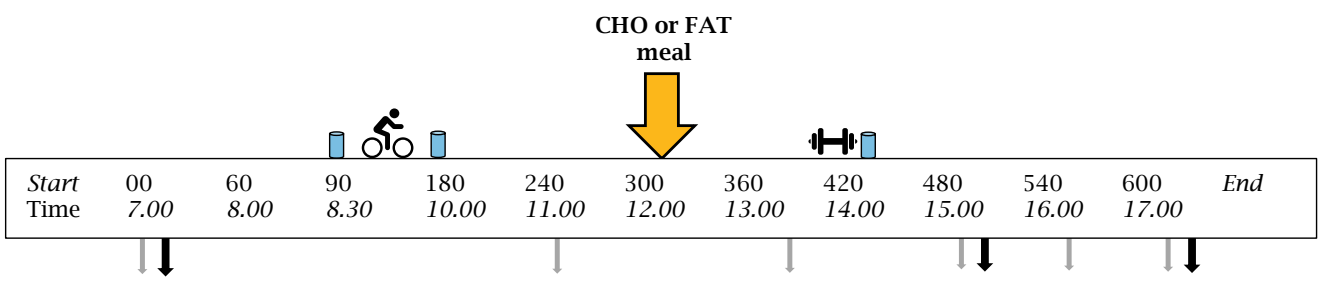

Figure 1. Schematic diagram of the experimental trials. This study adopted a counterbalanced crossover design where subjects completed both exercise trials with different nutritional treatments on separate occasions. Endurance exercise session: 90 -min cycling at $70 \% \mathrm{VO}_{2 \max }$. Resistance exercise sessions 5 sets of 8 repetitions for both leg press and leg extensions at $80 \% 1$-RM. Blue containers indicates protein beverage (from left to right; $10 \mathrm{~g}$ casein, $15 \mathrm{~g}$ casein and $25 \mathrm{~g}$ whey. Big orange arrow with black outline indicates lunch with carbohydrates or fat (nutritional intervention meal). Open white arrows indicates time point for blood sample; black arrow indicates sampling time point for muscle biopsy.

\section{Preliminary testing}

Maximal aerobic capacity $\left(V O_{2 \max }\right)$

Preliminary testing was performed in the week prior to the start of the first experimental day. Following a 30-min rest, subjects performed a ramped $\mathrm{VO}_{2 \max }$ test on an electrically braked cycle ergometer (Lode Excalibur, Groningen, The Netherlands). After a 5-min warm up at $50 \mathrm{~W}$, the subjects started cycling at $100 \mathrm{~W}$. Workload was progressively increased by $20 \mathrm{~W} \cdot \mathrm{min}$. ${ }^{1}$ until the subject reached volitional exhaustion. The $\mathrm{VO}_{2 \max }$ test was considered to be valid when two out of three criteria were met: I) levelling of $\mathrm{VO}_{2}$ with increasing workload; II) heart rate within 10 beats of the theoretically estimated maximum (220-age) and III) respiratory exchange ratio (RER) of 21.15. Oxygen consumption $\left(\mathrm{VO}_{2}\right)$ was measured through breath-by-breath sampling with an Oxycon Pro (Jaeger, Hoechberg, Germany) to define maximal oxygen consumption $\left(\mathrm{VO}_{2 \max }\right)$. Subjects were asked to maintain a cadence between $80-100 \mathrm{r} \cdot \mathrm{min}^{-1}$.

\section{Maximal strength (1RM)}

Subjects were asked to arrive fasted (at least $4 \mathrm{~h}$ ) and to avoid any strenuous physical activity $48 \mathrm{~h}$ before the preliminary tests. Each subject performed a bilateral one-repetition maximum (1RM) using the leg press and leg extension machine (Technogym, Cesena, Italy). Subjects were familiarized with the movement and warmed up prior to testing by performing six repetitions (at 
$\sim 40 \%$ of estimated 1RM) through a full range of motion with a 1-min rest. After each successful lift, the weight was increased until a failed attempt occurred with 3-min recovery between each attempt. The 1RM was attained within five attempts. Subjects performed a familiarization session for both the endurance and the resistance exercise session $\sim$ one week before the first experimental day.

\section{Diet and physical activity control}

Subjects were instructed to avoid alcohol, caffeine and physical activity during $48 \mathrm{~h}$ prior to the two experimental days. Diet and physical activity levels were recorded for $24 \mathrm{~h}$ before the first experimental day and subjects were asked to replicate dietary intake and physical activity prior to the second experimental day. A standardized meal for the subjects was provided the night before each trial (standard deep-frozen meal and ice-cream dessert; 43.80 kJ/kg BW; 15 Energy\% protein, 30 Energy\% fat and 55 Energy\% carbohydrate).

\section{Experimental days}

All subjects arrived in the laboratory at 07.00 being fasted since $10 \mathrm{pm}$ the evening before. After changing into sport gear, a catheter was inserted into the antecubital vein of the left arm. Fifteen minutes after insertion of the catheter baseline blood samples were taken followed by a baseline muscle biopsy. Approximately 10 minutes after the baseline biopsy a protein beverage containing 10 gram of casein dissolved in $350 \mathrm{ml}$ water was consumed $(\mathrm{t}=-05$ min). Within five minutes after consumption of the protein beverage, the subjects started with 90 minutes cycling $(\mathrm{t}=0 \mathrm{~min})$ at submaximal intensity $\left(70 \% \mathrm{VO}_{2 \max }\right)$. If subjects could not sustain the intensity of at least $60 \mathrm{RPM}$, resistance was decreased with $20 \mathrm{~W}$, and the same intensity protocol was repeated during the second training. All subjects performed same exercise intensity of both experimental days. Immediately after the endurance exercise bout, a beverage containing 15 gram of casein dissolved in $350 \mathrm{ml}$ water was consumed $(\mathrm{t}=90 \mathrm{~min})$. A second blood sample $(\sim 25 \mathrm{ml})$ was taken 1 hour after the end of the endurance exercise bout $(t=240 \mathrm{~min})$. Two hours after the endurance exercise bout $(\mathrm{t}=300 \mathrm{~min})$ subjects were randomly provided with either a carbohydrate rich low-fat meal or low-carbohydrate fat meal (see intervention meal for details). Ninety minutes after the meal $(t=390 \mathrm{~min}) \mathrm{a}$ third blood sample $(\sim 25 \mathrm{ml})$ was taken. At $\mathrm{t}=390 \mathrm{~min}$ subjects performed the resistance exercise bout that consisted of $5 \times 8$ (80\% 1RM) repetitions of bilateral leg press and leg extension with two minutes of rest in between the sets. If subjects could not sustain due to fatigue, the selected weight was decreased with steps of $10 \mathrm{~kg}$ or $5 \mathrm{~kg}$ for the leg press and leg extension, respectively. Immediately after the resistance exercise bout ( $=420 \mathrm{~min})$, a protein beverage containing 25 gram of whey protein dissolved in $350 \mathrm{ml}$ water was consumed. One and three hours after the resistance exercise bout a second 
$(\mathrm{t}=480 \mathrm{~min})$ and a third $(\mathrm{t}=600 \mathrm{~min})$ skeletal muscle biopsy was taken. All biopsies were taken from the same leg. Additional blood samples were taken at $\mathrm{t}=480,540$ and $600 \mathrm{~min}$. A timeline for the experimental day can be found in figure 1 . The whole experimental protocol was repeated on the $2^{\text {nd }}$ day, while the other meal was provided.

\section{Nutritional intervention meal}

Both meals were prepared by a research dietician of Wageningen University. Both the carbohydrate and fat meal consisted of commercially available meat, macaroni and vegetables with an energetic value of $\sim 3200 \mathrm{~kJ}$. The absolute macronutrient amounts can be found in table 2 .

Table 2. Overview of the energy and macronutrient composition intervention meal.

$\begin{array}{lll}\text { Energy \& Nutrient } & \text { Fat meal } & \text { Carbohydrate meal } \\ \text { Energy }(\mathrm{kJ}) & 3207 & 3124 \\ \text { Protein }(\mathrm{g}) & 52 & 52 \\ \text { Fat }(\mathrm{g}) & 51 & 9 \\ \text { Carbohydrates }(\mathrm{g}) & 20 & 110\end{array}$

\section{Nutritional strategy}

Although the findings on gene expression with exercise and carbohydrate restriction are inconsistent, carbohydrate restriction during and after endurance exercise may upregulate genes involved in mitochondrial biogenesis [23]. Therefore, we decided to provide our subjects $\sim 2 \mathrm{~h}$ postexercise with carbohydrates. The protein supplementation strategy used in our study was mainly based on muscle protein synthetic response findings after exercise. A substantial body of research suggests that post resistance exercise whey protein increases myofibrillar protein synthesis to a higher extend when compared with casein [24]. In contrast, little evidence exist for the optimal type of protein to maximise the mitochondrial protein synthetic response after endurance exercise. We therefore decided to provide our subjects with a slow digestible casein protein before and after the endurance exercise sessions. Our nutritional strategy has been recently proposed by others [25].

\section{Muscle biopsies}

Muscle biopsies were taken as described by Bergstrom [26]. Biopsies were taken under local anaesthesia (2-3 ml of 2\% Xylocaine) using a 5-mm Bergstrom needle modified with suction. All three muscle biopsies per experimental day were taken from the vastus lateralis of the same leg, with separate incisions $(\sim 1-1.5 \mathrm{~cm})$ apart and from distal to proximal direction. Muscle biopsies on the second test day were taken from the contralateral leg. Muscle biopsies were 
immediately frozen (in 5-10 s) in liquid nitrogen and stored at $-80^{\circ} \mathrm{C}$ for subsequent biochemical analysis, after being freed from visible fat, blood and connective tissue.

\section{Muscle glycogen}

Muscle tissue, $\sim 30 \mathrm{mg}$ wet weight, was freeze dried, after which collagen, blood, and non-muscle fibre materials were removed from the muscle fibres under a microscope. The isolated muscle fibre mass $(\sim 5-7 \mathrm{mg})$ was weighed, and $500 \mu \mathrm{L}$ of $1 \mathrm{M} \mathrm{HCl}$ was added. After heating for $3 \mathrm{~h}$ at $100^{\circ} \mathrm{C}$ to hydrolyse the glycogen to glycosyl units and cooling down to room temperature, $500 \mu \mathrm{L}$ of the solution was neutralized by adding $280 \mu \mathrm{L}$ of Tris-KOH (Tris $119 \mathrm{mM}$, $\mathrm{KOH} 2.14 \mathrm{M}$ ) and centrifuged at $1000 \mathrm{~g}$ and $4^{\circ} \mathrm{C}$ for $10 \mathrm{~min}$. Thereafter, $150 \mu \mathrm{L}$ of this solution was analysed for glucose concentration (Glucose HK CP A11A01667, ABX Pentra) with a COBAS FARA semiautomatic analyser (Roche).

\section{Blood samples and analyses}

All blood samples were immediately centrifuged at $1000 \mathrm{~g}$ at $4^{\circ} \mathrm{C}$ for 10 minutes, after which plasma was stored in $-80^{\circ} \mathrm{C}$ until further analysis. Blood samples were analysed for cortisol, creatine kinase, glucose and insulin (Gelderse Vallei hospital, Ede, NL). Cortisol was measured with immunometric chemilumiescence (sandwich) assay with Immulite XPi, (Siemens, the Netherlands). Creatine kinase was measured using Vista device (Siemens, the Netherlands). Free fatty acids were assessed using an enzymatic test kit according to the manufacturer's protocol (InstruChemie, Delfzijl, the Netherlands). Glucose was measured using absorption changes caused by the formation of NADH as a measure of glucose concentration and was measured bichromatic (340 and $383 \mathrm{~nm}$ ) by means of an end point technique (Siemens, the Netherlands). Insulin was measured using an solid-phase enzyme-linked chemilumiescent immunometric assay with Immulite 2000 XPi (Siemens, the Netherlands).

\section{RNA extraction and real-time quantitative PCR}

For RNA isolation, muscle samples $(27.8 \pm 13.5 \mathrm{mg})$ were homogenized using an Ultra Turrax (Qiagen, Venlo, Netherlands, cat no: 9001272) and TRIzolbased kit according to manufacturer's guidelines (Fisher Thermo Scientific, Amsterdam, the Netherlands, cat no: 15596026,). After homogenisation in TRIzol, RNA isolation was performed using an RNeasy micro-kit according to the manufacturer's guidelines (Qiagen, Venlo, the Netherlands, cat no: 74004). Briefly, chloroform was added to homogenized samples before centrifuging for 15 minutes at $10.000 \mathrm{rpm}$. Afterwards the aqueous phase was transferred to the RNeasy micro column and was washed for several times to isolate all RNA. Yield was quantified with a NanoDrop ND 1000 spectrophotometer (Nanodrop Technologies, Wilmington, United States of America), and integrity 
was measured with an Agilent 2100 Bioanalyzer with RNA 6000 Nano chips (Agilent Technologies, South Queensferry, United Kingdom).

\section{cDNA synthesis and real-time quantitative polymerase chain reaction}

RNA from all samples was reversely transcribed to cDNA using a Fermentas cDNA synthesis kit according to the manufacturer's protocol (Fischer Thermo Scientific, Amsterdam, the Netherlands, cat no: K1612). Briefly, 500 ng of isolated RNA was diluted in $10 \mu \mathrm{l}$ of RNase-free water and afterwards a mix for cDNA synthesis was added. When cDNA was formed, quantitative real-time polymerase chain reaction (qPCR) was conducted using SYBR Green on a BioRad CFX384 machine (Bio-Rad Laboratories BV, Veenendaal, the Netherlands). SensiMix (Bioline, London, United Kingdom) was used to carry out the PCR reaction. Primers for all genes, obtained from the Harvard PrimerBank [27], are shown in table 3. Samples were run in duplicate, and all samples from each subject were run on the same plate to allow direct relative comparisons. Relative changes in mRNA expression for the genes of interest were quantified using the relative standard curve method [28]. qPCR data were normalized using GAPDH as housekeeping gene for the human samples, since it has shown to be stable within skeletal muscle during exercise [29], and was stable between the time points (data not shown). The threshold cycle (Ct) values of the target gene were normalized to Ct values of the internal control GAPDH, and final results were calculated as relative expression against the standard curve as described previously [30]. Statistical analysis for all mRNA data was performed on the delta Ct values. The baseline muscle biopsy was given a value of 1 , and fold changes at $1 \mathrm{~h}$ post RE and $3 \mathrm{~h}$ post RE were calculated for figure presentation. 
Table 3. Primers used for qPCR.

\begin{tabular}{|c|c|c|c|}
\hline Gene & Forward primer & Reverse primer & Amplicon size \\
\hline HBEGF & ATCGTGGGGCTTCTCATGTTT & TTAGTCATGCCCAACTTCACTTT & 86 \\
\hline FOXO3A & CGGACAAACGGCTCACTCT & GGACCCGCATGAATCGACTAT & 150 \\
\hline IGF-1 & GCTCTTCAGTTCGTGTGTGGA & GCCTCCTTAGATCACAGCTCC & 133 \\
\hline INSIG-1 & CCTGGCATCATCGCCTGTT & AGAGTGACATTCCTCTGGATCTG & 103 \\
\hline MAFbx & GCCTTTGTGCCTACAACTGAA & CTGCCCTTTGTCTGACAGAAT & 187 \\
\hline MURF1 & CTTCCAGGCTGCAAATCCCTA & ACACTCCGTGACGATCCATGA & 116 \\
\hline Myostatin & TCCTCAGTAAACTTCGTCTGGA & CTGCTGTCATCCCTCTGGA & 127 \\
\hline PDK4 & GGAGCATTTCTCGCGCTACA & ACAGGCAATTCTTGTCGCAAA & 117 \\
\hline PGC-1 $\alpha$ & TCTGAGTCTGTATGGAGTGACAT & CCAAGTCGTTCACATCTAGTTCA & 112 \\
\hline SIRT1 & TAGCCTTGTCAGATAAGGAAGGA & ACAGCTTCACAGTCAACTTTGT & 160 \\
\hline VCP & CAAACAGAAGAACCGTCCCAA & TCACCTCGGAACAACTGCAAT & 114 \\
\hline
\end{tabular}

\section{Statistics}

Data was analysed using a two-way repeated measures ANOVA (two factor, time $\mathrm{x}$ treatment) from IBM SPSS version 23 statistical software (IBM, Armonk, $\mathrm{NY}$ ). When a main effect of condition or time or interaction was identified, a pairwise multiple comparison with a Bonferroni correction was done to identify differences. Statistical significance was set at the $\mathrm{P}<0.05$ level, and values were expressed as means \pm SEM or different when indicated. 


\section{Results}

\section{Endurance and resistance exercise performance}

Two subjects performed the endurance exercise sessions with a reduced workload. For one subject the workload was reduced with $20 \mathrm{~W}$ after 20 minutes whereas for the other subject the workload was reduced with $20 \mathrm{~W}$ after 30 minutes. There was no further reduction in workload during the remaining part of the endurance session. Additionally, both subjects were able to repeat this on the second experimental day. All thirteen subjects performed the resistance exercise training with exactly the same amount of work on the two experimental days.

\section{Muscle glycogen}

There were no differences in baseline muscle glycogen between the conditions (CHO $380 \mathrm{mmol} / \mathrm{kg}$ dry weight $(\mathrm{dw})$ versus FAT $441 \mathrm{mmol} / \mathrm{kg} \mathrm{dw} P>0.05$ Figure 2). As a result of exercise, muscle glycogen was significantly reduced compared to baseline in both conditions at $1 \mathrm{~h}$ and $3 \mathrm{~h}$ post-resistance exercise $(P<0.05)$ (carbohydrate 163 and $181 \mathrm{mmol} / \mathrm{kg} \mathrm{dw}$; fat 185 and $140 \mathrm{mmol} / \mathrm{kg}$ $\mathrm{dw})$, without any significant differences between the conditions $(P>0.05)$.

\section{Figure 2.}

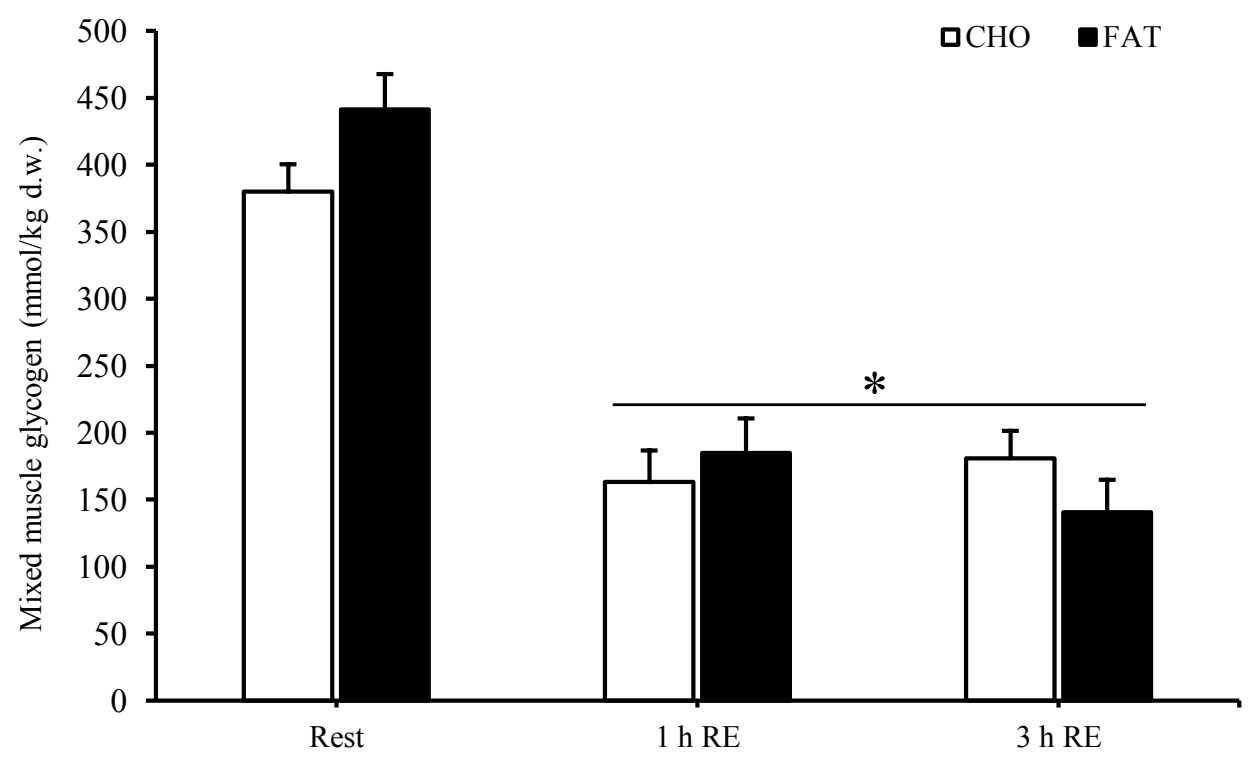

Figure 2. Mixed muscle glycogen at rest and $1 \mathrm{~h}$ and $3 \mathrm{~h}$ after 5 sets of 8 repetitions for both leg press and leg extensions at $80 \% 1 \mathrm{RM}$. Values are mean \pm SEM. * Significantly different $(P<$ 0.05 ) versus baseline. $\mathrm{CHO}=$ open bars, $\mathrm{FAT}=$ filled bars. 
Free fatty acids, glucose and insulin

One hour post meal, plasma free fatty acid concentration was higher in the FAT condition compared with the $\mathrm{CHO}$ condition and this effect remained significant after 1 and 2 hours post-resistance exercise $(P<0.05)$ (Figure 3). Both glucose and insulin in the FAT condition were significantly lower at $1 \mathrm{~h}$ post meal, and at 1, 2 and $3 \mathrm{~h}$ post-resistance exercise compared with the $\mathrm{CHO}$ condition $(P<0.05)$ (Figure 3$)$.

\section{Figure 3.}
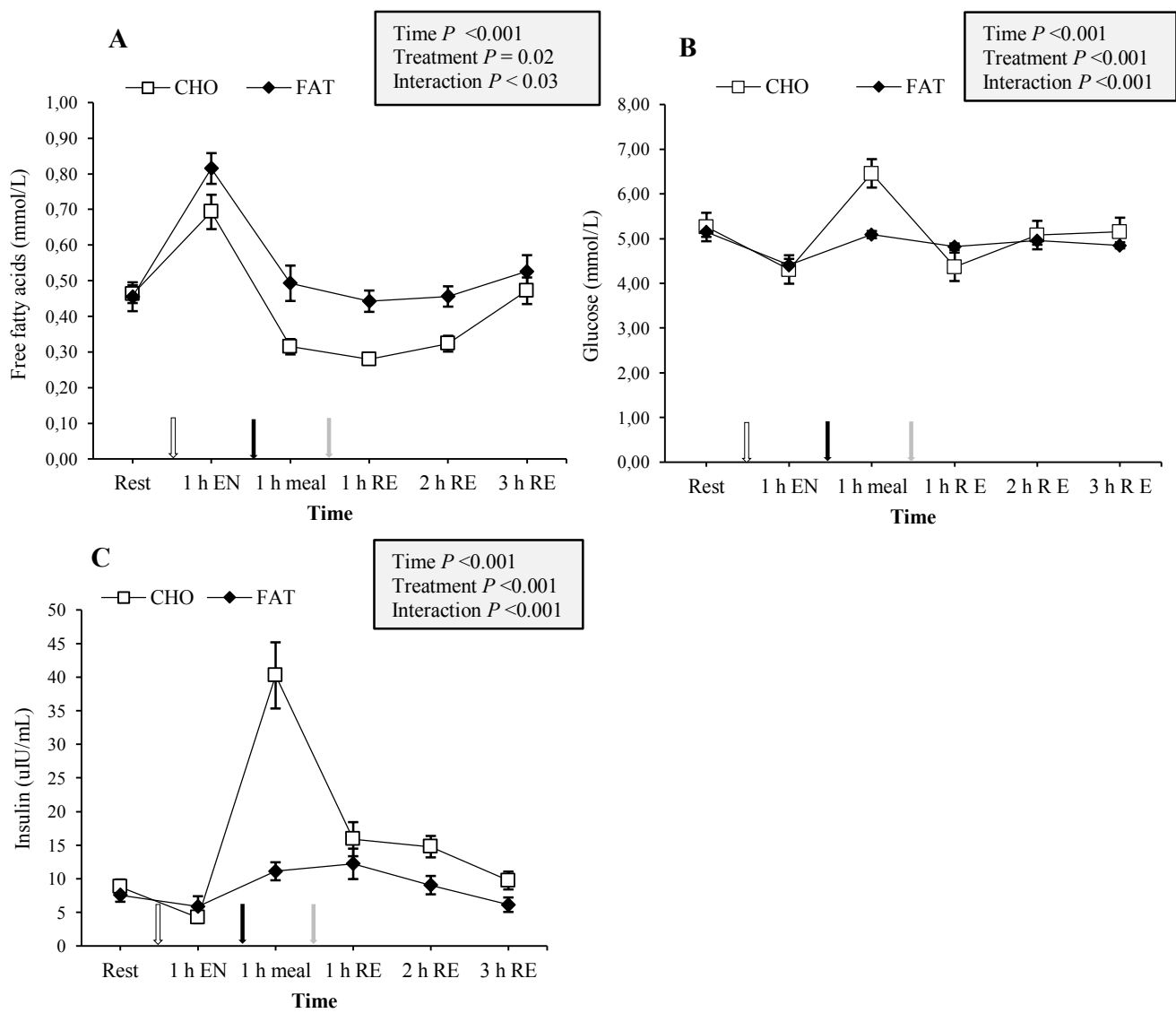

Figure 3. Plasma free fatty acids (A), glucose (B) and insulin (C) at rest and 1 hour after 90-min cycling 70\% $\mathrm{VO}_{2 \max }(1 \mathrm{~h} \mathrm{EN}), 1$ hour post meal $(1 \mathrm{~h} \mathrm{meal})$ and $1 \mathrm{~h}, 2 \mathrm{~h}$, and $3 \mathrm{~h}$ after 5 sets of 8 repetitions for both leg press and leg extensions at 80\% 1RM (1,2 and $3 \mathrm{~h}$ RE) Values are mean \pm SEM. White arrow: endurance exercise session; black arrow: nutritional intervention meal; grey arrow: resistance exercise session. 


\section{Cortisol and creatine kinase}

Changes in both plasma creatine kinase and cortisol did not show any difference between the $\mathrm{CHO}$ and FAT condition (Figure 4). Compared with baseline and $1 \mathrm{~h}$ post endurance exercise cortisol plasma levels were lower at all other time points during the day $(P<0.05)$. Plasma creatine kinase levels were higher at all-time points compared with baseline with no differences between the $\mathrm{CHO}$ and FAT condition.
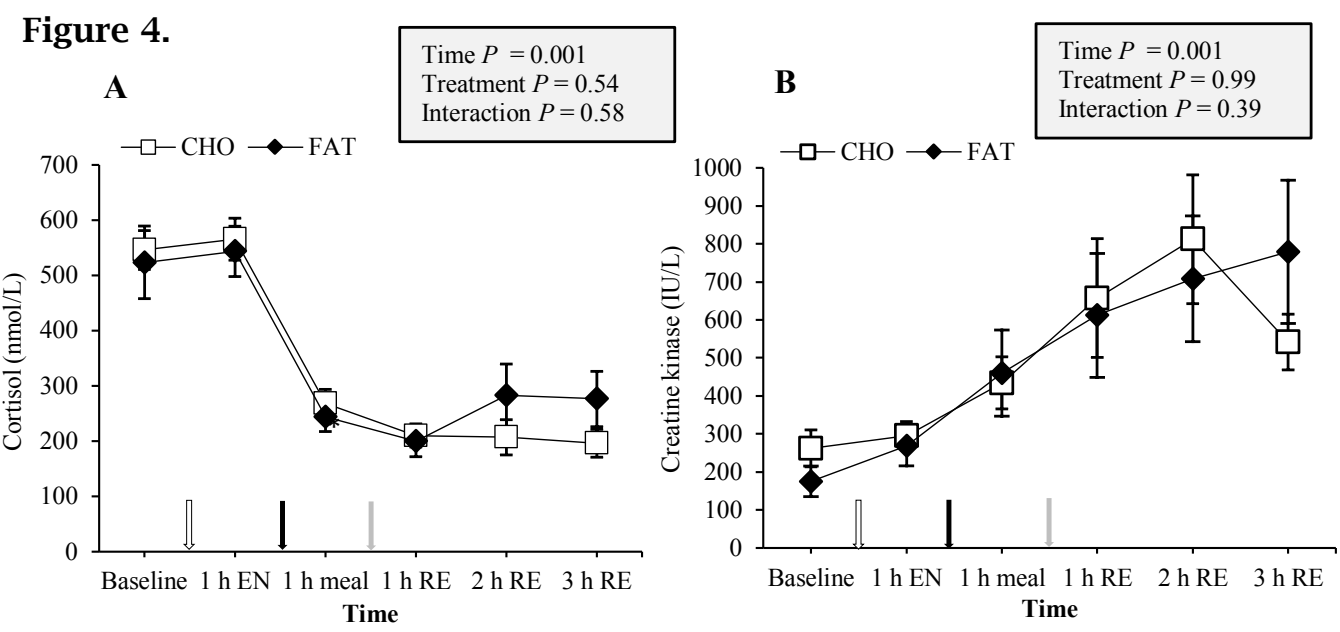

Figure 4. Plasma cortisol (A) and creatine kinase (B) at rest and 1 hour after 90-min cycling $70 \% \mathrm{VO}_{2 \max }(1 \mathrm{~h} \mathrm{EN}), 1$ hour post meal $(1 \mathrm{~h} \mathrm{meal})$ and $1 \mathrm{~h}, 2 \mathrm{~h}$, and $3 \mathrm{~h}$ after 5 sets of 8 repetitions for both leg press and leg extensions at $80 \% 1 \mathrm{RM}(1,2$ and $3 \mathrm{~h}$ RE) Values are mean \pm SEM. White arrow: endurance exercise session; black arrow: nutritional intervention meal; grey arrow: resistance exercise session.

\section{Skeletal muscle gene expression}

\section{Substrate metabolism}

There was a significant increase in HBEGF mRNA quantity at 1 and 3 hours post resistance exercise compared to baseline $(P<0.05)$, while no differences were observed between the treatments (Figure 5a). PDK4 mRNA was increased $1 \mathrm{~h}$ post resistance exercise $(P<0.05)$ in both conditions and significantly reduced at $3 \mathrm{~h}$ post resistance exercise (Figure 5c). Additionally, at $3 \mathrm{~h}$ post resistance PDK4 mRNA was higher in the FAT condition when compared with CHO $(P<0.05)$. The expression of INSIG1 increased at $1 \mathrm{~h}$ post resistance exercise in the FAT group, whereas the levels in the CHO group increased $3 \mathrm{~h}$ post resistance exercise compared to baseline (Figure $5 \mathbf{b}$ ). 
Figure 5.
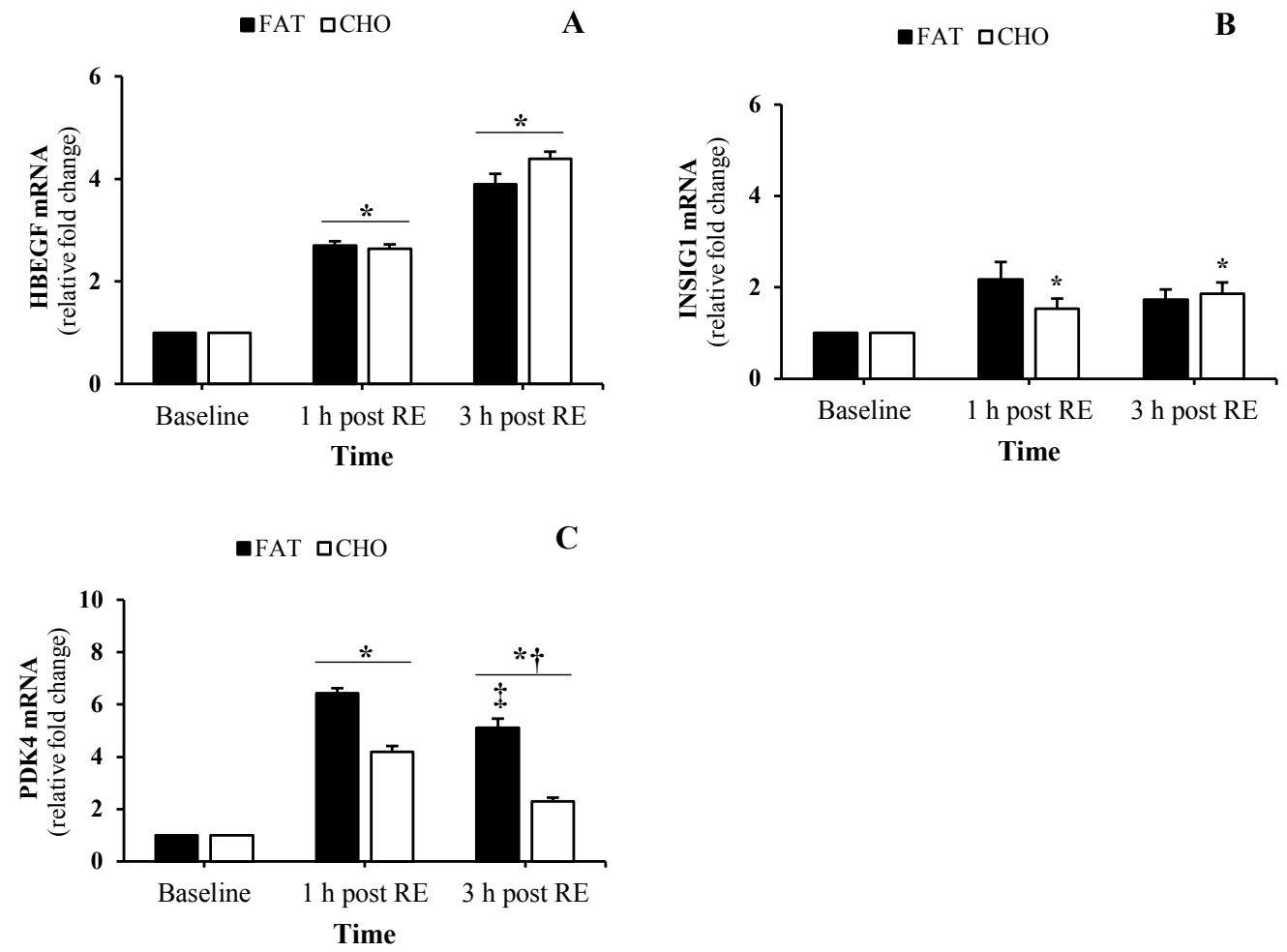

Figure 5. (substrate metabolism) HBEGF (A), INSIG1 (B) and PDK4 (C) mRNA quantity levels at rest and $1 \mathrm{~h}$ and $3 \mathrm{~h}$ post RE. Values are mean \pm SEM. *Significantly different $(P<0.05)$ versus baseline. $\dagger$ Significantly different $(P<0.05)$ compared to previous time point. $\ddagger$ Significant interaction $(P<0.05)$. CHO $=$ open bars, FAT $=$ filled bars.

\section{Proteolytic genes}

FOXO3A mRNA quantity did not change over the course of the day (Figure 6a). There was a reduction in both the CHO and FAT condition in MAFbx mRNA response at $3 \mathrm{~h}$ post-resistance resistance $(P<0.05)$ compared to baseline, however, no differences were found between the CHO and FAT condition at any time point (Figure 6b). MURF1 mRNA quantity increased in both conditions $1 \mathrm{~h}$ and $3 \mathrm{~h}$ post resistance exercise $(P<0.05)$ compared to baseline (Figure 6c). In addition MURF1 mRNA quantity decreased at $3 \mathrm{~h}$ post-resistance exercise when compared with $1 \mathrm{~h}$ post-resistance exercise $(P<0.05)$. No differences in MURF1 mRNA quantity was found between the FAT and CHO condition during the experimental days. VCP mRNA quantity was slightly higher at $3 \mathrm{~h}$ post resistance exercise in the FAT group $(P<0.05)$ (Figure $6 \mathrm{~d}$ ). 
Figure 6.

- FAT 口CHO

A

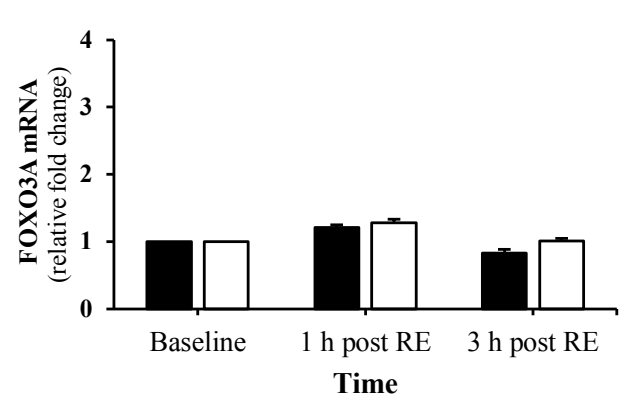

-FAT 口CHO

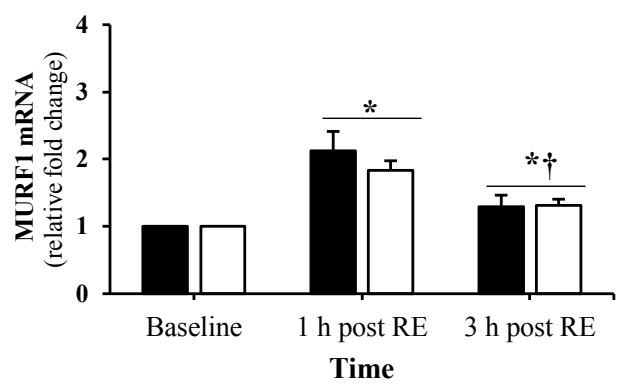

-FAT 口CHO

B

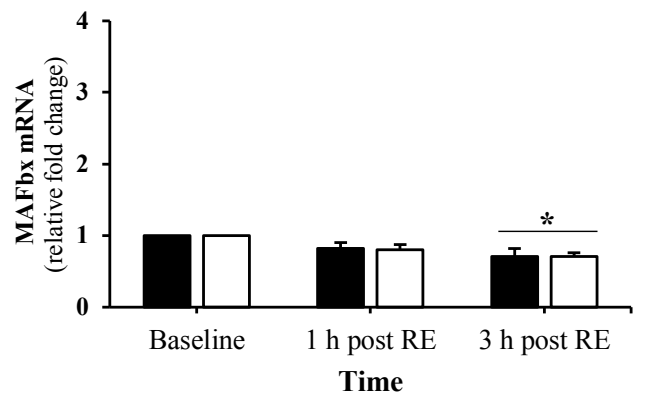

D

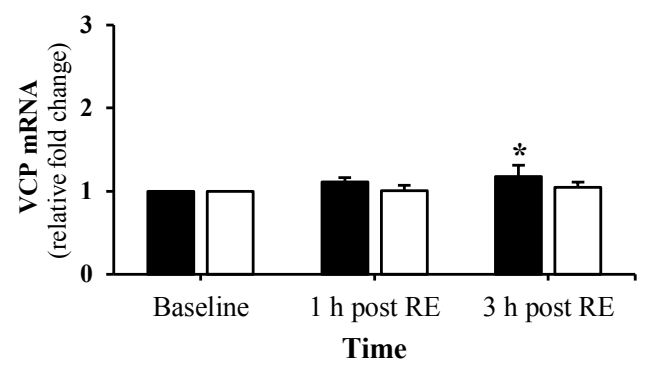

Figure 6. (protein degradation) FOXO3A (A), MAFbx (B), MURF1 (C), VCP (D) mRNA quantity levels at rest and $1 \mathrm{~h}$ and $3 \mathrm{~h}$ post RE. Values are mean \pm SEM. *Significantly different $(P<0.05)$ versus baseline. $\dagger$ Significantly different $(P<0.05)$ compared to previous time point. $\ddagger$ Significant interaction $(P<0.05) . \mathrm{CHO}=$ open bars, FAT $=$ filled bars.

\section{Mitochondrial biogenesis}

There was no effect of exercise nor nutrition on PGC- $1 \alpha$ mRNA quantity (Figure 7a). In contrast, SIRT1 mRNA levels increased at $1 \mathrm{~h}$ and $3 \mathrm{~h}$ post resistance exercise compared with baseline, no differences were found between the $\mathrm{CHO}$ and FAT condition in SIRT1 mRNA quantity (Figure 7b). 


\section{Figure 7.}

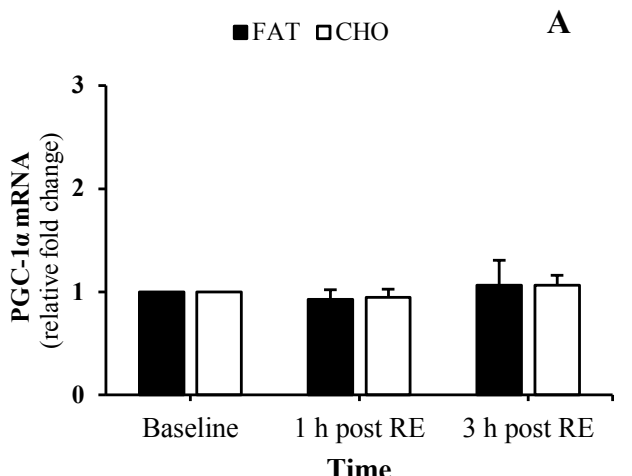

Time

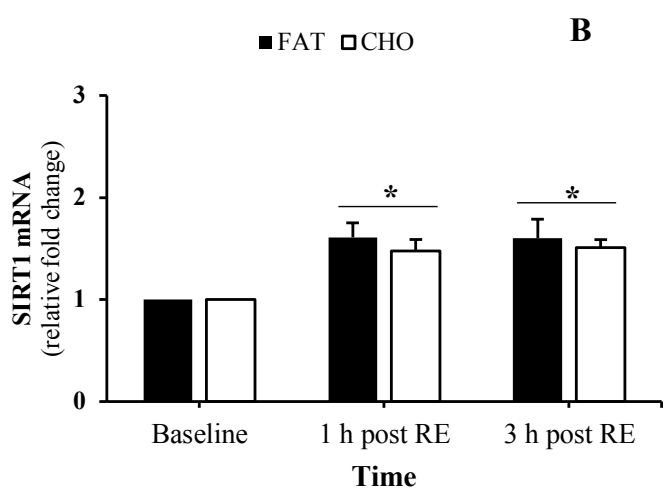

Figure 7. (mitochondrial biogenesis) PGC-1a (A) and SIRT1 (B) mRNA quantity levels at rest and $1 \mathrm{~h}$ and $3 \mathrm{~h}$ post RE. Values are mean \pm SEM. *Significantly different $(P<0.05)$ versus baseline. $\dagger$ Significantly different $(P<0.05)$ compared to previous time point. $¥$ Significant interaction $(P<0.05)$. CHO $=$ open bars, FAT $=$ filled bars.

\section{IFG-1 and myostatin}

IGF-1 mRNA expression levels remained unchanged over the course of the day (Figure 8a). Myostatin mRNA decreased at $1 \mathrm{~h}$ and $3 \mathrm{~h}$ post resistance compared with baseline $(P<0.05)$ without any differences between the nutritional conditions (Figure 8b).

\section{Figure 8.}

A

- FAT 口CHO

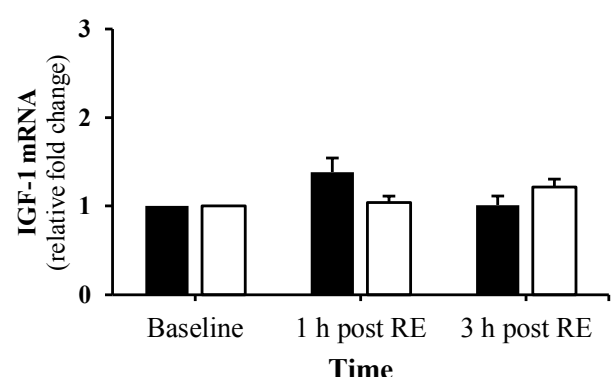

B

- FAT 口CHO

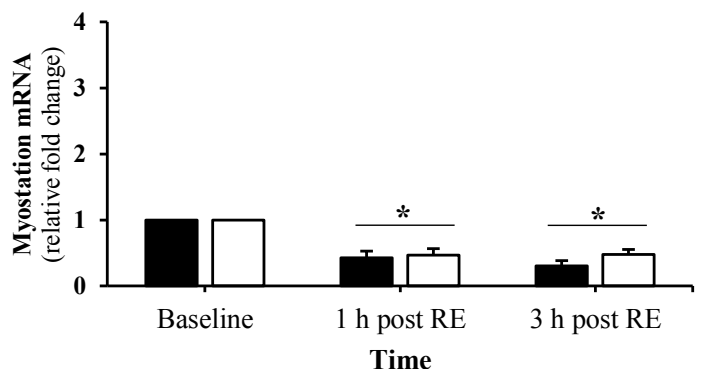

Figure 8. IGF-1 (A) and myostatin (B) mRNA quantity levels at rest and $1 \mathrm{~h}$ and $3 \mathrm{~h}$ post RE. Values are mean \pm SEM. *Significantly different $(P<0.05)$ versus baseline. † Significantly different $(P<0.05)$ compared to previous time point. $¥$ Significant interaction $(P<0.05)$. CHO $=$ open bars, $\mathrm{FAT}=$ filled bars. 


\section{Discussion}

The gene expression profiles we investigated post-resistance exercise are of interest as they may play a role in mitochondrial biogenesis, protein degradation and substrate metabolism. When compared with the CHO-rich meal condition, we observed an increase in PDK4 mRNA quantity suggesting that pre-exercise FAT meal in combination with the glycogen depletion potentially induced a shift in fuel selection from carbohydrate to fat in the post-resistance exercise period. However, we observed that the genes with a proposed role in muscle adaptation, responded as a result of exercise without any differences between the CHO and FAT condition. Therefore, we suggest that the acute post-resistance exercise response of genes involved in muscle remodelling is not affected by a pre-resistance exercise mixed meal containing different amounts of carbohydrates and fat.

Since athletes commonly combine divergent exercise sessions on the same day, we decided to include both endurance and resistance exercise on the same day in our protocol. Additionally, it has been recently proposed that, when combining divergent exercise sessions within the same day, the endurance session should be performed in the morning in the fasted state, with ample protein ingestion, while the afternoon resistance exercise session should be conducted only after carbohydrate replenishment with adequate postresistance exercise protein ingestion [25]. With our study we aimed to evaluate the effect of a pre-resistance exercise isocaloric $(\sim 3200 \mathrm{~kJ})$ mixed meal containing different amounts of carbohydrates and fat, on post-resistance exercise gene expression after glycogen depleting exercise earlier that day.

\section{Skeletal muscle glycogen}

Our subjects performed an endurance exercise bout (90 minutes at $~ 70 \% \mathrm{VO}_{2 \max }$ ) in the morning. It is generally assumed that full skeletal muscle glycogen stores are sufficient to fuel endurance type activities for approximately 60-90 minutes [10]. Therefore, it can be assumed that the endurance exercise resulted in a significant reduction of the skeletal muscle glycogen levels postendurance exercise. Two hours after the endurance exercise bout subjects were fed with either the CHO or FAT meal. Maehlum and Hermansen (1978) showed that omitting carbohydrates in the acute post-exercise period is accompanied with a skeletal muscle glycogen synthesis rate of only $1-2 \mathrm{mmol} / \mathrm{kg}$ wet weight (w.w.) of muscle/h through gluconeogenesis [31]. In contrast, when large amounts ( 100 g of carbohydrates per hour) of carbohydrates are ingested in the post-exercise period the rate of liver and muscle glycogen synthesis can be up to $5-10 \mathrm{mmol} / \mathrm{kg} \mathrm{w} . \mathrm{w} . / \mathrm{h}$ [32]. This increased rate of synthesis is primarily explained by insulin-mediated activation of glycogen synthase [33], exercise induced increase in insulin sensitivity [34] and enhanced muscle cell membrane permeability to glucose [35]. With our approach, both at 1 and $3 \mathrm{~h}$ 
post-resistance exercise, skeletal muscle glycogen stores were reduced compared with baseline. Although the amount of carbohydrates in the CHO condition $\left(\sim 1.44 \mathrm{~g} \cdot \mathrm{kg}^{-1}\right.$ carbohydrates) meets the recommendation to facilitate post-exercise muscle glycogen resynthesis [36], no differences in muscle glycogen were observed in the post-resistance exercise period when compared with the FAT condition ( $0.26 \mathrm{~g} \cdot \mathrm{kg}^{-1}$ carbohydrates). Since we have no data on the muscle glycogen levels prior to the resistance exercise bout, it remains elusive to what extent the meals affected the muscle glycogen stores. It also remains unclear to what extent the resistance exercise bout further reduced muscle glycogen stores. While the mixed meal with different amounts of carbohydrates and fat did not result in differences in skeletal muscle glycogen levels, significant differences in plasma glucose, free fatty acids and insulin were present. Therefore, we are convinced that the mixed meals resulted in a significant physiological difference with regards to macronutrient availability between the conditions.

\section{PDK4 mRNA}

PDK4 phosphorylates pyruvate dehydrogenase enzyme, the first component of the pyruvate dehydrogenase complex that contributes to the conversion of pyruvate into acetyl-CoA altering fuel selection from carbohydrate to fat [37]. Indeed, earlier work showed that PDK4 in human skeletal muscle is dependent on substrate availability rather than exercise-induced cellular perturbations [38, 39]. Likewise, exercise performed with normal skeletal muscle glycogen levels show higher levels of PDK4 mRNA quantity compared with low glycogen levels [39]. Since we observed no differences in post-resistance exercise skeletal muscle glycogen levels between the nutritional conditions, the exogenous provision of carbohydrates ostensibly reduced PDK4 mRNA expression. Interestingly, our finding that exogenous carbohydrate ingestion reduces PDK4 expression is in line with earlier investigations where PDK4 mRNA expression was reduced when exogenous carbohydrate was provided [38] or when skeletal muscle glycogen were normal compared to low [39].

\section{$P G C-1 \alpha m R N A$}

PGC- $1 \alpha$ has been proposed as the master regulator of mitochondrial biogenesis. Furthermore, PGC-1 $\alpha$ exists in different isoforms, which may have different roles in training adaptation. For instance, PGC-1 $\alpha 4$ has been implicated to play a role in the regulation of skeletal muscle hypertrophy [40]. Unexpectedly, PGC- $1 \alpha$ mRNA quantity remained unchanged during the postresistance exercise period. This was somewhat surprising since work by Camera, Hawley and Coffey (2015) recently demonstrated that performing resistance exercise with low skeletal muscle glycogen levels amplifies intramuscular PGC- $1 \alpha$ mRNA quantity when compared with normal glycogen 
levels [12]. Notably, the time course of the muscle biopsies differed between the studies. Camera et al., (2015) took muscle biopsies $2 \mathrm{~h}$ and $4 \mathrm{~h}$ post resistance exercise and found enhanced expression of PGC- $1 \alpha$ at the $4 \mathrm{~h}$ time point. We took biopsies $1 \mathrm{~h}$ and $3 \mathrm{~h}$ post resistance exercise and may therefore overlooked a potential effect of the intervention PGC- $1 \alpha$ mRNA quantity. Furthermore, our subjects were provided we a mixed meal in the pre-resistance exercise period which makes is difficult to compare the divergent findings of the studies. Lastly, it has been reported that BCAA provision attenuates the resistance exercise induced elevation of PGC-1 $\alpha 4$ mRNA, though, no effect of BCAA was found on PGC-1 1 1 and 2 mRNA [41]. Nevertheless, it may thus be possible that the post-exercise protein ingestion attenuated the PGC-1 $\alpha$ mRNA response.

\section{Gene expression of proteolytic genes}

We also analysed a set of genes with a proposed role in protein degradation (FOXO3A, MAFbx, MURF1, Myostatin and VCP). Myostatin mRNA quantity decreased post-resistance exercise, which is in accordance with findings of others [42]. Muscle catabolism is a fundamental process of muscle remodelling ensuring that damaged proteins or misfolded proteins during exercise are adequately removed from the cell [43]. As expected, mRNA involved in both ubiquitin proteasome and autophagy-mediated protein degradation systems responded as a result of exercise, however without any effect of the preresistance exercise mixed meal. We found a higher plasma insulin response in the carbohydrate group. According to Abdulla et al., (2016) insulin reduces protein degradation rates thereby facilitating an overall net protein balance [44]. Mechanistically, insulin activates the PI3K-Akt pathway by binding to its transmembrane insulin receptor on the sarcolemma and initiates translocation of the proteins to the cell membrane [45]. Earlier work in animals [46] and C2C12 cell lines $[47,48]$ demonstrated that Akt inhibits the expression of FOXO3A mRNA, a transcription factor implicated with gene expression with the ubiquitin proteasome pathway. In our study, the mixed meal with the higher amount of carbohydrates resulted in higher insulin response postresistance exercise, however, this effect did not translate into a difference in FOXO3A mRNA response between the $\mathrm{CHO}$ and FAT condition. The latter could be explained by the theory that the insulin mediated reduction in protein breakdown is more potent when amino acid availability is scarce [44, 49, 50]. This was not the case in our study since our subjects were provided with adequate protein ingestion post-resistance exercise [24]. Other reports confirm that when adequate protein is provided post-resistance exercise, the insulinogenic response seems to be redundant [24, 51]. 


\section{Conclusion}

In summary, resistance exercise with different carbohydrate/fat availability but ample protein provision did in general not influence intramuscular gene expression. Post-resistance exercise PDK4 mRNA quantity was higher in the CHO condition compared with the FAT condition suggesting a potential shift towards glucose oxidation. Furthermore, it appears that carbohydrate replenishment in between endurance and resistance exercise did not influence gene expression involved in the adaptive response after a subsequent bout of resistance exercise. Our findings support the view that pre-resistance exercise carbohydrate availability does not affect acute transcriptional responses associated with muscle recovery to resistance exercise. 


\section{References}

1. Coffey VG, Jemiolo B, Edge J, Garnham AP, Trappe SW, Hawley JA: Effect of consecutive repeated sprint and resistance exercise bouts on acute adaptive responses in human skeletal muscle. Am J Physiol Regul Integr Comp Physiol 2009, 297:R1441-1451.

2. Fluck M, Dapp C, Schmutz S, Wit E, Hoppeler H: Transcriptional profiling of tissue plasticity: role of shifts in gene expression and technical limitations. J Appl Physiol (1985) 2005, 99:397-413.

3. Pilegaard H, Ordway GA, Saltin B, Neufer PD: Transcriptional regulation of gene expression in human skeletal muscle during recovery from exercise. Am J Physiol Endocrinol Metab 2000, 279:E806-814.

4. Mahoney DJ, Parise G, Melov S, Safdar A, Tarnopolsky MA: Analysis of global mRNA expression in human skeletal muscle during recovery from endurance exercise. Faseb j 2005, 19:1498-1500.

5. Bickel CS, Slade J, Mahoney E, Haddad F, Dudley GA, Adams GR: Time course of molecular responses of human skeletal muscle to acute bouts of resistance exercise. $J$ Appl Physiol (1985) 2005, 98:482-488.

6. Yang Y, Creer A, Jemiolo B, Trappe S: Time course of myogenic and metabolic gene expression in response to acute exercise in human skeletal muscle. $J$ Appl Physiol (1985) 2005, 98:1745-1752.

7. Louis E, Raue U, Yang Y, Jemiolo B, Trappe S: Time course of proteolytic, cytokine, and myostatin gene expression after acute exercise in human skeletal muscle. J Appl Physiol (1985) 2007, 103:1744-1751.

8. Glass DJ: Skeletal muscle hypertrophy and atrophy signaling pathways. Int J Biochem Cell Biol 2005, 37:1974-1984.

9. Baar K: Nutrition and the adaptation to endurance training. Sports Med 2014, 44 Suppl 1:S5-12.

10. Bartlett JD, Hawley JA, Morton JP: Carbohydrate availability and exercise training adaptation: Too much of a good thing? Eur J Sport Sci 2015, 15:3-12.

11. Impey SG, Hammond KM, Shepherd SO, Sharples AP, Stewart C, Limb M, Smith K, Philp A, Jeromson S, Hamilton DL, et al: Fuel for the work required: a practical approach to amalgamating train-low paradigms for endurance athletes. Physiol Rep 2016, 4.

12. Camera DM, Hawley JA, Coffey VG: Resistance exercise with low glycogen increases p53 phosphorylation and PGC-1alpha mRNA in skeletal muscle. Eur J Appl Physiol 2015.

13. West DW, Burd NA, Coffey VG, Baker SK, Burke LM, Hawley JA, Moore DR, Stellingwerff T, Phillips SM: Rapid aminoacidemia enhances myofibrillar protein synthesis and anabolic intramuscular signaling responses after resistance exercise. Am J Clin Nutr 2011, 94:795-803.

14. Noakes T, Volek JS, Phinney SD: Low-carbohydrate diets for athletes: what evidence? $\mathrm{Br}$ J Sports Med 2014, 48:1077-1078.

15. Volek JS, Noakes T, Phinney SD: Rethinking fat as a fuel for endurance exercise. Eur J Sport Sci 2015, 15:13-20.

16. Burke LM: Re-Examining High-Fat Diets for Sports Performance: Did We Call the 'Nail in the Coffin' Too Soon? Sports Med 2015, 45 Suppl 1:S33-49.

17. Burke LM, Kiens B: "Fat adaptation" for athletic performance: the nail in the coffin? $J$ Appl Physiol (1985) 2006, 100:7-8.

18. Burke LM, Hawley JA: Effects of short-term fat adaptation on metabolism and performance of prolonged exercise. Med Sci Sports Exerc 2002, 34:1492-1498.

19. Cochran AJ, Myslik F, MacInnis MJ, Percival ME, Bishop D, Tarnopolsky MA, Gibala MJ: Manipulating Carbohydrate Availability Between Twice-Daily Sessions of High-intensity 
Interval Training Over Two Weeks Improves Time-trial Performance. Int J Sport Nutr Exerc Metab 2015.

20. Marquet LA, Brisswalter J, Louis J, Tiollier E, Burke LM, Hawley JA, Hausswirth C: Enhanced Endurance Performance by Periodization of Carbohydrate Intake: "Sleep Low" Strategy. Med Sci Sports Exerc 2016, 48:663-672.

21. Hulston CJ, Venables MC, Mann CH, Martin C, Philp A, Baar K, Jeukendrup AE: Training with low muscle glycogen enhances fat metabolism in well-trained cyclists. Med Sci Sports Exerc 2010, 42:2046-2055.

22. Morton JP, Croft L, Bartlett JD, Maclaren DP, Reilly T, Evans L, McArdle A, Drust B: Reduced carbohydrate availability does not modulate training-induced heat shock protein adaptations but does upregulate oxidative enzyme activity in human skeletal muscle. J Appl Physiol (1985) 2009, 106:1513-1521.

23. Margolis LM, Pasiakos SM: Optimizing intramuscular adaptations to aerobic exercise: effects of carbohydrate restriction and protein supplementation on mitochondrial biogenesis. Adv Nutr 2013, 4:657-664.

24. Morton RW, McGlory C, Phillips SM: Nutritional interventions to augment resistance training-induced skeletal muscle hypertrophy. Front Physiol 2015, 6:245.

25. Perez-Schindler J, Hamilton DL, Moore DR, Baar K, Philp A: Nutritional strategies to support concurrent training. Eur J Sport Sci 2015, 15:41-52.

26. Bergstrom J: Percutaneous needle biopsy of skeletal muscle in physiological and clinical research. Scand J Clin Lab Invest 1975, 35:609-616.

27. Spandidos A, Wang X, Wang H, Seed B: PrimerBank: a resource of human and mouse PCR primer pairs for gene expression detection and quantification. Nucleic acids research 2010, 38:D792-D799.

28. Larionov A, Krause A, Miller W: A standard curve based method for relative real time PCR data processing. BMC Bioinformatics 2005, 6:62.

29. Mahoney DJ, Carey K, Fu MH, Snow R, Cameron-Smith D, Parise G, Tarnopolsky MA: Real-time RT-PCR analysis of housekeeping genes in human skeletal muscle following acute exercise. Physiol Genomics 2004, 18:226-231.

30. Holloway TM, Snijders T, van Kranenburg J, van Loon LJ, Verdijk LB: Temporal Response of Angiogenesis and Hypertrophy to Resistance Training in Young Men. Med Sci Sports Exerc 2017.

31. Maehlum S, Hermansen L: Muscle glycogen concentration during recovery after prolonged severe exercise in fasting subjects. Scand J Clin Lab Invest 1978, 38:557-560.

32. Burke LM, van Loon LJC, Hawley JA: Postexercise muscle glycogen resynthesis in humans. J Appl Physiol (1985) 2017, 122:1055-1067.

33. Prats C, Helge JW, Nordby P, Qvortrup K, Ploug T, Dela F, Wojtaszewski JF: Dual regulation of muscle glycogen synthase during exercise by activation and compartmentalization. J Biol Chem 2009, 284:15692-15700.

34. Richter EA, Mikines KJ, Galbo H, Kiens B: Effect of exercise on insulin action in human skeletal muscle. J Appl Physiol (1985) 1989, 66:876-885.

35. Burke LM, van Loon LJ, Hawley JA: Post-exercise muscle glycogen resynthesis in humans. J Appl Physiol (1985) 2016:jap.00860.02016.

36. Moore DR: Nutrition to Support Recovery from Endurance Exercise: Optimal Carbohydrate and Protein Replacement. Curr Sports Med Rep 2015, 14:294-300.

37. Wang L, Sahlin K: The effect of continuous and interval exercise on PGC-1alpha and PDK4 mRNA in type I and type II fibres of human skeletal muscle. Acta Physiol (Oxf) 2012, 204:525-532.

38. Cluberton LJ, McGee SL, Murphy RM, Hargreaves M: Effect of carbohydrate ingestion on exercise-induced alterations in metabolic gene expression. J Appl Physiol (1985) 2005, 99:1359-1363. 
39. Psilander N, Frank P, Flockhart M, Sahlin K: Exercise with low glycogen increases PGC1alpha gene expression in human skeletal muscle. Eur J Appl Physiol 2013, 113:951963.

40. Ruas JL, White JP, Rao RR, Kleiner S, Brannan KT, Harrison BC, Greene NP, Wu J, Estall JL, Irving BA, et al: A PGC-1alpha isoform induced by resistance training regulates skeletal muscle hypertrophy. Cell 2012, 151:1319-1331.

41. Samuelsson H, Moberg M, Apro W, Ekblom B, Blomstrand E: Intake of branched-chain or essential amino acids attenuates the elevation in muscle levels of PGC-1alpha4 mRNA caused by resistance exercise. Am J Physiol Endocrinol Metab 2016, 311:E246251.

42. Camera DM, West DW, Burd NA, Phillips SM, Garnham AP, Hawley JA, Coffey VG: Low muscle glycogen concentration does not suppress the anabolic response to resistance exercise. J Appl Physiol (1985) 2012, 113:206-214.

43. Nader GA, von Walden F, Liu C, Lindvall J, Gutmann L, Pistilli EE, Gordon PM: Resistance exercise training modulates acute gene expression during human skeletal muscle hypertrophy. J Appl Physiol (1985) 2014, 116:693-702.

44. Abdulla H, Smith K, Atherton PJ, Idris I: Role of insulin in the regulation of human skeletal muscle protein synthesis and breakdown: a systematic review and metaanalysis. Diabetologia 2016, 59:44-55.

45. Marcotte GR, West DW, Baar K: The molecular basis for load-induced skeletal muscle hypertrophy. Calcif Tissue Int 2015, 96:196-210.

46. Mikura M, Yamaoka I, Doi M, Kawano Y, Nakayama M, Nakao R, Hirasaka K, Okumura Y, Nikawa T: Glucose infusion suppresses surgery-induced muscle protein breakdown by inhibiting ubiquitin-proteasome pathway in rats. Anesthesiology 2009, 110:81-88.

47. Latres E, Amini AR, Amini AA, Griffiths J, Martin FJ, Wei Y, Lin HC, Yancopoulos GD, Glass DJ: Insulin-like growth factor-1 (IGF-1) inversely regulates atrophy-induced genes via the phosphatidylinositol 3-kinase/Akt/mammalian target of rapamycin (PI3K/Akt/mTOR) pathway. J Biol Chem 2005, 280:2737-2744.

48. Stitt TN, Drujan D, Clarke BA, Panaro F, Timofeyva Y, Kline WO, Gonzalez M, Yancopoulos GD, Glass DJ: The IGF-1/PI3K/Akt pathway prevents expression of muscle atrophy-induced ubiquitin ligases by inhibiting FOXO transcription factors. Mol Cell 2004, 14:395-403.

49. Bird SP, Tarpenning KM, Marino FE: Liquid carbohydrate/essential amino acid ingestion during a short-term bout of resistance exercise suppresses myofibrillar protein degradation. Metabolism 2006, 55:570-577.

50. Bird SP, Tarpenning KM, Marino FE: Independent and combined effects of liquid carbohydrate/essential amino acid ingestion on hormonal and muscular adaptations following resistance training in untrained men. Eur J Appl Physiol 2006, 97:225-238.

51. Staples AW, Burd NA, West DW, Currie KD, Atherton PJ, Moore DR, Rennie MJ, Macdonald MJ, Baker SK, Phillips SM: Carbohydrate does not augment exercise-induced protein accretion versus protein alone. Med Sci Sports Exerc 2011, 43:1154-1161. 


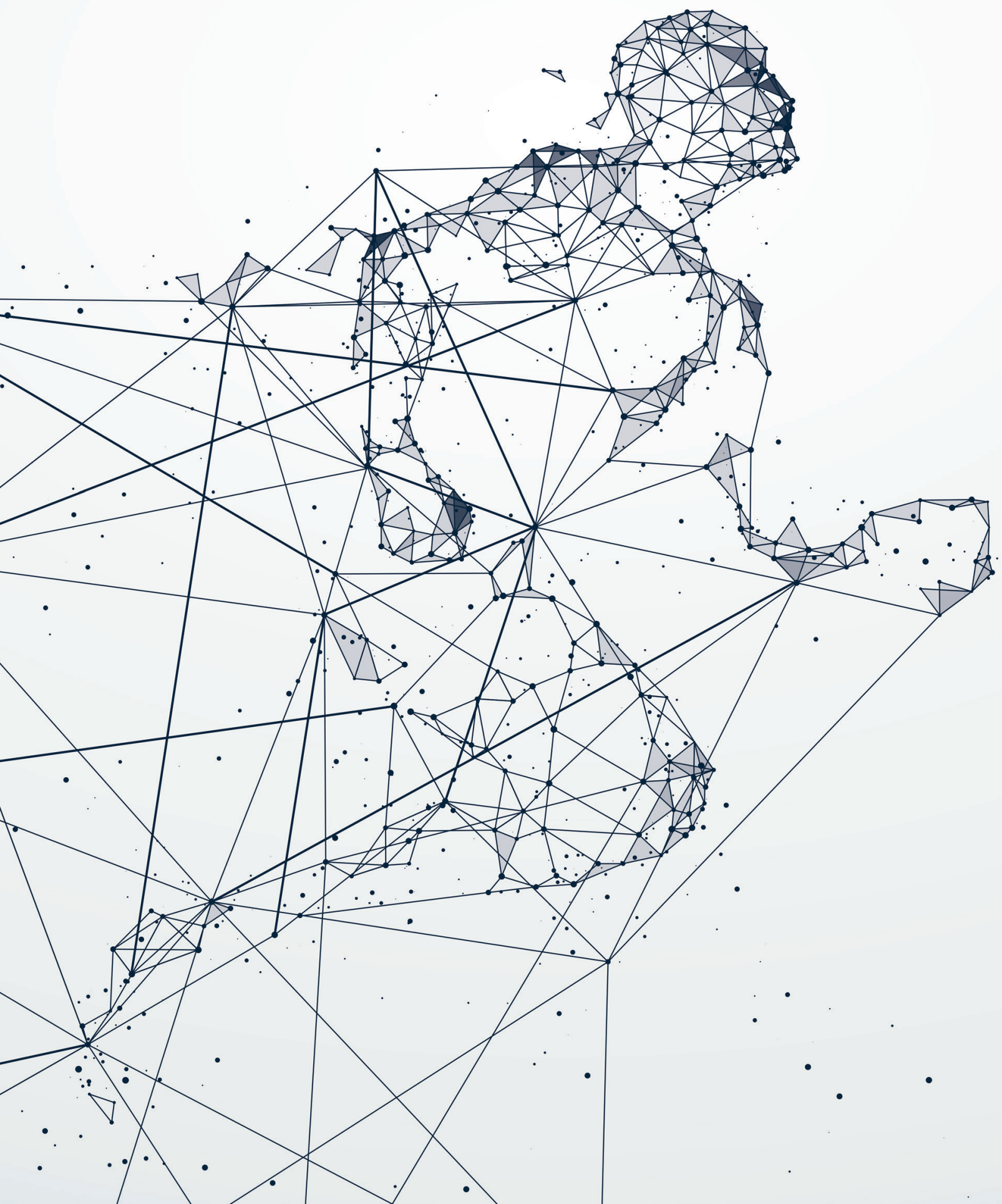




\section{Chapter 4}

Plasma cytokine responses to resistance exercise with different nutrient availability on a concurrent exercise day in trained healthy males

Pim Knuiman

Maria Hopman

Roland Hangelbroek

Marco Mensink 


\begin{abstract}
Carbohydrate availability is proposed as a potential regulator of cytokine responses. We aimed to evaluate the effect of a pre-resistance exercise carbohydrate meal versus fat meal on plasma cytokine responses to resistance exercise after an endurance exercise earlier that day. Thirteen young, healthy, recreationally active males performed two experimental days with endurance exercise in the morning and resistance exercise in the afternoon. Either a carbohydrate (110g carbohydrate, 52g protein, 9g fat; $\sim 750 \mathrm{kcal}$ ) or an isocaloric fat meal (20 gr carbohydrate, $52 \mathrm{~g}$ protein, $51 \mathrm{~g}$ fat) was provided $2 \mathrm{~h}$ before resistance exercise. Blood was taken at baseline and at regular time intervals to measure circulating plasma cytokine levels (e.g. IL-6, IL-8, IL-10, IL15, TNF $\alpha$, ANGPTL4, Decorin and MCP-1). Plasma glucose and insulin were higher in the postprandial period before the start of the resistance exercise on the carbohydrate condition, while free fatty acids were reduced. At $2 \mathrm{~h}$ post resistance exercise, IL-6 concentrations were higher in the fat condition compared to the carbohydrate condition $(P<0.05)$. In addition, in both conditions IL-6 levels were higher at all timepoints compared with baseline ( $P$ $<0.05)$. The pattern of increase in plasma IL-8 and IL-10 did not differ significantly between conditions $(P>0.05)$. There were no differences between conditions on TNF $\alpha$ levels and levels remain constant when compared with baseline $(P>0.05)$. ANGPTL4, IL-15, Decorin and MCP-1 showed no differences between the fat and carbohydrate condition $(P>0.05)$. The composition of the pre-exercise meal did in general not influence cytokine responses in the postresistance exercise period, except post-resistance exercise circulating plasma IL-6 levels being higher in the fat condition compared with carbohydrate. Our findings support the view that pre-resistance exercise carbohydrate availability does not have a major impact on acute responses of circulating plasma cytokines in humans.
\end{abstract}




\section{Introduction}

Cytokines are small proteins produced and released by several cells that play an integrative and regulatory role in local and systemic intercellular communication $(1,2)$. Up to now, many studies have assessed the effect of endurance and resistance exercise on circulating concentrations of cytokines (3). Even though the precise biological function of the majority of the cytokines is presently unclear, exercise-induced elevations of circulating cytokine concentrations such as interleukin 6 (IL-6), 8 (IL-8), 15 (IL-15), Decorin, monocyte chemoattractant protein-1 (MCP-1) and 4 (MCP-4) may play a role in adaptation of skeletal muscle $(1,4,5)$. However, the proposed role of cytokines in skeletal muscle regulation is mainly derived from mechanistic cell and animal studies, as a consequence, data from human studies is highly limited. It is well established that exercise parameters such as mode, intensity, duration and type of exercise largely modulate cytokine response following exercise (3). In addition, nutrition (e.g. carbohydrates) appears to play a role as well in the modulation of circulating cytokines following exercise, particularly IL-6 (1). For instance, circulating IL-6 concentrations decrease with glucose ingestion during endurance exercise $(6,7)$, whereas low pre-exercise muscle glycogen content augments these responses $(8,9)$. Furthermore, work by Nieman et al (2004) demonstrated that carbohydrate ingestion before and during a $2 \mathrm{~h}$ intensive resistance training did not alter circulating plasma levels of IL-1ra, IL-6, IL-8, IL-10 (10). Remarkably, the role of pre-exercise fat intake on plasma cytokines remains to be elucidated.

To our knowledge, not much work has been done on the effects of pre-exercise nutrient availability on circulating cytokine concentrations following resistance exercise in humans. Since some of these cytokines appear to play a role in skeletal muscle growth, we were specifically interested in the effects of nutrient availability on circulating cytokines that have been implicated to play a role in muscle reconditioning. In our study we aimed to evaluate the effects of a pre-resistance exercise carbohydrate meal versus fat meal on circulating cytokine concentrations to resistance exercise after an endurance exercise earlier that day. We designed an experimental protocol where endurance and resistance exercise were performed in the morning and afternoon respectively, with ample protein ingestion throughout the day. The nutritional difference between the conditions was induced by a pre-resistance exercise meal that differed in macronutrient content. Specifically, in one condition the subjects were provided with a meal rich in carbohydrate (CHO condition), whereas in the other condition an isocaloric meal high in fat (FAT condition) was provided. It is hypothesized that some of the selected cytokines will differ between nutritional conditions, but that the majority of the circulating cytokines with a possible role in skeletal muscle growth do not respond differently. 


\section{Methods}

\section{Subjects}

Fourteen healthy recreationally-active males volunteered to participate in this study (age; $21.2 \pm 0.5$ years, height; $1.87 \pm 0.0 \mathrm{~m}$, mass; $76.7 \pm 1.3 \mathrm{~kg}$ ). One subject dropped out after test day 1 because of the discomfort of the muscle biopsies, therefore final analysis was performed on 13 subjects. All subjects were non-smokers, free of injury and not taking any medication or nutritional supplements. All subjects provided full-written informed consent. The Medical Ethical Committee of Wageningen University approved all study procedures.

\section{Subject characteristics}

Physical characteristics of 13 volunteers are shown in Table 1.

Table 1. Physical characteristics of 13 volunteers.

$$
\text { Mean } \pm \text { SE }
$$

\begin{tabular}{ll} 
Age (years) & $21.2 \pm 0.5$ \\
Height $(\mathbf{m})$ & $1.87 \pm 0.0$ \\
Weight $(\mathbf{k g})$ & $76.7 \pm 1.3$ \\
$\mathbf{B M I}\left(\mathbf{~ k g} / \mathbf{m}^{2}\right)$ & $22.0 \pm 0.2$ \\
$\mathrm{~W}_{\text {max }}(\mathrm{W})$ & $346 \pm 7.6$ \\
$\mathrm{VO}_{2 \max }\left(\mathbf{m l} / \mathbf{k g} / \mathbf{m i n}^{-1}\right)$ & $51.3 \pm 1.3$ \\
Leg press 1-RM (kg) & $266 \pm 8.2$ \\
\hline Leg extension 1-RM (kg) & $111 \pm 3.0$
\end{tabular}

\section{Study Design}

This study used a randomised counterbalanced crossover design (Fig. 1). On both experimental days subjects completed the same exercise sessions: an endurance exercise session in the morning and a resistance exercise session in the afternoon with a resting period of 4 hours between sessions. The subjects received a nutritional treatment in between the exercise sessions (carbohydrate or fat meal). Each trial was separated by a minimum of 12 days (range: 12-30 days), during which time the subjects were instructed to maintain their habitual lifestyle. 


\section{Figure 1.}

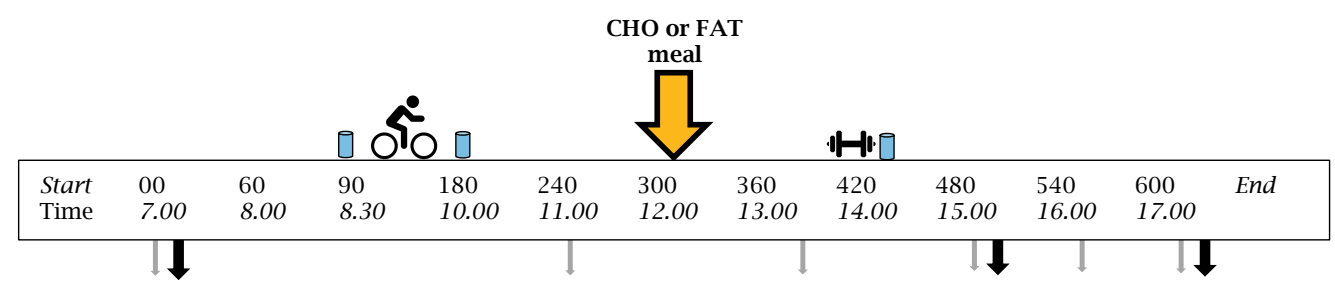

Figure 1. Schematic diagram of the experimental trials. This study adopted a counterbalanced crossover design where subjects completed both exercise trials with different nutritional treatments on separate occasions. Endurance exercise session: 90 -min cycling at $70 \% \mathrm{VO}_{2 \max }$. Resistance exercise sessions 5 sets of 8 repetitions for both leg press and leg extensions at $80 \%$ 1-RM. Blue containers indicates protein beverage (from left to right; $10 \mathrm{~g}$ casein, $15 \mathrm{~g}$ casein and 25g whey. Big orange arrow with black outline indicates lunch with carbohydrates or fat (nutritional intervention meal). Grey arrows indicates time point for blood sample; black arrows indicates sampling time point for muscle biopsy.

\section{Preliminary testing}

$V O_{2 \max }$

Maximal aerobic capacity $\left(\mathrm{VO}_{2 \max }\right)$

Preliminary testing was performed in the week prior to the start of the first experimental day. Following a 30-min rest, subjects performed a ramped $\mathrm{VO}_{2 \max }$ test on an electrically braked cycle ergometer (Lode Excalibur, Groningen, The Netherlands). After a 5-min warm up at $50 \mathrm{~W}$, the subjects started cycling at $100 \mathrm{~W}$. Workload was progressively increased by $20 \mathrm{~W} \cdot \mathrm{min}$ ${ }^{1}$ until the subject reached volitional exhaustion. The $\mathrm{VO}_{2 \max }$ test was considered to be valid when two out of three criteria were met: I) levelling of $\mathrm{VO}_{2}$ with increasing workload; II) heart rate within 10 beats of the theoretically estimated maximum (220-age) and III) respiratory exchange ratio (RER) of $\geq 1.15$. Oxygen consumption $\left(\mathrm{VO}_{2}\right)$ was measured through breath-by-breath sampling with an Oxycon Pro (Jaeger, Hoechberg, Germany) to define maximal oxygen consumption $\left(\mathrm{VO}_{2 \max }\right)$. Subjects were asked to maintain a cadence between $80-100 \mathrm{r} \cdot \mathrm{min}^{-1}$.

\section{Maximal strength}

Maximal muscle strength was determined by one-repetition maximum (1RM) strength tests on leg press and leg extension machine (Technogym, Cesena, Italy). Subjects were familiarized with the movement and warmed up prior to testing by performing six repetitions (at $\sim 40 \%$ of estimated $1 \mathrm{RM}$ ) through a full range of motion with a 1-min rest. After each successful lift the weight was increased until a failed attempt occurred with 3-min recovery between each attempt. The $1 \mathrm{RM}$ was attained within five attempts. For each preliminary test, 
subjects were fasted for at least $4 \mathrm{~h}$ and were instructed to avoid strenuous physical activity $48 \mathrm{~h}$ before.

\section{Diet and physical activity control}

Subjects were instructed to avoid alcohol, caffeine and physical activity during $48 \mathrm{~h}$ prior to the two main experimental trials. Diet and physical activity levels were recorded for $24 \mathrm{~h}$ before the first experimental trials and subjects were asked to replicate dietary intake and physical activity prior to the second experimental trial. Dietary intake records were analysed using Eetmeter Software 2005 (version 1.4.0;Voedingscentrum). A standardized meal for the subjects was provided the night before each trial (standard deep-frozen meal and ice-cream dessert; $43.80 \mathrm{~kJ} / \mathrm{kg}$ BW; 15 Energy\% protein, 30 Energy\% fat and 55 Energy\% carbohydrate).

\section{Experimental days}

All subjects arrived at 07.00 in the morning in the fasted state at the laboratory of our university. After changing into sport gear, a catheter was inserted into the antecubital vein of the left arm. Fifteen minutes after insertion of the catheter baseline blood samples were taken followed by a baseline muscle biopsy. Approximately 10 minutes after the baseline biopsy a protein beverage containing 10 gram of casein dissolved in $350 \mathrm{ml}$ water was consumed $(\mathrm{t}=-05$ min). Within five minutes after consumption of the protein beverage, the subjects started with 90 minutes cycling $(t=0 \mathrm{~min})$ at submaximal intensity $\left(70 \% \mathrm{VO}_{2 \max }\right)$. If subjects could not sustain the intensity of at least $60 \mathrm{RPM}$, resistance was decreased with $20 \mathrm{~W}$, and the same intensity protocol was repeated during the second training. All subjects performed the same exercise intensity of both experimental days. Immediately after the endurance exercise bout, a beverage containing 15 gram of casein dissolved in $350 \mathrm{ml}$ water was consumed $(\mathrm{t}=90 \mathrm{~min})$. A second blood sample $(\sim 25 \mathrm{ml})$ was taken 1 hour after the end of the endurance exercise bout $(t=150 \mathrm{~min})$. Two hours after the endurance exercise bout $(\mathrm{t}=210 \mathrm{~min})$ subjects were randomly provided with either a carbohydrate rich low-fat meal or low-carbohydrate fat meal (see intervention meal for details). Ninety minutes after the meal $(t=300 \mathrm{~min}) \mathrm{a}$ third blood sample $(\sim 25 \mathrm{ml})$ was taken. At $\mathrm{t}=330 \mathrm{~min}$ subjects performed the resistance exercise bout that consisted of $5 \times 8$ (80\% 1RM) repetitions of bilateral leg press and leg extension with two minutes of rest in between the sets. If subjects could not sustain due to fatigue, the selected weight was decreased with steps of $10 \mathrm{~kg}$ or $5 \mathrm{~kg}$ for the leg press and leg extension, respectively. Immediately after the resistance exercise bout $(t=360 \mathrm{~min})$, a protein beverage containing 25 gram of whey protein dissolved in $350 \mathrm{ml}$ water was consumed. One and three hours after the resistance exercise bout a second $(\mathrm{t}=480 \mathrm{~min})$ and a third $(\mathrm{t}=600 \mathrm{~min})$ skeletal muscle biopsy was taken. All biopsies were taken from the same leg. Additional blood samples were taken 
at $\mathrm{t}=480,540$ and $600 \mathrm{~min}$. A timeline for the experimental day can be found in figure 1 . The whole experimental protocol was repeated on the $2^{\text {nd }}$ day, while the other meal was provided.

\section{Nutritional intervention}

Both meals were cooked and prepared by a research dietician of Wageningen University. Both the carbohydrate and fat meal consisted of commercially available meat, macaroni and vegetables with an energetic value of $\sim 3200 \mathrm{~kJ}$. The absolute macronutrient amounts were chemically analysed as described previously (11) and can be found in table 2 .

Table 2. Overview of the energy and macronutrient composition intervention meal.

\begin{tabular}{lll} 
Energy \& Nutrient & Fat meal & Carbohydrate meal \\
\hline Energy (kJ) & 3207 & 3124 \\
Protein $(\mathrm{g})$ & 52 & 52 \\
Fat $(\mathrm{g})$ & 51 & 9 \\
Carbohydrates $\mathbf{( g )}$ & 20 & 110 \\
\hline
\end{tabular}

\section{Exercise protocol}

Since athletes commonly combine divergent exercise sessions on the same day, we decided to include both endurance and resistance exercise on the same day in our protocol. Additionally, it has been recently proposed that, when combining divergent exercise sessions within the same day, the endurance session should be performed in the morning in the fasted state, with ample protein ingestion, while the afternoon resistance exercise session should be conducted only after carbohydrate replenishment with adequate postresistance exercise protein ingestion (Perez-Schindler et al., 2015). With our study we aimed to evaluate the effect of a pre-resistance exercise isocaloric $(\sim 3200 \mathrm{~kJ})$ mixed meal containing different amounts of carbohydrates and fat, on post-resistance exercise plasma cytokines after glycogen depleting exercise earlier that day.

\section{Muscle biopsies}

Muscle biopsies were taken as described by Bergstrom (12). Biopsies were taken under local anaesthesia (2-3 ml of 2\% Xylocaine) using a 5-mm Bergstrom needle modified with suction. All three muscle biopsies on one experimental day were taken from the vastus lateralis of the same leg, with separate incisions $(\sim 1-1.5 \mathrm{~cm})$ apart and from distal to proximal direction. Muscle biopsies on the second test day were taken from the contralateral leg. Muscle biopsies were immediately frozen (in 5-10 s) in liquid nitrogen and stored at $-80^{\circ} \mathrm{C}$ for subsequent biochemical analysis, after being freed from visible fat, blood and connective tissue. 


\section{Muscle glycogen}

Muscle tissue, $\sim 30 \mathrm{mg}$ wet weight, was freeze dried, after which collagen, blood, and non-muscle fibre materials were removed from the muscle fibres under a microscope. The isolated muscle fibre mass $(\sim 5-7 \mathrm{mg})$ was weighed, and $500 \mu \mathrm{L}$ of $1 \mathrm{MHCI}$ was added. After heating for $3 \mathrm{~h}$ at $100^{\circ} \mathrm{C}$ to hydrolyse the glycogen to glycosyl units and cooling down to room temperature, $500 \mu \mathrm{L}$ of the solution was neutralized by adding $280 \mu \mathrm{L}$ of Tris-KOH (Tris $119 \mathrm{mM}$, $\mathrm{KOH} 2.14 \mathrm{M}$ ) and centrifuged at $1000 \mathrm{~g}$ and $4^{\circ} \mathrm{C}$ for $10 \mathrm{~min}$. Thereafter, $150 \mu \mathrm{L}$ of this solution was analysed for glucose concentration (Glucose HK CP A11A01667, ABX Pentra) with a COBAS FARA semiautomatic analyser (Roche).

\section{Glucose, insulin and free fatty acids}

Blood was collected in EDTA-containing tubes. The samples were immediately centrifuged at $1000 \mathrm{~g}$ at $4^{\circ} \mathrm{C}$ for 10 minutes, after which plasma was stored in $-80^{\circ} \mathrm{C}$ until further analysis. Blood samples were analysed for glucose and insulin (Gelderse Vallei hospital, Ede, the Netherlands). Free fatty acids were assessed using an enzymatic test kit according to the manufacturer's protocol (InstruChemie, Delfzijl, the Netherlands).

\section{ANGPTL4 and Decorin}

All plasma samples were kept on ice until centrifugation and stored at $-80^{\circ} \mathrm{C}$ until further analysis. Angiopoietin-like 4 (ANGPTL4) and Decorin were assessed using human ELISA kits according to the manufacturer's protocol.

\section{IL-6, IL-8, IL-10, IL-15,MCP-1 and TNF- $\alpha$}

Blood samples were taken at baseline, $1 \mathrm{~h}$ post endurance exercise, $1 \mathrm{~h}$ post meal, $1 \mathrm{~h}, 2 \mathrm{~h}$ and $3 \mathrm{~h}$ post resistance exercise. Participants were seated for 5 min after which blood samples were taken from the cephalic vein. Blood was collected in a $4 \mathrm{ml}$ EDTA vacutainer (Becton-Dickinson, New Jersey, United States of America). The vacutainer was immediately put on melting ice water $\left(4^{\circ} \mathrm{C}\right)$ and centrifuged at $1200 \mathrm{~g}$ for 15 minutes at $4^{\circ} \mathrm{C}$. Serum was transferred to polypropylene tubes and stored at $-80^{\circ} \mathrm{C}$ until Cytokine analysis. We measured IL-6, IL-8, IL-10, IL-15, MCP-1 and TNF- $\alpha$ concentrations using the ultrasensitive MesoScale Discovery (MSD) QuickPlex SQ 120 Instrument with Multi-spot assay (Human Proinflammatory Panel 1, K15049D, MSD, Maryland, United States of America) according to the manufacturers' recommendations. The lower detection limit was 0.043-0.107, 0.039-0.059, 0.022-0.034, 0.46-0.54, 0.09-0.16 and $0.055-0.087 \mathrm{pg} / \mathrm{ml}$, respectively, varying per plate. Precision of these validated kits was as follows: The intra-run $\% \mathrm{CV}$ for the high-low controls were 3.6-4.5\%, 2.7-3.0\%, 2.6-3.7\%, 3.3-4.1\% and 2.7-3.4\% for IL-6, IL-8, IL-10, IL-1 $\beta$ and TNF- $\alpha$, respectively. The Inter-run \% CV for the high-low controls were 5.2-7.3\%, 5.0-7.1\%, 5.7-10.1\%, 5.5-7.7\% and 6.1-10.1 \% for IL-6, IL-8, IL-10, IL-1 $\beta$ and TNF- 
$\alpha$, respectively. With the high-low concentrations being as follows: 239-18.4 $\mathrm{pg} / \mathrm{ml}, 166-12.5 \mathrm{pg} / \mathrm{ml}, 107-7.18 \mathrm{pg} / \mathrm{ml}, 152-11.2 \mathrm{pg} / \mathrm{ml}$, and $75.5-4.45 \mathrm{pg} / \mathrm{ml}$, for IL-6, IL-8, IL-10, IL-1 $\beta$ and TNF- $\alpha$, respectively.

\section{Statistics}

Data was analysed using a two-way repeated measures ANOVA (two factor, time $x$ treatment) from IBM SPSS version 23 statistical software (IBM, Armonk, $\mathrm{NY}$ ). When a main effect of trial of time or interaction was identified, a pairwise multiple comparisons with a Bonferroni correction was done to identify differences. Statistical significance was set at the $\mathrm{P}<0.05$ level, and values were expressed as means \pm SEM or different when indicated. 


\section{Results}

\section{Endurance and resistance exercise performance}

Two subjects performed the endurance exercise sessions with a reduced workload. For one subject the workload was reduced with $20 \mathrm{~W}$ after $20 \mathrm{~min}$ whereas for the other subject the workload was reduced with $20 \mathrm{~W}$ after 30 min. There was no further reduction in workload during the remaining part of the endurance session. Additionally, both subjects were able to repeat this on the second experimental day. All 13 subjects performed the resistance exercise training with exactly the same amount of work on the 2 experimental days.

\section{Muscle glycogen}

There were no differences in baseline muscle glycogen between the conditions (carbohydrate $380 \pm 20.4 \mathrm{mmol} / \mathrm{kg}$ dry weight $(\mathrm{dw})$ versus fat $441 \pm 26.3$ $\mathrm{mmol} / \mathrm{kg} \mathrm{dw} ; P>0.05$ Figure 2). As a result of endurance exercise, muscle glycogen was significantly reduced compared to baseline in both conditions at $1 \mathrm{~h}$ and $3 \mathrm{~h}$ post-resistance exercise $(P<0.05)$ (carbohydrate $163 \pm 23.5$ and $181 \pm 20.3 \mathrm{mmol} / \mathrm{kg} \mathrm{dw}$; fat $185 \pm 25.8$ and $140 \pm 24.4 \mathrm{mmol} / \mathrm{kg} \mathrm{dw}$ ), without any significant differences between the conditions $(P>0.05)$.

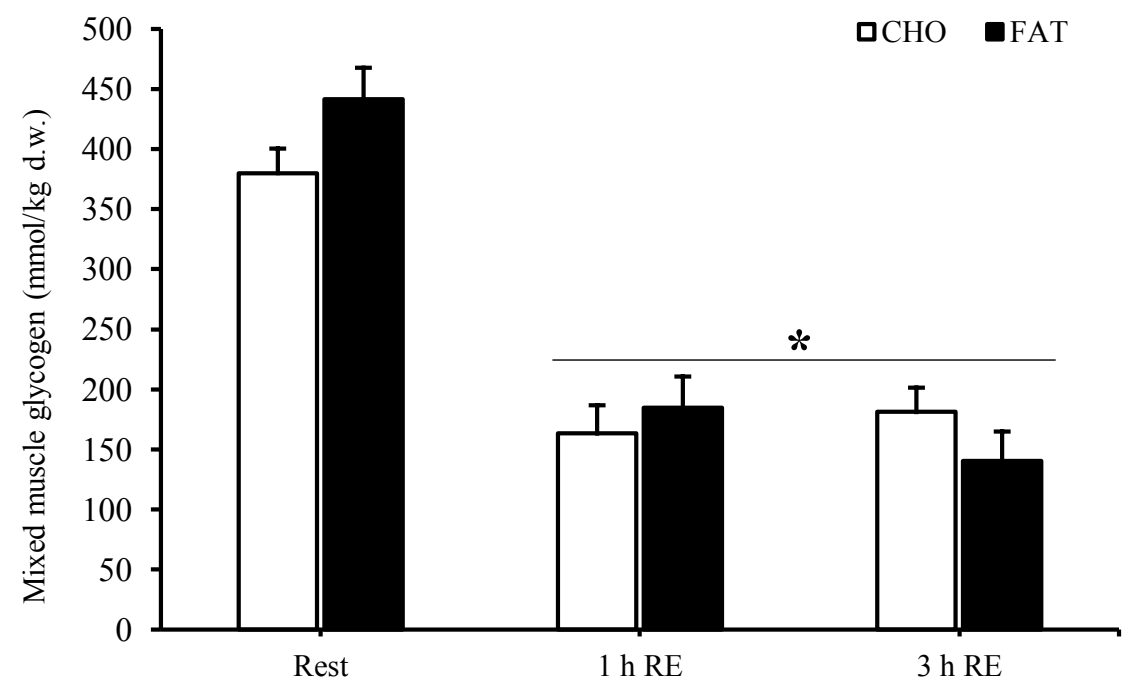

Figure 2. Mixed muscle glycogen at rest and $1 \mathrm{~h}$ and $3 \mathrm{~h}$ after 5 sets of 8 repetitions for both leg press and leg extensions at 80\% 1RM (1, 2 and 3h RE) Values are mean \pm SEM.

$*$ Significantly different $(P<0.05)$ versus rest. $\mathrm{CHO}=$ open bars, FAT $=$ filled bars. 
Free fatty acids, glucose and insulin

One hour post meal, plasma free fatty acid concentration was higher in the fat condition compared with the carbohydrate condition and this effect remained significant after 1 and 2 hours post-resistance exercise $(P<0.05)$ (Fig. 3). Both glucose and insulin in the fat condition were significantly lower at $1 \mathrm{~h}$ post meal, and at 1,2 and $3 \mathrm{~h}$ post-resistance exercise compared with the carbohydrate condition $(P<0.05)$ (Fig. 3$)$.

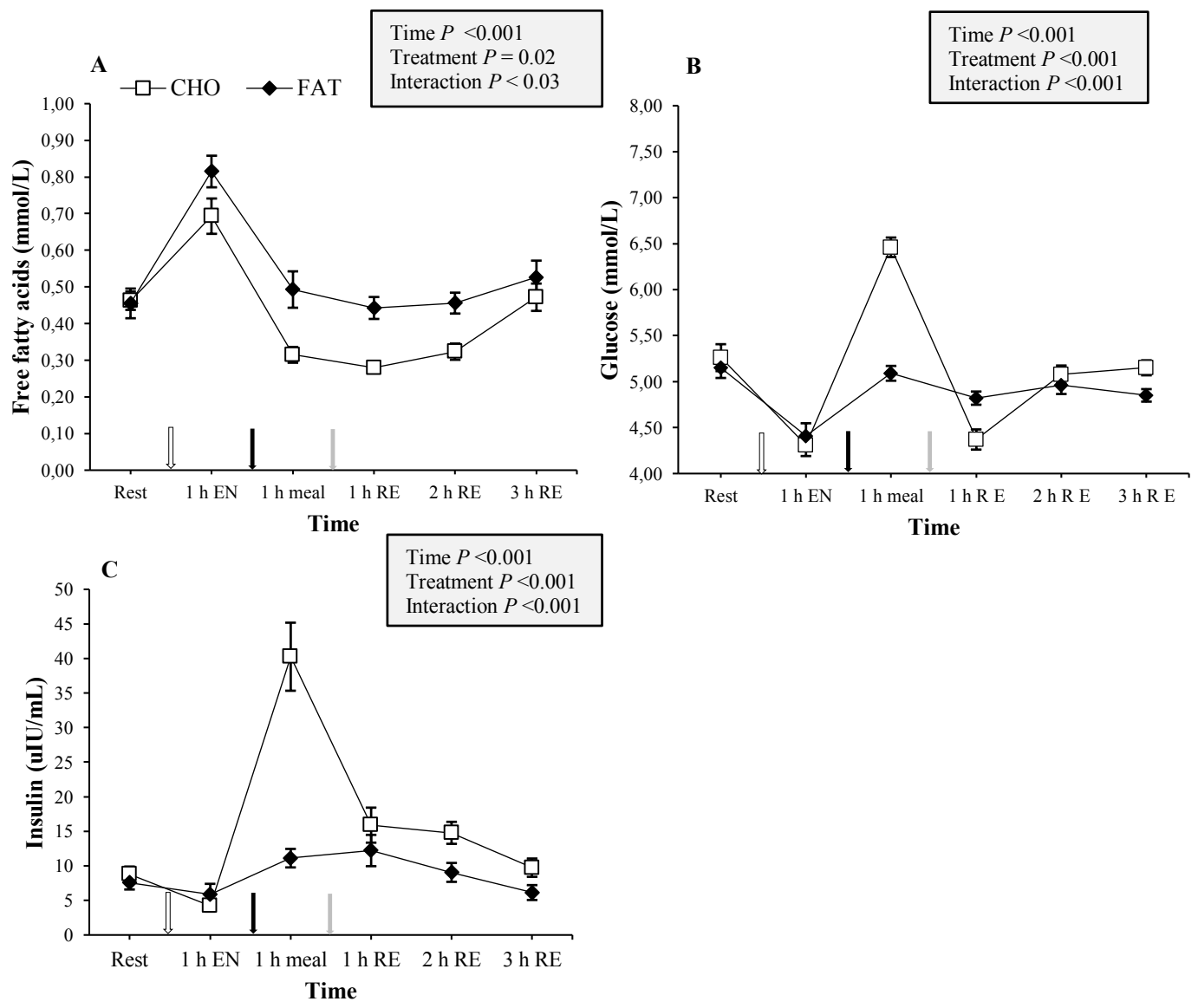

Figure 3. Plasma free fatty acids (a), glucose (b) and insulin (c) at rest and 1 hour after 90-min cycling 70\% $\mathrm{VO}_{2 \max }(1 \mathrm{~h} \mathrm{EN}), 1$ hour post meal $(1 \mathrm{~h}$ meal) and $1 \mathrm{~h}, 2 \mathrm{~h}$, and $3 \mathrm{~h}$ after 5 sets of 8 repetitions for both leg press and leg extensions at 80\% 1RM (1,2 and $3 \mathrm{~h}$ RE) Values are mean \pm SEM. White arrow: endurance exercise session; black arrow: nutritional intervention meal; grey arrow: resistance exercise session. 


\section{IL-6, IL-8, IL-10 and TNF $\alpha$}

At $2 \mathrm{~h}$ post resistance exercise, IL-6 concentrations were higher in the fat condition compared to the carbohydrate condition $(P<0.05)$ (Fig. 4). In addition, in both conditions IL-6 levels were higher at all timepoints compared with baseline $(P<0.05)$. The pattern of increase in plasma IL- 8 and IL-10 did not differ significantly between conditions $(P>0.05)$ (Fig. 4$)$. As a result of the endurance session in the morning, concentrations of both IL- 8 and IL-10 were increased $1 \mathrm{~h}$ post endurance exercise $(P<0.05)$. Furthermore, compared to baseline, IL- 8 was still increased $1 \mathrm{~h}$ post meal and $1 \mathrm{~h}$ post resistance exercise $(P<0.05)$, with no differences between meal conditions $(P>0.05)$. There were no differences between conditions on TNF $\alpha$ levels and levels remain constant when compared with baseline $(P>0.05)$.

\section{口CHO DFAT}
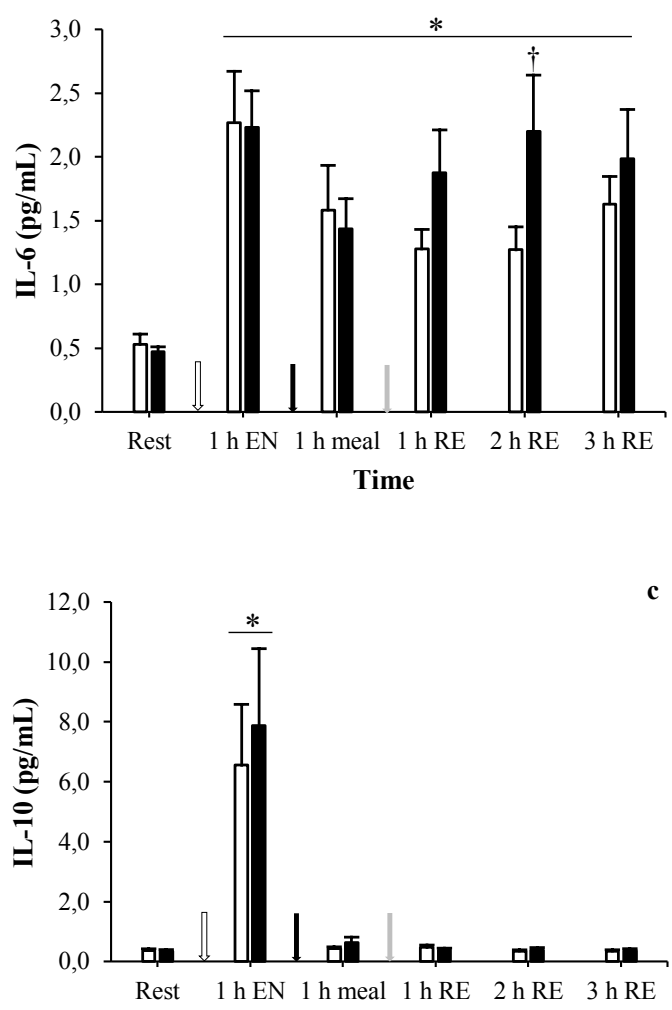

Time

a b
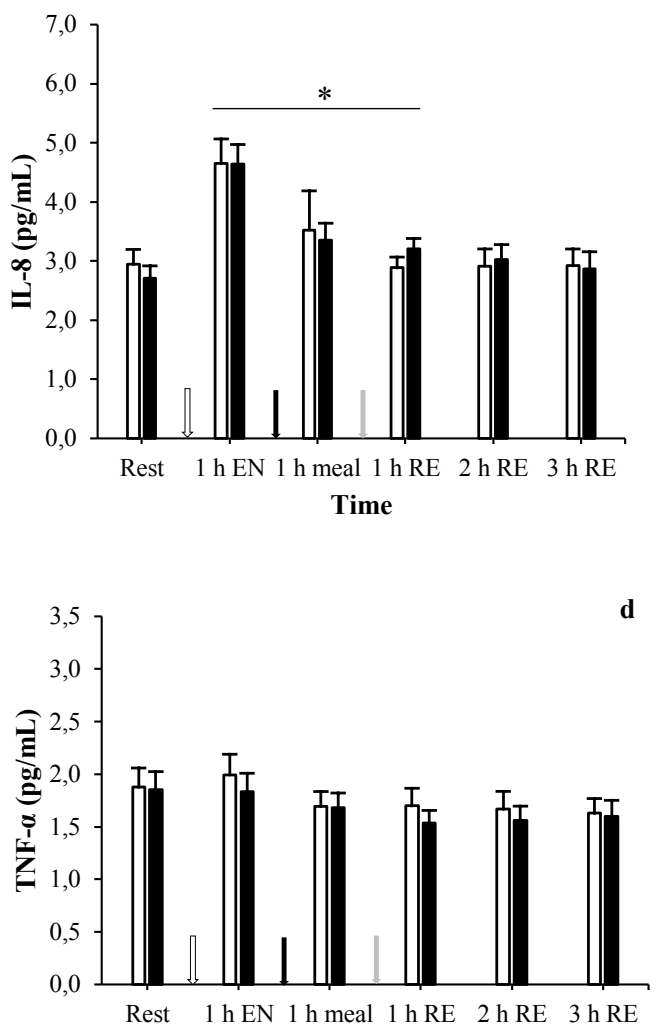

Time

Figure 4. IL-6 (a), IL-8 (b), IL-10 (c) and TNF $\alpha$ (d) at rest and 1 hour after 90-min cycling 70\% $\mathrm{VO}_{2 \max }(1 \mathrm{~h} \mathrm{EN}), 1$ hour post meal $(1 \mathrm{~h}$ meal) and $1 \mathrm{~h}, 2 \mathrm{~h}$, and $3 \mathrm{~h}$ after 5 sets of 8 repetitions for both leg press and leg extensions at $80 \% 1 \mathrm{RM}(1,2$ and $3 \mathrm{~h}$ RE) Values are mean \pm SEM. *Significantly different $(P<0.05)$ versus rest. †Significantly different $(P<0.05)$ between 
conditions. White arrow: endurance exercise session; black arrow: nutritional intervention meal; grey arrow: resistance exercise session.

\section{ANGPTL4, IL-15, Decorin and MCP-1}

ANGPTL4, IL-15, Decorin and MCP-1 showed no differences between the fat and carbohydrate condition $(P>0.05)$ (Figure 5). ANGPTL 4 levels were higer compared to baseline in both conditions at all timepoints $(P<0.05)$. IL-15 was higher than baseline in the carbohydrate condition $1 \mathrm{~h}$ post meal and $1 \mathrm{~h}$ post resistance exercise, whereas in the fat condition an increase compared with baseline was found only $1 \mathrm{~h}$ post resistance exercise $(P<0.05)$. Decorin levels were not different from baseline at any time point for both conditions $(P>$ 0.05). MCP-1 levels were higher than baseline in the fat condition at any time point except 2 hour post resistance exercise $(P<0.05)$. In the carbohydrate condition at 2 and $3 \mathrm{~h}$ post resistance exercise the MCP-1 levels were elevated compared to baseline $(P<0.05)$.
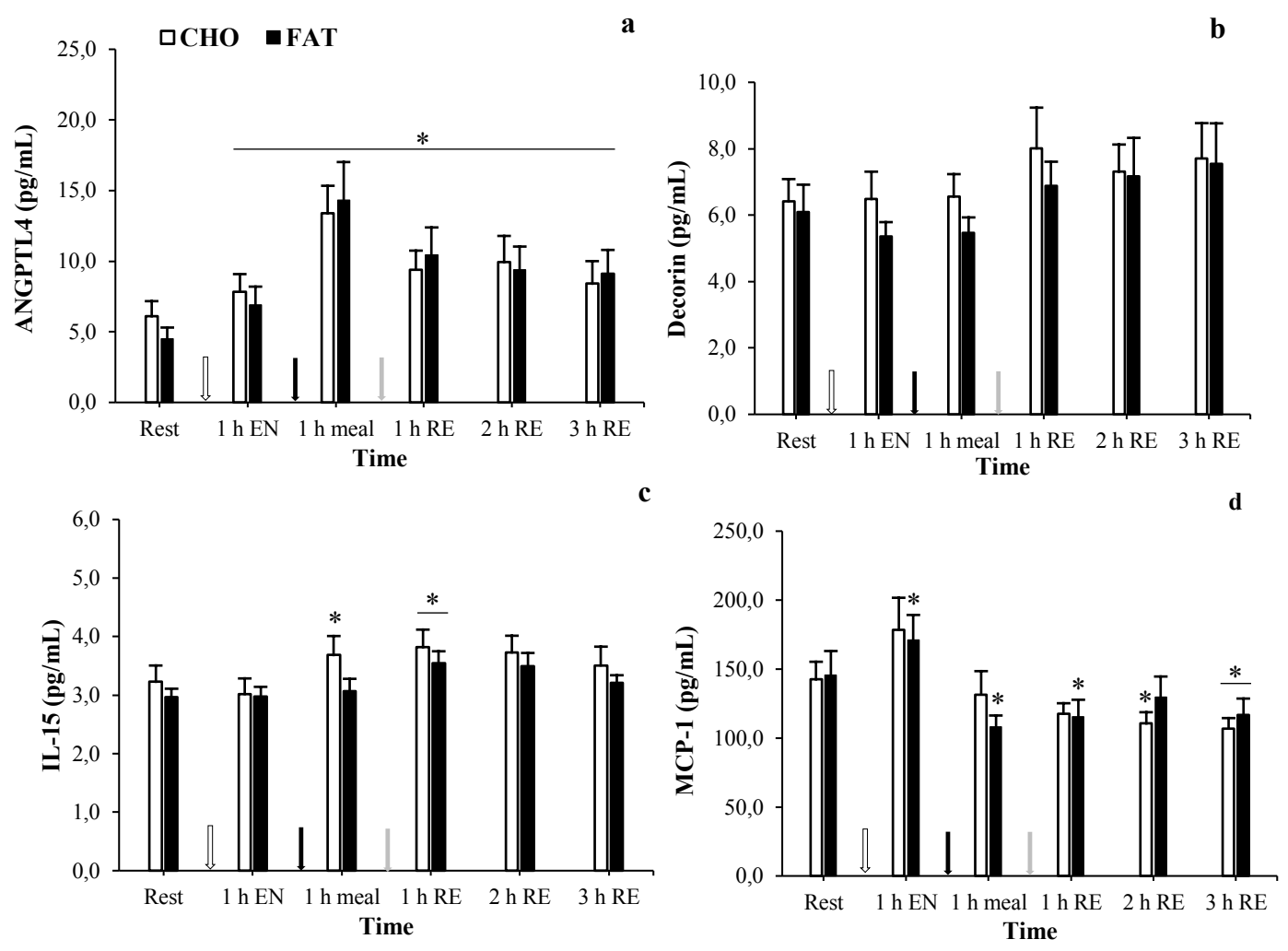

Figure 5. ANGPTL4 (a), Decorin (b), IL-15 (c) and MCP-1 (d) at rest and 1 hour after 90-min cycling $70 \% \mathrm{VO}_{2 \max }(1 \mathrm{~h} \mathrm{EN}), 1$ hour post meal $(1 \mathrm{~h}$ meal) and $1 \mathrm{~h}, 2 \mathrm{~h}$, and $3 \mathrm{~h}$ after 5 sets of 8 repetitions for both leg press and leg extensions at 80\% 1RM (1,2 and 3h RE) Values are mean \pm SEM. *Significantly different $(\mathrm{P}<0.05)$ versus rest. White arrow: endurance exercise session; black arrow: nutritional intervention meal; grey arrow: resistance exercise session. 


\section{Discussion}

In this study we investigated whether pre-exercise nutrient availability such as carbohydrates and fat influenced circulating cytokines concentrations with resistance exercise on a concurrent exercise day. We observed that the majority of the circulating cytokines (ANGPTL4, Decorin, IL-8, IL-10, IL-15, MCP-1 and TNF- $\alpha$ ) are not affected by differences in pre-resistance exercise carbohydrate or fat availability during the early post-resistance exercise recovery period on a concurrent exercise day. We were especially interested in circulating IL-6, IL8, IL-15, Decorin and MCP-1, since elevations of these cytokines may contribute or reflect adaptations of skeletal muscle $(5,13)$. The only cytokine of our selective set of circulating cytokines that responded differently between the nutritional conditions was IL-6.

\section{Cytokines that have been implicated in skeletal muscle hypertrophy}

IL-6 is one of the most discussed cytokines (1) that responds primarily to acute muscle contraction and peaks immediately after exercise (2), as was also observed in our study after the endurance session in the morning. In addition, it can be assumed that the significant reduction of hepatic and skeletal muscle glycogen levels post-endurance exercise contributed to the observed rise in plasma IL-6. Previous animal- and cell-culture work showed that IL-6 is probably an important regulator of satellite cell-mediated skeletal muscle hypertrophy (14). We found that two hours post-resistance exercise circulating IL-6 was significantly higher in the low carbohydrate condition compared with the high carbohydrate condition. Although we cannot exclude the possibility that this was partly due to a difference in muscle glycogen content during the resistance exercise bout, it is most likely due to the difference in carbohydrate availability in the pre-exercise meal since we found no differences in skeletal muscle glycogen in the post-resistance exercise period. Indeed, increased circulating levels of IL-6 have been found to be sensitive to changes in blood glucose levels (6), but also to pre-exercise muscle glycogen content (9). Likewise, pre-exercise reduced intramuscular glycogen augments IL-6 mRNA transcription factors and plasma IL-6 concentrations $(8,15)$, possibly explained through activation of AMPK (16) and p38MAPK (15). In addition, increased plasma IL-6 may act as a signal for hepatic glucose release to maintain blood glucose levels during exercise (1). Since we compared two isocaloric meals with different amounts of carbohydrates we cannot conclude whether the low carbohydrate availability augmented expressions of IL-6 plasma or that the high carbohydrate availability attenuated IL-6 plasma levels. In addition to circulating IL-6 we had particular interest in the responses of circulating IL-15 since this cytokine has been implicated in the regulation of skeletal muscle turnover (17-22). The responses of the circulating $\mathrm{IL}-15$ with exercise vary between studies, but it seems that IL-15 primarily responds to 
resistance exercise in both trained and untrained individuals $(22,23)$. Overexpression of $\mathrm{IL}-15$ in cultured skeletal myotubes affects protein metabolism by stimulation of protein synthesis and inhibition of protein degradation, suggesting a possible role for $\mathrm{IL}-15$ in muscle growth and wasting (20). Furthermore, it has been suggested that IL-15 plays a role in muscle adipose tissue interaction (24). Our plasma data of IL-15 showed an increase at $1 \mathrm{~h}$ post-resistance exercise without a difference between the carbohydrate and fat condition suggesting that circulating plasma IL-15 is not affected by the pre-resistance exercise difference in availability of carbohydrate or fat. The evidence that IL-15 plays an important role in skeletal muscle growth with exercise is mainly derived from in vitro and animal work and its relevance in terms of physiological adaptation in humans remains to be determined (18, $20,25,26)$.

The majority of the selected cytokines responded as a result of exercise, this was also the case for circulating Decorin. We found a mild increase, although not significant in plasma Decorin at 1, 2 and $3 \mathrm{~h}$ post-resistance exercise when compared to circulating levels of Decorin at baseline. However, no differences were found between the low and high carbohydrate condition. Decorin is a protein secreted by skeletal muscle cells, and promotes skeletal muscle hypertrophy by binding with myostatin (27). It has recently been demonstrated that plasma Decorin increases in response to acute resistance exercise (27). The somewhat moderate response in our study of plasma Decorin compared to the study of Kanzleiter et al. (2014) could be explained by exercise volume and time points of measurement. Indeed, Kanzleiter et al. used seven different exercises of three sets and measured plasma Decorin during and immediately after, every 30 minutes until 120 minutes post-resistance exercise (27). In their study, which clearly had a higher exercise load, plasma Decorin peaked immediately after exercise, a time point we are lacking in our study (27). The last cytokine we investigated with a possible role in skeletal muscle growth is MCP-1. Previous studies show that MCP-1 is both a cytokine and exercise factor. MCP-1 appears to be vital for muscle recovery and adaptation $(28,29)$. Divergent exercise modes increase skeletal muscle gene expression levels of MCP-1 (30-33). Yet, MCP-1 responded as a result of exercise while no differences were seen between the nutritional conditions.

\section{ANGPTL4}

In our nutritional intervention we compared two isocaloric pre-exercise meals that differ in macronutrient profile. Specifically, in the FAT condition, the carbohydrates were almost completely replaced by fat. Therefore, we also looked to the responses of ANGPTL4 since this protein appears to be sensitive to glucose ingestion (34). ANGPTL4 is found in both skeletal muscle and adipose tissue and is regulated by exercise via free elevated free fatty acids 
(34). ANGPTL4 stimulates degradation of lipids and thereby the release of glycerol and free fatty acids to the circulation. Furthermore circulating plasma ANGPTL4 responds to exercise and previous work by Kersten et al. (2009) demonstrated that exercise-induced ANGPTL4 plasma responses are partly inhibited when subjects are given oral glucose (34). It is theorized that glucose inhibits ANGPTL4 possibly caused by the rise of insulin, via suppression of lipolysis and reduced plasma free fatty acids concentration $(34,35)$. Our data confirmed findings of others that plasma ANGPTL4 increases significantly after endurance exercise (34). The increase in ANGPTL4 was further elevated 1 $\mathrm{h}$ post meal possibly because of a positive feedback loop of plasma free fatty acids raising ANGPTL4 levels and ANGPTL4 promoting adipose tissue lipolysis, raising free fatty acids plasma levels (34). Despite a significant difference in circulating free fatty acids, glucose and insulin between feeding conditions, no differences in plasma ANGPTL4 were detected.

\section{Study limitations}

A limitation of the present study is that there was no muscle biopsy taken preresistance exercise and therefore the muscle glycogen content between the different nutritional conditions when commencing the resistance exercise bout remains unclear. Furthermore, our blood samples in the post exercise period were not immediately collected after the bout but at 1,2 and $3 \mathrm{~h}$ post exercise. Consequently, potential differences in cytokines between the nutritional conditions could have been overlooked since the established cytokines reach a peak during and immediately after exercise (2). In addition, the effects of the nutritional intervention are possibly obscured by the physiological effects of endurance exercise. Multiple time-points in a shorter period of time during and after exercise may reveal more additional insights about how nutrient availability influence cytokine responses. Another limitation is the intensity and duration of the resistance exercise bout, we cannot rule out the possibility that alternative resistance exercise bouts higher in volume and intensity with different carbohydrate or fat availability may affect the post-resistance exercise cytokine responses differently. Moreover, the post-resistance exercise plasma cytokine responses may be affected by the endurance exercise earlier that day, however, since we did not have a third condition without the endurance exercise we were not able to correct for this potential confounder. At last, another shortcoming of this study is that possible changes within the muscle such as mRNA quantity and protein content were not determined. Therefore, a possible effect of the intervention meal may have been overlooked. 


\section{Conclusion}

In summary, resistance exercise with different carbohydrate/fat availability did not influence most plasma cytokine responses in the early post-resistance exercise period. Post-resistance exercise plasma IL-6 expression was higher in the low carbohydrate condition compared with high carbohydrate availability. Our findings support the view that the pre-resistance exercise carbohydrate availability does not affect acute cytokine responses to resistance exercise. 


\section{References}

1. Hennigar SR, McClung JP, Pasiakos SM. Nutritional interventions and the IL-6 response to exercise. FASEB journal : official publication of the Federation of American Societies for Experimental Biology. 2017;31(9):3719-28.

2. Pedersen BK, Febbraio MA. Muscles, exercise and obesity: skeletal muscle as a secretory organ. Nature reviews Endocrinology. 2012;8(8):457-65.

3. Peake JM, Della Gatta P, Suzuki K, Nieman DC. Cytokine expression and secretion by skeletal muscle cells: regulatory mechanisms and exercise effects. Exercise immunology review. 2015;21:8-25.

4. Gorgens SW, Eckardt K, Jensen J, Drevon CA, Eckel J. Exercise and Regulation of Adipokine and Myokine Production. Progress in molecular biology and translational science. 2015;135:313-36.

5. Catoire M, Kersten S. The search for exercise factors in humans. FASEB journal : official publication of the Federation of American Societies for Experimental Biology. 2015;29(5):1615-28.

6. Febbraio MA, Steensberg A, Keller C, Starkie RL, Nielsen HB, Krustrup P, et al. Glucose ingestion attenuates interleukin-6 release from contracting skeletal muscle in humans. The Journal of physiology. 2003;549(Pt 2):607-12.

7. Nieman DC, Davis JM, Henson DA, Walberg-Rankin J, Shute M, Dumke CL, et al. Carbohydrate ingestion influences skeletal muscle cytokine mRNA and plasma cytokine levels after a 3-h run. Journal of applied physiology. 2003;94(5):1917-25.

8. Keller C, Steensberg A, Pilegaard H, Osada T, Saltin B, Pedersen BK, et al. Transcriptional activation of the IL-6 gene in human contracting skeletal muscle: influence of muscle glycogen content. FASEB J. 2001;15(14):2748-50.

9. Steensberg A, Febbraio MA, Osada T, Schjerling P, van Hall G, Saltin B, et al. Interleukin-6 production in contracting human skeletal muscle is influenced by preexercise muscle glycogen content. The Journal of physiology. 2001;537(Pt 2):633-9.

10. Nieman DC, Davis JM, Brown VA, Henson DA, Dumke CL, Utter AC, et al. Influence of carbohydrate ingestion on immune changes after $2 \mathrm{~h}$ of intensive resistance training. Journal of applied physiology. 2004;96(4):1292-8.

11. Koreissi-Dembele Y, Doets EL, Fanou-Fogny N, Hulshof PJ, Moretti D, Brouwer ID. Comparing intake estimations based on food composition data with chemical analysis in Malian women. Public health nutrition. 2017;20(8):1351-61.

12. Bergstrom J. Percutaneous needle biopsy of skeletal muscle in physiological and clinical research. Scandinavian journal of clinical and laboratory investigation. 1975;35(7):609-16.

13. Perez-Lopez A, McKendry J, Martin-Rincon M, Morales-Alamo D, Perez-Kohler B, Valades D, et al. Skeletal muscle IL-15/IL-15Ralpha and myofibrillar protein synthesis after resistance exercise. Scandinavian journal of medicine \& science in sports. 2017.

14. Serrano AL, Baeza-Raja B, Perdiguero E, Jardi M, Munoz-Canoves P. Interleukin-6 is an essential regulator of satellite cell-mediated skeletal muscle hypertrophy. Cell metabolism. 2008;7(1):33-44.

15. Chan MH, McGee SL, Watt MJ, Hargreaves M, Febbraio MA. Altering dietary nutrient intake that reduces glycogen content leads to phosphorylation of nuclear p38 MAP kinase in human skeletal muscle: association with IL-6 gene transcription during contraction. FASEB journal : official publication of the Federation of American Societies for Experimental Biology. 2004;18(14):1785-7.

16. MacDonald C, Wojtaszewski JF, Pedersen BK, Kiens B, Richter EA. Interleukin-6 release from human skeletal muscle during exercise: relation to AMPK activity. Journal of applied physiology. 2003;95(6):2273-7. 
17. Busquets S, Figueras MT, Meijsing S, Carbo N, Quinn LS, Almendro V, et al. Interleukin-15 decreases proteolysis in skeletal muscle: a direct effect. International journal of molecular medicine. 2005;16(3):471-6.

18. Furmanczyk PS, Quinn LS. Interleukin-15 increases myosin accretion in human skeletal myogenic cultures. Cell biology international. 2003;27(10):845-51.

19. Pistilli EE, Siu PM, Alway SE. Interleukin-15 responses to aging and unloading-induced skeletal muscle atrophy. American journal of physiology Cell physiology. 2007;292(4):C1298-304.

20. Quinn LS, Anderson BG, Drivdahl RH, Alvarez B, Argiles JM. Overexpression of interleukin-15 induces skeletal muscle hypertrophy in vitro: implications for treatment of muscle wasting disorders. Experimental cell research. 2002;280(1):55-63.

21. Quinn LS, Haugk KL, Grabstein KH. Interleukin-15: a novel anabolic cytokine for skeletal muscle. Endocrinology. 1995;136(8):3669-72.

22. Riechman SE, Balasekaran G, Roth SM, Ferrell RE. Association of interleukin-15 protein and interleukin-15 receptor genetic variation with resistance exercise training responses. Journal of applied physiology. 2004;97(6):2214-9.

23. Nielsen AR, Mounier R, Plomgaard P, Mortensen OH, Penkowa M, Speerschneider T, et al. Expression of interleukin-15 in human skeletal muscle effect of exercise and muscle fibre type composition. The Journal of physiology. 2007;584(Pt 1):305-12.

24. Argiles JM, Lopez-Soriano J, Almendro V, Busquets S, Lopez-Soriano FJ. Cross-talk between skeletal muscle and adipose tissue: a link with obesity? Medicinal research reviews. 2005;25(1):49-65.

25. Bell GJ, Syrotuik D, Martin TP, Burnham R, Quinney HA. Effect of concurrent strength and endurance training on skeletal muscle properties and hormone concentrations in humans. European journal of applied physiology. 2000;81(5):418-27.

26. Pistilli EE, Alway SE. Systemic elevation of interleukin-15 in vivo promotes apoptosis in skeletal muscles of young adult and aged rats. Biochemical and biophysical research communications. 2008;373(1):20-4.

27. Kanzleiter T, Rath M, Gorgens SW, Jensen J, Tangen DS, Kolnes AJ, et al. The myokine decorin is regulated by contraction and involved in muscle hypertrophy. Biochemical and biophysical research communications. 2014;450(2):1089-94.

28. Staiger H, Haas C, Machann J, Werner R, Weisser M, Schick F, et al. Muscle-derived angiopoietin-like protein 4 is induced by fatty acids via peroxisome proliferatoractivated receptor (PPAR)-delta and is of metabolic relevance in humans. Diabetes. 2009;58(3):579-89.

29. Schwarz N, Pruessmeyer J, Hess FM, Dreymueller D, Pantaler E, Koelsch A, et al. Requirements for leukocyte transmigration via the transmembrane chemokine CX3CL1. Cellular and molecular life sciences : CMLS. 2010;67(24):4233-48.

30. Vella L, Caldow MK, Larsen AE, Tassoni D, Della Gatta PA, Gran P, et al. Resistance exercise increases NF-kappaB activity in human skeletal muscle. American journal of physiology Regulatory, integrative and comparative physiology. 2012;302(6):R667-73.

31. Tantiwong P, Shanmugasundaram K, Monroy A, Ghosh S, Li M, DeFronzo RA, et al. NFkappaB activity in muscle from obese and type 2 diabetic subjects under basal and exercise-stimulated conditions. American journal of physiology Endocrinology and metabolism. 2010;299(5):E794-801.

32. Suzuki K, Nakaji S, Yamada M, Liu Q, Kurakake S, Okamura N, et al. Impact of a competitive marathon race on systemic cytokine and neutrophil responses. Medicine and science in sports and exercise. 2003;35(2):348-55.

33. Mathers JL, Farnfield MM, Garnham AP, Caldow MK, Cameron-Smith D, Peake JM. Early inflammatory and myogenic responses to resistance exercise in the elderly. Muscle \& nerve. 2012;46(3):407-12. 
34. Kersten S, Lichtenstein L, Steenbergen E, Mudde K, Hendriks HF, Hesselink MK, et al. Caloric restriction and exercise increase plasma ANGPTL4 levels in humans via elevated free fatty acids. Arteriosclerosis, thrombosis, and vascular biology. 2009;29(6):969-74.

35. Catoire M, Alex S, Paraskevopulos N, Mattijssen F, Evers-van Gogh I, Schaart G, et al. Fatty acid-inducible ANGPTL4 governs lipid metabolic response to exercise. Proceedings of the National Academy of Sciences of the United States of America. 2014;111(11):E1043-52. 


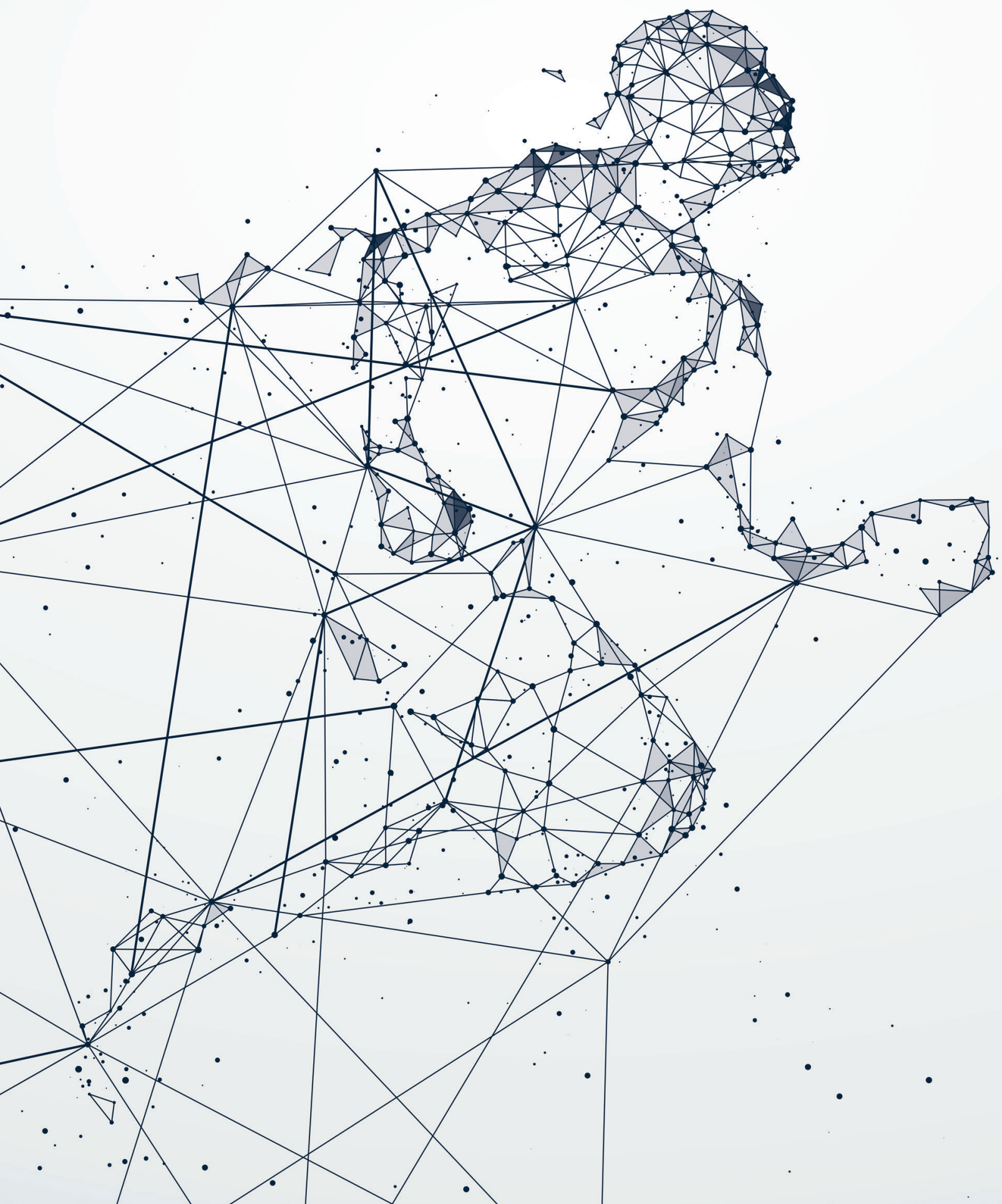




\title{
Chapter 5
}

Protein and the adaptive response with endurance training: wishful thinking or a competitive edge?

\author{
Pim Knuiman \\ Maria Hopman \\ Conor Verbruggen \\ Marco Mensink
}




\begin{abstract}
The significance of carbohydrates for endurance training has been well established, whereas the role of protein and the adaptive response with endurance training is unclear. Therefore, the aim of this perspective is to discuss the current evidence on the role of dietary protein and the adaptive response with endurance training. On a metabolic level, a single bout of endurance training stimulates the oxidation of several amino acids. Although the amount of amino acids as part of total energy expenditure during exercise is relatively low compared to other substrates (e.g. carbohydrates and fat), it may depress the rates of skeletal muscle protein synthesis, and thereby have a negative effect on training adaptation. A low supply of amino acids relative to that of carbohydrates may also have negative effects on the synthesis of capillaries, synthesis and turn-over of mitochondrial proteins and proteins involved in oxygen transport including haemoglobin and myoglobin. Thus far, the scientific evidence demonstrating the significance of dietary protein is mainly derived from research with resistance exercise training regimes. This is not surprising since the general paradigm states that endurance training has insignificant effects on skeletal muscle growth. This could have resulted in an underappreciation of the role of dietary protein for the endurance athlete. To conclude, evidence of the role of protein on endurance training adaptations and performance remains scarce and is mainly derived from acute exercise studies. Therefore, future human intervention studies must unravel whether dietary protein is truly capable of augmenting endurance training adaptations and ultimately performance.
\end{abstract}




\section{Introduction}

Nutritional strategies to maximise recovery from exercise are widely used by recreational as well as elite athletes. Post-exercise carbohydrate ingestion is considered to facilitate muscle glycogen resynthesis (1), and that of proteins to repair the exercise-induced damage to the contractile proteins and for the de novo synthesis of proteins (2). Thus far, scientific evidence demonstrating the significance of dietary protein is mainly derived from research with resistance exercise training regimes (3). This is not surprising since the general paradigm states that endurance training has insignificant effects on skeletal muscle growth. This could have resulted in an underappreciation of the role of dietary protein for the endurance athlete. However, a recent review on endurance training and skeletal muscle hypertrophy revealed that both acute and chronic endurance training enhances muscle protein synthesis and skeletal muscle growth respectively (4). Particularly, they reported that eight out of nine studies on the effects of endurance training on skeletal muscle demonstrated significant muscle growth in both younger and older individuals (4). Further evidence for increased protein-needs of individuals participating in endurance training regimes comes from studies on amino acid oxidation during exercise (5) and hypothetically for capillarisation, synthesis and turnover of mitochondrial proteins and proteins involved in oxygen transport including haemoglobin and myoglobin. Just as with resistance exercise, exogenous essential amino acids are required to repair the endurance exerciseinduced muscle damage. From these considerations it becomes clear that the role of dietary protein in optimising endurance training adaptations requires further study. Therefore, the aim of this perspective is to discuss the current evidence on the role of dietary protein and the adaptive response (e.g. biochemical and physiological endpoints) with endurance training. In addition, since the mechanisms underpinning these adaptations are not fully understood, we propose a novel hypothesis (Figure 1) based on our unpublished observations and the current literature why protein intake may potentially be advantageous for individuals participating in endurance training regimes. 


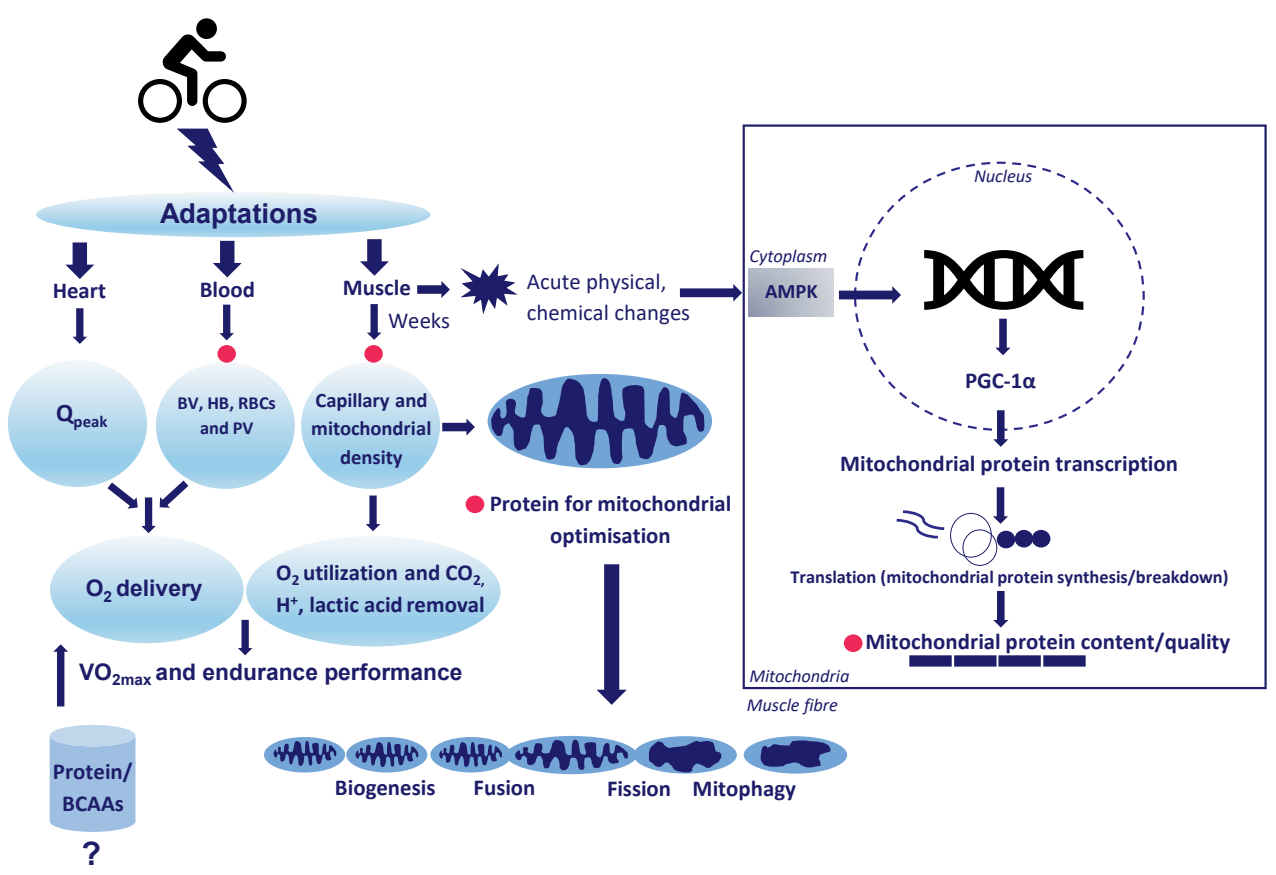

Figure 1. Simplified schematic figure representing the regulation of endurance traininginduced adaptation and the hypothetical role of dietary protein herein. Changes in heart such as maximal cardiac output and blood e.g. blood and plasma volume, haemoglobin, red blood cell volume enhances $\mathrm{O}_{2}$ oxygen-carrying capacity of the blood, whereas skeletal muscle adaptations potentially contribute to $\mathrm{O}_{2}$ extraction. Pink circles indicates where dietary proteins might play a role in adaptation with endurance training. AMPK: 5'adenosine monophosphate-activated protein kinase; BV: blood volume; HB: haemoglobin; PGC-1 $\alpha$ : peroxisome-activated receptor gamma coactivator 1-alpha; PV: plasma volume; $\mathrm{Q}_{\text {peak }}$ : peak cardiac output; RBCs: red blood cells.

\section{Adaptation to endurance training}

Endurance exercise performance roughly depends on three major aspects: I) maximal oxygen consumption $\left(\mathrm{VO}_{2 \max }\right)$, II) the percentage of $\mathrm{VO}_{2 \max }$ that can be sustained during endurance exercise, which in turn is largely dictated by the lactate threshold, and III) mechanical efficiency, defined as the energy cost to sustain a power output or velocity (6). Training these limiting factors may lead to an increase in oxidative capacity through haematological and metabolic adaptations and associated enhanced $\mathrm{O}_{2}$ transport and utilization (7). $\mathrm{O}_{2}$ transport is primarily regulated via cardiac (e.g. stroke volume) and circulatory (e.g. blood volume, $\mathrm{O}_{2}$ carrying capacity) adaptations, while improvements in $\mathrm{O}_{2}$ diffusion (involving capillaries) and utilization (involving mitochondria) are mainly the result of adaptations within skeletal muscle (e.g. mitochondrial capacity, capillary density, myoglobin, oxidative enzymes/proteins). 


\section{Protein requirements for the endurance athlete}

Synthesis and degradation rates of skeletal muscle proteins are usually in balance, ensuring that the amount of skeletal muscle proteins remains unchanged in healthy individuals (8). However, acute changes in different intramuscular protein fractions (mitochondrial, myofibrillar, sarcolemma) could be training specific. It has been proposed that endurance training augments the concentration of mitochondrial proteins without any changes in muscle size (9). Based on this idea, one could expect that different types of training would stimulate the intramuscular protein fractions differently. However, various authors reported similar increases of the effect of different exercise modes (endurance, resistance or concurrent) on mitochondrial protein synthesis during the early post-exercise period (10-15). An increased need for dietary protein could partly arise from enhanced amino acid oxidation during endurance training $(16,17)$. Indeed, earlier studies have demonstrated increased amino acid oxidation rates through stimulation of protein breakdown rates (18-21). Additionally, it has been theorised that endurance training affects amino acid requirements for an increased need of enzymes, for capillarisation, and for haemoglobin and myoglobin synthesis (16). The current sport science consensus statements on nutrition and athletic performance advises 1.2-1.4 g protein $\cdot \mathrm{kg}^{-1} \cdot \mathrm{d}^{-1}$ for endurance-trained athletes $(22,23)$. However, Kato et al (2016) studied the average protein requirements in endurance athletes during an acute 3-day training period using the indicator amino acid oxidation method and reported a recommended protein intake that is greater than the RDA $\left(0.8 \mathrm{~g} \cdot \mathrm{kg}^{1} \cdot \mathrm{d}^{1}\right)$ and the current recommendations for endurance athletes $\left(1.2-1.4 \mathrm{~g} \cdot \mathrm{kg}^{-1} \cdot \mathrm{d}^{-1}\right)(5)$. Moreover, they reported an estimated average requirement and a recommended protein intake of 1.6 of $1.8 \mathrm{~g}$ protein $\cdot \mathrm{kg}^{-1} \cdot \mathrm{d}^{-1}$ respectively. Therefore, it remains to be established whether these recommendations are optimal for individuals participating in endurance training regimes and whether this is affected by the training phase of the individual and other training parameters including intensity, type and frequency.

\section{Significance of protein ingestion before and during endurance training}

Only a few investigations have addressed the role of protein ingestion before and during endurance training modalities. In line with previous work on protein ingestion prior to and during resistance exercise (24), Coffey and colleagues reported that protein ingestion before a single bout of repeated sprints increases post-exercise myofibrillar protein synthesis (13). However, short high-intensity endurance bursts such as repeated sprints differ both energetically and metabolically from prolonged continuous endurance training. For example, prolonged endurance training stimulates the oxidation 
of amino acids, in particular isoleucine, leucine and valine, otherwise known as the branched chain amino acids (BCAAs). Even though mitochondria are capable of oxidizing a variety of amino acids, they preferentially oxidize BCAAs (25-27). These amino acids including BCAAs can be used as a substitute for carbohydrates and fat as fuel source for ATP resynthesis. When compared to carbohydrates and fat, leucine oxidation during endurance exercise is relatively low $(16,25,26,28)$, yet, the absolute leucine oxidation increases because of the increase in total energy demand during endurance exercise. Since leucine is an essential amino acid and considered to be important for its role in translational machinery (29), increased oxidation rates could depress the rates of skeletal muscle protein synthesis (30) and negatively affect protein requirements (16). Other work by Koopman and colleagues demonstrated that the combined ingestion of protein and carbohydrate throughout a prolonged endurance exercise bout (2.5 h cycling, $1 \mathrm{~h}$ of running and $2.5 \mathrm{~h}$ of cycling) improves whole body net protein balance at rest, as well as during exercise and post-exercise (31). The enhanced whole body net protein balance with protein ingestion may be partly explained by the diminished muscle protein breakdown during endurance exercise (32). Furthermore, the favoured enhanced net protein balance has been proposed as the theoretical basis for a potential ergogenic effect of protein ingestion during endurance exercise. Yet, findings of combined carbohydrate and protein ingestion during endurance exercise on performance outcomes are controversial (33). For instance, in a study by Saunders et al (2009), male cyclists performed two $60-\mathrm{km}$ time trials with either carbohydrate or carbohydrate + protein beverage every $5 \mathrm{~km}(200$ $\mathrm{ml}$ ) and post-exercise $(500 \mathrm{ml})$. No significant difference in $60-\mathrm{km}$ total time between the conditions was found. In spite of that, the addition of protein hydrolysate to the carbohydrate beverage explained a significant amount of variance in performance times between conditions during the final stages (20 $\mathrm{km}$ and $5 \mathrm{~km}$ ) of the time trial (34). The latter suggests a favourable effect of protein ingestion during exercise on endurance performance. Lastly, the addition of protein to a carbohydrate supplement consumed during exercise does not improve recovery or performance in elite cyclists despite high demands of daily exhaustive sessions during a one-week training camp (35). In summary, there is currently little evidence for improved endurance performance with protein intake before and during endurance exercise. Nevertheless, findings of abovementioned studies underline the importance of exogenous protein for remodelling/repair of the exercise-induced damaged protein. 


\section{Significance of protein ingestion after endurance exercise}

Since most of the research so far has focused on protein ingestion with resistance exercise, these findings form generally the basis for protein ingestion recommendations for individuals participating in endurance-based programs. However, the skeletal muscle adaptive response during postexercise recovery is strongly affected by food intake. Post-exercise supplementation in the form of protein after exercise has been the focus of many acute exercise interventions $(13,19,36,37)$. Only a few studies have examined the responses of dietary protein on mitochondrial protein synthesis after endurance exercise. Breen and colleagues (2011) examined the role of dietary protein on both mitochondrial and myofibrillar protein synthesis (12). In their study, trained healthy males cycled for $90 \mathrm{~min}$ at $\sim 77 \% \mathrm{VO}_{2 \max }$. Such intensity $\left(\sim 77 \% \mathrm{VO}_{2 \max }\right)$ can be considered as vigorous endurance exercise (38) and results in more mitochondrial mass and improved skeletal muscle oxidative capacity when applied chronically. Immediately and 30 min following the exercise bout, subjects ingested a carbohydrate beverage and in one condition a total of $20 \mathrm{~g}$ of whey protein was added. It was shown that the coingestion of whey protein with carbohydrate augments the myofibrillar protein synthetic response up to $4 \mathrm{~h}$ after exercise (12). Their finding, namely that endurance exercise with post-exercise dietary protein ingestion enhances myofibrillar protein synthesis, is in accordance with previous findings where subjects ingested protein after high-intensity sprint exercise (13). Noteworthy, the authors did not find a difference between the conditions on mitochondrial protein synthesis. It might be possible that the timing of the biopsy overlooked any potential increase in mitochondrial protein synthesis. Indeed, recent work by Hill et al (2013) demonstrated that the acute PGC-1 $\alpha$ mRNA, considered as the master regulator of mitochondrial biogenesis, was enhanced after a 60-min endurance bout $\left(\sim 70 \% \mathrm{VO}_{2 \max }\right)$ at $6 \mathrm{~h}$ when subjects were exposed to a 2-week dietary intervention with co-ingestion of carbohydrates + whey protein isolate (39). Their finding that carbohydrates + whey protein isolate enhanced a marker of mitochondrial recovery is in contrast with the findings of Breen et al (12). The different findings are possibly explained by the timing of the muscle biopsies and the applied nutritional strategy. For example, subjects in the study of Hill and colleagues were supplemented for two weeks with either carbohydrates or carbohydrates + whey protein isolate (39), whereas subjects in the study of Breen et al (2011) were merely supplemented post-exercise (12). Lastly, even though mitochondrial protein synthesis and PGC- $1 \alpha$ mRNA can be both used as a marker for mitochondrial recovery, comparison of findings remains difficult. 


\section{Significance of protein ingestion during the prolonged recovery period after endurance exercise}

At this moment, there is not much research on the effects of protein ingestion during the prolonged recovery period after endurance exercise (from 3 up to $12 \mathrm{~h}$ post-exercise). However, Areta and colleagues (2013) reported that the distribution of protein ingestion during the $12 \mathrm{~h}$ after resistance exercise affects the rates of myofibrillar protein synthesis (40). Specifically, in their study they compared three isocaloric timing strategies for protein ingestion during a $12 \mathrm{~h}$ period after resistance exercise: I) 2 x 40 g every $6 \mathrm{~h}$ (bolus); II) $4 \times 20$ g every $4 \mathrm{~h}$ (intermediate); and III) $8 \times 10$ g every $1.5 \mathrm{~h}$ (pulse). It was concluded that intermediate feeding was superior to either bolus or pulse feeding for stimulation of myofibrillar protein synthesis. Albeit somewhat speculative, it is likely that individuals participating in an endurance training regime also benefit from an intermediate protein ingestion strategy. Further on this notion, work from Breen and colleagues (2011) showed that the addition of protein to a carbohydrate drink in the early post-endurance exercise did not show increases in mitochondrial protein synthesis compared with a carbohydrate drink only (12). However, mitochondrial protein synthesis measurements were taken in the early post-exercise endurance period, since the latency of mitochondrial protein synthesis is currently unclear, it could be that a response at a later stage was overlooked.

\section{Long-term endurance training and the role of protein}

Unfortunately, to the best of our knowledge, the current literature still lacks studies exploring the role of dietary protein with a robust period of endurance training (> 6 weeks). The period of the endurance training intervention is an important aspect when looking at how skeletal muscle adaptations can be influenced by dietary protein. Indeed, recent work by Montero et al (2015) demonstrated that the increase in $\mathrm{VO}_{2 \text { peak }}$ with six weeks of endurance training (3-4 endurance sessions per week at $\sim 65 \% \mathrm{~W}_{\max }$ ) was primarily explained by an increase in peak cardiac output and oxygen-carrying capacity of the blood (7). Moreover, in their study, skeletal muscle adaptations related to muscle capillarisation and mitochondrial volume density did not substantially contribute to the improvements in $\mathrm{VO}_{2 \text { peak }}$ following the six weeks of endurance training. It is therefore important to conduct endurance training intervention studies over a longer period (e.g. 8, 12 or 20 weeks), especially when the purpose of the study is to explore the role of protein within the entire spectrum of the physiological adaptive response to endurance training. Only a few studies investigated the effects of protein supplementation during "longterm" (4-6 weeks) endurance training in healthy young men (41) and older adults (42). In the study of Robinson et al. (2011) young and old participants performed 3 treadmill-based aerobic sessions weekly for 6 weeks (30 minutes; 
intensity increased progressively ranging from $\sim 65 \%-85 \% \mathrm{HR}_{\max }$ ) and were provided with a post-exercise beverage containing either carbohydrates or isocaloric protein. The absolute $\mathrm{VO}_{2 \max }$ increased in the protein group but not in the carbohydrate group following six weeks of aerobic training (42). The finding that protein supplementation improves endurance training-induced oxidative adaptations is supported by the study of Ferguson-Stegall et al. (2011). In this study it was demonstrated that 60 minutes of cycling, five times a week $\left(\sim 75 \%-80 \% \mathrm{VO}_{2 \max }\right)$ for four weeks with intake of a post-exercise chocolate milk beverage, improves $\mathrm{VO}_{2 \max }$ and body composition to a greater extent compared to carbohydrates alone. Somewhat surprisingly, markers of mitochondrial adaptation such as citrate synthase activity, succinate dehydrogenase activity and PGC- $1 \alpha$ increased as a result of training independent of the type of nutritional intervention (41). Finally, supplementation of a mixture BCAAs in mice increased mitochondrial biogenesis and whole body physical endurance as measured as the time till exhaustion in a treadmill test (43). Since sport specific performance outcomes were not included in aforementioned studies, it remains unclear whether the increase in $\mathrm{VO}_{2 \max }$ improved the performance.

\section{The role of protein source}

The superiority of one protein source over another in terms of exercise adaptation has not been convincingly demonstrated (44), though type and quality can influence bioavailability (22). The choice of protein source is of additional relevance to athletes given the environmental/ethical, overall health, and bioactivity differences which have been reported (45-48). In the context of this perspective, it is the bioactivity of different protein sources that is of primary consideration, given the potential beneficial effects on oxygen diffusion and utilization. The "food first" approach to sports nutrition is widely touted, but food structure can influence the suitability of protein sources via altered kinetics of amino acid availability $(49,50)$ and digestive discomfort (51). For these reasons as well as convenience, powder-form supplements are often recommended. Given the further geo-logistic, time, and dosage demands of endurance sport, tablet-form protein supplements may be of greater facility in some instances. On a metabolic level, the presence or absence of essential amino acids (52), leucine content (53), and type of protein (48) have been shown to alter the muscle protein synthetic response and body compositional changes, prompting the development of a number of assessment methods. Despite a range of assessment scales existing (22, 52), comparisons of protein sources have centred largely on biological value (proportion of nitrogen used for tissue formation) and digestion rate $(50,54)$. Multiple authors have reported differences in biological value between protein sources $(52,54)$. In addition, it has been demonstrated that more rapidly 
digested sources (i.e. whey) seem to confer increased insulin response, postexercise muscle protein synthesis, resting muscle protein synthesis and blood leucine enrichment in the first hour after consumption (48). However, the suitability of the existing assessment scales varies with respect to their relevance to endurance athletes (as does the use of an inappropriately short 1hour assessment window). For instance, the Protein Efficiency Ratio (PER), representing mass gain per g of protein ingested, represents an inverse of suitability for most endurance athletes. Biological value too may be of limited use to endurance athletes as it considers only the tissue-related nitrogen use (thus omitting protein synthesis of oxidative enzymes and haematopoiesis, for instance). The Protein Digestibility Corrected Amino Acids Score (PDCAAS) is the most widely used assessment, but it too is limited by its lack of consideration of ileal digestibility, and the short-sightedness of determining protein quality based on the content of a single amino acid (which may be sufficiently abundant in the habitual diet). Endurance athletes demonstrate prolonged periods of increased muscle protein synthesis while still engaged in exercise, meaning protein requirements are elevated while in a state of compromised gastric function and reduced feeding opportunities (55). The PDCAAS may be of assistance to athletes engaging in ultra-endurance events, by informing a decision which should maximise essential amino acids per weight consumed, to minimise the risk of gastrointestinal distress. Coupled with personal experience of irritability triggers, this approach may be particularly practical for ultra-endurance runners and triathletes (events $>3 \mathrm{~h}$ duration).

\section{Amino acid profile bioavailability}

There is a lack of understanding concerning the practical relevance of established differences in source bioactivity on the adaptive response to endurance training, though some reports when combined suggest an adaptive advantage $(4,48)$. Unpublished data from our own study of supplementary effects of proteins on endurance training adaptation showed a response effect of habitual carbohydrate intake, before controlling for the expected variation due to casein supplementation. This suggests that the adaptation effect of supplementing even a robust bioavailable protein source is relatively low in the context of dietary effects on training outcomes, and so the importance of protein source is somewhat diminished.

Wolfe in his 2000 article raised the suggestion that endurance athletes' optimal protein intake may seek to maximise recovery (protein synthesis) while avoiding weight gain (protein deposition) (56). With this goal, one may seek to provide an endurance-tailored amino acid profile which avoids a hypertrophyoriented profile (e.g. high in leucine) and instead provides an amino acid profile more specific to the requirements of oxygen utilisation. I.e. those 
necessary for mitochondrial biogenesis (PGCs), fission (Fiss1, MPP, Drp1), mitophagy (Pink1, Parkin), fusion (Opa1, Mfn1/2), and the production of ratelimiting mitochondrial enzymes (pyruvate dehydrogenase, carnitine palmitoyl transferase). The amino acid composition of the parenthesised drivers of these processes may serve as a start-point for the elucidation of an endurancespecific ideal in terms of amino acid profile. However, the profile of downstream products, endogenous amino acid bioavailability, and the quantities involved ought to be considered. The leucine-induced increase in muscle protein synthesis is contested in humans, and high quantities may decrease autophagy (a vital aspect of endurance-specific adaptation) (Glynn et al., 2010). As such, the mechanisms of leucine's effects on body composition, muscle protein synthesis initiation factors (e.g. 4E-BP1) and autophagic regulators (e.g. ULK1) should be shown to be preferential in an endurance setting before disproportionate inclusion in supplements.

\section{$B C A A s$, casein or whey}

It has been reported that BCAAs are preferentially oxidised (ahead of unbranched amino acids) during endurance exercise $(57,58)$. Given that BCAAs are also essential and that muscle protein synthesis is elevated following but also during exercise (59), extended endurance exercise may evoke an environment of suboptimal BCAA availability. For this reason it may be beneficial to the overall adaptive response and/or performance (via substrate availability) to provide a source rich in BCAAs during extensive exercise (e.g. whey, soy or casein). When used concurrently with less intensive endurance training, high intensity and/or strength training will evoke a greater myofibrillar protein synthetic response $(60,61)$, which may improve performance adaptation (Howarth et al., 2009). The existing wisdom regarding protein supplementation is thus more likely to hold true; a readily digested source of protein with high leucine content (e.g. whey) may be preferable to maximise post-exercise muscle protein synthesis (48). In these situations protein supplementation may aid in satiety as well as achieving protein intake targets while total energy demands of training are likely decreased.

As described earlier in this paper, mitochondrial protein synthesis demonstrates a delayed response post-exercise when compared to myofibrillar protein synthesis $(60,62)$. It then follows that the acute protein requirement for endurance athletes immediately following exercise may be reduced, while the window of elevated utilisation may exist for a longer time-period compared to strength trainers. If true, the existing advice paradigm of rapidly absorbed protein to be ingested as soon as possible post-exercise may sub-optimally support the protein-synthetic adaptive response to endurance training. In consideration of this observation, protein with a slower digestion rate may be preferable. However, it has been suggested that essential amino acid content 
and rapid digestion tend to coexist in protein sources (48). Furthermore, the greater insulin response reported to accompany these properties, which may contribute to digestion rate, is likely unavoidable in the context of post endurance exercise refuelling of muscle glycogen. Consumption of postexercise protein in a whole-food form including dietary fibre to prolong the period of elevated amino acid availability is one simple solution. Division of the dose between two meals may also be necessary in order to optimally provide for protein availability over the $6+$ hrs of elevated mitochondrial/cytosolic protein synthesis.

\section{Conclusion}

To summarize, evidence of the role of protein on endurance training adaptations and performance is scarce. Yet, a number of acute endurance exercise studies have raised interesting hypotheses. However, these hypotheses are mainly based on studies measuring muscle protein synthesis, physiological (e.g. amino acid oxidation) and biochemical (e.g. activation/phosphorylation of specific enzymes/proteins or mRNA profiles) endpoints which do not necessarily reflect an improved adaptation and performance. Even though the findings of acute exercise studies contribute to the understanding of the mechanisms that underpin adaptation with endurance training, it is no direct proof that individuals performing endurance training benefit from additional protein. Future evidence must be derived from long-term endurance training studies that combine performance outcomes and biochemical/physiological endpoints. 


\section{References}

1. Burke LM, van Loon LJC, Hawley JA. Postexercise muscle glycogen resynthesis in humans. Journal of applied physiology 2017;122(5):1055-67. doi: 10.1152/japplphysiol.00860.2016.

2. Phillips SM. Dietary protein requirements and adaptive advantages in athletes. The British journal of nutrition 2012;108 Suppl 2:S158-67. doi: $10.1017 / \mathrm{s} 0007114512002516$.

3. Cermak NM, Res PT, de Groot LC, Saris WH, van Loon LJ. Protein supplementation augments the adaptive response of skeletal muscle to resistance-type exercise training: a meta-analysis. The American journal of clinical nutrition 2012;96(6):1454-64. doi: 10.3945/ajcn.112.037556.

4. Konopka AR, Harber MP. Skeletal muscle hypertrophy after aerobic exercise training. Exercise and sport sciences reviews 2014;42(2):53-61. doi: 10.1249/jes.0000000000000007.

5. Kato H, Suzuki K, Bannai M, Moore DR. Protein Requirements Are Elevated in Endurance Athletes after Exercise as Determined by the Indicator Amino Acid Oxidation Method. PloS one 2016;11(6):e0157406. doi: 10.1371/journal.pone.0157406.

6. Wackerhage H. Molecular Exercise Physiology: An Introduction: Taylor \& Francis, 2014.

7. Montero D, Cathomen A, Jacobs RA, Fluck D, de Leur J, Keiser S, Bonne T, Kirk N, Lundby AK, Lundby C. Haematological rather than skeletal muscle adaptations contribute to the increase in peak oxygen uptake induced by moderate endurance training. The Journal of physiology 2015;593(20):4677-88. doi: 10.1113/jp270250.

8. Burd NA, Tang JE, Moore DR, Phillips SM. Exercise training and protein metabolism: influences of contraction, protein intake, and sex-based differences. Journal of applied physiology 2009;106(5):1692-701. doi: 10.1152/japplphysiol.91351.2008.

9. Holloszy JO, Booth FW. Biochemical adaptations to endurance exercise in muscle. Annual review of physiology 1976;38:273-91. doi: 10.1146/annurev.ph.38.030176.001421.

10. Wilkinson SB, Phillips SM, Atherton PJ, Patel R, Yarasheski KE, Tarnopolsky MA, Rennie MJ. Differential effects of resistance and endurance exercise in the fed state on signalling molecule phosphorylation and protein synthesis in human muscle. The Journal of physiology 2008;586(Pt 15):3701-17. doi: 10.1113/jphysiol.2008.153916.

11. Robinson MM, Richards JC, Hickey MS, Moore DR, Phillips SM, Bell C, Miller BF. Acute \{beta\}-adrenergic stimulation does not alter mitochondrial protein synthesis or markers of mitochondrial biogenesis in adult men. American journal of physiology Regulatory, integrative and comparative physiology 2010;298(1):R25-33. doi: 10.1152/ajpregu.00524.2009.

12. Breen L, Philp A, Witard OC, Jackman SR, Selby A, Smith K, Baar K, Tipton KD. The influence of carbohydrate-protein co-ingestion following endurance exercise on myofibrillar and mitochondrial protein synthesis. The Journal of physiology 2011;589(Pt 16):4011-25. doi: 10.1113/jphysiol.2011.211888.

13. Coffey VG, Moore DR, Burd NA, Rerecich T, Stellingwerff T, Garnham AP, Phillips SM, Hawley JA. Nutrient provision increases signalling and protein synthesis in human skeletal muscle after repeated sprints. European journal of applied physiology 2011;111(7):1473-83. doi: 10.1007/s00421-010-1768-0.

14. Burd NA, Andrews RJ, West DW, Little JP, Cochran AJ, Hector AJ, Cashaback JG, Gibala MJ, Potvin JR, Baker SK, et al. Muscle time under tension during resistance exercise stimulates differential muscle protein sub-fractional synthetic responses in men. The Journal of physiology 2012;590(Pt 2):351-62. doi: 10.1113/jphysiol.2011.221200. 
15. Donges CE, Burd NA, Duffield R, Smith GC, West DW, Short MJ, Mackenzie R, Plank LD, Shepherd PR, Phillips SM, et al. Concurrent resistance and aerobic exercise stimulates both myofibrillar and mitochondrial protein synthesis in sedentary middle-aged men. Journal of applied physiology 2012;112(12):1992-2001. doi: 10.1152/japplphysiol.00166.2012.

16. Tarnopolsky M. Protein requirements for endurance athletes. Nutrition 2004;20(78):662-8. doi: 10.1016/j.nut.2004.04.008.

17. Moore DR, Camera DM, Areta JL, Hawley JA. Beyond muscle hypertrophy: why dietary protein is important for endurance athletes. Applied physiology, nutrition, and metabolism $=$ Physiologie appliquee, nutrition et metabolisme 2014;39(9):987-97. doi: 10.1139/apnm-2013-0591.

18. Bowtell JL, Leese GP, Smith K, Watt PW, Nevill A, Rooyackers O, Wagenmakers AJ, Rennie MJ. Effect of oral glucose on leucine turnover in human subjects at rest and during exercise at two levels of dietary protein. The Journal of physiology 2000;525 Pt $1: 271-81$.

19. Harber MP, Konopka AR, Jemiolo B, Trappe SW, Trappe TA, Reidy PT. Muscle protein synthesis and gene expression during recovery from aerobic exercise in the fasted and fed states. American journal of physiology Regulatory, integrative and comparative physiology 2010;299(5):R1254-62. doi: 10.1152/ajpregu.00348.2010.

20. Howarth KR, Phillips SM, MacDonald MJ, Richards D, Moreau NA, Gibala MJ. Effect of glycogen availability on human skeletal muscle protein turnover during exercise and recovery. Journal of applied physiology 2010;109(2):431-8. doi: 10.1152/japplphysiol.00108.2009.

21. Lemon PW, Mullin JP. Effect of initial muscle glycogen levels on protein catabolism during exercise. Journal of applied physiology: respiratory, environmental and exercise physiology 1980;48(4):624-9.

22. Jager R, Kerksick CM, Campbell BI, Cribb PJ, Wells SD, Skwiat TM, Purpura M, Ziegenfuss TN, Ferrando AA, Arent SM, et al. International Society of Sports Nutrition Position Stand: protein and exercise. Journal of the International Society of Sports Nutrition 2017;14:20. doi: 10.1186/s12970-017-0177-8.

23. American Dietetic A, Dietitians of C, American College of Sports M, Rodriguez NR, Di Marco NM, Langley S. American College of Sports Medicine position stand. Nutrition and athletic performance. Medicine and science in sports and exercise 2009;41(3):70931. doi: 10.1249/MSS.0b013e31890eb86.

24. Tipton KD, Elliott TA, Cree MG, Aarsland AA, Sanford AP, Wolfe RR. Stimulation of net muscle protein synthesis by whey protein ingestion before and after exercise. American journal of physiology Endocrinology and metabolism 2007;292(1):E71-6. doi: 10.1152/ajpendo.00166.2006.

25. McKenzie S, Phillips SM, Carter SL, Lowther S, Gibala MJ, Tarnopolsky MA. Endurance exercise training attenuates leucine oxidation and BCOAD activation during exercise in humans. American journal of physiology Endocrinology and metabolism 2000;278(4):E580-7. doi: 10.1152/ajpendo.2000.278.4.E580.

26. Phillips SM, Atkinson SA, Tarnopolsky MA, MacDougall JD. Gender differences in leucine kinetics and nitrogen balance in endurance athletes. Journal of applied physiology 1993;75(5):2134-41. doi: 10.1152/jappl.1993.75.5.2134.

27. Lamont LS, McCullough AJ, Kalhan SC. Comparison of leucine kinetics in endurancetrained and sedentary humans. Journal of applied physiology 1999;86(1):320-5. doi: 10.1152/jappl.1999.86.1.320.

28. Lamont LS, Patel DG, Kalhan SC. Leucine kinetics in endurance-trained humans. Journal of applied physiology 1990;69(1):1-6. doi: 10.1152/jappl.1990.69.1.1. 
29. Churchward-Venne TA, Burd NA, Mitchell CJ, West DW, Philp A, Marcotte GR, Baker SK, Baar K, Phillips SM. Supplementation of a suboptimal protein dose with leucine or essential amino acids: effects on myofibrillar protein synthesis at rest and following resistance exercise in men. The Journal of physiology 2012;590(11):2751-65. doi: 10.1113/jphysiol.2012.228833.

30. Rose AJ, Richter EA. Regulatory mechanisms of skeletal muscle protein turnover during exercise. Journal of applied physiology 2009;106(5):1702-11. doi: 10.1152/japplphysiol.91375.2008.

31. Koopman R, Pannemans DL, Jeukendrup AE, Gijsen AP, Senden JM, Halliday D, Saris WH, van Loon LJ, Wagenmakers AJ. Combined ingestion of protein and carbohydrate improves protein balance during ultra-endurance exercise. American journal of physiology Endocrinology and metabolism 2004;287(4):E712-20. doi: 10.1152/ajpendo.00543.2003.

32. Hulston CJ, Wolsk E, Grondahl TS, Yfanti C, G VANH. Protein intake does not increase vastus lateralis muscle protein synthesis during cycling. Medicine and science in sports and exercise 2011;43(9):1635-42. doi: 10.1249/MSS.0b013e31821661ab.

33. Saunders MJ. Coingestion of carbohydrate-protein during endurance exercise: influence on performance and recovery. International journal of sport nutrition and exercise metabolism 2007;17 Suppl:S87-103.

34. Saunders MJ, Moore RW, Kies AK, Luden ND, Pratt CA. Carbohydrate and protein hydrolysate coingestions improvement of late-exercise time-trial performance. International journal of sport nutrition and exercise metabolism 2009;19(2):136-49.

35. Hansen M, Bangsbo J, Jensen J, Krause-Jensen M, Bibby BM, Sollie O, Hall UA, Madsen $K$. Protein intake during training sessions has no effect on performance and recovery during a strenuous training camp for elite cyclists. Journal of the International Society of Sports Nutrition 2016;13:9. doi: 10.1186/s12970-016-0120-4.

36. Howarth KR, Moreau NA, Phillips SM, Gibala MJ. Coingestion of protein with carbohydrate during recovery from endurance exercise stimulates skeletal muscle protein synthesis in humans. Journal of applied physiology 2009;106(4):1394-402. doi: 10.1152/japplphysiol.90333.2008.

37. Lunn WR, Pasiakos SM, Colletto MR, Karfonta KE, Carbone JW, Anderson JM, Rodriguez NR. Chocolate milk and endurance exercise recovery: protein balance, glycogen, and performance. Medicine and science in sports and exercise 2012;44(4):682-91. doi: 10.1249/MSS.0b013e3182364162.

38. Garber CE, Blissmer B, Deschenes MR, Franklin BA, Lamonte MJ, Lee IM, Nieman DC, Swain DP. American College of Sports Medicine position stand. Quantity and quality of exercise for developing and maintaining cardiorespiratory, musculoskeletal, and neuromotor fitness in apparently healthy adults: guidance for prescribing exercise. Medicine and science in sports and exercise 2011;43(7):1334-59. doi: 10.1249/MSS.0b013e318213fefb.

39. Hill KM, Stathis CG, Grinfeld E, Hayes A, McAinch AJ. Co-ingestion of carbohydrate and whey protein isolates enhance PGC-1alpha mRNA expression: a randomised, single blind, cross over study. Journal of the International Society of Sports Nutrition 2013;10(1):8. doi: 10.1186/1550-2783-10-8.

40. Areta JL, Burke LM, Ross ML, Camera DM, West DW, Broad EM, Jeacocke NA, Moore DR, Stellingwerff T, Phillips SM, et al. Timing and distribution of protein ingestion during prolonged recovery from resistance exercise alters myofibrillar protein synthesis. The Journal of physiology 2013;591(Pt 9):2319-31. doi: 10.1113/jphysiol.2012.244897.

41. Ferguson-Stegall L, McCleave E, Ding Z, Doerner Iii PG, Liu Y, Wang B, Healy M, Kleinert M, Dessard B, Lassiter DG, et al. Aerobic exercise training adaptations are increased by 
postexercise carbohydrate-protein supplementation. Journal of nutrition and metabolism 2011;2011:623182. doi: 10.1155/2011/623182.

42. Robinson MM, Turner SM, Hellerstein MK, Hamilton KL, Miller BF. Long-term synthesis rates of skeletal muscle DNA and protein are higher during aerobic training in older humans than in sedentary young subjects but are not altered by protein supplementation. FASEB journal : official publication of the Federation of American Societies for Experimental Biology 2011;25(9):3240-9. doi: 10.1096/fj.11-186437.

43. D'Antona G, Ragni M, Cardile A, Tedesco L, Dossena M, Bruttini F, Caliaro F, Corsetti G, Bottinelli R, Carruba MO, et al. Branched-chain amino acid supplementation promotes survival and supports cardiac and skeletal muscle mitochondrial biogenesis in middleaged mice. Cell metabolism 2010;12(4):362-72. doi: 10.1016/j.cmet.2010.08.016.

44. Campbell B, Kreider RB, Ziegenfuss T, La Bounty P, Roberts M, Burke D, Landis J, Lopez $\mathrm{H}$, Antonio J. International Society of Sports Nutrition position stand: protein and exercise. Journal of the International Society of Sports Nutrition 2007;4(1):8. doi: 10.1186/1550-2783-4-8.

45. Grunert KG, Bech-Larsen T, Bredahl L. Three issues in consumer quality perception and acceptance of dairy products. International Dairy Journal 2000;10(8):575-84. doi: https://doi.org/10.1016/S0958-6946(00)00085-6.

46. Giromini C, Fekete AA, Givens DI, Baldi A, Lovegrove JA. Short-Communication: A Comparison of the In Vitro Angiotensin-1-Converting Enzyme Inhibitory Capacity of Dairy and Plant Protein Supplements. Nutrients 2017;9(12). doi: 10.3390/nu9121352.

47. Song M, Fung TT, Hu FB, Willett WC, Longo VD, Chan AT, Giovannucci EL. Association of Animal and Plant Protein Intake With All-Cause and Cause-Specific Mortality. JAMA internal medicine 2016;176(10):1453-63. doi: 10.1001/jamainternmed.2016.4182.

48. Tang JE, Moore DR, Kujbida GW, Tarnopolsky MA, Phillips SM. Ingestion of whey hydrolysate, casein, or soy protein isolate: effects on mixed muscle protein synthesis at rest and following resistance exercise in young men. Journal of applied physiology 2009;107(3):987-92. doi: 10.1152/japplphysiol.00076.2009.

49. Fardet A, Dupont D, Rioux LE, Turgeon SL. Influence of food structure on dairy protein, lipid and calcium bioavailability: A narrative review of evidence. Critical reviews in food science and nutrition 2018:1-24. doi: 10.1080/10408398.2018.1435503.

50. Dangin M, Boirie Y, Guillet C, Beaufrere B. Influence of the protein digestion rate on protein turnover in young and elderly subjects. The Journal of nutrition 2002;132(10):3228s-33s. doi: 10.1093/jn/131.10.3228S.

51. de Oliveira EP, Burini RC, Jeukendrup A. Gastrointestinal complaints during exercise: prevalence, etiology, and nutritional recommendations. Sports medicine 2014;44 Suppl 1:S79-85. doi: 10.1007/s40279-014-0153-2.

52. Hoffman JR, Falvo MJ. Protein - Which is Best? Journal of sports science \& medicine 2004;3(3):118-30.

53. Norton LE, Layman DK, Wilson GJ, Moulton C, Rupassara SI, Garlick PJ. Leucine contents of isonitrogenous protein sources predict changes in body composition and muscle mass in rats. The FASEB Journal 2010;24(1_supplement):97.5-.5. doi: 10.1096/fasebj.24.1_supplement.97.5.

54. Bauer J, Biolo G, Cederholm T, Cesari M, Cruz-Jentoft AJ, Morley JE, Phillips S, Sieber C, Stehle P, Teta D, et al. Evidence-based recommendations for optimal dietary protein intake in older people: a position paper from the PROT-AGE Study Group. Journal of the American Medical Directors Association 2013;14(8):542-59. doi: 10.1016/j.jamda.2013.05.021.

55. van Wijck K, Lenaerts K, Grootjans J, Wijnands KA, Poeze M, van Loon LJ, Dejong CH, Buurman WA. Physiology and pathophysiology of splanchnic hypoperfusion and intestinal injury during exercise: strategies for evaluation and prevention. American 
journal of physiology Gastrointestinal and liver physiology 2012;303(2):G155-68. doi: 10.1152/ajpgi.00066.2012.

56. Wolfe RR. Protein supplements and exercise. The American journal of clinical nutrition 2000;72(2 Suppl):551s-7s.

57. Hood DA, Terjung RL. Amino acid metabolism during exercise and following endurance training. Sports medicine 1990;9(1):23-35.

58. MacLean DA, Graham TE, Saltin B. Branched-chain amino acids augment ammonia metabolism while attenuating protein breakdown during exercise. The American journal of physiology 1994;267(6 Pt 1):E1010-22. doi: 10.1152/ajpendo.1994.267.6.E1010.

59. Konopka AR, Castor WM, Wolff CA, Musci RV, Reid JJ, Laurin JL, Valenti ZJ, Hamilton KL, Miller BF. Skeletal muscle mitochondrial protein synthesis and respiration in response to the energetic stress of an ultra-endurance race. Journal of applied physiology 2017;123(6):1516-24. doi: 10.1152/japplphysiol.00457.2017.

60. Philp A, Schenk S, Perez-Schindler J, Hamilton DL, Breen L, Laverone E, Jeromson S, Phillips SM, Baar K. Rapamycin does not prevent increases in myofibrillar or mitochondrial protein synthesis following endurance exercise. The Journal of physiology 2015;593(18):4275-84. doi: 10.1113/jp271219.

61. Egan B, Zierath JR. Exercise metabolism and the molecular regulation of skeletal muscle adaptation. Cell metabolism 2013;17(2):162-84. doi: 10.1016/j.cmet.2012.12.012.

62. Di Donato DM, West DW, Churchward-Venne TA, Breen L, Baker SK, Phillips SM. Influence of aerobic exercise intensity on myofibrillar and mitochondrial protein synthesis in young men during early and late postexercise recovery. American journal of physiology Endocrinology and metabolism 2014;306(9):E1025-32. doi: 10.1152/ajpendo.00487.2013. 


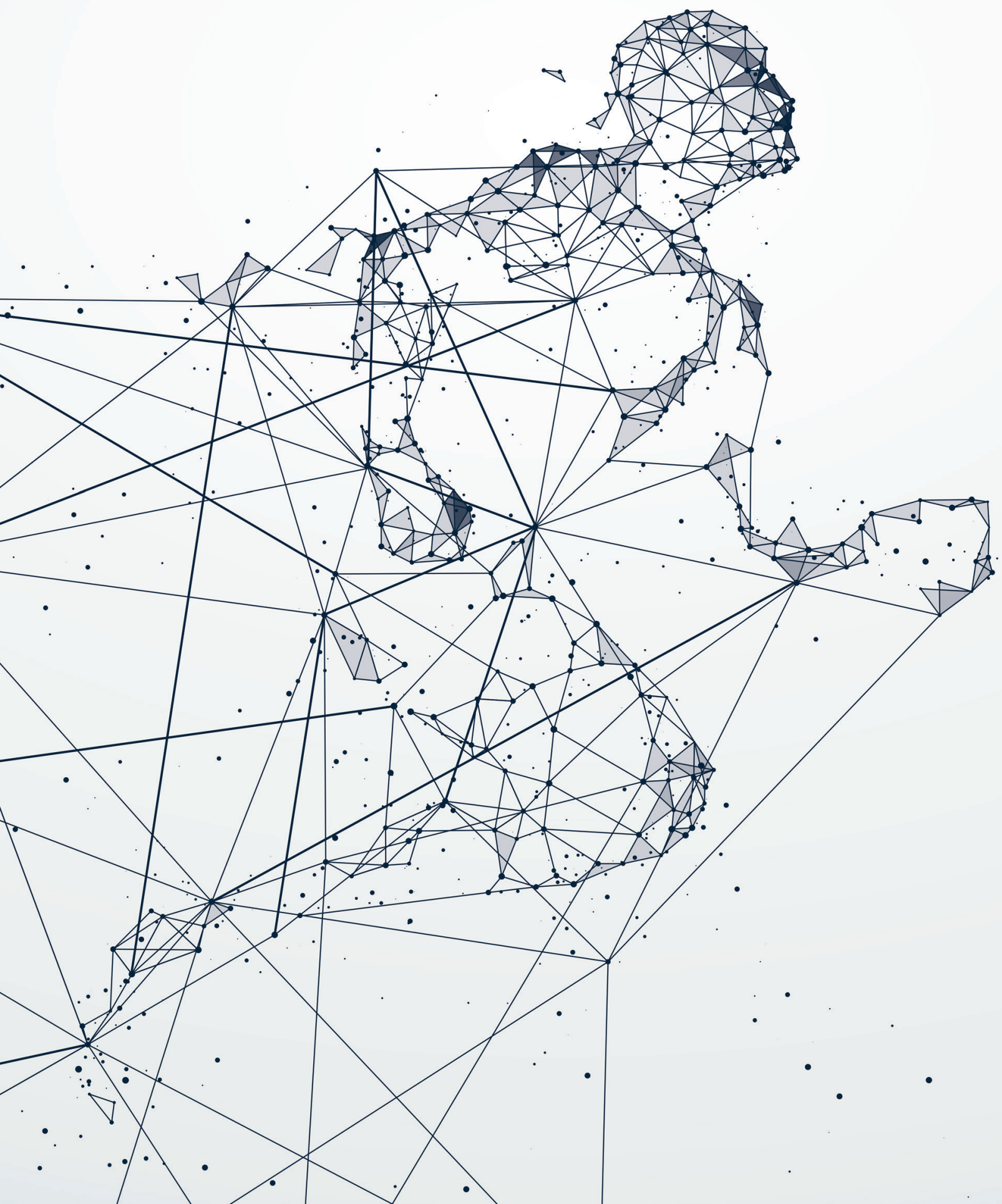




\title{
Chapter 6
}

Protein supplementation elicits greater gains in maximal oxygen uptake capacity and stimulates lean mass accretion during prolonged endurance training: a double-blind randomized controlled trial

\author{
Pim Knuiman \\ Luc van Loon \\ Jeroen Wouters \\ Maria Hopman \\ Marco Mensink
}




\section{Abstract}

Background: Endurance training induces numerous cardiovascular and skeletal muscle adaptations thereby increasing maximal oxygen uptake capacity $\left(\mathrm{VO}_{2 \max }\right)$. Whether protein supplementation enhances these adaptations remains unclear.

Objective: This study was designed to determine the impact of protein supplementation on changes in $\mathrm{VO}_{2 \max }$ during prolonged endurance training.

Design: We used a double-blind randomized controlled trial with repeated measures among 44 recreationally active, young males. Subjects performed 3 endurance training sessions per week for 10-weeks. Supplements were provided immediately after each exercise session and daily before-sleep providing either protein (PRO; $n=19 ; 21.5 \pm 0.4$ y) or an isocaloric amount of carbohydrate as control (CON; $n=21 ; 22.5 \pm 0.5 \mathrm{y}$ ). $\mathrm{VO}_{2 \max }$, simulated $10-\mathrm{km}$ time trial performance, and body composition (dual-energy X-ray absorptiometry) were measured before and after 5 and 10 weeks of endurance training. Fasting skeletal muscle tissue samples were taken before and after 5 and 10 weeks to measure skeletal muscle oxidative capacity, fasting blood samples were taken every two weeks to measure haematological factors.

Results: $\mathrm{VO}_{2 \max }$ increased to a greater extent in the PRO compared with CON group after 5 weeks (from $49.9 \pm 0.8$ to $54.9 \pm 1.1$ vs $50.8 \pm 0.9$ to $53.0 \pm 1.1 \mathrm{~mL} \cdot \mathrm{kg}$ ${ }^{1} \cdot \mathrm{min}^{-1} ; p<0.05$ ) and 10 weeks (from $49.9 \pm 0.8$ to $55.4 \pm 0.9$ vs $50.8 \pm 0.9$ to $\left.53.9 \pm 1.2 \mathrm{~mL} \cdot \mathrm{kg}^{-1} \cdot \mathrm{min}^{-1} ; p<0.05\right)$. Lean body mass increased in the PRO group whereas the CON group remained stable the first 5 weeks of $(1.5 \pm 0.2$ vs $0.1 \pm 0.3$ $\mathrm{kg} ; p<0.05)$ and after 10 weeks ( $1.5 \pm 0.3$ vs $0.4 \pm 0.3 \mathrm{~kg} ; p<0.05)$. Throughout the intervention fat mass reduced significantly in the PRO with no changes in the CON group after $5(-0.59 \pm 0.2$ vs $-0.10 \pm 0.2 \mathrm{~kg} ; p=0.09)$ and 10 weeks $(-1.24 \pm 0.4$ vs $-0.20 \pm 0.2 \mathrm{~kg} ; p=0.02)$.

Conclusions: Protein supplementation elicited greater gains in $\mathrm{VO}_{2 \max }$ and stimulated lean mass accretion but did not improve skeletal muscle oxidative capacity and endurance performance during 10 weeks of endurance training in healthy young males. 


\section{Introduction}

Endurance training represents an effective strategy to increase maximal oxygen uptake capacity $\left(\mathrm{VO}_{2 \max }\right)(1,2)$. An increase in $\mathrm{VO}_{2 \max }$ is independently associated with a reduction in all-cause mortality, which emphasizes the important clinical benefits of endurance training (3). Increases in $\mathrm{VO}_{2 \max }$ as a result of endurance training can be attributed to adaptive responses of several organ systems involved in oxygen transport and utilization chain, from lungs, heart, vasculature to the mitochondria in muscle tissue (4-7). Impact of different endurance training regimes on both cardiovascular (8-11) and skeletal muscle $(5,12-15)$ adaptations have been thoroughly investigated. In contrast, few studies have determined the impact of protein supplementation on the adaptive response to endurance training, with conflicting findings (1618). Additionally, these studies were either underpowered (17), not doubleblinded (18), or exercise training sessions were not fully monitored by investigators (16), which makes it difficult to draw conclusions about the potential effectiveness of protein supplementation for endurance training adaptation. Clearly there is a strong need for well-powered double-blind randomized controlled trials to establish whether protein supplementation impacts the adaptive response to endurance training.

Therefore, we designed a double-blind randomized controlled trial with a supplementation strategy that theoretically should be most effective based upon previous post-exercise and before-sleep protein fractional synthetic rate measurements $(19,20)$. Our main purpose was to determine the impact of protein supplementation on changes in $\mathrm{VO}_{2 \max }$ following 10-weeks of endurance training. Secondarily, we were also interested in skeletal muscle oxidative capacity, endurance performance, haematological factors and body composition. To gain insight into the timespan of adaptations we assessed all outcome measures after both 5 and 10 weeks of training. We hypothesized that protein supplementation facilitates the adaptive response to endurance training. 


\section{Methods}

\section{Subjects}

Forty-four young healthy males volunteered and gave full-written informed consent to participate in a 10-wk endurance training program, with or without additional protein supplementation. Primary inclusion criteria were nonsmokers, free of injury and not using any medication or nutritional supplements. Additional exclusion criteria that would preclude successful participation in the training study included (diagnosed) lactose intolerance and/or dairy protein allergy, cardiorespiratory-related illness and musculoskeletal-related injuries impeding with the endurance training sessions. All subjects were physically active, performing sports on a noncompetitive basis between one and four hours per week. None of the participants had a history of participating in any structured endurance training programs to improve performance over the past two years. This study was carried out in accordance with the guidelines for human research of The Medical Ethical Committee of Wageningen University. The Medical Ethical Committee of Wageningen University approved all study procedures and complied with the guidelines set by the Declaration of Helsinki of 1975 as revised in 1983. This trial was registered at clinicaltrials.gov as NCT03462381.

\section{Experimental design}

Subjects completed a progressive endurance training protocol with three exercise sessions per week for in total 10 weeks and consumed a post-exercise and pre-sleep drink providing either protein or an isocaloric amount of carbohydrate. The total study duration, including a series of mid-term and end measurements, was $\sim 12 \mathrm{wk}$. After inclusion, subjects were randomly assigned to either a protein-supplemented (PRO) or carbohydrate-supplemented control (CON) group. Before (wk 0), during (wk 6), and after (wk 12) the exercise training program, anthropometric measurements (height, body mass, and waist circumference), $\mathrm{VO}_{2 \max }$ ramp tests, simulated 10-km time-trials, and DXA scans were carried out. In addition, muscle biopsy specimens, dietary intake records, and physical activity records were collected (Figure 1). Fasting blood samples were taken at week 0 (pre), 2, 4, 6 (mid), 8, 10, and 12 (end). The subjects were instructed to maintain their normal dietary habits and physical activity patterns throughout the intervention period. A standardized meal was provided the evening before each test day (standard deep-frozen meal and icecream dessert; $43.80 \mathrm{~kJ} / \mathrm{kg}$ BW; 15 Energy\% protein, 30 Energy\% fat and 55 Energy\% carbohydrate; Roerbaksensatie, Iglo, Utrecht, the Netherlands). Subjects refrained from continuous physical activity for at least $72 \mathrm{~h}$ before testing. At the different test days, subjects arrived at the laboratory after an overnight fast. 


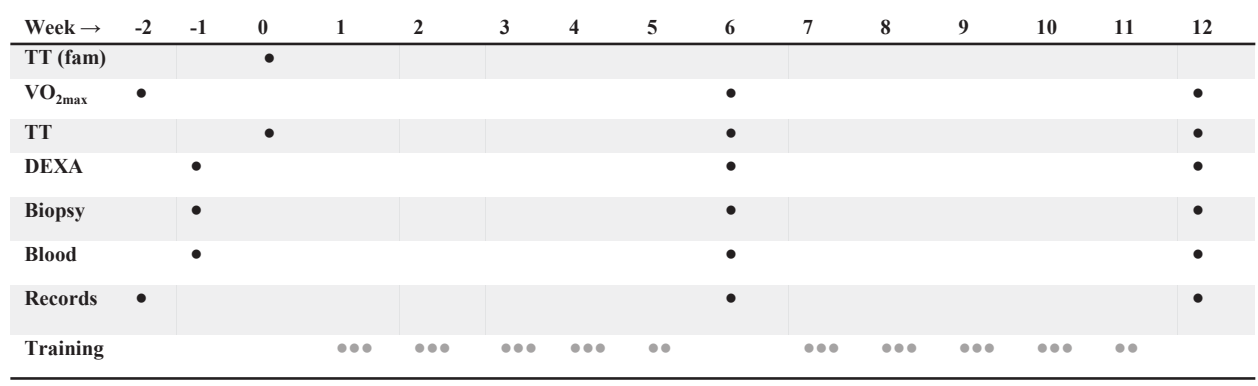

Figure 1. 40 subjects completed 10 weeks of exercise training while consuming either $29 \mathrm{~g}$ calcium casein protein or $29 \mathrm{~g}$ carbohydrates post-exercise and daily before-sleep. Measurements and biopsies were performed at Pre (week 0), Mid (week 6), and End (week 12), whereas blood samples were taken at week $0,2,4,6,8,10$ and 12. TT (fam): 10-km time-trial familiarization, TT: $10-\mathrm{km}$ time-trial, $\mathrm{VO}_{2 \max }$ : maximal oxidative capacity exercise test. Black dots: measurement points, grey dots: exercise training sessions. TT fam and TT baseline were performed within the same week with 3-4 days between time trials.

\section{Endurance training program}

Training intervention was divided in two blocks of 5 weeks with one week (week 6) in between the blocks to perform the mid-term measurements, and a final week (week 12) to perform the end-measurements. The first four weeks subjects participated in 3 endurance exercise sessions/wk alternated with one day of rest between each session. The fifth week subjects performed 2 endurance exercise sessions. This was repeated in the second part of the study (week 7-11), see Figure 1. In total, subjects performed 28 endurance training sessions. After a 10-min warm-up on a cycle ergometer, the endurance training session consisted of 60-min continuous cycling. All training sessions were conducted under supervision of a researcher using indoor, mechanically braked spinning bikes (body bike smart ${ }^{\circ}$, Denmark) with participants free to adjust resistance and cadence as desired. Heart rate (HR) for each session was recorded (Polar Electro, USA), HR and rate of perceived exertion (RPE) were taken at the start and every 5 min thereafter by the supervisor. Music and verbal motivation were provided during training sessions which were conducted in ambient conditions at sea level at thermal-neutral conditions $\left(21^{\circ} \mathrm{C}, 40 \%\right.$ relative humidity). Each endurance training session ended with a 10-min cooling down period on the same cycle ergometer. Exercise intensity was determined using the Karvonen formula (21): 
Intensity $=$ HRreserve $\cdot 0.85+$ HRrest

Where HRreserve is the calculated difference between HRmax (determined during $\mathrm{VO}_{2 \max }$ ramp test) and HRrest. According to the American College of Sports Medicine, the selected exercise intensity can be considered as "vigorous" (22).

\section{Protein and control supplementation}

Subjects consumed a $250 \mathrm{~mL}$ beverage containing either a 29 gram of casein protein or an isocaloric amount of carbohydrate immediately after cessation of each exercise session ( 3 per wk) and every day before sleep ( 7 per wk). In addition, all subjects received two slices of gingerbread directly after every training session (total energy $280 \mathrm{Kcal} ; 63.2 \mathrm{~g}$ of carbohydrates; $1.4 \mathrm{~g}$ fat; 2.4 $\mathrm{g}$ protein). An overview of the energy and macronutrient composition of the beverages can be found in Table 1. Nutritional content of the supplements was analysed in duplicate by an independent laboratory (Nutrilab bv, Rijswijk, the Netherlands) and reported analogous nutritional values as given by the producer. The protein and control beverages were masked for taste and smell by adding several additives. In addition, beverages were masked for colour and produced in white non-transparent containers. Allocation to the PRO or CON group was done using block randomization (group 1, $n=24$; group 2, $n=20$ ) by an independent researcher not involved in the study. Study drink boxes/beverages were sequentially numbered on subject number.

Table 1. Nutritional composition of the intervention drinks (250 mL)

\begin{tabular}{lll} 
Energy \& Nutrient & Control beverage (CON) & Protein beverage \\
\hline Energy (Kcal) & $\sim 129$ & $\sim 127$ \\
Protein (casein) (g) & 0.6 & 28.7 \\
Fat (g) & 2.4 & 0.3 \\
$\begin{array}{l}\text { Carbohydrates (maltodextrin } \\
\text { and sucrose) (g) }\end{array}$ & 26.3 & 2.7 \\
\hline
\end{tabular}




\section{Assessment of blinding success}

Determination of blinding success was done using the blinding index method described by James, Bloch, Lee, Kraemer and Fuller (23). Following the intervention subjects were asked what treatment they thought they have had and could choose between carbohydrate/protein/"I do not now". Subsequently, weights were given for subject's guess ( 0 for correct guess; 0.5 for incorrect guess; and 1 for "I do not know").

\section{Habitual dietary intake and physical activity}

Over the course of the intervention period, subjects maintained their habitual dietary intake and physical activity pattern. Subjects recorded 3-d (days were randomized, but in general 2 weekdays and 1 weekend day) weighted dietary intake records to assess potential changes in daily food intake that might have occurred over the course of the intervention period (week 5), before the onset of the intervention (week 0) and at week 10 of the intervention. Dietary intake records were analysed using Compl-eat (Human Nutrition, Wageningen University \& Research, the Netherlands). Habitual physical activity and supplemental exercise were assessed using the extended version of the International Physical Activity Questionnaires (IPAQ). The extended IPAQ is a self-administered 7-day physical activity recall questionnaire. Calculation and quantification of physical activity scores were determined according the guidelines for data processing and analysis of the international physical activity questionnaire, as described elsewhere (24).

\section{Body composition}

DXA measurements were carried out after an overnight fast using a Lunar Prodigy Advanced DXA scanner (GE Health Care, Madison, WI, United States of America). Each morning at the different test days, a quality assurance test was performed to ensure system suitability and precision of the scanner. Whole body scans were performed according to the manufacturer's protocol and identical scan protocols were used for all subjects. Subsequently, different regions for fat mass and lean mass were assessed. Anthropometrics were assessed using standardized procedures, body weight by digital scale to within $100 \mathrm{~g}$, height by stadiometer to within $0.5 \mathrm{~cm}$ and waist circumference by tape measure to within $0.5 \mathrm{~cm}$ (SECA, Hamburg, Germany).

$\mathrm{VO}_{2 \max }$

A ramped $\mathrm{VO}_{2 \max }$ test was performed at baseline (- $2 \mathrm{wk}$ ), mid-term and end (23 days after the last training sessions) between 9 am and $5 \mathrm{pm}$. Ninety minutes before each test, subjects consumed a standardized meal consisting of an 
energy bar (3.7 g fat, $29.2 \mathrm{~g}$ carbohydrates, $2 \mathrm{~g}$ protein, $158.1 \mathrm{Kcal}$ ), an apple (granny smith) and $500 \mathrm{ml}$ water. Following a 30-min rest, subjects performed a ramped $\mathrm{VO}_{2 \max }$ test on an electrically braked cycle ergometer (Lode Excalibur, Groningen, the Netherlands). After a 5-min warm up at $50 \mathrm{~W}$, the subjects started cycling at $100 \mathrm{~W}$. Workload was progressively increased by $20 \mathrm{~W} \cdot \mathrm{min}-1$ until the subject reached volitional exhaustion. The $\mathrm{VO}_{2 \max }$ test was considered to be valid when two out of three criteria were met: (I) levelling of $\mathrm{VO}_{2}$ with increasing workload; (II) heart rate within 10 beats of the theoretically estimated maximum (220-age); and (III) respiratory exchange ratio (RER) of $\geq 1.15$. Oxygen consumption $\left(\mathrm{VO}_{2}\right)$ was measured through breath-by-breath sampling with an Oxycon Pro (Jaeger, Hoechberg, Germany) to define maximal oxygen consumption $\left(\mathrm{VO}_{2 \text { max }}\right)$. Subjects were asked to maintain a cadence between 80 and $100 \mathrm{r} \cdot \mathrm{min}^{-1}$.

\section{Endurance exercise performance (simulated 10-km time trial)}

Familiarization was performed in the week after the start of the first experimental day (anthropometrics, DXA, blood and biopsy). Three or four days thereafter another time trial was conducted (baseline measurement) and this was repeated at mid-term and end. Subjects performed a simulated $\sim 10$ $\mathrm{km}$ cycling time trial. The data from the baseline $\mathrm{VO}_{2 \max }$ test was used for the amount of work to be performed and calculated as follows: total amount of work $(\mathrm{J})=0.85 *$ Wmax $* 900$ (s) (25). The ergometer was set in linear-mode so that $85 \%$ Wmax was achieved when subjects cycled at their preferred pedalling rate of $85 \pm 7 \mathrm{rpm}$, as determined during familiarization. Subjects received no verbal or physiological feedback during the time-trial, and were only aware of the absolute (kJ) and relative (\%) amount of work performed. Ratings of perceived exertion (RPE) were assessed after each 30-min submaximal exercise test and after the time-trial using the Borg 6-20 scale (Borg, 1982). All testing was performed under standardized conditions $\left(21{ }^{\circ} \mathrm{C}, 40 \%\right.$ relative humidity) on the same time of day, and the same day in the week. 


\section{Blood sampling \& analysis}

Resting blood samples were collected after an overnight fast at week 0, 2, 4, 6, 8, 10 and 12 in EDTA-coated Vacutainer tubes (BD Biosciences, Franklin Lakes, NJ, USA) by venipuncture. Whole blood was analysed for red blood cells, haemoglobin concentration and haematocrit.

\section{Muscle Biopsies}

Muscle biopsies were taken after an overnight fast 3-4 days prior the start of the first training session (pre), 5-7 days after the $14^{\text {th }}$ (mid-term) and $28^{\text {th }}$ (end) training session. Muscle biopsies were taken as described by Bergstrom (1974) (26). Biopsies were taken under local anaesthesia (2-3 $\mathrm{mL}$ of $2 \%$ adrenaline) using a 5-mm Bergstrom needle modified with suction. Biopsies were taken from the vastus lateralis of the same leg, with separate incisions $(\sim 1-1.5 \mathrm{~cm}$ apart) and from distal to proximal direction. Muscle biopsies were immediately frozen (within 5-10 s) in liquid nitrogen and stored at $-80^{\circ} \mathrm{C}$ for subsequent biochemical analysis, after being freed from visible fat, blood, and connective tissue.

\section{Oxidative enzymes}

Wet muscle was used for determining indices of skeletal muscle oxidative capacity. In approximately $30 \mathrm{mg}$ muscle tissue (maximal) citrate synthase (CS) and cytochrome $\mathrm{C}$ oxidase $(\mathrm{CytC})$ activity were measured according to methods published previously (27). Both enzyme activities are expressed as micromoles of product (citrate and reduced cytochrome C for CS and CytC, respectively) generated per gram of wet muscle tissue per min during the assay $\left(\mu \mathrm{mol} \cdot \mathrm{g}^{-1} \cdot \mathrm{min}^{-1}\right)$.

\section{Statistics}

Power calculation: Sample size $(n)$ was calculated with $90 \%$ power and type I error probability of 0.05 based on the primary outcome of $\mathrm{VO}_{2 \max }$ increase. An expected and/or relevant difference in $\mathrm{VO}_{2 \max }$ seen with endurance training is $0.32 \pm 0.30\left(\mathrm{~L} \cdot \mathrm{min}^{-1}\right)(28)$. To demonstrate a statistically significant greater increase in $\mathrm{VO}_{2 \max }$ by a nutritional supplement 16 participants/group have been shown to be sufficient (18). Considering a drop-out rate of $20-30 \%$, the final number of the participants included was 22/group.

General statistics: An independent $t$ test was carried out to verify that groups were similar at baseline. Data were assessed for normality with the use of a Shapiro-Wilk test, and any non - normal data (time-trial, CS and CytC) were 
corrected with the use of transformation with the type of transformation based on the nature of the skewedness of the data. Repeated measures of analysis of variance (two-way mixed ANOVA), was used to determine statistical significance for the dependent variables over time. The analysis of variance model for the dependent variables with three testing time points was described as $S_{40} \times T_{3} \times G_{2}$ as such that (S; number of subjects) are crossed with testing time (T; three testing times: Pre (week 0), Mid (week 6), and End (week 12) and group (G; CON and PRO), and for blood sample analysis $S_{40} \times T_{7} \times G_{2}$. Where two-way mixed ANOVA revealed significant interaction, a Tukey's post hoc test was conducted for multiple comparisons to further analyse within group effects and unpaired $t$-tests to compare between groups at specific time points. In case two-way mixed ANOVA revealed no significant interaction but significant main effects of time and/or group pairwise comparisons with Tukey's post hoc correction were done. Data management and statistical analysis were carried out using SPSS software version 23 (SPSS Inc., Chicago, IL). Statistical significance was declared when $p<0.05$. Figures were prepared using GraphPad Prism 8.01 for Windows (San Diego, CA). All data are expressed as mean \pm SEM. 


\section{Results}

\section{Baseline characteristics}

Four subjects dropped out during the study, one because of relocation, one because of a hamstring injury, one because of a knee injury and one because of appendicitis. Final analysis was performed on the 40 subjects who completed the training program (CON: $n=21$ vs PRO: $n=19$ ) (Figure 2).

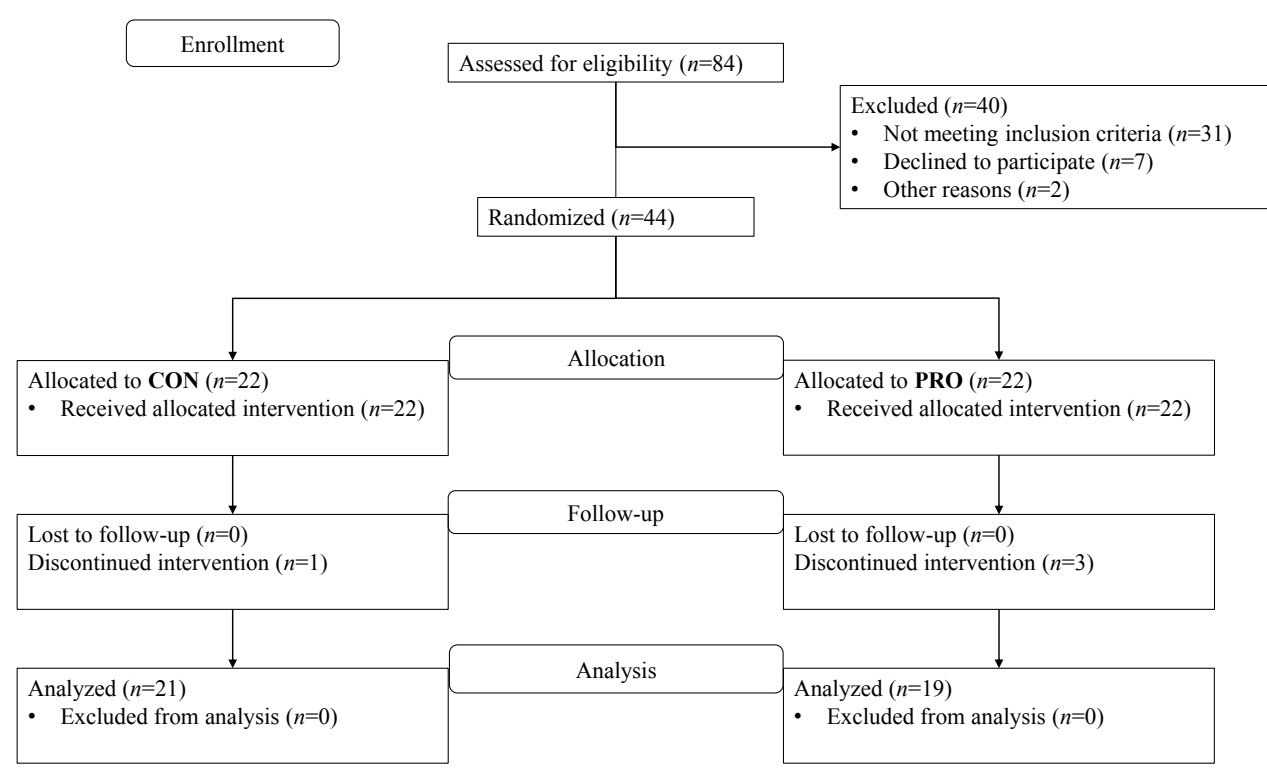

Figure 2. Subject recruitment and flow through the protocol. CON (carbohydrate supplementation, $n=21$ ); PRO (protein supplementation, $n=19$ ). 
Baseline characteristics of both groups prior to the endurance training are summarized in Table 2 . There were no differences at baseline between the CON and PRO groups in any of the variables of interest.

Table 2. Baseline characteristics

\begin{tabular}{lll} 
Characteristic & $\begin{array}{l}\text { CON }(\boldsymbol{n}= \\
\text { 21) }\end{array}$ & PRO $(\boldsymbol{n}=\mathbf{1 9})$ \\
\hline Age $(\mathrm{y})$ & $22.5 \pm 0.5$ & $21.5 \pm 0.4$ \\
Body mass $(\mathrm{kg})$ & $77.2 \pm 1.6$ & $76.3 \pm 1.3$ \\
Height $(\mathrm{m})$ & $1.85 \pm 0.0$ & $1.85 \pm 0.0$ \\
$\mathrm{BMI}\left(\mathrm{kg} \cdot \mathrm{m}^{2}\right)$ & $22.4 \pm 0.3$ & $22.3 \pm 0.4$ \\
$\mathrm{VO}_{2 \max }\left(\mathrm{mL} \cdot \mathrm{kg}^{-1} \cdot \mathrm{min}^{-1}\right)$ & $50.8 \pm 0.9$ & $49.9 \pm 0.8$ \\
\hline
\end{tabular}

1 Values are means \pm SEM. No significant differences were observed between groups. CON, carbohydrate-supplemented; PRO, protein -supplemented.

\section{Endurance training adherence \& supplement intake}

All training sessions were performed between 9 am and 9 pm with no differences between groups. On average, subjects attended $98 \pm 0.3 \%$ and $98.7 \% \pm 0.3$ of the sessions in the CON and PRO group, respectively, with no differences between groups. There was no significant time-by-treatment interaction for exercise intensity as measured by heart rate per min $(p=0.37)$ or rate of perceived exertion $(p=0.78)$ over the course of the training intervention. The post-exercise drinks were consumed under supervision resulting in a $100 \%$ compliance. The consumption of the pre-sleep drinks had an overall compliance of $98.3 \pm 0.3 \%$, with no differences between groups. Blinding success was based on the upper bound of the confidence interval of the blinding index. Confidence interval was below 0.5 indicating there was insufficient evidence for unblinding (Table 3.)

Table 3. Assessment for success of blinding

\begin{tabular}{lllllll} 
Guess N (\%) & CON & PRO & Do not know & Total & BI & 95\% CI \\
\hline CON & $7(17)$ & $6(15)$ & $8(20)$ & $21(52)$ & 0.5 & $0.32,0.72$ \\
PRO & $3(8)$ & $10(25)$ & $6(15)$ & $19(48)$ & 0.4 & $0.17,0.62$ \\
Total & $10(25)$ & $16(40)$ & $14(35)$ & $40(100)$ & &
\end{tabular}

1 Subject's guess, $n$ (\%). Determination of blinding success was done using the blinding index method described by James, Bloch, Lee, Kraemer and Fuller (23). 


\section{Habitual dietary intake and physical activity level}

Statistical analysis revealed no differences in energy intake between the groups and/or over time (Table 4.). The carbohydrate supplement increased carbohydrate intake significantly over time on training days and non-training days, while carbohydrate intake remained stable in the PRO group. In contrast, the protein supplement increased protein intake significantly over time on training days (baseline: $1.3 \pm 0.1$; mid-term: $1.8 \pm 0.1$ end: $1.8 \pm 0.1 \mathrm{~g} \cdot \mathrm{kg}^{-1} \cdot \mathrm{d}^{-1}$ ) and non-training days (baseline: $1.3 \pm 0.1$; mid-term: $1.5 \pm 0.1$ end: $1.7 \pm 0.1 \mathrm{~g} \cdot \mathrm{kg}^{-1} \cdot \mathrm{d}$ $\left.{ }^{1}\right)$, while protein intake remained stable in the CON group on training days (baseline: $1.3 \pm 0.1$; mid-term: $1.2 \pm 0.1$ end: $1.3 \pm 0.1 \mathrm{~g} \cdot \mathrm{kg}^{-1} \cdot \mathrm{d}^{-1}$ ) and non-training days (baseline: $1.3 \pm 0.1$; mid-term: $1.2 \pm 0.1$ end: $1.3 \pm 0.1 \mathrm{~g} \cdot \mathrm{kg}^{-1} \cdot \mathrm{d}^{-1}$ ). In addition to diet, habitual physical activity/exercise was also monitored. There were no differences in MET $\cdot \mathrm{min}^{-1} \cdot \mathrm{wk}^{-1}$ (excluding exercise sessions) between the groups at baseline, mid-term and end. Habitual physical activity tended to decrease after the onset of the exercise intervention in both the CON (baseline: 2415 \pm 248 ; mid-term: $1982 \pm 196$ end: $2243 \pm 248 \mathrm{MET} \cdot \mathrm{min}^{-1} \cdot \mathrm{wk}^{-1}$ ) and PRO group (baseline: $2532 \pm 275$; mid-term: $2169 \pm 246$ end: $2233 \pm 305$ MET $\cdot$ min $^{-1}$. $\left.\mathrm{wk}^{-1}\right)$.

\section{$\mathrm{VO}_{2 \max }$}

Statistical analysis revealed a significant time-by-treatment interaction for $\mathrm{VO}_{2 \max }(p=0.033) . \mathrm{VO}_{2 \max }$ increased to a greater extent in the PRO compared with CON group after 5 weeks (from $49.9 \pm 0.8$ to $54.9 \pm 1.1$ vs $50.8 \pm 0.9$ to $53.0 \pm 1.1 \mathrm{~mL} \cdot \mathrm{kg}^{-1} \cdot \mathrm{min}^{-1} ; p=0.017$ ) and after 10 weeks (from $49.9 \pm 0.8$ to $55.4 \pm 0.9$ vs $50.8 \pm 0.9$ to $53.9 \pm 1.2 \mathrm{~mL} \cdot \mathrm{kg}^{-1} \cdot \mathrm{min}^{-1} ; p=0.045$ ) (Figure $3 \mathbf{a}$ and $3 \mathbf{b}$ ). Changes in absolute $\mathrm{VO}_{2 \max }$, absolute and relative maximal aerobic power (W) were all in line with the changes in $\mathrm{VO}_{2 \max }$ and are displayed in Table 5. 


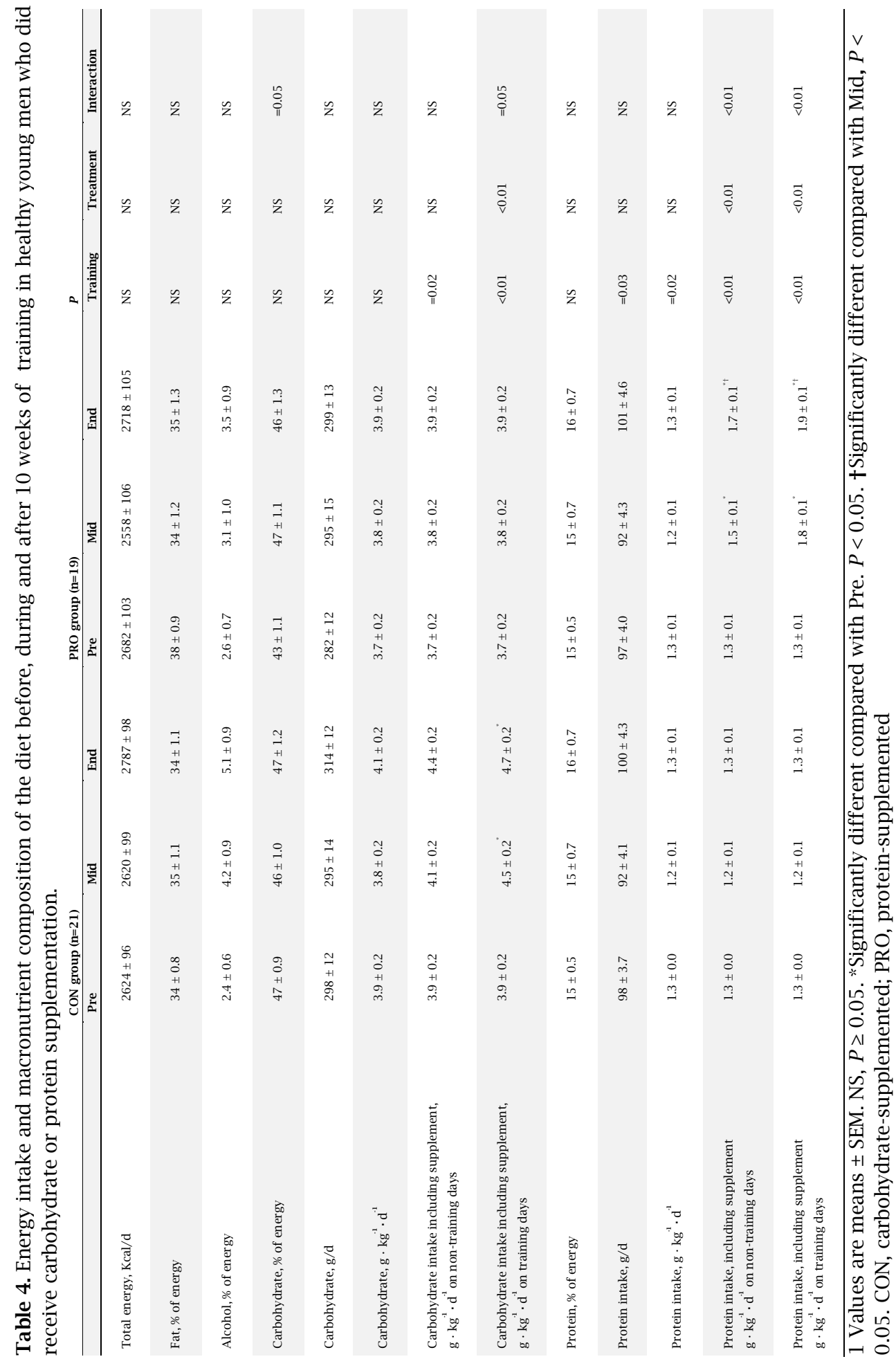




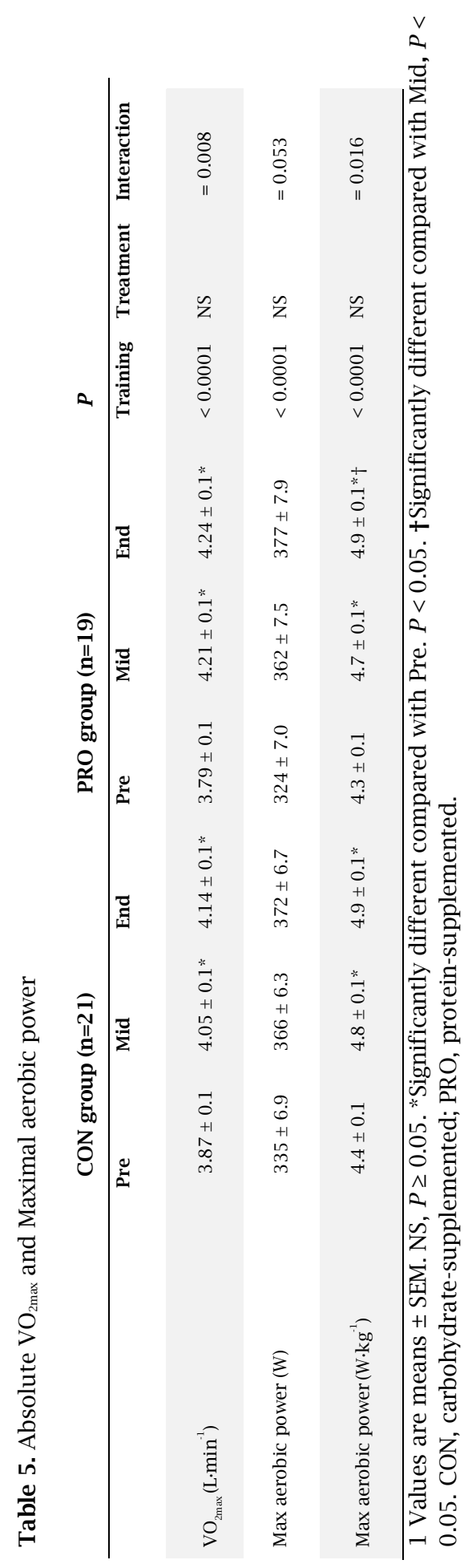




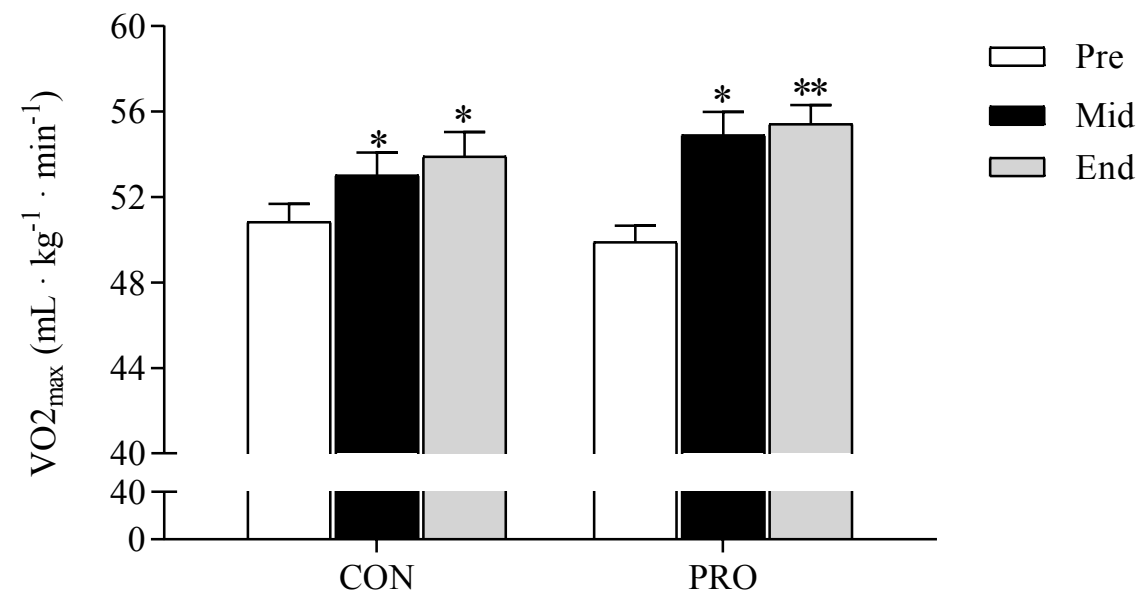

Figure 3a. Maximal oxygen uptake capacity throughout the intervention. $\mathrm{VO}_{2 \max }\left(\mathrm{mL} \cdot \mathrm{kg}^{-1} \cdot \min \right.$ $\left.{ }^{1}\right)$ during 10 -weeks of endurance training (CON, $n=21$; PRO, $\left.n=19\right)$. Values are presented as group mean \pm SEM. Data were analysed using two-way mixed ANOVA for time-by treatment interaction $(P=0.033)$. Tukey's post hoc test was conducted for multiple comparisons within each group. $*=P<0.05$ significant main effect of time compared with Pre. ${ }^{* *}=P<0.0001$ significant main effect of time compared with Pre

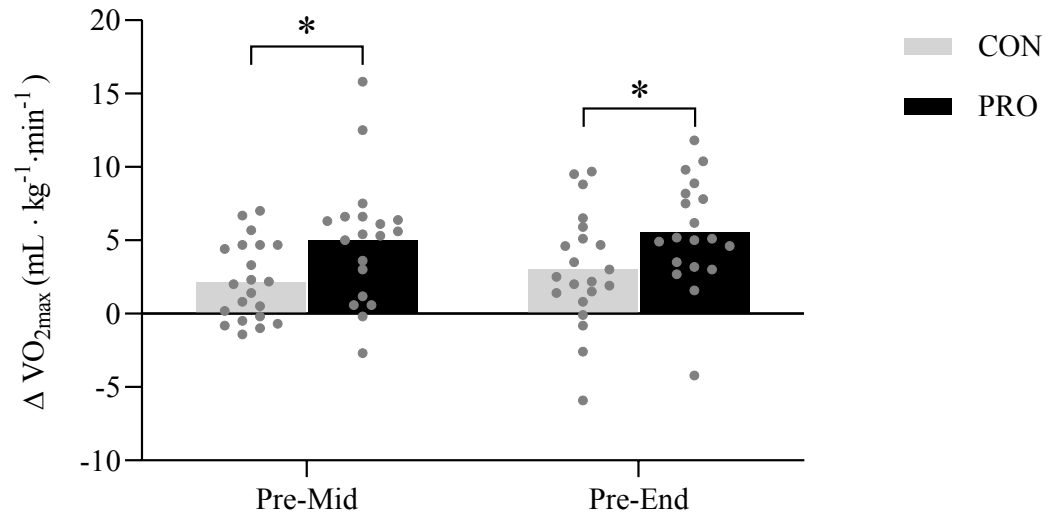

Figure 3b. Maximal oxygen uptake capacity change. Delta change in $\mathrm{VO}_{2 \max }\left(\mathrm{mL} \cdot \mathrm{kg}^{-1} \cdot \mathrm{min}^{-1}\right)$ from Pre-Mid and Pre-End during prolonged endurance training (CON, $n=21$; PRO, $n=19$ ). Values are presented as mean group difference. Grey dots indicate individual subject responses. Data were first analysed using two-way mixed ANOVA to detect time-by treatment interaction $(P=0.033)$. Unpaired $t$-tests were used to compare delta changes between groups from Pre-Mid and Pre-End. * $=P<0.05$ significantly different compared with CON. 


\section{0-km simulated time trial performance}

As a result of endurance training, 10-km time trial performance improved in both groups $(p<0.0001)$. However, protein supplementation did not enhance the exercise-induced improvements in performance (time-by-treatment interaction $p=0.64$ ) (Figure 4).

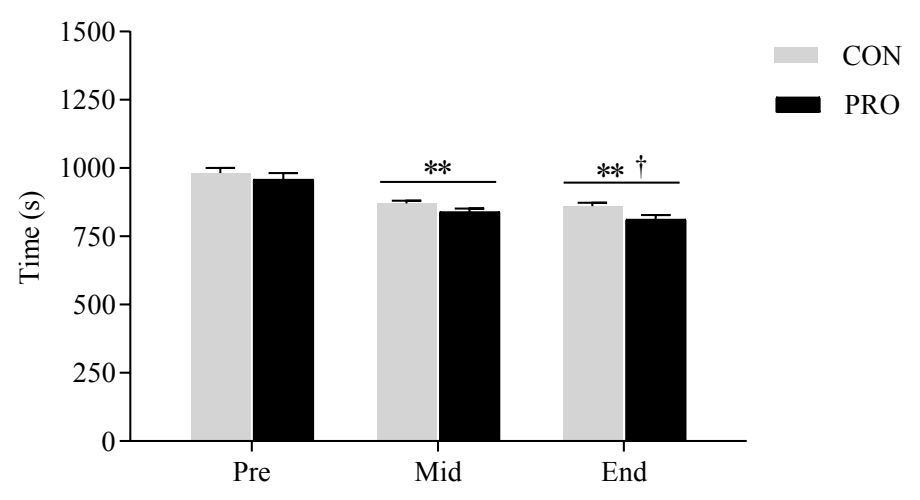

Figure 4. Endurance performance (seconds) as measured by a simulated $10-\mathrm{km}$ time trial performance bicycle test during 10-weeks of endurance training (CON, $n=21$; PRO, $n=19$ ). Values are presented as group mean \pm SEM. Data were analysed using two-way mixed ANOVA for time-by treatment interaction $(P=0.642)$. Pairwise comparison with Tukey's post hoc correction were used to determine main effects of time and group. $* * *=0.0001$ significant main effect of time compared with Pre; $\dagger=P<0.05$ significant main effect of time compared with Mid.

\section{Skeletal muscle mitochondrial enzyme activities}

Endurance training increased maximal CS activity in the CON and PRO groups after $5\left(21.7 \pm 1.3\right.$ to $28.7 \pm 1.1$ vs $23.4 \pm 1.4$ to $31.9 \pm 1.1 \mathrm{umol} \cdot \mathrm{g}^{-1} \cdot \mathrm{min}^{-1} ; p$ $<0.05)$ and 10 weeks $(21.7 \pm 1.3$ to $29.8 \pm 1.1$ vs $23.4 \pm$ to $33.9 \pm 1.2 \mathrm{umol} \cdot \mathrm{g}$ $\left.{ }^{1} \cdot \min ^{-1} ; p<0.05\right)$ of training. However, the increases in CS were not statistically different between groups at mid-term $(p=0.21)$ and end $(p=0.11)$ (Figure 5). There were no differences in changes between the CON and PRO group in maximal CytC activity after $5(24.8 \pm 0.5$ to $24.6 \pm 0.4$ vs $25.2 \pm 0.7$ to $24.0 \pm$ $\left.\left.0.7 \mathrm{umol} \cdot \mathrm{g}^{-1} \cdot \mathrm{min}^{-1}\right) ; p>0.05\right)$ and 10 weeks $(24.8 \pm 0.5$ to $23.9 \pm 0.5$ vs $25.2 \pm$ 0.7 to $\left.22.9 \pm 0.7 \mathrm{umol} \cdot \mathrm{g}^{-1} \cdot \mathrm{min}^{-1}\right) ; p>0.05$ ) of training (Figure 5). 


\section{Citrate synthase \\ Cytochrome C}

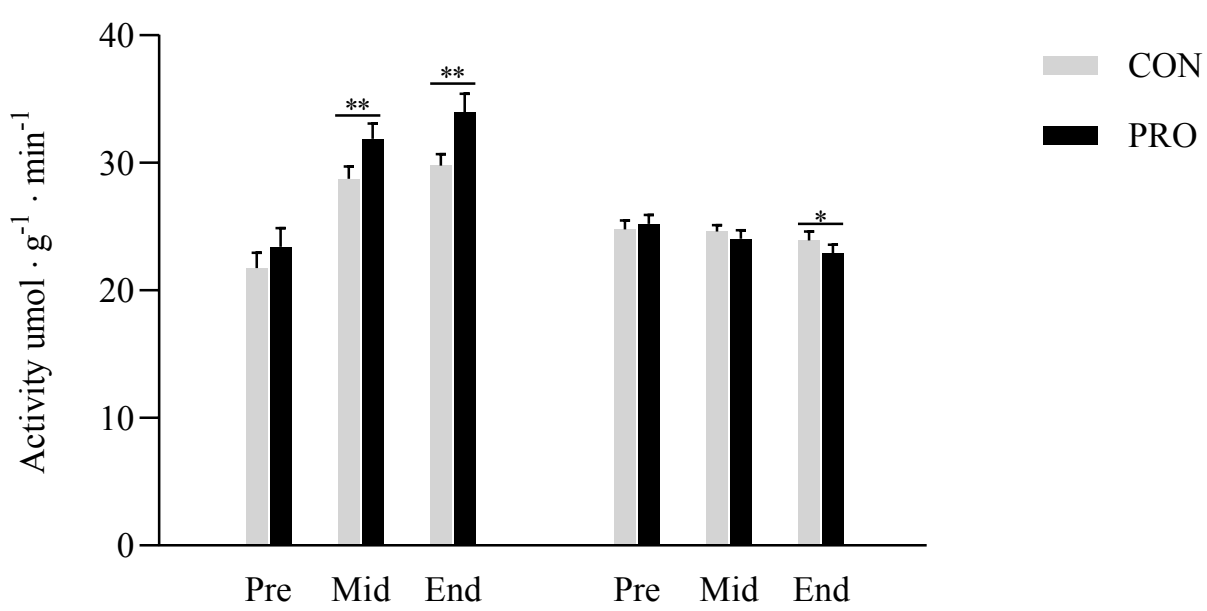

Figure 5. Skeletal muscle citrate synthase and cytochrome $C$ oxidase activity during 10-weeks of endurance training (CON, $n=21$; PRO, $n=19$ ). Values are presented as group mean \pm SEM. Enzyme activities are expressed as micromoles of product (citrate and reduced cytochrome C) generated per gram of wet tissue per min during the assay $\left(\mu \mathrm{mol} \cdot \mathrm{g}^{-1} \cdot \mathrm{min}^{-1}\right)$. Data were analysed using two-way mixed ANOVA for time-by treatment interaction for citrate synthase $(P=0.179)$ and cytochrome C $(P=0.292)$. Pairwise comparison with Tukey's post hoc correction were used to determine main effects of time and group. ${ }^{*}=P<0.05$ significant main effect of time compared with Pre; $* *=P<0.0001$ significant main effect of time compared with Pre.

\section{Haematological factors}

Compared with baseline, endurance training caused significant reductions in erythrocytes, hemoglobin, hematocrit throughout the training period while all three factors returned to baseline levels after 10 weeks of training. There was no time-by treatment interaction for any of the haematological factors (Figure 6).

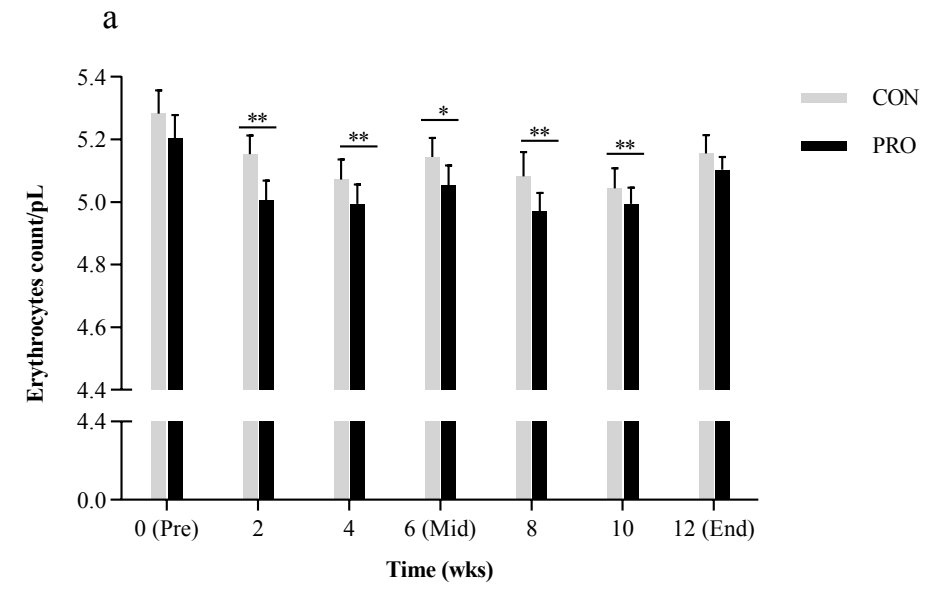


$\mathrm{b}$
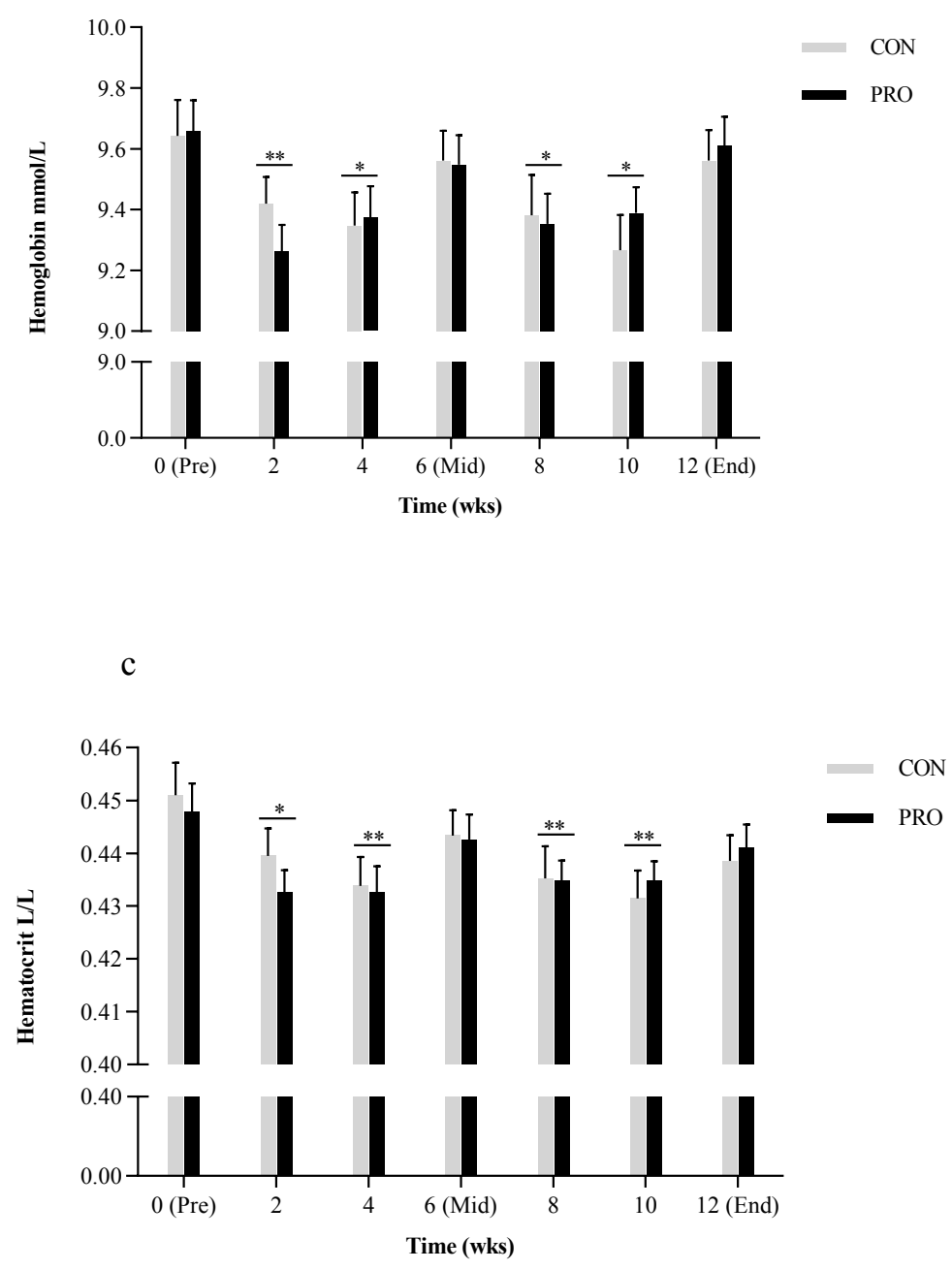

Figure 6. Haematological factors throughout the intervention. a)Erythrocytes (count/pL), b)hemoglobin $(\mathrm{mmol} / \mathrm{L})$ and c)hematocrit $(\mathrm{L} / \mathrm{L})$ during 10-weeks of endurance training (CON, $n=21$; PRO, $n=19$ ). Values are presented as group mean \pm SEM. Data were analysed using two-way mixed ANOVA for time-by treatment interaction for erythrocytes $(P=0.771)$, hemoglobin $(P=0.483)$ and hematocrit $(P=0.699)$.. Pairwise comparison with Tukey's post hoc correction were used to determine main effects of time and group. $*=P<0.05$ significant main effect of time compared with Pre; ${ }^{* *}=P<0.0001$ significant main effect of time compared with Pre. 


\section{Body composition}

There was time-by-treatment interaction $(p=0.049)$ for total body mass. Compared to baseline, body mass increased in PRO group after 5 weeks of training from $76.3 \pm 1.3$ to $77.2 \pm 1.4 \mathrm{~kg}(p=0.001)$ but returned to $76.5 \pm 1.3$ $\mathrm{kg}(p=0.73)$ after 10 weeks of training. Body mass in the CON group remained stable over the course of the intervention (baseline: $77.2 \pm 1.6$; mid-term: 77.2 \pm 1.6 ; end: $77.4 \pm 1.6 \mathrm{~kg})(p=0.82)$. A significant time-by-treatment interaction $(p=0.001)$ for whole-body lean mass was observed (Table 6). Compared to CON, lean mass increases in the PRO group were significant at week 5 ( $p<$ $0.001)$ and week 10 ( $p=0.0057)$ (Figure 7). Furthermore, there was a significant time-by-treatment interaction $(p=0.015)$ for fat mass. The decrease in fat mass between PRO and CON was statistically not different at wk $5(p=0.089)$ but reached statistical significance at wk $10(p=0.021)$ (Figure 7). Bone mineral density remained unchanged throughout the intervention in both groups. 


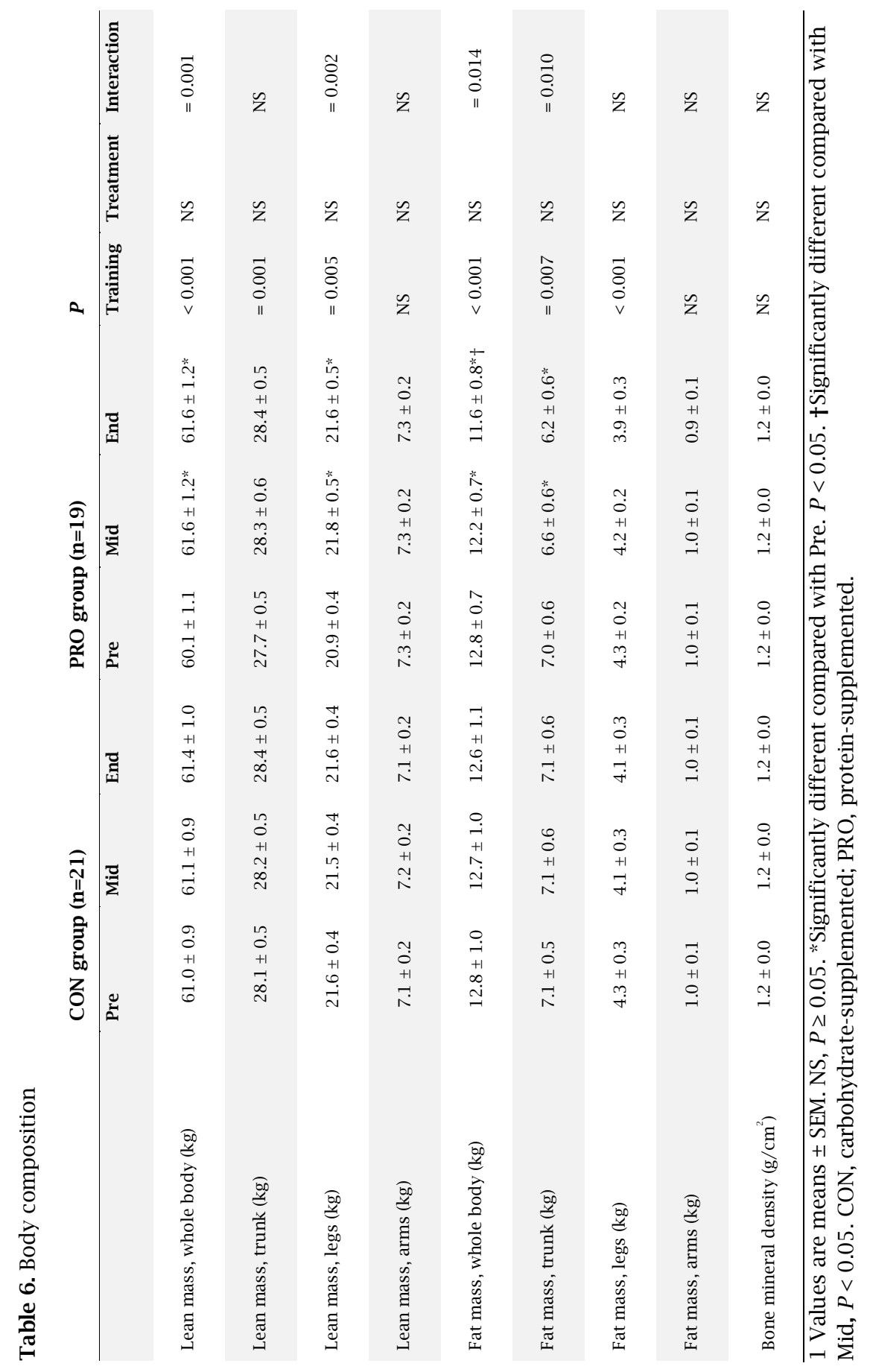


Lean mass

Fat mass

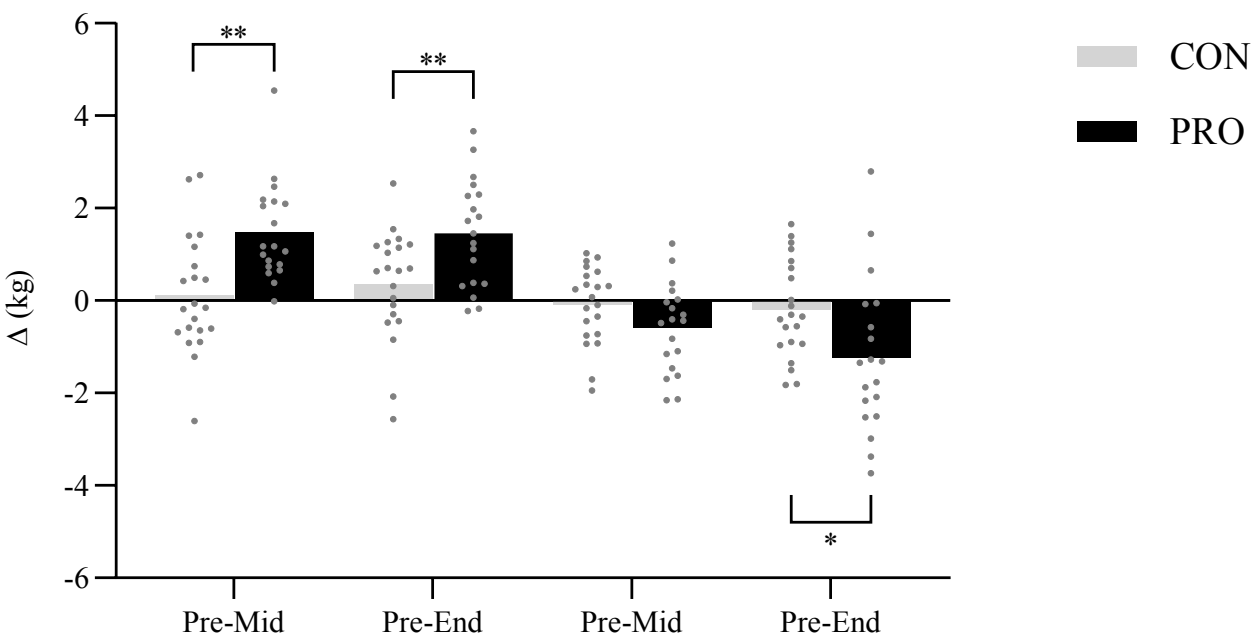

Figure 7. Delta changes in lean mass and fat mass from Pre-Mid and Pre-End during prolonged endurance training (CON, $n=21$; PRO, $n=19$ ). Values are presented as mean group difference. Grey dots indicate individual subject responses. Data were first analysed using two-way mixed ANOVA to detect time-by treatment interaction for lean mass $(P=0.001)$ and fat mass $(P=$ $0.015)$. Unpaired $t$-tests were used to compare delta changes between groups from Pre-Mid and Pre-End. ${ }^{*}=P<0.05$ significantly different compared with CON. ${ }^{* *}=P<0.0001$ significantly different compared with CON. 


\section{Discussion}

Ten weeks of endurance training increased $\mathrm{VO}_{2 \max }$, skeletal muscle oxidative capacity, and 10-km time trial performance. Adding protein supplementation elicited greater gains in $\mathrm{VO}_{2 \max }$ and stimulated lean mass accretion, while promoting fat mass loss. However, protein supplementation did not improve skeletal muscle oxidative capacity and $10-\mathrm{km}$ time-trial performance. Our findings confirm our hypothesis that protein supplementation facilitates the adaptive response during prolonged endurance training in young, healthy males.

It is well known that endurance training increases $\mathrm{VO}_{2 \max }(1)$. Our endurance training protocol substantially increased $\mathrm{VO}_{2 \max }$ after 5 and 10 weeks, which is in line with previous reports following 5-10 weeks of endurance training in healthy young males (29-31). However, after controlling for supplementation group, participants in the PRO group showed a greater increase in $\mathrm{VO}_{2 \max }$ compared to the $\mathrm{CON}$ group. The mechanism by which protein supplementation increased $\mathrm{VO}_{2 \max }$ is most likely explained by adaptive responses in both the cardiovascular and musculoskeletal system. Interestingly, in the PRO group, the increase in $\mathrm{VO}_{2 \max }$ during 5 weeks of training was accompanied by a substantial gain in lean mass, whereas lean mass remained unchanged in the CON group. In younger healthy individuals, lean mass has been well associated with $\mathrm{VO}_{2 \max }(32)$, as it was the case in our study $\left(r^{2}=0.42: p<0.0001\right)$. Yet, the strongest correlation was found between leg lean mass and $\mathrm{VO}_{2 \max }$ at week $5\left(r^{2}=0.59 ; p<0.0001\right)$. Changes in leg lean mass correlated mildly but significant with changes in $\mathrm{VO}_{2 \max }$ after 5 weeks of training $\left(r^{2} 0.20 ; p=0.003\right)$. The greater increase in $\mathrm{VO}_{2 \max }$ we found may also relate to changes in skeletal muscle oxidative capacity such as mitochondrial density and/or function (33-37). Therefore, we measured CS and CytC activity on a skeletal muscle tissue level as proxy for mitochondrial content and function $(33,38)$. The increase in CS activity in skeletal muscle tissue tended to be greater in the PRO vs CON group, but this difference did not reach statistical significance. Because of the biological individual variation in CS it was not fully unexpected that we did not reach statistical significance between groups (38). Endurance training slightly decreased maximal CytC activity in the PRO group. This could be explained by the shorter half-life of CytC compared to CS (39). Specifically, muscle biopsies were taken eight days following the last exercise training session, considering the relatively short half-life of CytC it could be argued that its activity dropped to pre-training levels and that we may have missed peak levels of maximal activity of CytC throughout the training period $(39,40)$.

While a discussion on the main determinants of improvements in $\mathrm{VO}_{2 \max }$ falls outside the scope of this investigation, recent evidence suggests that 
haematological adaptations may play a key role herein $(28,41)$. Yet, we found similar changes in concentrations of erythrocytes, hemoglobin and hematocrit between the PRO and CON group, suggesting that the differences in $\mathrm{VO}_{2 \max }$ between the groups cannot be explained by changes in oxygen-carrying capacity of blood. Adaptations in maximal cardiac output (e.g. stroke volume) and blood volume may also contribute to the greater increase in $\mathrm{VO}_{2 \max }$ in the PRO group, however, we were not able to measure this. Thus, based on our findings, the greater increase in $\mathrm{VO}_{2 \max }$ in the PRO group can be partly explained by changes in lean mass and skeletal muscle oxidative capacity.

It has previously been demonstrated that endurance training induces skeletal muscle hypertrophy (42-44). We found mild but non-significant increases in lean mass as a result of endurance training in the control group. In contrast, protein supplementation substantially increased lean mass after 5 weeks of endurance training. Our finding that lean mass had increased after 5 weeks of endurance training only when protein supplements were provided underlines the importance of adequate protein intake for skeletal muscle reconditioning during endurance training. Since endurance exercise increases muscle protein synthesis $(45,46)$, it is not surprising that studies have documented considerable muscle hypertrophy following prolonged endurance training $(42,44)$. The mechanism by which protein supplementation promotes lean mass gain is most likely the greater response following the exerciseinduced stimulation in myofibrillar protein synthesis. Indeed, it has been previously shown that ingesting protein further stimulates myofibrillar muscle protein synthesis rates during recovery from a bout of cycling exercise (46). Furthermore, protein feeding following endurance exercise modulates mRNAspecific pathways involved in myogenesis and type-I fibre remodelling (47). In addition to the gain in lean mass, we also observed a substantial loss of fat mass in the PRO group $(-1.2 \pm 0.4 \mathrm{~kg})$. The loss of fat mass could have been resulted from the gain in lean mass through increased resting energy expenditure, thereby eliciting a caloric deficit. Furthermore, fat mass loss was inversely correlated with the gain in lean mass in the PRO group $\left(r^{2}=0.5\right.$, $p=<0.001$ ). The greater increase in $\mathrm{VO}_{2 \max }$ and improved body composition as a result of protein supplementation did not increase the exercise-induced improvements in 10-km time trial performance when compared with control. Acknowledging the inter-individual variation on the $10-\mathrm{km}$ time trial, this study was probably underpowered and/or of too short duration to detect potential differences on endurance performance as a result of protein supplementation. Therefore, the benefits of protein supplementation during prolonged endurance training on exercise performance remain to be established and future work is needed to define the impact of the greater increase in $\mathrm{VO}_{2 \max }$ on various types of endurance performance, where duration and intensity may be of key importance. 
The findings observed in this study mirror findings of some $(17,18)$ but not all (16) previous studies that have determined the impact of protein supplementation on changes in $\mathrm{VO}_{2 \max }$, skeletal muscle oxidative capacity, endurance performance and body composition following prolonged endurance training. These discrepancies are most likely attributed to methodological differences between studies. For instance, aspects such as cohort size, applied exercise variables (e.g. type, duration, intensity), degree of monitoring, as well as the amount, type and timing of protein supplementation could largely affect study findings. We speculate that in our study the vigorous intensity of the exercise training performed in combination with the type of protein supplement and supplemental strategy may have contributed largely to the additional effects of protein supplementation. We decided to provide isocaloric supplements in both groups. Consequently, we provided the CON group with an isocaloric carbohydrate drink (28 g oligosaccharides). Hence, given that the carbohydrate beverage increased carbohydrate intake in the CON group it cannot be stated conclusively that merely the protein was responsible for the different responses between groups. For example, omission of post-exercise carbohydrate provision could have increased postexercise molecular signalling responses thereby improving endurance training adaptations in the PRO group (48). However, it should be noted that all subjects received two slices of gingerbread (providing 2 x $28 \mathrm{~g}$ carbohydrate) immediately after every training session implying that protein (in)availability was the key factor responsible for the findings reported here. Furthermore, analysis of habitual macronutrient intake and physical activity levels revealed no differences between the PRO and CON groups.

This is to our knowledge the first double-blind randomized controlled trial with repeated measures providing a protein supplementation strategy designed to optimize protein availability to support training adaptation during prolonged endurance training. We chose to apply a supplementation strategy that theoretically should be most effective based upon previous post-exercise and before-sleep protein fractional synthetic rate measurements. Provision of $30 \mathrm{~g}$ calcium caseinate protein after each exercise session $(19,20)$ and daily before-sleep has previously been shown effective to increase gains in muscle mass and strength following prolonged resistance training (48). Though, it must be noted that subjects in our study were provided with a protein beverage post-exercise and before-sleep, based on the supplemental strategy utilized we cannot formulate inferences as to the effectiveness of the individual supplemental strategy, or potential superiority of combining postexercise and before-sleep protein supplementation. Thus, combining the recent knowledge on the impact of protein ingestion during recovery from exercise and the impact on post-exercise muscle protein synthesis rates, we show that such a supplementation strategy effectively increases $\mathrm{VO}_{2 \max }$ and 
stimulate lean mass gain thereby enhancing the efficiency of endurance training reconditioning.

In conclusion, protein supplementation elicited greater gains in $\mathrm{VO}_{2 \max }$ and stimulated lean mass accretion, while promoting fat mass loss during 10 weeks of endurance training in healthy, young males. Protein supplementation did not improve skeletal muscle oxidative capacity and endurance performance. Therefore, protein supplementation seems to form an effective dietary strategy to enhance the adaptive response to endurance training in healthy, young males. 


\section{References}

1. Milanovic Z, Sporis G, Weston M. Effectiveness of High-Intensity Interval Training (HIT) and Continuous Endurance Training for VO2max Improvements: A Systematic Review and Meta-Analysis of Controlled Trials. Sports medicine 2015;45(10):1469-81. doi: 10.1007/s40279-015-0365-0.

2. Bacon AP, Carter RE, Ogle EA, Joyner MJ. VO2max trainability and high intensity interval training in humans: a meta-analysis. PloS one 2013;8(9):e73182. doi: 10.1371/journal.pone.0073182.

3. Kodama S, Saito K, Tanaka S, Maki M, Yachi Y, Asumi M, Sugawara A, Totsuka K, Shimano H, Ohashi Y, et al. Cardiorespiratory fitness as a quantitative predictor of allcause mortality and cardiovascular events in healthy men and women: a meta-analysis. Jama 2009;301(19):2024-35. doi: 10.1001/jama.2009.681.

4. Holmberg HC, Rosdahl H, Svedenhag J. Lung function, arterial saturation and oxygen uptake in elite cross country skiers: influence of exercise mode. Scandinavian journal of medicine \& science in sports 2007;17(4):437-44. doi: 10.1111/j.16000838.2006.00592.x.

5. Jacobs RA, Lundby C. Mitochondria express enhanced quality as well as quantity in association with aerobic fitness across recreationally active individuals up to elite athletes. Journal of applied physiology 2013;114(3):344-50. doi: 10.1152/japplphysiol.01081.2012.

6. Kjellberg SR, Rudhe U, SJÖSTRAND T. Increase of the amount of hemoglobin and blood volume in connection with physical training. Acta physiologica Scandinavica 1949;19(2-3):146-51.

7. Ogawa T, Spina RJ, Martin WH, 3rd, Kohrt WM, Schechtman KB, Holloszy JO, Ehsani AA. Effects of aging, sex, and physical training on cardiovascular responses to exercise. Circulation 1992;86(2):494-503.

8. Ekblom B, Astrand PO, Saltin B, Stenberg J, Wallstrom B. Effect of training on circulatory response to exercise. J Appl Physiol 1968;24(4):518-28. doi: 10.1152/jappl.1968.24.4.518.

9. Saltin B, Blomqvist G, Mitchell JH, Johnson RL, Wildenthal K, Chapman CB, Frenkel E, Norton W, Siperstein M, Suki W. A longitudinal study of adaptive changes in oxygen transport and body composition. Circulation 1968;38(5S7):VII-1-VII-78.

10. Sawka MN, Convertino VA, Eichner ER, Schnieder SM, Young AJ. Blood volume: importance and adaptations to exercise training, environmental stresses, and trauma/sickness. Medicine and science in sports and exercise 2000;32(2):332-48.

11. Bonne TC, Doucende G, Fluck D, Jacobs RA, Nordsborg NB, Robach P, Walther G, Lundby C. Phlebotomy eliminates the maximal cardiac output response to six weeks of exercise training. American journal of physiology Regulatory, integrative and comparative physiology 2014;306(10):R752-60. doi: 10.1152/ajpregu.00028.2014.

12. Klausen K, Secher NH, Clausen JP, Hartling O, Trap-Jensen J. Central and regional circulatory adaptations to one-leg training. Journal of applied physiology: respiratory, environmental and exercise physiology 1982;52(4):976-83. doi: 10.1152/jappl.1982.52.4.976.

13. Weng TP, Huang SC, Chuang YF, Wang JS. Effects of interval and continuous exercise training on CD4 lymphocyte apoptotic and autophagic responses to hypoxic stress in sedentary men. PloS one 2013;8(11):e80248. doi: 10.1371/journal.pone.0080248.

14. Murias JM, Kowalchuk JM, Ritchie D, Hepple RT, Doherty TJ, Paterson DH. Adaptations in capillarization and citrate synthase activity in response to endurance training in older and young men. The journals of gerontology Series A, Biological sciences and medical sciences 2011;66(9):957-64. doi: 10.1093/gerona/glr096. 
15. Hoppeler H, Luthi P, Claassen H, Weibel ER, Howald H. The ultrastructure of the normal human skeletal muscle. A morphometric analysis on untrained men, women and welltrained orienteers. Pflugers Archiv : European journal of physiology 1973;344(3):21732.

16. Roberson PA, Romero MA, Mumford PW, Osburn SC, Haun CT, Vann CG, Kluess HA, Roberts MD. Protein supplementation throughout 10 weeks of progressive run training is not beneficial for time trial improvement. Frontiers in Nutrition 2018;5:97.

17. Robinson MM, Turner SM, Hellerstein MK, Hamilton KL, Miller BF. Long-term synthesis rates of skeletal muscle DNA and protein are higher during aerobic training in older humans than in sedentary young subjects but are not altered by protein supplementation. FASEB journal : official publication of the Federation of American Societies for Experimental Biology 2011;25(9):3240-9. doi: 10.1096/fj.11-186437.

18. Ferguson-Stegall L, McCleave E, Ding Z, Doerner Iii PG, Liu Y, Wang B, Healy M, Kleinert M, Dessard B, Lassiter DG, et al. Aerobic exercise training adaptations are increased by postexercise carbohydrate-protein supplementation. Journal of nutrition and metabolism 2011;2011:623182. doi: 10.1155/2011/623182.

19. Moore DR, Robinson MJ, Fry JL, Tang JE, Glover EI, Wilkinson SB, Prior T, Tarnopolsky MA, Phillips SM. Ingested protein dose response of muscle and albumin protein synthesis after resistance exercise in young men. The American journal of clinical nutrition 2009;89(1):161-8. doi: 10.3945/ajcn.2008.26401.

20. Witard OC, Jackman SR, Breen L, Smith K, Selby A, Tipton KD. Myofibrillar muscle protein synthesis rates subsequent to a meal in response to increasing doses of whey protein at rest and after resistance exercise. The American journal of clinical nutrition 2014;99(1):86-95. doi: 10.3945/ajcn.112.055517.

21. Karvonen J, Vuorimaa T. Heart rate and exercise intensity during sports activities. Practical application. Sports medicine 1988;5(5):303-11.

22. Garber CE, Blissmer B, Deschenes MR, Franklin BA, Lamonte MJ, Lee IM, Nieman DC, Swain DP. American College of Sports Medicine position stand. Quantity and quality of exercise for developing and maintaining cardiorespiratory, musculoskeletal, and neuromotor fitness in apparently healthy adults: guidance for prescribing exercise. Medicine and science in sports and exercise 2011;43(7):1334-59. doi: 10.1249/MSS.0b013e318213fefb.

23. James KE, Bloch DA, Lee KK, Kraemer HC, Fuller RK. An index for assessing blindness in a multi-centre clinical trial: disulfiram for alcohol cessation--a VA cooperative study. Statistics in medicine 1996;15(13):1421-34. doi: 10.1002/(sici)10970258(19960715)15:13<1421::aid-sim266>3.0.co;2-h.

24. Hagstromer M, Bergman P, De Bourdeaudhuij I, Ortega FB, Ruiz JR, Manios Y, Rey-Lopez JP, Phillipp K, von Berlepsch J, Sjostrom M. Concurrent validity of a modified version of the International Physical Activity Questionnaire (IPAQ-A) in European adolescents: The HELENA Study. International journal of obesity (2005) 2008;32 Suppl 5:S42-8. doi: 10.1038/ijo.2008.182.

25. Jeukendrup A, Saris WH, Brouns F, Kester AD. A new validated endurance performance test. Medicine and science in sports and exercise 1996;28(2):266-70.

26. Bergstrom J. Percutaneous needle biopsy of skeletal muscle in physiological and clinical research. Scandinavian journal of clinical and laboratory investigation 1975;35(7):609-16.

27. Lowry OH, Passonneau JV. A flexible system of enzymatic analysis: Academic Press, 1972.

28. Montero D, Cathomen A, Jacobs RA, Fluck D, de Leur J, Keiser S, Bonne T, Kirk N, Lundby AK, Lundby C. Haematological rather than skeletal muscle adaptations 
contribute to the increase in peak oxygen uptake induced by moderate endurance training. The Journal of physiology 2015;593(20):4677-88. doi: 10.1113/jp270250.

29. Lee CM, Wood RH, Welsch MA. Influence of short-term endurance exercise training on heart rate variability. Medicine and science in sports and exercise 2003;35(6):961-9. doi: 10.1249/01.mss.0000069410.56710.da.

30. Phillips SM, Green HJ, Tarnopolsky MA, Heigenhauser GJ, Grant SM. Progressive effect of endurance training on metabolic adaptations in working skeletal muscle. The American journal of physiology 1996;270(2 Pt 1):E265-72. doi: 10.1152/ajpendo.1996.270.2.E265.

31. Spina RJ, Chi MM, Hopkins MG, Nemeth PM, Lowry OH, Holloszy JO. Mitochondrial enzymes increase in muscle in response to 7-10 days of cycle exercise. Journal of applied physiology 1996;80(6):2250-4. doi: 10.1152/jappl.1996.80.6.2250.

32. Kim C-H, Wheatley CM, Behnia M, Johnson BD. The effect of aging on relationships between lean body mass and VO2max in rowers. PloS one 2016;11(8):e0160275.

33. Larsen S, Nielsen J, Hansen CN, Nielsen LB, Wibrand F, Stride N, Schroder HD, Boushel R, Helge JW, Dela F, et al. Biomarkers of mitochondrial content in skeletal muscle of healthy young human subjects. The Journal of physiology 2012;590(14):3349-60. doi: 10.1113/jphysiol.2012.230185.

34. Holloszy JO. Biochemical adaptations in muscle. Effects of exercise on mitochondrial oxygen uptake and respiratory enzyme activity in skeletal muscle. The Journal of biological chemistry 1967;242(9):2278-82.

35. Holloszy JO, Booth FW. Biochemical adaptations to endurance exercise in muscle. Annual review of physiology 1976;38:273-91. doi: 10.1146/annurev.ph.38.030176.001421.

36. Holloszy JO, Coyle EF. Adaptations of skeletal muscle to endurance exercise and their metabolic consequences. Journal of applied physiology: respiratory, environmental and exercise physiology 1984;56(4):831-8.

37. Holloszy JO, Oscai LB, Don IJ, Mole PA. Mitochondrial citric acid cycle and related enzymes: adaptive response to exercise. Biochemical and biophysical research communications 1970;40(6):1368-73.

38. Vigelso A, Andersen NB, Dela F. The relationship between skeletal muscle mitochondrial citrate synthase activity and whole body oxygen uptake adaptations in response to exercise training. International journal of physiology, pathophysiology and pharmacology 2014;6(2):84-101.

39. Henriksson J, Reitman JS. Time course of changes in human skeletal muscle succinate dehydrogenase and cytochrome oxidase activities and maximal oxygen uptake with physical activity and inactivity. Acta physiologica Scandinavica 1977;99(1):91-7. doi: 10.1111/j.1748-1716.1977.tb10356.x.

40. Terjung RL. The turnover of cytochrome c in different skeletal-muscle fibre types of the rat. The Biochemical journal 1979;178(3):569-74.

41. Montero D, Lundby C. Regulation of Red Blood Cell Volume with Exercise Training. Comprehensive Physiology 2018;9(1):149-64. doi: 10.1002/cphy.c180004.

42. Harber MP, Konopka AR, Undem MK, Hinkley JM, Minchev K, Kaminsky LA, Trappe TA, Trappe S. Aerobic exercise training induces skeletal muscle hypertrophy and agedependent adaptations in myofiber function in young and older men. Journal of applied physiology 2012;113(9):1495-504. doi: 10.1152/japplphysiol.00786.2012.

43. Konopka AR, Harber MP. Skeletal muscle hypertrophy after aerobic exercise training. Exercise and sport sciences reviews 2014;42(2):53-61. doi: 10.1249/jes.0000000000000007.

44. Harber MP, Konopka AR, Douglass MD, Minchev K, Kaminsky LA, Trappe TA, Trappe S. Aerobic exercise training improves whole muscle and single myofiber size and function 
in older women. American journal of physiology Regulatory, integrative and comparative physiology 2009;297(5):R1452-9. doi: 10.1152/ajpregu.00354.2009.

45. Short KR, Vittone JL, Bigelow ML, Proctor DN, Nair KS. Age and aerobic exercise training effects on whole body and muscle protein metabolism. American journal of physiology Endocrinology and metabolism 2004;286(1):E92-101. doi: 10.1152/ajpendo.00366.2003.

46. Breen L, Philp A, Witard OC, Jackman SR, Selby A, Smith K, Baar K, Tipton KD. The influence of carbohydrate-protein co-ingestion following endurance exercise on myofibrillar and mitochondrial protein synthesis. The Journal of physiology 2011;589(Pt 16):4011-25. doi: 10.1113/jphysiol.2011.211888.

47. Rowlands DS, Thomson JS, Timmons BW, Raymond F, Fuerholz A, Mansourian R, Zwahlen MC, Metairon S, Glover E, Stellingwerff T, et al. Transcriptome and translational signaling following endurance exercise in trained skeletal muscle: impact of dietary protein. Physiological genomics 2011;43(17):1004-20. doi: 10.1152/physiolgenomics.00073.2011.

48. Bartlett JD, Hawley JA, Morton JP. Carbohydrate availability and exercise training adaptation: Too much of a good thing? European journal of sport science 2015;15(1):312. doi: 10.1080/17461391.2014.920926. 


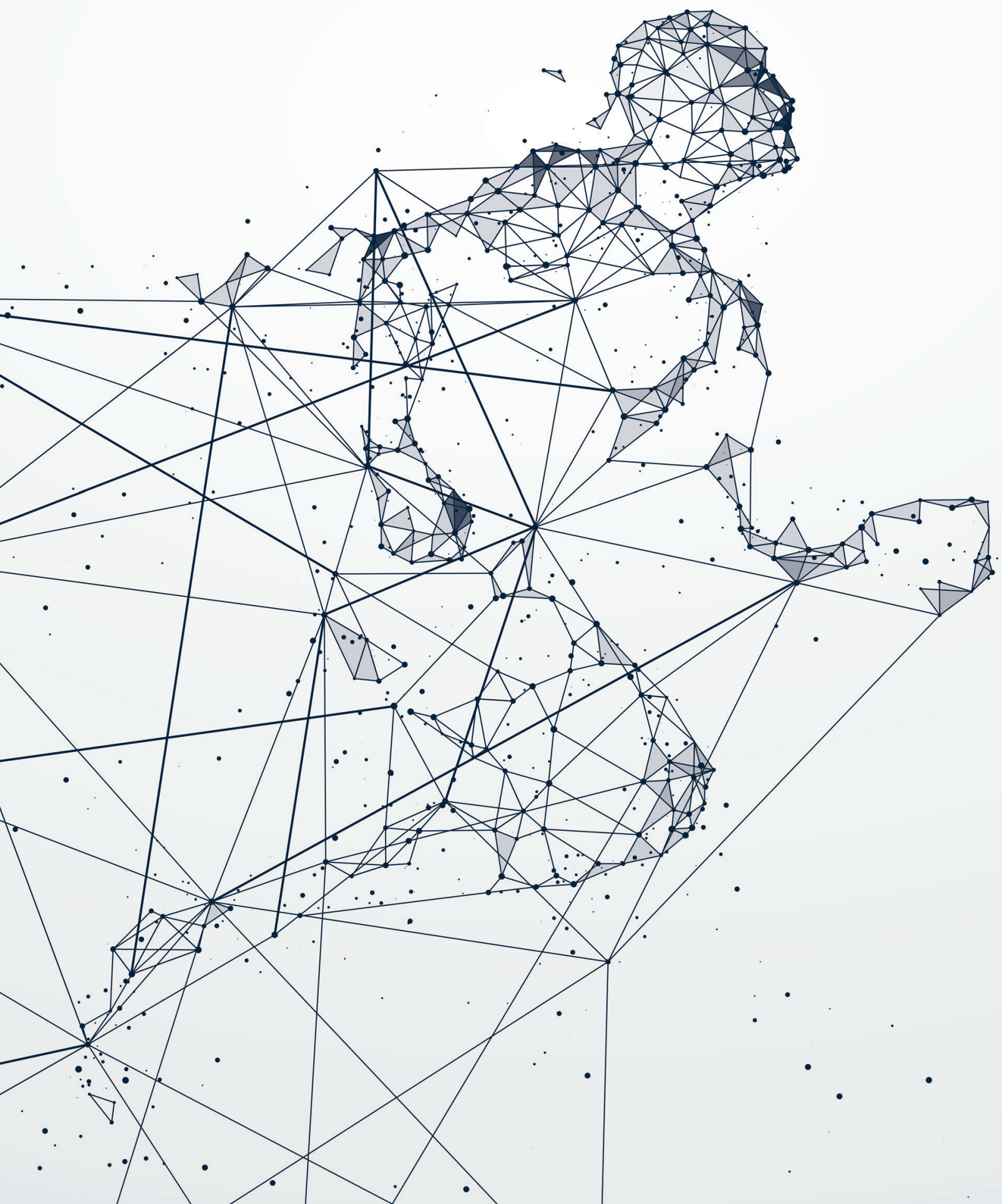




\title{
Chapter 7
}

\section{Regulation of skeletal muscle transcriptome is increased by protein supplementation and reflects the extent of physiological adaptation to endurance training}

\author{
Pim Knuiman \\ Roland Hangelbroek \\ Mark Boekschoten \\ Maria Hopman \\ Marco Mensink
}




\section{Abstract}

Background: Protein supplementation has shown to enhance physiological adaptation to endurance training. Whether protein supplementation affect the adaptive skeletal muscle transcriptome response to endurance training remains unknown. The present analysis was executed to determine the impact of protein supplementation on changes in the skeletal muscle transcriptome following prolonged endurance training.

Methods: We used a double-blind randomized controlled trial among 44 recreationally active young males. Subjects performed three endurance training sessions per week for five weeks. Supplements were provided immediately after each exercise session and daily before sleep providing either protein (PRO; $n=19 ; 21.5 \pm 0.4$ y) or an isocaloric amount of carbohydrate as control (CON; $n=21 ; 22.5 \pm 0.5$ y). Fasting skeletal muscle tissue samples from the vastus lateralis were taken before and after five weeks to measure skeletal muscle transcriptome.

Results: Endurance training significantly induced gene expression related to extracellular matrix remodelling and oxidative phosphorylation. Gene expression changes as a result of endurance training was overall larger in the protein group than in the control group. Regulation of skeletal muscle gene expression transcripts related to extracellular matrix remodelling tended to be greater in the protein group than in control group.

Conclusions: Endurance training increased gene expression transcripts related to the extracellular matrix organization and oxidative phosphorylation. Transcriptional changes in skeletal muscle due to endurance training tended to be increased by protein supplementation. The subtle differing extracellular matrix expression profile may reflect the enhanced physiological adaptation as result of protein supplementation. 


\section{Background}

Skeletal muscle is an extraordinary malleable tissue which is demonstrated by its rapid remodelling and adaptation to several kinds of stress, such as exercise $(1,2)$. Repetitive bouts of endurance exercise, e.g. endurance training, lead to various metabolic and morphological adaptations in skeletal muscle (3, 4). At the myocellular level, long term skeletal muscle adaptation is the result of repeated modifications in transcriptional and translational responses of each exercise bout thereby increasing the synthesis of specific proteins required for remodelling (5-8). Skeletal muscle transcriptome analysis provides an unbiased examination of the molecular alterations to exercise training, thereby potentially unravelling novel pathways involved in adaption to endurance training (9-11).

Protein feeding following endurance exercise has shown to affect mRNAspecific pathways involved in extracellular matrix, myogenesis, immunogenic response, and energy metabolism (12). We recently demonstrated that protein supplementation increased physiological adaptation to prolonged endurance training, where the major part of the increase in physiological variables was observed during the first 5 weeks of the 10 week training intervention (Knuiman et al., 2019, in press). Whether the beneficial effects of protein supplementation during prolonged endurance training are also pronounced at the skeletal muscle transcriptional level remains unknown. To this end, we assessed the impact of protein supplementation during 5 weeks of endurance training on changes in the skeletal muscle transcriptome. We hypothesize that protein supplementation elicits greater changes in the skeletal muscle transcriptome when compared to carbohydrate supplementation. 


\section{Methods}

\section{Subjects}

Forty-four young healthy males volunteered and gave full-written informed consent to participate in a 10-wk endurance training program, with or without additional protein supplementation. Primary inclusion criteria were nonsmokers, free of injury and not using any medication or nutritional supplements. Additional exclusion criteria that would preclude successful participation in the training study included (diagnosed) lactose intolerance and/or dairy protein allergy, cardiorespiratory-related illness and musculoskeletal-related injuries impeding with the endurance training sessions. All subjects were physically active, performing sports on a noncompetitive basis between one and four hours per week. None of the participants had a history of participating in any structured endurance training programs to improve performance over the past two years. This study was carried out in accordance with the guidelines for human research of The Medical Ethical Committee of Wageningen University. The Medical Ethical Committee of Wageningen University approved all study procedures and complied with the guidelines set by the Declaration of Helsinki of 1975 as revised in 1983. This trial was registered at clinicaltrials.gov as NCT03462381 and adheres to CONSORT guidelines for clinical trials.

\section{Experimental design}

Subjects completed a progressive endurance training protocol with three exercise sessions per week for in total 10 weeks and consumed a post-exercise and pre-sleep drink providing either protein or an isocaloric amount of carbohydrate. The total study duration, including a series of mid-term and end measurements, was $\sim 12 \mathrm{wk}$. After inclusion, subjects were randomly assigned to either a protein-supplemented (PRO) or carbohydrate-supplemented control (CON) group. Before (wk 0), during (wk 6), and after (wk 12) the exercise training program, anthropometric measurements (height, body mass, and waist circumference), $\mathrm{VO}_{2 \max }$ ramp tests, simulated $10-\mathrm{km}$ time-trials, and DEXA scans were carried out. In addition, muscle biopsy specimens, dietary intake records, and physical activity records were collected (Figure 1). Fasting blood samples were taken at week 0 (pre), 2, 4, 6 (mid), 8, 10, and 12 (end). The subjects were instructed to maintain their normal dietary habits and physical activity patterns throughout the intervention period. A standardized meal was provided the evening before each test day (standard deep-frozen meal and icecream dessert; $43.80 \mathrm{~kJ} / \mathrm{kg}$ BW; 15 Energy\% protein, 30 Energy\% fat and 55 Energy\% carbohydrate; Roerbaksensatie, Iglo, Utrecht, the Netherlands). Subjects refrained from continuous physical activity for at least $72 \mathrm{~h}$ before 
testing. At the different test days, subjects arrived at the laboratory after an overnight fast.

\section{Endurance training program}

Training intervention was divided in two blocks of five weeks with one week (week 6) in between the blocks to perform the mid-term measurements, and a final week (week 12) to perform the end-measurements. The first four weeks subjects participated in three endurance exercise sessions/wk alternated with one day of rest between each session. The fifth week subjects performed 2 endurance exercise sessions, see Figure 1.

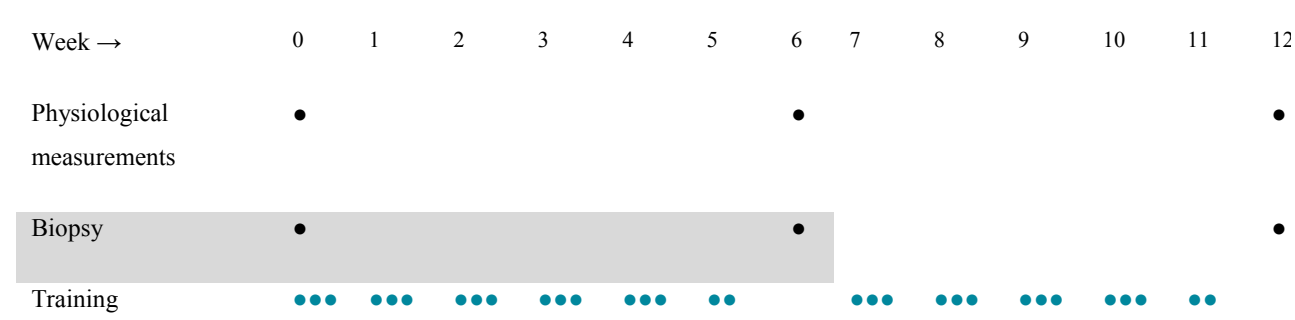

Figure 1. Schematic overview of the study protocol. 40 subjects completed $10 \mathrm{wk}$ of progressive endurance training while consuming either $25 \mathrm{~g}$ carbohydrates or $25 \mathrm{~g}$ protein post-exercise and daily before sleep. All measurements were assessed before, midterm (week 6) and after (week 12). Strongest effect of protein supplementation was observed following 5 weeks of endurance training. To gain more insight into mechanisms underlying greater physiological adaptation as a result of protein supplementation we analysed skeletal muscle transcriptome data from baseline to midterm. Black dots: measurement points, bleu dots: exercise sessions. Grey part: contains physiological and microarray data analysed for this manuscript.

In total, subjects performed 28 endurance exercise training sessions. After a 10-min warm-up on a cycle ergometer, the endurance training session consisted of 60-min continuous cycling. All training sessions were conducted under supervision of a researcher using indoor, mechanically braked spinning bikes (Body Bike Smart ${ }^{\circ}$, Denmark) with participants free to adjust resistance and cadence as desired. Heart rate (HR) for each session was recorded (Polar Electro, United States of America), HR and rate of perceived exertion (RPE) were taken at the start and every 5 min thereafter by the supervisor. Music and verbal motivation were provided during training sessions which were conducted in ambient conditions at sea level at thermal-neutral conditions $\left(21^{\circ} \mathrm{C}, 40 \%\right.$ relative humidity). Each endurance training session ended with a 
10-min cooling down period on the same cycle ergometer. Exercise intensity was determined using the Karvonen formula (13):

$$
\text { Intensity }=\text { HRreserve } \cdot 0.85+\text { HRrest }
$$

Where HRreserve is the calculated difference between HRmax (determined during $\mathrm{VO}_{2 \max }$ ramp test) and HRrest. According to the American College of Sports Medicine, the selected exercise intensity can be considered as "vigorous" (14).

\section{Protein and control supplementation}

Subjects consumed a $250 \mathrm{~mL}$ beverage containing either a 29 gram of casein protein or an isocaloric amount of carbohydrate immediately after cessation of each exercise session (3 per wk) and every day before sleep ( 7 per wk). In addition, all subjects received two slices of gingerbread directly after every training session (total energy $280 \mathrm{Kcal} ; 63.2 \mathrm{~g}$ of carbohydrates; $1.4 \mathrm{~g}$ fat; 2.4 g protein). An overview of the energy and macronutrient composition of the beverages can be found in Table 1. Nutritional content of the supplements was analysed in duplicate by an independent laboratory (Nutrilab B.V., Rijswijk, the Netherlands) and reported analogous nutritional values as given by the producer. The protein and control beverages were masked for taste and smell by adding several additives. In addition, beverages were masked for colour and produced in white non-transparent containers. Allocation to the PRO or CON group was done using block randomization (group 1, $n=24$; group 2, $n=20$ ) by an independent researcher not involved in the study. Study drink boxes/beverages were sequentially numbered on subject number.

Table 1. Nutritional composition of the intervention drinks (250 mL)

\begin{tabular}{lll} 
Energy \& Nutrient & Control beverage (CON) & Protein beverage \\
\hline Energy (Kcal) & $\sim 129$ & $\sim 127$ \\
Protein (casein) (g) & 0.6 & 28.7 \\
Fat (g) & 2.4 & 0.3 \\
$\begin{array}{l}\text { Carbohydrates (maltodextrin and } \\
\text { sucrose) }(\mathrm{g})\end{array}$ & 26.3 & 2.7 \\
\hline
\end{tabular}

\section{Body composition}

DEXA measurements were carried out using a Lunar Prodigy Advanced DEXA scanner (GE Health Care, Madison, WI, United States of America). Each morning at the different test days, a quality assurance test was performed to ensure system suitability and precision of the scanner. Whole body scans were 
performed according to the manufacturer's protocol and identical scan protocols were used for all subjects. Subsequently, different regions for fat mass and lean mass were assessed. Anthropometrics were assessed using standardized procedures, body weight by digital scale to within $100 \mathrm{~g}$, height by stadiometer to within $0.5 \mathrm{~cm}$ and waist circumference by tape measure to within $0.5 \mathrm{~cm}$ (SECA, Hamburg, Germany).

$\mathrm{VO}_{2 \max }$

A ramped $\mathrm{VO}_{2 \max }$ test was performed at baseline (- $2 \mathrm{wk}$ ), mid-term and end (23 days after the last training sessions) between 9 am and $5 \mathrm{pm}$. Ninety minutes before each test, subjects consumed a standardized meal consisting of an energy bar (3.7 g fat, $29.2 \mathrm{~g}$ carbohydrates, $2 \mathrm{~g}$ protein, $158.1 \mathrm{Kcal}$ ), an apple (Granny Smith) and 500ml water. Following a 30-min rest, subjects performed a ramped $\mathrm{VO}_{2 \max }$ test on an electrically braked cycle ergometer (Lode Excalibur, Groningen, the Netherlands). After a 5-min warm up at $50 \mathrm{~W}$, the subjects started cycling at $100 \mathrm{~W}$. Workload was progressively increased by $20 \mathrm{~W} \cdot \mathrm{min}-1$ until the subject reached volitional exhaustion. The $\mathrm{VO}_{2 \max }$ test was considered to be valid when two out of three criteria were met: (I) levelling of $\mathrm{VO}_{2}$ with increasing workload; (II) heart rate within 10 beats of the theoretically estimated maximum (220-age); and (III) respiratory exchange ratio (RER) of $\geq 1.15$. Oxygen consumption $\left(\mathrm{VO}_{2}\right)$ was measured through breath-by-breath sampling with an Oxycon Pro (Jaeger, Hoechberg, Germany) to define maximal oxygen consumption $\left(\mathrm{VO}_{2 \max }\right)$. Subjects were asked to maintain a cadence between 80 and $100 \mathrm{r} \cdot \mathrm{min}^{-1}$.

\section{Endurance exercise performance (simulated 10-km time trial)}

Familiarization was performed in the week after the start of the first experimental day (anthropometrics, DEXA, blood and biopsy). Three or four days thereafter another time trial was conducted (baseline measurement) and this was repeated at mid-term and end. Subjects performed a simulated $~ 10$ $\mathrm{km}$ cycling time trial. The data from the baseline $\mathrm{VO}_{2 \max }$ test was used for the amount of work to be performed and calculated as follows: total amount of work $(\mathrm{J})=0.85^{*} \mathrm{Wmax}^{*} 900$ (s) (15). The ergometer was set in linear-mode so that $85 \%$ Wmax was achieved when subjects cycled at their preferred pedalling rate of $85 \pm 7 \mathrm{rpm}$, as determined during familiarization. Subjects received no verbal or physiological feedback during the time-trial, and were only aware of the absolute $(\mathrm{kJ})$ and relative (\%) amount of work performed. Ratings of perceived exertion (RPE) were assessed after each 30-min submaximal exercise test and after the time-trial using the Borg 6-20 scale (Borg, 1982). All testing 
was performed under standardized conditions $\left(21{ }^{\circ} \mathrm{C}, 40 \%\right.$ relative humidity) on the same time of day, and the same day in the week.

\section{Muscle Biopsies}

Muscle biopsies were taken after an overnight fast 3-4 days prior the start of the first training session (pre), 5-7 days after de $14^{\text {th }}$ (mid-term) and $28^{\text {th }}$ (end) training session. Muscle biopsies were taken as described by Bergstrom (1975) (16). Biopsies were taken under local anaesthesia (2-3 $\mathrm{mL}$ of $2 \%$ adrenaline) using a 5-mm Bergstrom needle modified with suction. Biopsies were taken from the vastus lateralis of the same leg, with separate incisions $(\sim 1-1.5 \mathrm{~cm}$ apart) and from distal to proximal direction. Muscle biopsies were immediately frozen (within 5-10 s) in liquid nitrogen and stored at $-80^{\circ} \mathrm{C}$ for subsequent biochemical analysis, after being freed from visible fat, blood, and connective tissue.

\section{Sample preparation and microarray analysis}

Total RNA was isolated from the skeletal muscle tissue by using Trizol reagent (Invitrogen, Breda, Netherlands). Thereafter, RNA was purified using the Qiagen RNeasy Micro kit (Qiagen, Venlo, the Netherlands), and RNA quality was checked using an Agilent 2100 bioanalyzer (Agilent Technologies, Amsterdam, the Netherlands). Total RNA (100 ng) was labelled using an Affymetrix WT plus reagent kit (Life Technologies, Bleiswijk, the Netherlands) and hybridized to human whole genome Genechip Human Gene 2.1 ST arrays, (Life Technologies, Bleiswijk, the Netherlands). Sample labelling, hybridization to chips, and image scanning were performed according manufacturer's instructions.

\section{Statistics}

\section{Power calculation}

Sample size (n) was calculated with $90 \%$ power and type I error probability of 0.05 based on the primary outcome of $\mathrm{VO}_{2 \max }$ increase. An expected and/or relevant difference in $\mathrm{VO}_{\text {2max }}$ seen with endurance training is $0.32 \pm 0.30(\mathrm{~L} \cdot \mathrm{min}$ $\left.{ }^{1}\right)$ (17). To demonstrate a statistically significant greater increase in $\mathrm{VO}_{2 \max }$ by a nutritional supplement 16 participants/group have been shown to be sufficient (18). Considering a drop-out rate of $20-30 \%$, the final number of the participants included was 22/group. 


\section{Physiological data}

Data were assessed for normality with the use of a Shapiro-Wilk test, and any non - normal data were corrected with the use of transformation with the type of transformation based on the nature of the skewedness of the data. Repeated measures of analysis of variance (two-way mixed ANOVA), was used to determine statistical significance for the dependent variables over time. The analysis of variance model for the dependent variables with two testing time points was described as $S_{40} \times T_{2} \times G_{2}$ as such that (S; number of subjects) are crossed with testing time (T; three testing times: Pre (week 0) and Post (week 6) and group (G; CON and PRO). Where two-way mixed ANOVA revealed significant interaction, a Tukey's post hoc test was conducted for multiple comparisons to further analyse within group effects and unpaired $t$-tests to compare between groups at specific time points. In case two-way mixed ANOVA revealed no significant interaction but significant main effects of time and/or group pairwise comparisons with Tukey's post hoc correction were done. Data management and statistical analysis were carried out using SPSS software version 23 (SPSS Inc., Chicago, IL, United States of America). Statistical significance was declared when $p<.05$. Physiological data are expressed as mean \pm SEM.

\section{Microarray data}

Statistical analysis of gene expression changes was performed using limma $\mathrm{R}$ library (19). Contrasts were set for endurance training effect in both groups and an interaction term was used to determine the effect of protein supplementation (protein group versus the control group). P-values were calculated using Intensity Based Moderated t-tests (IBMT) (20). Significant genes were first selected using the False Discovery Rate Adjusted F-statistic pvalue $<0.05$. Unadjusted $p$-values below 0.01 for the contrasts were considered statistically significant within the genes that passed the F-test. Gene set enrichment analysis was done using pre-ranked lists ranked by the t-values from the limma contrasts $(21,22)$. We used the most recent library of canonical pathways from MsigDb (21). An adjusted p-value (q-value) of 0.10 was considered significant for the gene rest enrichment analysis results. Venn diagram and Heatmaps were made using the ComplexHeatmap library (23) and GraphPad Prism 8.01 for Windows (San Diego, CA, United States of America). EnrichR was used to determine differences in GO biological processes $(24,25)$. 


\section{Results}

\section{Baseline characteristics}

Four subjects dropped out during the study, one because of relocation, one because of a hamstring injury, one because of a knee injury and one because of appendicitis. Final analysis was performed on the 40 subjects who completed the training program (CON: $n=21$ vs PRO: $n=19$ ) (Figure 2). Baseline characteristics of both groups prior to the endurance training are summarized in Table 2. There were no differences at baseline between the CON and PRO groups in any of the variables of interest.

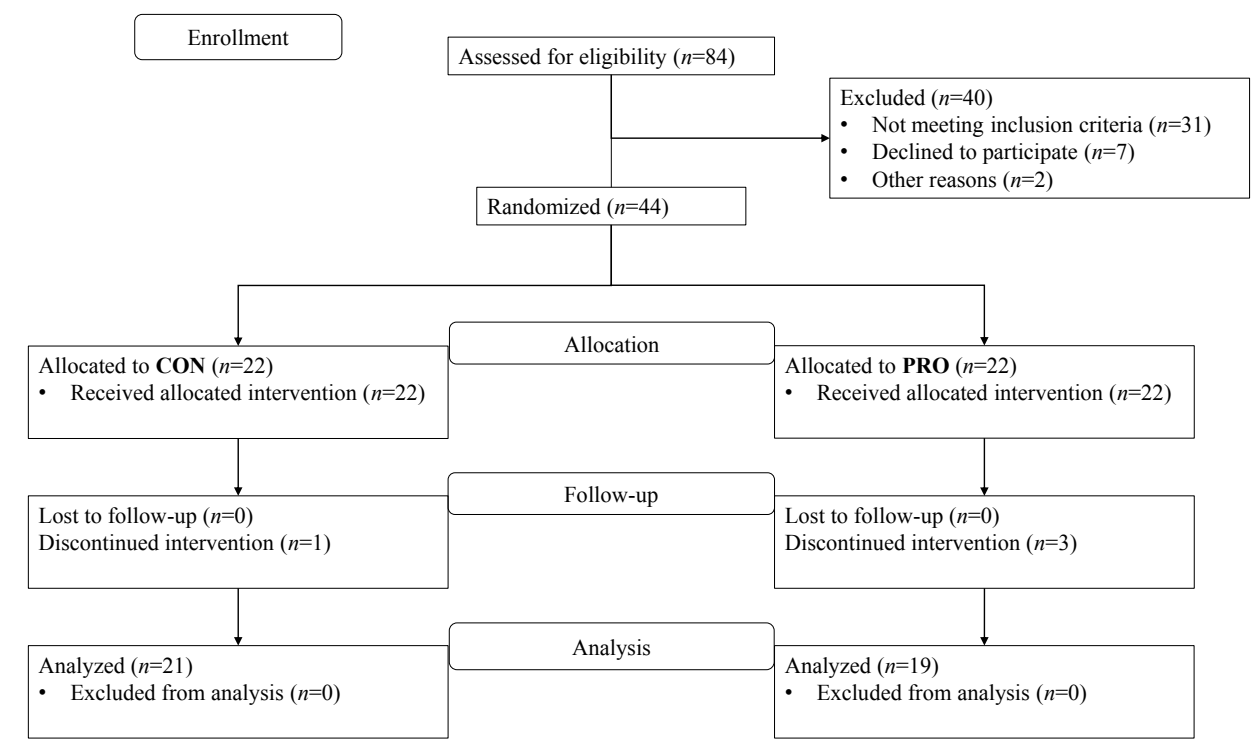

Figure 2. Subject recruitment and flow through the protocol. CON (carbohydrate supplementation, $n=21$ ); PRO (protein supplementation, $n=19$ ).

\section{Endurance training effect}

Five weeks of endurance training significantly increased maximal aerobic capacity and skeletal muscle oxidative capacity. $\mathrm{VO}_{2 \max }$ increased by $2.2 \pm 2.6$ $\mathrm{mL} \cdot \mathrm{kg}^{-1} \cdot \mathrm{min}^{-1}$ and maximal activity of citrate synthase increased by $6.99 \pm 3.50$ $\mu \mathrm{mol} \cdot \mathrm{g}^{-1} \cdot \mathrm{min}^{-1}$. These changes were accompanied by improved endurance performance, as revealed by a reduction in time on a simulated $10-\mathrm{km}$ time trial of 111.2 seconds. Protein supplementation elicited a greater increase in maximal aerobic capacity and stimulated lean mass gain but did not improve skeletal muscle oxidative capacity and endurance performance (Table 2). A full discussion of the physiological effects of endurance training with or without protein supplementation can be found elsewhere (Knuiman et al., 2019, in press). 
Table 2. Baseline characteristics and physiological effects of 5-weeks endurance training. Values are means \pm standard deviation. P-values are from mixed model analysis. $\mathrm{CON}=$ control group. $\mathrm{PRO}=$ protein group.

\begin{tabular}{|c|c|c|c|c|c|c|c|}
\hline & CON group & $(n=21)$ & PRO group & $(n=19)$ & P-values & & \\
\hline & 0 weeks & 5 weeks & 0 weeks & 5 weeks & Training & Treatment & Interaction \\
\hline Age (yr) & $22.5 \pm 2.3$ & & $21.5 \pm 1.6$ & & & & \\
\hline Body mass (kg) & $77.2 \pm 7.2$ & & $76.3 \pm 5.4$ & & & & \\
\hline Height (m) & $1.85 \pm 0.1$ & & $1.85 \pm 0.1$ & & & & \\
\hline BMI $\left(\mathrm{kg} / \mathrm{m}^{-2}\right)$ & $22.4 \pm 1.3$ & & $22.3 \pm 1.5$ & & & & \\
\hline Lean mass (kg) & $61.0 \pm 4.2$ & $61.1 \pm 4.1$ & $60.1 \pm 4.8$ & $61.6 \pm 5.3$ & $=0.0001$ & $=0.9$ & $=0.000$ \\
\hline Fat mass $(\mathrm{kg})$ & $12.8 \pm 4.5$ & $12.7 \pm 4.6$ & $12.8 \pm 2.9$ & $12.2 \pm 3.1$ & $=0.02$ & $=0.8$ & $=0.089$ \\
\hline $\mathrm{VO}_{2 \max }\left(\mathrm{L} \cdot \mathrm{min}-{ }^{\mathrm{I}}\right)$ & $3.9 \pm 0.3$ & $4.1 \pm 0.3$ & $3.8 \pm 0.4$ & $4.2 \pm 0.5$ & $=<0.0001$ & $=0.7$ & $=0.004$ \\
\hline $\mathrm{VO}_{2 \max }(\mathrm{mL} \cdot \mathrm{kg}-1 \cdot \min -1)$ & $50.8 \pm 3.9$ & $53.0 \pm 4.9$ & $49.9 \pm 3.4$ & $54.9 \pm 4.8$ & $=<0.0001$ & $=0.7$ & $=0.016$ \\
\hline Citrate synthase $(\mu \mathrm{mol} \cdot \mathrm{g}-1 \cdot \mathrm{min}-1)$ & $21.8 \pm 5.4$ & $28.7 \pm 4.4$ & $23.4 \pm 6.2$ & $31.9 \pm 5.2$ & $=<0.0001$ & $=0.1$ & $=0.206$ \\
\hline Time-trial performance (seconds) & $982.3 \pm 86.1$ & $871.1 \pm 45.8$ & $957.8 \pm 106.5$ & $839.1 \pm 53.4$ & $=<0.0001$ & $=0.1$ & $=0.796$ \\
\hline
\end{tabular}

\section{Muscle transcriptome}

Endurance training induced significant changes in the muscle transcriptome in both the CON and the PRO group. The activity of more genes was altered by endurance training in the PRO group than in the CON group (893 vs. 441, respectively, F-test q-value $<0.05$ ). Table 3 shows the top 20 significant genes based on level of significance for both CON group and PRO group. Among the top 20 significant genes for the CON group are genes related to extracellular matrix organization including collagen type IV alpha chain (COL4A2), collagen type IV alpha 1 chain (COL4A1), laminin subunit alpha 4 (LAMA4), laminin subunit beta 1 (LAMB1) and alpha-2-macroglobulin (A2M). Top 20 significant genes for the PRO group were comparable with those of the CON group and relate to extracellular matrix organization including collagen type III alpha 1 chain (COL3A1), secreted protein acidic and cysteine rich (SPARC), collagen type IV alpha 2 chain (COL4A2), collagen type IV alpha 1 chain (COL4A1), laminin subunit alpha 4 (LAMA4), peroxidasin (PXDN), laminin subunit beta 1 (LAMB1), alpha-2-macroglbulin (A2M) and nidogen 1 (NID1). 
Table 3. Top 20 significant genes in the CON and PRO group sorted on level of significance (Ftest q-value $<0.0001$ ) in the CON (A) and PRO (B) group. Q-values for CON and pro group as well as the interaction effect of endurance exercise training with protein supplementation are adjusted IMBT p-values. FC is the signed fold change. CON is the change in the control group. PRO is the change in the protein group. Inter is the interaction effect between protein supplementation and endurance training.

\begin{tabular}{|c|c|c|c|c|c|c|}
\hline $\begin{array}{l}\text { A } \\
\text { Gene }\end{array}$ & FC CON & FC PRO & Q-val. CON & Q-val. PRO & P-val. Inter & Q-val. Inter \\
\hline$\overline{L A M A 4}$ & 1.39 & 1.57 & 0.000 & 0.000 & 0.051 & 0.821 \\
\hline$C O L 4 A 1$ & 1.69 & 1.87 & 0.000 & 0.000 & 0.311 & 0.933 \\
\hline$A 2 M$ & 1.22 & 1.33 & 0.000 & 0.000 & 0.029 & 0.796 \\
\hline MYOIB & 1.37 & 1.44 & 0.000 & 0.000 & 0.476 & 0.957 \\
\hline$C D 34$ & 1.28 & 1.33 & 0.000 & 0.000 & 0.496 & 0.958 \\
\hline$N F I X$ & -1.12 & -1.09 & 0.000 & 0.001 & 0.288 & 0.926 \\
\hline THBS4 & 1.61 & 1.94 & 0.000 & 0.000 & 0.081 & 0.853 \\
\hline COL $4 A 2$ & 1.54 & 1.77 & 0.000 & 0.000 & 0.144 & 0.881 \\
\hline RYR3 & 1.42 & 1.12 & 0.000 & 0.336 & 0.003 & 0.647 \\
\hline FXYD1 & -1.15 & -1.13 & 0.000 & 0.000 & 0.612 & 0.974 \\
\hline COX4II & 1.19 & 1.15 & 0.000 & 0.001 & 0.441 & 0.952 \\
\hline TMEM159 & -1.41 & -1.23 & 0.000 & 0.026 & 0.083 & 0.854 \\
\hline SMTNL1 & -1.55 & -1.39 & 0.000 & 0.003 & 0.298 & 0.929 \\
\hline$L A M B 1$ & 1.46 & 1.79 & 0.000 & 0.000 & 0.025 & 0.782 \\
\hline$A L D H 1 B 1$ & 1.35 & 1.25 & 0.000 & 0.005 & 0.254 & 0.916 \\
\hline RHOJ & 1.32 & 1.15 & 0.000 & 0.090 & 0.035 & 0.799 \\
\hline SMOC2 & 1.31 & 1.37 & 0.000 & 0.000 & 0.482 & 0.958 \\
\hline$L X N$ & 1.41 & 1.28 & 0.000 & 0.007 & 0.254 & 0.916 \\
\hline ANKRD29 & 1.42 & 1.16 & 0.000 & 0.198 & 0.020 & 0.756 \\
\hline DECRI & 1.19 & 1.17 & 0.000 & 0.000 & 0.767 & 0.989 \\
\hline
\end{tabular}

\begin{tabular}{|c|c|c|c|c|c|c|}
\hline Gene & FC PRO & FC CON & Q-val. CON & Q-val. PRO & P-val. Inter & Q-val. Inter \\
\hline$L A M A 4$ & 1.57 & 1.39 & 0.000 & 0.000 & 0.051 & 0.821 \\
\hline$A 2 M$ & 1.33 & 1.22 & 0.000 & 0.000 & 0.029 & 0.796 \\
\hline$L A M B 1$ & 1.79 & 1.46 & 0.000 & 0.000 & 0.025 & 0.782 \\
\hline COL4A1 & 1.87 & 1.69 & 0.000 & 0.000 & 0.311 & 0.933 \\
\hline THBS4 & 1.94 & 1.61 & 0.000 & 0.000 & 0.081 & 0.853 \\
\hline COL4A2 & 1.77 & 1.54 & 0.000 & 0.000 & 0.144 & 0.881 \\
\hline MYOIB & 1.44 & 1.37 & 0.000 & 0.000 & 0.476 & 0.957 \\
\hline NIDI & 1.48 & 1.26 & 0.002 & 0.000 & 0.022 & 0.756 \\
\hline CD34 & 1.33 & 1.28 & 0.000 & 0.000 & 0.496 & 0.958 \\
\hline$S P A R C$ & 1.45 & 1.29 & 0.000 & 0.000 & 0.075 & 0.848 \\
\hline COL15A1 & 1.43 & 1.25 & 0.001 & 0.000 & 0.045 & 0.816 \\
\hline UTRN & 1.22 & 1.12 & 0.003 & 0.000 & 0.029 & 0.796 \\
\hline$E D N R B$ & 1.70 & 1.34 & 0.005 & 0.000 & 0.016 & 0.756 \\
\hline$P X D N$ & 1.75 & 1.48 & 0.000 & 0.000 & 0.107 & 0.863 \\
\hline ETS1 & 1.43 & 1.26 & 0.001 & 0.000 & 0.063 & 0.839 \\
\hline$M X R A 5$ & 2.51 & 1.90 & 0.000 & 0.000 & 0.110 & 0.863 \\
\hline COL3A1 & 2.06 & 1.70 & 0.000 & 0.000 & 0.178 & 0.893 \\
\hline$I G F B P 7$ & 1.35 & 1.26 & 0.000 & 0.000 & 0.233 & 0.914 \\
\hline$A N X A 5$ & 1.35 & 1.10 & 0.268 & 0.000 & 0.001 & 0.558 \\
\hline CAPN6 & 1.83 & 1.46 & 0.003 & 0.000 & 0.060 & 0.836 \\
\hline
\end{tabular}




\section{Effect of protein supplementation}

Figure 3 shows the number of genes regulated as a result of endurance training for each the CON group and the PRO group and the groups combined. After 5 weeks of endurance training, gene expression count was greater in the PRO group compared with CON. In addition, the top 20 and overall gene transcript change in muscle transcriptome was consistently greater in the PRO group when compared to the CON group (figure $3 \& 4$ ). The greater changes in the PRO group are visualized in figure 5.

Figure 3. Venn diagram showing the number of significantly changed genes per group. Selected genes (F-test q-value $<0.05$ ) for each the CON group and the PRO group and the groups combined (raw p-value $<0.0001$ ).

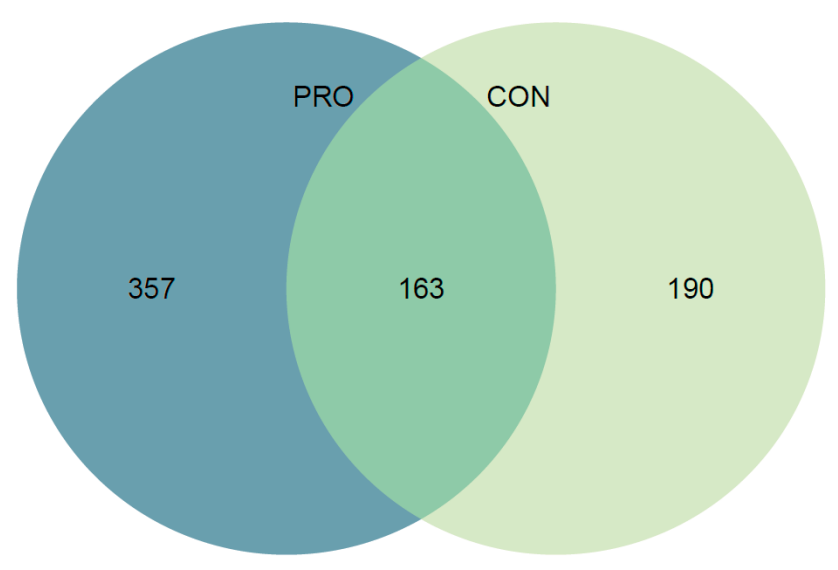


Figure 4. Heatmaps based on top 20 significant genes for each group. Genes are sorted on FC (F-test q-value $<0.0001$ ) in the CON (A) and PRO (B) group. Q-values for CON and PRO group are adjusted IMBT p-values. FC is the signed fold change. CON is the change in the control group. PRO is the change in the protein group.

A

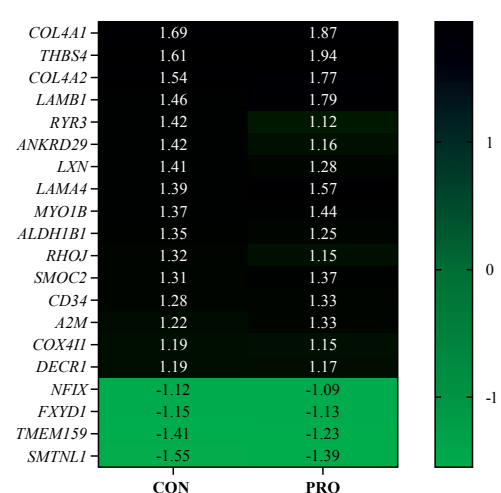

B

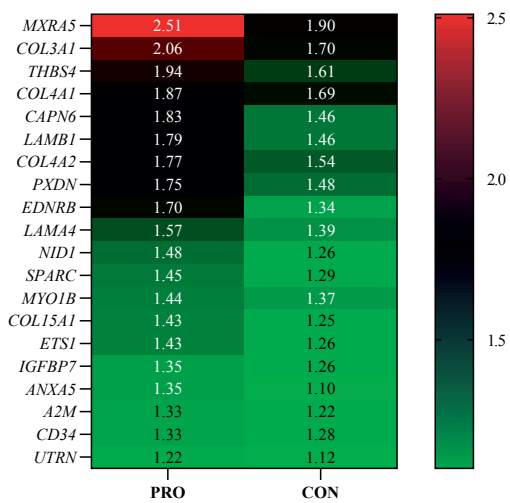

Figure 5. Scatterplots with line of identity to visualize the magnitude of change in muscle transcriptome per group. Figures A \& B are based on the total number of genes changed per group (184 for CON (A) and 384 for PRO (B), F-test q-value<0.05). Figures C \& D are based on the top 20 significant genes changes in the CON (C) and PRO (D) group.
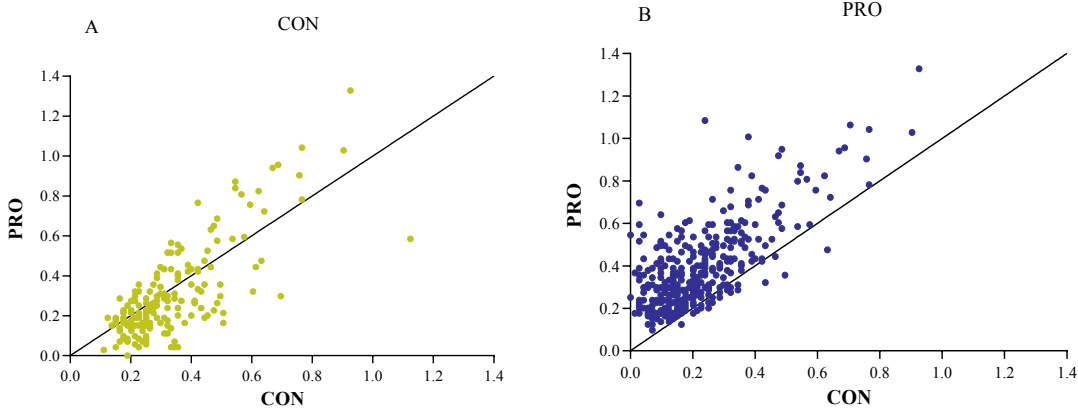

D
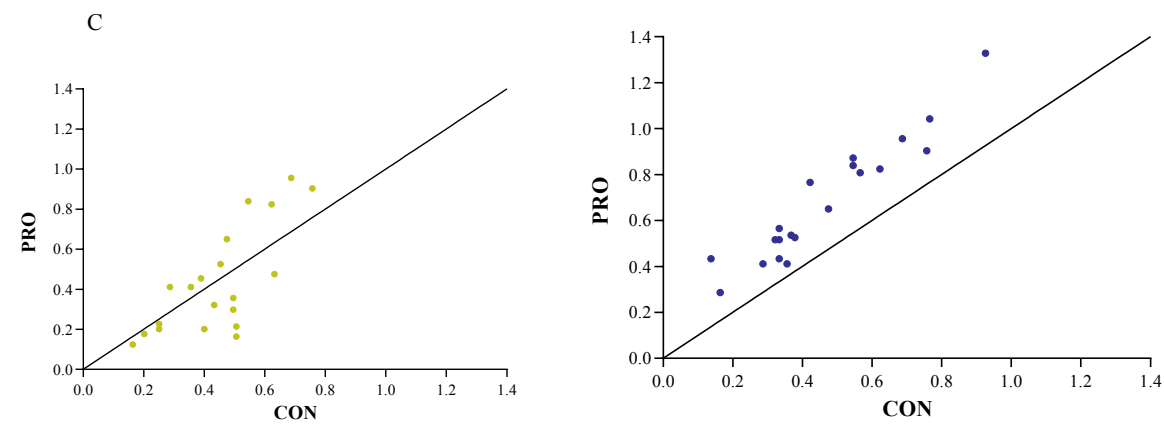
Figure 6. Heatmap of changes in gene expression per group. (F-test q-value $<0.0001$ ) in the CON (left) and PRO (right) groups.

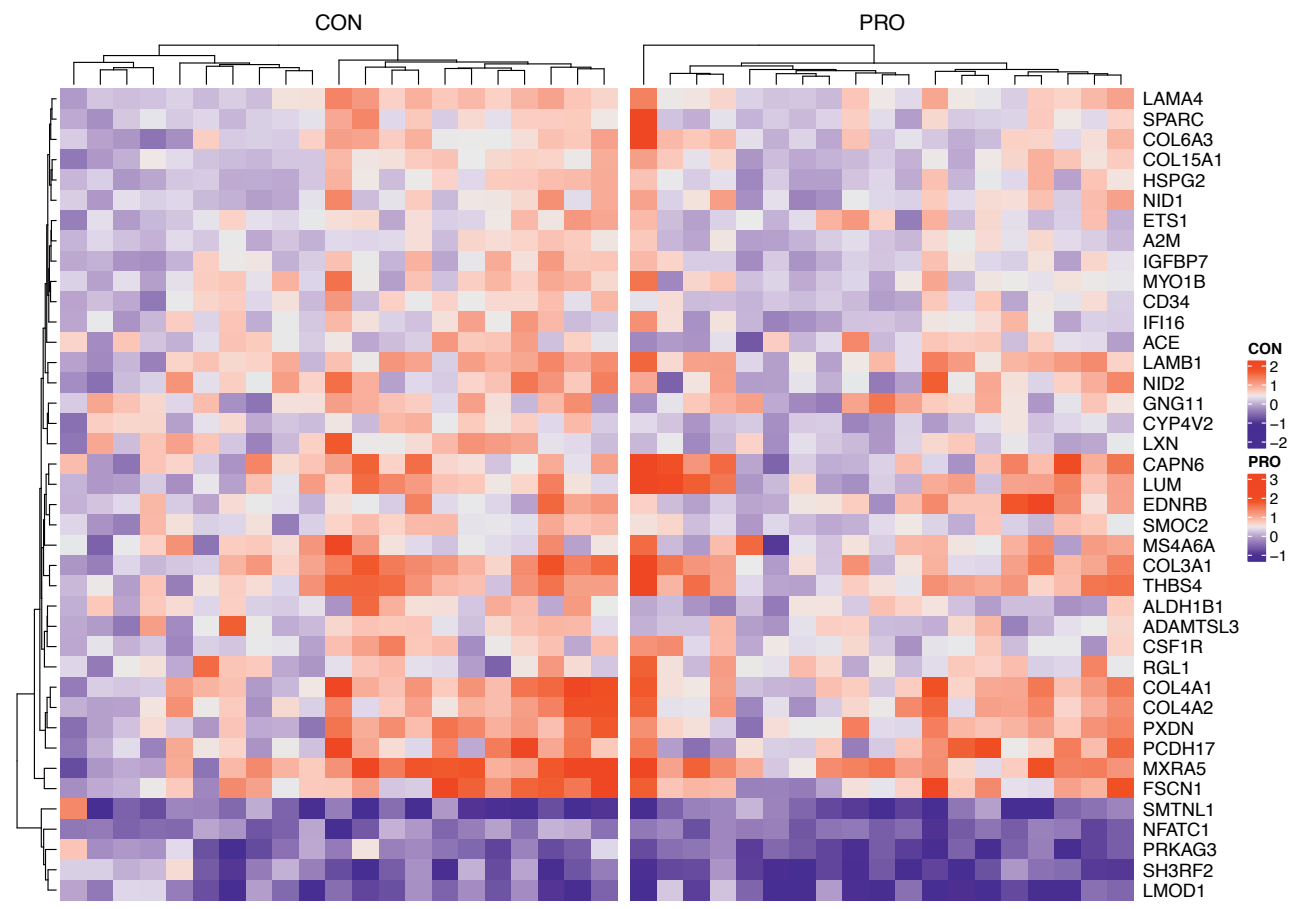


Figure 6 shows a heatmap of the genes that significantly changed by endurance training in both the CON group and PRO group (40 genes, F-test qvalue $<0.0001)$. The changes in gene expression following 5 weeks of endurance training did not markedly differ between the CON group and PRO group (timeby treatment interaction, F-test q-value $>0.05$ ). No major differences can be observed with regard to training response between the PRO and CON group. Gene-set-enrichment analysis showed a similar result, as gene sets that were significant for the CON group were generally also significant for the PRO group.

\section{Biological processes}

Based on all significant genes altered (F-test q-value $<0.05$ ) in each group, gene ontology biological processes revealed extracellular matrix organization as the process with the highest change in gene expression profile in both the CON group and the PRO group (table 3). In the CON group 25 genes were linked to extracellular matrix organization whereas 55 genes in the PRO group. Accordingly, gene set enrichment analysis (table 4) showed time-by treatment interaction for extracellular matrix organization processes such as extracellular matrix receptor interaction (q-value $<0.001$ ), extracellular matrix glycoproteins (q-value=0.006) and collagen formation (q-value=0.041). Gene set enrichment also showed significant increases in energy metabolism and oxidative phosphorylation with no clear differences between the CON group and the PRO group.

Table 4. Top 10 gene ontology biological processes from EnrichR regulated in the CON group (A) and PRO group (B) based on the total number of genes that was significantly regulated in the CON group $(n=440)$ and PRO group $(n=892)$ group (F-test q-value $<0.05)$.

\begin{tabular}{clcccc}
$\mathbf{A}$ & Name of biological process & Genes $(\boldsymbol{n})$ & P-value & Q-value & Z-score \\
\hline 1 & extracellular matrix organization & 25 & 0.000 & 0.000 & -1.65 \\
2 & sarcomere organization & 7 & 0.000 & 0.002 & -2.30 \\
3 & muscle contraction & 19 & 0.000 & 0.000 & -1.18 \\
4 & positive regulation of sprouting angiogenesis & 7 & 0.000 & 0.001 & -1.88 \\
5 & positive regulation of B cell differentiation & 3 & 0.001 & 0.041 & -3.10 \\
6 & regulation of angiogenesis & 16 & 0.000 & 0.001 & -1.77 \\
\hline 7 & mitochondrial ATP synthesis coupled proton transport & 3 & 0.012 & 0.180 & -4.85 \\
8 & regulation of release of sequestered calcium ion into cytosol & 8 & 0.000 & 0.003 & -1.89 \\
9 & actomyosin structure organization & 11 & 0.000 & 0.000 & -1.46 \\
10 & myofibril assembly & 8 & 0.000 & 0.002 & -1.81 \\
\hline
\end{tabular}


Protein supplementation during endurance training impacts the muscle transcriptome

\begin{tabular}{|c|c|c|c|c|c|}
\hline B & Name of biological process & Genes $(n)$ & P-value & Q-value & Z-score \\
\hline 1 & extracellular matrix organization & 55 & 0.000 & 0.000 & -1.65 \\
\hline 2 & regulation of smooth muscle cell migration & 8 & 0.001 & 0.000 & -2.21 \\
\hline 3 & mitochondrial ATP synthesis coupled proton transport & 5 & 0.002 & 0.075 & -4.89 \\
\hline 4 & collagen fibril organization & 11 & 0.000 & 0.000 & -1.58 \\
\hline 5 & regulation of angiogenesis & 25 & 0.000 & 0.000 & -1.77 \\
\hline 6 & positive regulation of cell migration & 27 & 0.000 & 0.001 & -1.91 \\
\hline 7 & positive regulation of smooth muscle cell migration & 4 & 0.001 & 0.049 & -3.44 \\
\hline 8 & regulated exocytosis & 19 & 0.000 & 0.005 & -2.27 \\
\hline 9 & basement membrane organization & 4 & 0.000 & 0.026 & -2.81 \\
\hline 10 & cellular protein modification process & 76 & 0.000 & 0.001 & -1.73 \\
\hline
\end{tabular}

Table 5. Top 10 significant enriched gene sets in both the CON group and the PRO group (interaction effect). CON is the training, Inter is the interaction effect. ES is the enrichment score.

\begin{tabular}{clcccc} 
GSEA & Name of biological process & ES CON & ES Inter & q-value CON & q-value Inter \\
\hline 1 & Kegg ECM receptor interaction & 0.70 & 0.58 & 0.000 & 0.000 \\
2 & Naba core matrisome & 0.73 & 0.47 & 0.000 & 0.000 \\
3 & Naba ECM glycoproteins & 0.73 & 0.46 & 0.000 & 0.006 \\
4 & Pid integrin1 pathway & 0.69 & 0.54 & 0.000 & 0.007 \\
5 & Reactome integrin cell surface interactions & 0.63 & 0.51 & 0.000 & 0.012 \\
6 & Biocarta RHO pathway & 0.81 & 0.62 & 0.000 & 0.019 \\
7 & Pid TCR pathway & 0.64 & 0.51 & 0.000 & 0.032 \\
8 & Reactome collagen formation & 0.60 & 0.52 & 0.000 & 0.041 \\
9 & Pid syndecan 1 pathway & 0.73 & 0.53 & 0.000 & 0.051 \\
10 & Pid integrin 3 pathway & 0.53 & 0.54 & 0.000 & 0.051 \\
\hline
\end{tabular}




\section{Discussion}

Five weeks of endurance training increased maximal aerobic capacity. Adding protein supplementation elicited a greater increase in maximal aerobic capacity and stimulated lean mass gain. At the skeletal muscle transcriptional level, endurance training caused relatively small $(\mathrm{FC}<2)$ but consistent and statistically robust changes in the skeletal muscle transcriptome. Furthermore, changes in the skeletal muscle transcriptome tended to be greater in the protein group as compared to the control group. However, the differences in gene regulation between the two groups are far less clear. This lack of clear differences in skeletal muscle gene expression transcripts between the protein and control group is likely due to timing of muscle tissue sampling, low sample size and high inter-individual variation.

In this study we demonstrated that the physiological adaptive response to endurance training was accompanied by significant changes in the skeletal muscle transcriptome. Gene set enrichment analysis showed that endurance training caused significant changes in gene expression transcripts involved in extracellular matrix and oxidative phosphorylation, which is in line with previous reports that investigated changes in skeletal muscle transcriptome following prolonged endurance training $(10,11)$. There is currently an incomplete understanding of the molecular mechanisms that regulate physiological adaptation to endurance training. Several upregulated genes among the top 20 genes are involved in extracellular matrix organization, including COL4A2, COL4A1, LAMA41, LAMB1 and A2M . The results of geneontology biological processes and gene set enrichment analysis are consistent with the top 20 genes, showing increased extracellular matrix remodelling. The observed changes in gene expressions transcripts related to extracellular matrix remodelling tended to be more pronounced in the protein group than the control group. The latter suggests that the greater changes in skeletal muscle transcriptome, in particular the extracellular matrix, may reflect the greater physiological adaptations observed in the protein group.

The extracellular matrix is composed of collagen, glycoproteins and proteoglycans (26). Moreover, extracellular matrix remodelling is a primary adaptation to endurance training (4). The extracellular matrix is important for muscle cell development, structure maintenance, force transmission, and tissue remodelling through the modulation of growth factors and extracellular molecule interactions (27). Extracellular matrix degradation is an important morphological adaptation by allowing growth of new capillaries from existing ones in response to endurance training (28-33). Whether the exercise-induced growth of capillaries was further stimulated by protein supplementation and contributed to the larger increase in maximal aerobic capacity cannot be concluded from these data. 
Our observation that protein supplementation increases extracellular matrix remodelling to endurance training is new and further elaborates on previous work, which demonstrates that addition of protein to post-exercise carbohydrate-lipid nutrition differentially alters the transcriptome involved in tissue structure and remodelling through regulation of extracellular matrix (12). General skeletal muscle adaptations to exercise training include regulation of angiogenesis, mitochondrial biogenesis, myogenesis and alterations in structural support such as the extracellular matrix (34, 35). There is surprisingly little known about the role of the extracellular matrix in response to endurance training. Our data show that the gene expression transcriptional response to endurance training in skeletal muscle is related to extracellular matrix components and that protein supplementation tended to enlarge this adaptive response. In this study, it could be that the extent in which the extracellular matrix remodelled reflects the degree of muscle growth. Lean mass substantially increased in the protein group and this was accompanied by stronger regulations in gene expression transcripts related to extracellular matrix remodelling. Previous research postulated that remodelling of the extracellular matrix is required for exercise-training induced muscle growth (36).

In contrast to the observed effect of protein supplementation on physiological adaptation, we were unable to find a clear additional effect of protein supplementation on the skeletal muscle transcriptome besides the extracellular matrix. It is possible that the effects of protein supplementation already started to manifest during the early hours of recovery from exercise, when mRNA abundance generally peaks $(8,37)$. Although the precise mechanisms by which protein supplementation elicited a greater increase in maximal aerobic capacity to endurance training cannot be derived from this analysis, it is likely that protein supplementation enhanced the gene/protein expression changes after each exercise session thereby improving skeletal muscle tissue adaptation, resulting in cumulatively meaningful changes in recovery and phenotypic adaptation over a prolonged period of time.

In conclusion, five weeks of endurance training changed expressions of genes involved in extracellular matrix organization and oxidative phosphorylation. Changes in extracellular matrix organization tended to be greater in the protein group than in the control group and these greater transcriptional changes may reflect the enhanced physiological adaptation as a result of protein supplementation.

\section{Perspectives and significance}

Thus far, much attention has been given to the acute molecular responses to a single bout of exercise, and the current theory suggests that acute signals predict/drive phenotypic adaptation over time. For example, the AMP- 
activated protein kinase and peroxisome proliferator-activated receptor-y coactivator-1a, have been proposed as primary regulators of muscle tissue adaptation in response to endurance training (38-41). Our transcriptomic analysis revealed that the extracellular matrix may be an important factor for skeletal muscle adaptation in response to prolonged endurance training. The current data suggest/demonstrate that protein supplementation enhances physiological adaptation and elicit greater changes in skeletal muscle gene expression transcripts related to the extracellular matrix. These changes in extracellular matrix gene expression may reflect modulation of the physiological adaptation to endurance training (4), leading to enhanced cumulative effects with regard to endurance performance and muscle size. 


\section{References}

1. Charge SB, Rudnicki MA. Cellular and molecular regulation of muscle regeneration. Physiological reviews 2004;84(1):209-38. doi: 10.1152/physrev.00019.2003.

2. Hawley JA, Hargreaves M, Joyner MJ, Zierath JR. Integrative biology of exercise. Cell 2014;159(4):738-49. doi: 10.1016/j.cell.2014.10.029.

3. Keller P, Vollaard NB, Gustafsson T, Gallagher IJ, Sundberg CJ, Rankinen T, Britton SL, Bouchard C, Koch LG, Timmons JA. A transcriptional map of the impact of endurance exercise training on skeletal muscle phenotype. Journal of applied physiology 2011;110(1):46-59. doi: 10.1152/japplphysiol.00634.2010.

4. Timmons JA, Jansson E, Fischer H, Gustafsson T, Greenhaff PL, Ridden J, Rachman J, Sundberg CJ. Modulation of extracellular matrix genes reflects the magnitude of physiological adaptation to aerobic exercise training in humans. BMC biology 2005;3:19. doi: 10.1186/1741-7007-3-19.

5. Pilegaard H, Ordway GA, Saltin B, Neufer PD. Transcriptional regulation of gene expression in human skeletal muscle during recovery from exercise. American journal of physiology Endocrinology and metabolism 2000;279(4):E806-14.

6. Hildebrandt AL, Pilegaard H, Neufer PD. Differential transcriptional activation of select metabolic genes in response to variations in exercise intensity and duration. American journal of physiology Endocrinology and metabolism 2003;285(5):E1021-7. doi: 10.1152/ajpendo.00234.2003.

7. Mahoney DJ, Parise G, Melov S, Safdar A, Tarnopolsky MA. Analysis of global mRNA expression in human skeletal muscle during recovery from endurance exercise. FASEB journal : official publication of the Federation of American Societies for Experimental Biology 2005;19(11):1498-500. doi: 10.1096/fj.04-3149fje.

8. Egan B, Zierath JR. Exercise metabolism and the molecular regulation of skeletal muscle adaptation. Cell metabolism 2013;17(2):162-84. doi: 10.1016/j.cmet.2012.12.012.

9. Vissing K, Schjerling P. Simplified data access on human skeletal muscle transcriptome responses to differentiated exercise. Scientific data 2014;1:140041. doi: 10.1038/sdata.2014.41.

10. Nishida Y, Tanaka H, Tobina T, Murakami K, Shono N, Shindo M, Ogawa W, Yoshioka M, St-Amand J. Regulation of muscle genes by moderate exercise. International journal of sports medicine 2010;31(9):656-70. doi: 10.1055/s-0030-1255065.

11. Radom-Aizik S, Hayek S, Shahar I, Rechavi G, Kaminski N, Ben-Dov I. Effects of aerobic training on gene expression in skeletal muscle of elderly men. Medicine and science in sports and exercise 2005;37(10):1680-96.

12. Rowlands DS, Thomson JS, Timmons BW, Raymond F, Fuerholz A, Mansourian R, Zwahlen MC, Metairon S, Glover E, Stellingwerff T, et al. Transcriptome and translational signaling following endurance exercise in trained skeletal muscle: impact of dietary protein. Physiological genomics 2011;43(17):1004-20. doi: 10.1152/physiolgenomics.00073.2011.

13. Karvonen J, Vuorimaa T. Heart rate and exercise intensity during sports activities. Practical application. Sports medicine 1988;5(5):303-11.

14. Garber CE, Blissmer B, Deschenes MR, Franklin BA, Lamonte MJ, Lee IM, Nieman DC, Swain DP. American College of Sports Medicine position stand. Quantity and quality of exercise for developing and maintaining cardiorespiratory, musculoskeletal, and neuromotor fitness in apparently healthy adults: guidance for prescribing exercise. Medicine and science in sports and exercise 2011;43(7):1334-59. doi: 10.1249/MSS.0b013e318213fefb.

15. Jeukendrup A, Saris WH, Brouns F, Kester AD. A new validated endurance performance test. Medicine and science in sports and exercise 1996;28(2):266-70. 
16. Bergstrom J. Percutaneous needle biopsy of skeletal muscle in physiological and clinical research. Scandinavian journal of clinical and laboratory investigation 1975;35(7):609-16.

17. Montero D, Cathomen A, Jacobs RA, Fluck D, de Leur J, Keiser S, Bonne T, Kirk N, Lundby AK, Lundby C. Haematological rather than skeletal muscle adaptations contribute to the increase in peak oxygen uptake induced by moderate endurance training. The Journal of physiology 2015;593(20):4677-88. doi: 10.1113/jp270250.

18. Ferguson-Stegall L, McCleave E, Ding Z, Doerner Iii PG, Liu Y, Wang B, Healy M, Kleinert M, Dessard B, Lassiter DG, et al. Aerobic exercise training adaptations are increased by postexercise carbohydrate-protein supplementation. Journal of nutrition and metabolism 2011;2011:623182. doi: 10.1155/2011/623182.

19. Ritchie ME, Phipson B, Wu D, Hu Y, Law CW, Shi W, Smyth GK. limma powers differential expression analyses for RNA-sequencing and microarray studies. Nucleic acids research 2015;43(7):e47. doi: 10.1093/nar/gkv007.

20. Sartor MA, Tomlinson CR, Wesselkamper SC, Sivaganesan S, Leikauf GD, Medvedovic M. Intensity-based hierarchical Bayes method improves testing for differentially expressed genes in microarray experiments. BMC bioinformatics 2006;7:538. doi: 10.1186/1471-2105-7-538.

21. Subramanian A, Tamayo P, Mootha VK, Mukherjee S, Ebert BL, Gillette MA, Paulovich A, Pomeroy SL, Golub TR, Lander ES, et al. Gene set enrichment analysis: a knowledgebased approach for interpreting genome-wide expression profiles. Proceedings of the National Academy of Sciences of the United States of America 2005;102(43):15545-50. doi: 10.1073/pnas.0506580102.

22. Mootha VK, Lindgren CM, Eriksson K-F, Subramanian A, Sihag S, Lehar J, Puigserver P, Carlsson E, Ridderstråle M, Laurila E, et al. PGC- $1 \alpha$-responsive genes involved in oxidative phosphorylation are coordinately downregulated in human diabetes. Nature Genetics 2003;34:267. doi: 10.1038/ng1180

23. Gu Z, Eils R, Schlesner M. Complex heatmaps reveal patterns and correlations in multidimensional genomic data. Bioinformatics (Oxford, England) 2016;32(18):2847-9. doi: 10.1093/bioinformatics/btw313.

24. Chen EY, Tan CM, Kou Y, Duan Q, Wang Z, Meirelles GV, Clark NR, Ma'ayan A. Enrichr: interactive and collaborative HTML5 gene list enrichment analysis tool. BMC bioinformatics 2013;14:128. doi: 10.1186/1471-2105-14-128.

25. Kuleshov MV, Jones MR, Rouillard AD, Fernandez NF, Duan Q, Wang Z, Koplev S, Jenkins SL, Jagodnik KM, Lachmann A, et al. Enrichr: a comprehensive gene set enrichment analysis web server 2016 update. Nucleic acids research 2016;44(W1):W907. doi: 10.1093/nar/gkw377.

26. Sanes JR. The basement membrane/basal lamina of skeletal muscle. The Journal of biological chemistry 2003;278(15):12601-4. doi: 10.1074/jbc.R200027200.

27. Katz BZ, Yamada KM. Integrins in morphogenesis and signaling. Biochimie 1997;79(8):467-76.

28. Jensen L, Pilegaard H, Neufer PD, Hellsten Y. Effect of acute exercise and exercise training on VEGF splice variants in human skeletal muscle. American journal of physiology Regulatory, integrative and comparative physiology 2004;287(2):R397-402. doi: 10.1152/ajpregu.00071.2004.

29. Hoppeler H, Baum O, Lurman G, Mueller M. Molecular mechanisms of muscle plasticity with exercise. Comprehensive Physiology 2011;1(3):1383-412. doi: 10.1002/cphy.c100042.

30. Saltin B, Gollnick PDJHoPSM. Skeletal muscle adaptability: significance for metabolism and performance. 1983;10:555-631. 
31. Sundberg CJ. Exercise and training during graded leg ischaemia in healthy man with special reference to effects on skeletal muscle. Acta physiologica Scandinavica Supplementum 1994;615:1-50.

32. Blomqvist CG, Saltin B. Cardiovascular adaptations to physical training. Annual review of physiology 1983;45:169-89. doi: 10.1146/annurev.ph.45.030183.001125.

33. Haas TL, Milkiewicz M, Davis SJ, Zhou AL, Egginton S, Brown MD, Madri JA, Hudlicka O. Matrix metalloproteinase activity is required for activity-induced angiogenesis in rat skeletal muscle. Am J Physiol Heart Circ Physiol 2000;279(4):H1540-7. doi: 10.1152/ajpheart.2000.279.4.H1540.

34. Areta JL, Burke LM, Ross ML, Camera DM, West DW, Broad EM, Jeacocke NA, Moore DR, Stellingwerff T, Phillips SM, et al. Timing and distribution of protein ingestion during prolonged recovery from resistance exercise alters myofibrillar protein synthesis. The Journal of physiology 2013;591(Pt 9):2319-31. doi: 10.1113/jphysiol.2012.244897.

35. Yan Z, Okutsu M, Akhtar YN, Lira VA. Regulation of exercise-induced fiber type transformation, mitochondrial biogenesis, and angiogenesis in skeletal muscle. Journal of applied physiology 2011;110(1):264-74. doi: 10.1152/japplphysiol.00993.2010.

36. Goody MF, Sher RB, Henry CA. Hanging on for the ride: adhesion to the extracellular matrix mediates cellular responses in skeletal muscle morphogenesis and disease. Developmental biology 2015;401(1):75-91. doi: 10.1016/j.ydbio.2015.01.002.

37. Perry CG, Lally J, Holloway GP, Heigenhauser GJ, Bonen A, Spriet LL. Repeated transient mRNA bursts precede increases in transcriptional and mitochondrial proteins during training in human skeletal muscle. The Journal of physiology 2010;588(Pt 23):4795810. doi: 10.1113/jphysiol.2010.199448.

38. Akimoto T, Ribar TJ, Williams RS, Yan Z. Skeletal muscle adaptation in response to voluntary running in $\mathrm{Ca} 2+$ /calmodulin-dependent protein kinase IV-deficient mice. American journal of physiology Cell physiology 2004;287(5):C1311-9. doi: 10.1152/ajpcell.00248.2004.

39. Handschin C, Spiegelman BM. The role of exercise and PGC1alpha in inflammation and chronic disease. Nature 2008;454(7203):463-9. doi: 10.1038/nature07206.

40. Jorgensen SB, Jensen TE, Richter EA. Role of AMPK in skeletal muscle gene adaptation in relation to exercise. Applied physiology, nutrition, and metabolism = Physiologie appliquee, nutrition et metabolisme 2007;32(5):904-11. doi: 10.1139/h07-079.

41. Leick L, Wojtaszewski JF, Johansen ST, Kiilerich K, Comes G, Hellsten Y, Hidalgo J, Pilegaard H. PGC-1alpha is not mandatory for exercise- and training-induced adaptive gene responses in mouse skeletal muscle. American journal of physiology Endocrinology and metabolism 2008;294(2):E463-74. doi: 10.1152/ajpendo.00666.2007. 


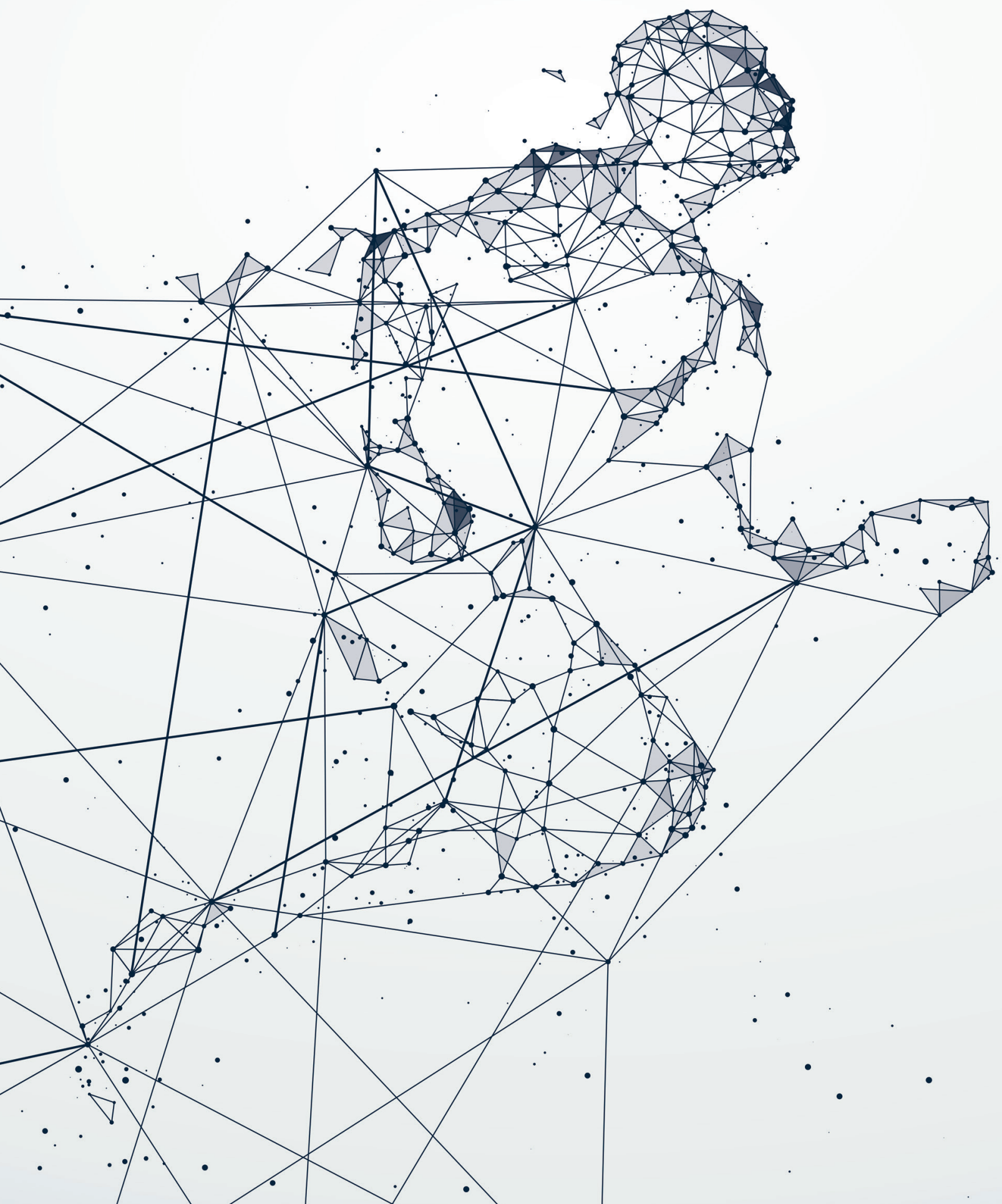


Chapter 8

General discussion 
The aim of this thesis was to study the nutritional impact on physiological and skeletal muscle adaptation to exercise. The first part (chapters $2-4$ ) focussed on carbohydrate availability with resistance exercise, whereas the second part (chapters 5 - 7) specifically addresses the effects and potential of protein supplementation with endurance training. As a start, Chapter 2 reviewed the existing knowledge on glycogen and carbohydrate availability on the adaptive response to endurance and resistance exercise. Chapter 3 addresses the results of a study on the effects of carbohydrate availability during resistance exercise on selected mRNA profile changes in skeletal muscle. We were able to demonstrate that a selection of muscle mRNAs related to mitochondrial biogenesis, muscle degradation and muscle hypertrophy was minimally affected by different pre-exercise meals that differ in macronutrient profile. Chapter 4 discusses the relationship between carbohydrate availability and plasma cytokine response with resistance exercise from the same study. Our main conclusion was that pre-exercise meal in general not influenced plasma cytokine responses in the post-resistance exercise period.

Shifting our focus to proteins, we first reviewed effects and possible underlying physiological mechanisms of protein supplementation on the adaptive response to endurance training in Chapter 5. To further explore these insights, we performed a double-blind randomised controlled trial with repeated measures to determine whether protein supplementation impacts adaptations to prolonged endurance training. The results of this trial as presented and discussed in chapter 6 indicated that protein supplementation can be beneficial in improving adaptation to endurance training. Finally in chapter 7 , we also analysed the skeletal muscle transcriptome from the intervention study aiming to reveal mechanisms underlying the effect of protein supplementation on the adaptive processes to endurance training.

\section{Carbohydrate availability and resistance exercise}

Macronutrients represent potent modulators of acute exercise response and chronic adaptation, due to their effects on substrate use during rest and exercise, gene expression and physiological changes $(1,2)$. Carbohydrates are mainly known for their role as fuel during endurance exercise, as well as potential modulator of the molecular response to endurance training $(3,4)$. It is well established that moderate to high daily intake of carbohydrates (5 and$12 \mathrm{~g} / \mathrm{kg}$ bodyweight/day) is beneficial for prolonged high-intensity endurance exercise $(5,6)$. However, resistance exercise and endurance exercise involve metabolically different processes, while also inducing different adaptive responses at a cellular level (7). The resistance exercise-specific adaptation is primarily induced by mechanical stress $(8,9)$, whereas the adaptation to endurance exercise training mainly occurs as a result of metabolic stress (10). 
Therefore, carbohydrate availability may affect both exercise modalities differently. In spite of this notion, not much research has been done with regard to carbohydrate availability and resistance exercise. In addition, specific carbohydrate intake recommendations for individuals participating in resistance exercise training regimes are scarce $(11,12)$. Most recommendations are general and usually in a range between 3 and $7 \mathrm{~g} / \mathrm{kg}$ bodyweight/day (13, 14). However, there is also evidence that lower intakes of carbohydrates do not interfere with resistance exercise performance $(15,16)$ (Table 1.1).

Table1.1 Overview of studies assessing carbohydrate (CHO) intake and resistance exercise performance (22).

\begin{tabular}{|c|c|c|c|}
\hline Authors & Participants & CHO intervention & Performance outcomes \\
\hline Dipla et al.(17) & 10 active $q$ & $\begin{array}{l}7 \mathrm{~d} \text { of } 30 \% \mathrm{CHO} \\
7 \mathrm{~d} \text { of } 55 \% \mathrm{CHO}\end{array}$ & $\begin{array}{l}\leftrightarrow \text { Knee flexion (fatigue) } \\
\leftrightarrow \text { Knee extension (fatigue) }\end{array}$ \\
\hline Hatfield et al. (18) & 8 resistance trained $\pi$ & $\begin{array}{l}4 \mathrm{~d} \text { of } 50 \% \mathrm{CHO} \\
4 \mathrm{~d} \text { of } 80 \% \mathrm{CHO}\end{array}$ & $\leftrightarrow$ Squat jump (peak power) \\
\hline $\begin{array}{l}\text { Leveritt \& Abernathy } \\
\text { (19) }\end{array}$ & 6 active $\delta^{2}+q$ & $\begin{array}{l}\text { Glycogen depleted protocol }+2 \mathrm{~d} \text { of } \\
1.26 \mathrm{~g} / \mathrm{kg} \text { per } \mathrm{d} \text { of } \mathrm{CHO}\end{array}$ & $\begin{array}{l}\downarrow \text { Squats (failure) } \\
\leftrightarrow \text { Knee extension (torque) }\end{array}$ \\
\hline Mitchell et al.(15) & 11 trained $\delta$ & $\begin{array}{l}\text { Glycogen depleted protocol }+2 \mathrm{~d} \text { of } 0.4 \\
\mathrm{~g} / \mathrm{kg} \text { per } \mathrm{d} \text { of } \mathrm{CHO}\end{array}$ & $\begin{array}{l}\leftrightarrow \text { Back squats (total work) } \\
\leftrightarrow \text { Leg press (total work) } \\
\leftrightarrow \text { Knee extension (total work) }\end{array}$ \\
\hline Paoli et al.(20) & 9 athletes $\widehat{\delta}$ & $30 \mathrm{~d} 4.5 \%$ CHO vs. $30 \mathrm{~d} 46.8 \%$ CHO & $\begin{array}{l}\leftrightarrow \text { Squat jump (height) } \\
\leftrightarrow \text { CMJ (height) } \\
\leftrightarrow \text { Reverse grip chin up (failure) } \\
\leftrightarrow \text { Push ups (failure) } \\
\leftrightarrow \text { Dips (failure) }\end{array}$ \\
\hline Sawyer et al. (16) & 31 resistance trained $\hat{\delta}+q$ & $\begin{array}{l}7 \mathrm{~d} \text { of } 40.7 \% \text { CHO, vs. } 7 \mathrm{~d} \text { of } 5.4 \% \\
\text { CHO }\end{array}$ & $\begin{array}{l}\uparrow \text { Back squat (1-RM) } \\
\leftrightarrow \text { Bench press (1-RM) } \\
\leftrightarrow \text { Upper body (max power) } \\
\uparrow \text { CMJ (height) } \\
\leftrightarrow \text { Wingate peak power } \\
\uparrow \text { Handgrip strength }\end{array}$ \\
\hline Van Zant et al. (21) & $\begin{array}{l}6 \text { aerobic trained } \hat{\delta} \\
6 \text { resistance trained } \hat{\partial} \\
6 \text { sedentary } \hat{\partial}\end{array}$ & 3 weeks of $42 \% \mathrm{CHO}$ vs. $62 \%$ of $\mathrm{CHO}$ & $\begin{array}{l}\leftrightarrow \text { Knee extension (total work) } \\
\leftrightarrow \text { Bench press (1-RM) }\end{array}$ \\
\hline
\end{tabular}

In chapters 3 and 4 we have shown that carbohydrate availability during a single bout of resistance exercise has minimal impact on skeletal muscle gene expression and plasma cytokine response in the post-exercise period. Moreover, there were only mild but non-significant differences between preexercise fat or carbohydrate feeding on post-resistance exercise muscle glycogen levels, suggesting a relatively small pre-exercise meal effect in terms of macronutrient composition on muscle glycogen resynthesis. In theory, it could have been expected that low carbohydrate availability during resistance exercise would be associated with lower muscle glycogen levels, thereby inducing AMPK activity, which in turn regulates several processes involved in adaptation. Interestingly, our findings are in line with several other studies also reporting that the acute adaptive response to resistance exercise remains 
unaffected by differences in carbohydrate availability (22-25), including translation initiation and the myofibrillar protein synthetic response $(22,23)$ (Table 1.2).

Table 1.2 A summary of studies assessing carbohydrate (CHO) intake and acute resistance exercise muscular response (22).

\begin{tabular}{|c|c|c|c|c|c|}
\hline Authors & Participants & $\begin{array}{l}\text { CHO } \\
\text { intervention }\end{array}$ & $\begin{array}{l}\text { Resistance } \\
\text { exercise }\end{array}$ & $\begin{array}{l}\text { Pre -exercise } \\
\text { glycogen } \\
\text { concentrations }\end{array}$ & $\begin{array}{l}\text { Post-exercise } \\
\text { cellular } \\
\text { response }\end{array}$ \\
\hline Camera et al. (22) & 16 active $\delta$ & $\begin{array}{l}1 \mathrm{~g} / \mathrm{kg} \mathrm{CHO} \\
\text { evening meal } \\
\text { following glycogen } \\
\text { depletion protocol }\end{array}$ & $\begin{array}{l}8 \times 5 \text { unilateral leg } \\
\text { press } \\
80 \% 1-\mathrm{RM} \text { (fasted) }\end{array}$ & $\begin{array}{l}184 \mathrm{mmol} / \mathrm{kg} \mathrm{DM} \\
\text { Vs. } \\
382 \mathrm{mmol} / \mathrm{kg} \mathrm{DM}\end{array}$ & $\begin{array}{l}\leftrightarrow \text { Myofibrillar } \\
\text { protein synthesis } 1 \mathrm{~h} \\
\text { and } 4 \mathrm{~h}\end{array}$ \\
\hline $\begin{array}{l}\text { Churchley et al. } \\
\text { (24) }\end{array}$ & $\begin{array}{l}7 \text { resistance trained } \\
0\end{array}$ & $\begin{array}{l}1 \mathrm{~g} / \mathrm{kg} \mathrm{CHO} \\
\text { evening meal } \\
\text { following glycogen } \\
\text { depletion protocol }\end{array}$ & $\begin{array}{l}8 \times 5 \text { unilateral leg } \\
\text { press } \\
80 \% 1-\mathrm{RM} \text { (fasted) }\end{array}$ & $\begin{array}{l}193 \mathrm{mmol} / \mathrm{kg} \mathrm{DM} \\
\text { Vs. } \\
435 \mathrm{mmol} / \mathrm{kg} \mathrm{DM}\end{array}$ & $\begin{array}{l}\leftrightarrow \text { mRNA responses } \\
\text { at } 3 \mathrm{~h}\end{array}$ \\
\hline Creer et al. (23) & 7 cyclists ${ }^{\pi}$ & $\begin{array}{l}2 \% \mathrm{CHO} \text { vs. } 80 \% \\
\mathrm{CHO}\end{array}$ & $\begin{array}{l}3 \times 10 \text { bilateral } \\
\text { knee extension } 70 \% \\
1-\mathrm{RM} \text { (fasted) }\end{array}$ & $\begin{array}{l}174 \mathrm{mmol} / \mathrm{kg} \mathrm{DM} \\
\text { Vs. } \\
591 \mathrm{mmol} / \mathrm{kg} \mathrm{DM}\end{array}$ & $\leftrightarrow$ Protein signalling \\
\hline $\begin{array}{l}\text { Knuiman et al. (26, } \\
\text { 27) }\end{array}$ & 14 active $\delta$ & $\begin{array}{l}\text { Glycogen depletion } \\
\text { protocol followed } \\
\text { by } 1.5 \mathrm{~g} / \mathrm{kg} \text { of } \mathrm{CHO} \\
\mathrm{vs.} 0.3 \mathrm{~g} / \mathrm{kg} \text { of } \\
\mathrm{CHO} \text { before } \\
\text { resistance exercise }\end{array}$ & $\begin{array}{l}8 \times 5 \text { bilateral leg } \\
\text { press and extension } \\
80 \% 1-\mathrm{RM} \text { (fed } \\
\text { state) }\end{array}$ & $\begin{array}{l}380 \mathrm{mmol} / \mathrm{kg} \mathrm{DM} \\
\text { Vs. } \\
441 \mathrm{mmol} / \mathrm{kg} \mathrm{DM}\end{array}$ & $\begin{array}{l}\leftrightarrow \mathrm{mRNA} \text { responses } \\
\text { at } 1 \mathrm{~h} \text { and } 3 \mathrm{~h} \\
\leftrightarrow \text { plasma cytokines }\end{array}$ \\
\hline
\end{tabular}

At the transcriptional level we found that PDK4 was the only gene in muscle tissue that was differently expressed between the carbohydrate and fat condition. An increase in PDK4 mRNA would be in line with a shift towards fat oxidation and reduced glucose oxidation, hence simply reflecting a shift in substrate use due to substrate availability. In addition, plasma insulin was higher in the carbohydrate condition. However, an increase in plasma insulin elicited by carbohydrates does not further stimulate the muscle protein synthetic response (28), and thus does not affect muscle anabolism negatively per se. Additionally, the increased insulin response in the carbohydrate condition is not necessarily required to stimulate or augment the muscle protein synthetic response when amino acid availability is sufficient (e.g. reduce protein breakdown) (28-30), which was the case in our study. From the plasma cytokine analysis (chapter 4), IL-6 was the only cytokine that responded mildly different to differences in carbohydrate availability. This finding was not surprising since IL- 6 has been found to be sensitive to changes in blood glucose levels (31), but also to pre-exercise muscle glycogen content (32).

Findings of chapter 3 and 4 contribute to the view that carbohydrate availability during resistance exercise is of minor importance when aiming for 
an anabolic skeletal muscle adaptive response. At present it might be premature to change carbohydrate recommendations for individuals performing resistance exercise. However, data from our study do call into question the importance of carbohydrates as both substrate for resistance exercise training and as modulator of the skeletal muscle response that underlies adaptation.

\section{Protein supplementation and endurance training}

In chapter 6 we were able to demonstrate a proof-of-concept that protein supplementation elicits greater increases in $\mathrm{VO}_{2 \max }$ and stimulated lean mass gain in response to prolonged endurance training. To our knowledge, this was the first double-blind randomised controlled trial with repeated measures showing that protein supplementation enhances the adaptive response to endurance training. These remarkable effects of protein on $\mathrm{VO}_{2 \max }$ that were observed give rise to questions regarding their underlying mechanisms. Interestingly, the greater increase in $\mathrm{VO}_{2 \max }$ elicited by protein supplementation the first 5 weeks was accompanied by a substantial gain in lean mass. Based on this finding we questioned to what extent the lean mass gain contributed to the greater increase in $\mathrm{VO}_{\text {2max }}$. To this end, we analysed the associations between these two variables. Overall, lean body mass and leg lean mass were well associated with absolute $\mathrm{VO}_{2 \max }$ (Figure 1.1), but the strongest correlation was found between leg lean mass and $\mathrm{VO}_{2 \max }$ at week $5\left(r^{2}=0.59 ; p<0.0001\right)$. Changes in lean body mass and leg lean mass correlated mildly but significant with changes in absolute $\mathrm{VO}_{2 \max }$ after 5 weeks of training (Figure 1.2).
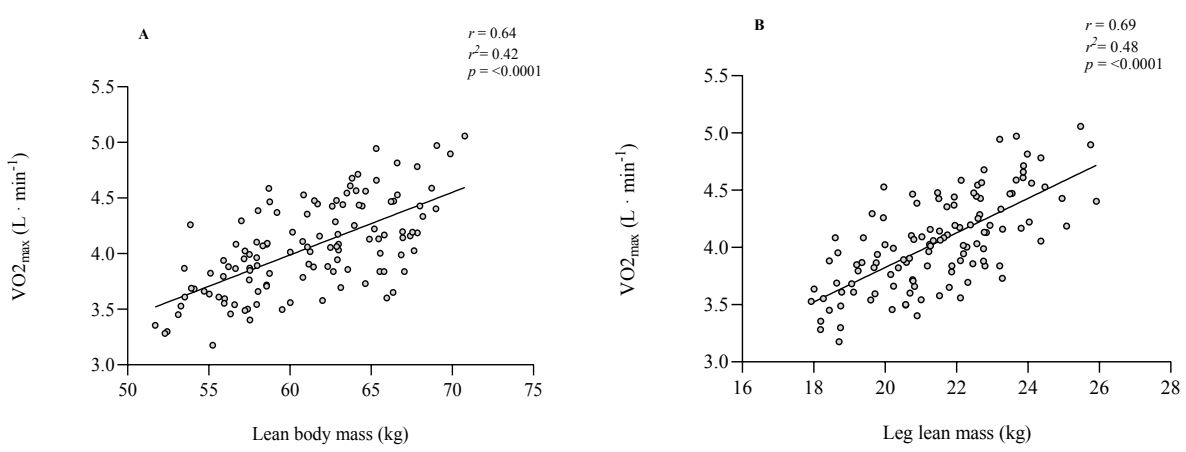

Figure 1.1 Scatter plot of the correlation between absolute $\mathrm{VO}_{2 \max }\left(\mathrm{L} \cdot \mathrm{min}^{-1}\right)$ and (a) lean body mass $(\mathrm{kg})$ or (b) leg lean mass $(\mathrm{kg})$. Merged data (control and protein supplemented group) from Pre (0 weeks), Mid (5 weeks) and End (10 weeks), $(n=120)$. 

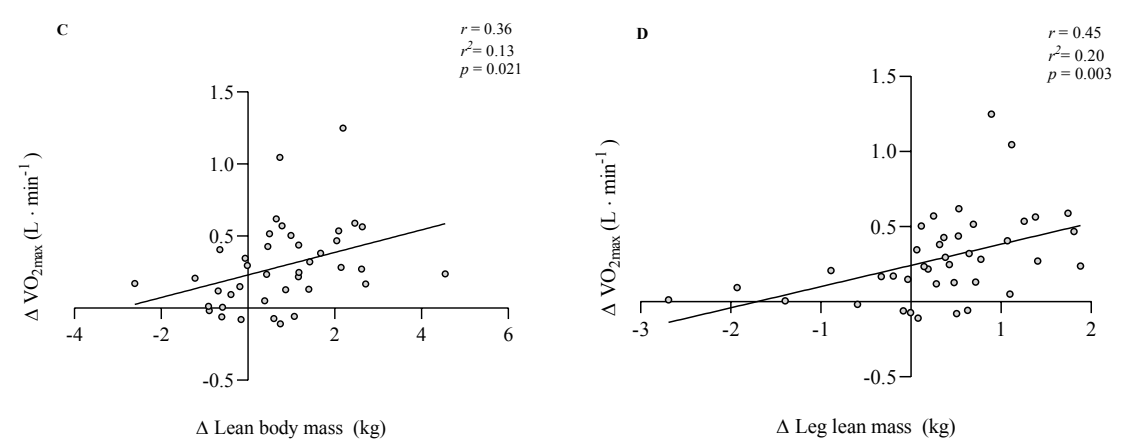

Figure 1.2 Scatter plot of the correlation between change in absolute $\mathrm{VO}_{2 \max }\left(\mathrm{L} \cdot \mathrm{min}^{-1}\right)$ and (c) change lean body mass $(\mathrm{kg})$ or $(\mathbf{d})$ change in leg lean mass $(\mathrm{kg})$ in the protein supplemented group $(n=19)$ following 5 weeks of endurance training.

Thus, the correlation found between (leg) lean mass and $\mathrm{VO}_{2 \max }$ is interesting and based on this finding we decided to focus on the mechanisms by which protein supplementation enhanced the skeletal muscle adaptive response to endurance training.

\section{Potential mechanisms underlying}

Throughout the years, numerous studies have investigated the mechanisms by which endurance training increases $\mathrm{VO}_{2 \max }$ (33-41). Endurance trainingassociated increases in $\mathrm{VO}_{2 \max }$ are considered to result from central and peripheral adaptations $(42,43)$. Central adaptations include cardiac hypertrophy, increased plasma and red blood cell volume $(44,45)$, whereas peripheral adaptations include vascular resistance $(46,47)$, as well as skeletal muscle adaptations such as capillarisation (48), and increased mitochondrial content and function $(41,49)$. Previous research postulated that chronic endurance training alters the skeletal muscle transcriptome by down- and upregulating numerous pathways involved in adaptation (50, 51). Transcriptome analysis has previously only been used to a limited extent in the study of exercise and nutrition, notwithstanding its substantial impact for nutrition science in general. Most studies examining skeletal muscle phenotypic regulation at the mRNA level are hypothesis-driven in nature, and suppose predetermined single genes/myocellular pathways, trying to connect specific regulatory pathways to specific types of skeletal muscle adaptation responses (52-59). Consequently, such studies are unlikely to reveal yet unknown molecular effects and pathways such as redundant and oppositely acting mechanisms. Thus, skeletal muscle transcriptome analysis holds many 
promises to the field by unravelling mechanisms underlying phenotypic adaptations to exercise training and the subtle effects of nutrition.

In chapter 7 we aimed to unravel mechanisms by which protein supplementation elicited a greater increase in $\mathrm{VO}_{2 \max }$. To this end, we analysed the muscle transcriptome to gain insight into changes in the steady-state gene expression. Although the endurance training clearly induced changes in the skeletal muscle transcriptome, its quantitative effects in terms of signal changes were relatively small. These relatively small changes can be explained by the time the muscle tissues were taken in our study (6-8 days after the last exercise session). Generally, greatest increases in mRNA expression are observed at 3-12 hr after ending exercise and return to baseline levels within $24 \mathrm{hr}(7,60)$. Moreover, long-term training adaptation is the result of the expression of a selection of genes after each acute exercise bout that subsequently increases the type and amount of proteins that drive the phenotypic alteration. As protein half-lives are usually much longer than those of mRNA, changes in protein content are more readily observed than changes in transcript expression in response to training as opposed to acute exercise (7) (figure 2).

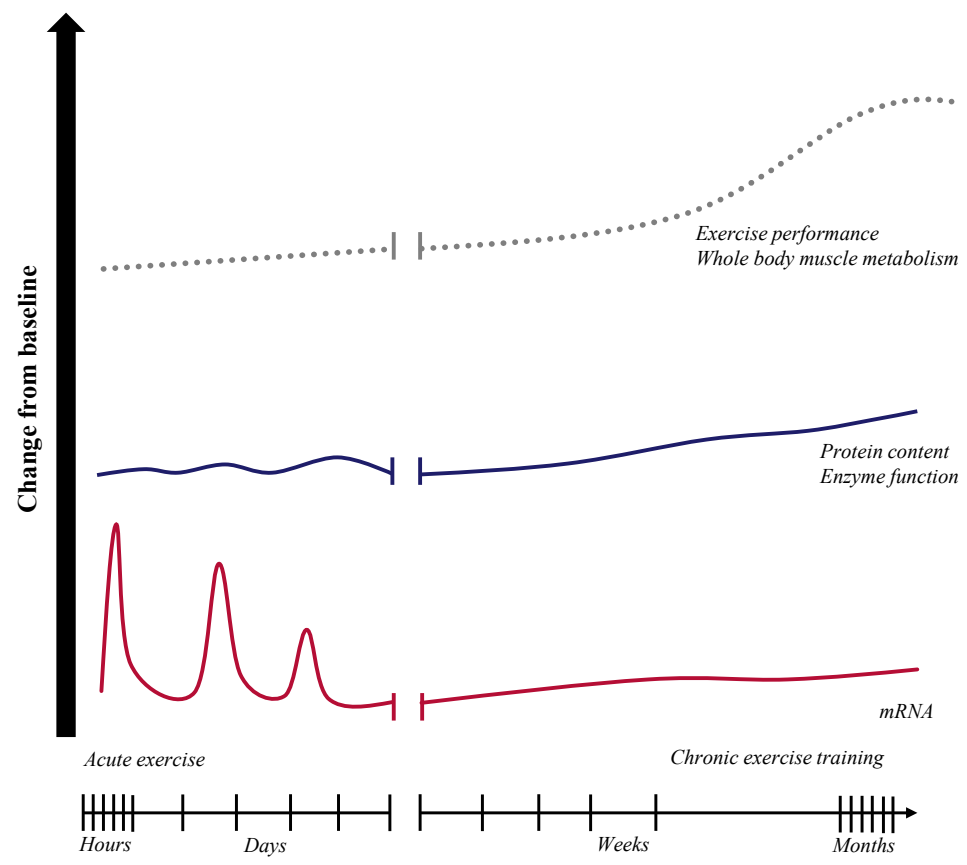

Figure 2 General model based on the signal transduction hypothesis for adaptation to exercise training (2), highlighting the importance of timing for sampling. Model adapted from Egan and Zierath (2013) (7). 
Using analysis of skeletal muscle transcriptome we were not able to bring out clear mechanisms by which protein supplementation enhanced the skeletal muscle adaptive response in response to prolonged endurance training. Yet, we did find that protein supplementation induced greater changes in gene expression transcripts related to the extracellular matrix organisation. The extracellular matrix is composed by a variety of proteins including elastin, collagens, glycoproteins and matricellular proteins (61). In addition to its role in physical and mechanical properties of tissue, it appears that extracellular matrix remodelling is a vital adaptation in providing protection against exercise-induced skeletal muscle injury (62). Previous research has demonstrated that modulation of extracellular matrix genes reflects the magnitude of physiological adaptation to prolonged endurance training in humans (63). Our findings complement previous findings that the extent to which the extracellular matrix adapts reflects to a certain extent the degree of physiological adaptations. Additionally, we were also able to demonstrate a subtle effect of protein supplementation on top of the endurance training effect at the skeletal muscle transcriptional level. Thus, in chapter 7 we demonstrated that prolonged endurance training changed expression of genes involved in extracellular matrix organisation, energy metabolism and oxidative phosphorylation. Changes in extracellular matrix organization tended to be greater in the protein group than in the control group and these greater transcriptional changes may reflect the enhanced physiological adaptation as a result of protein supplementation. Future research is needed to identify the specific role of the extracellular matrix within physiological adaptation to endurance training.

\section{Future perspectives}

Findings of chapter 6 and 7 could also have potential for ageing and diseased populations. An increase in $\mathrm{VO}_{2 \max }$ has been well associated with an improved endurance exercise performance (70). From a clinical perspective, an increase in $\mathrm{VO}_{2 \max }$ is independently associated with a reduction in all-cause morbidity and mortality, which emphasizes the important clinical benefits of endurance training (71). During aging there is a linear decline in $\mathrm{VO}_{2 \max }$ (Figure 3) (72). Lower levels of $\mathrm{VO}_{2 \max }$ contribute to loss of independence, increased incidence of disability, and reduced quality of life in older people. Endurance training is a well-established strategy to improve $\mathrm{VO}_{2 \max }$ and offers a wide range of health benefits to older adults. Whether an increased intake of dietary protein enhances cardiovascular and skeletal muscle adaptive response to endurance training in the elderly population presents an interesting question for future research. 
Age associated decline in $\mathrm{VO}_{2 \max }$

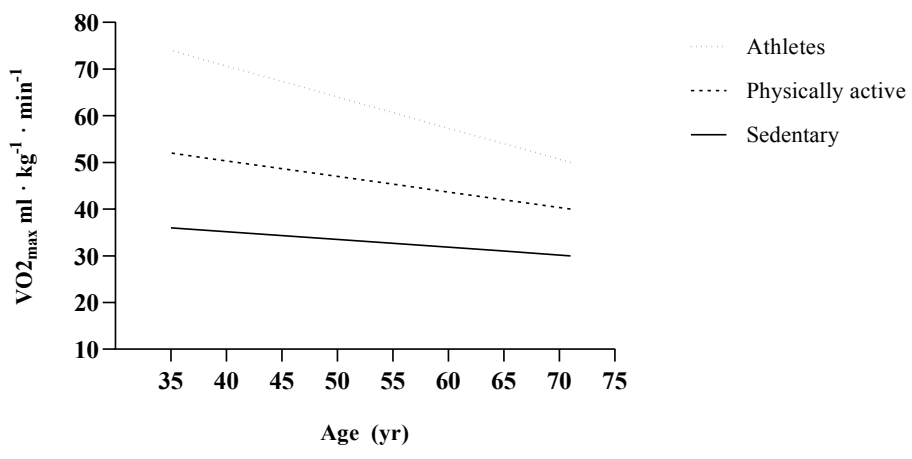

Figure 3 Simplistic model showing the age associated decline in $\mathrm{VO}_{2 \max }$, adapted from Strasser and Burtscher (2018) (73).

\section{Prerehabilitation}

Findings of chapter 6 and 7 may also have potential as part of a prerehabilitation intervention. Prerehabilitation is an intervention to enhance functional capacity in anticipation of a forthcoming physiological stressor, such as surgery (74). Evidence indicates that preoperative exercise training can improve postoperative outcome in patients undergoing major elective major surgery. Preoperative endurance training increases $\mathrm{VO}_{2 \max }$, and a higher preoperative $\mathrm{VO}_{2 \max }$ has been shown to be effective in reducing the incidence of postoperative complications, decreasing the length of hospital stay (e.g. days of intensive care unit stay), disease and death after major abdominal, cardiac and vascular surgery $(74,75)$. Additionally, high-intensity endurance training appears feasible and safe in elderly and/or multimorbid candidates undergoing major surgery (75). Thus, our findings highlight the potential clinical importance of dietary protein intake with endurance training and may have considerable potential as part of a prerehabilitation program for patients undergoing major elective surgery.

\section{Perspectives mechanisms of adaptation}

Thus far, much attention has been given to the acute molecular responses to a single bout of exercise, and the current theory suggests that acute signals predict/drive phenotypic adaptation over time. For example, the AMPactivated protein kinase and peroxisome proliferator-activated receptor- $\gamma$ coactivator-1a (PGC-1 alpha), has been proposed as primary regulators of muscle tissue adaptation in response to endurance training (64-67). Findings of chapter 7 demonstrate that the extracellular matrix may be an important 
factor for skeletal muscle adaptation in response to prolonged endurance training. Our findings suggest that protein supplementation enhances physiological adaptation and elicit greater changes in skeletal muscle gene expression transcripts related to the extracellular matrix. These changes in extracellular matrix gene expression may reflect modulation of the physiological adaptation to endurance training (69), leading to enhanced cumulative effects with regard to endurance performance and muscle size. More experimental work is warranted to further scrutinize this topic.

\section{Final conclusions}

In this thesis we have studied the role of nutrition on the skeletal muscle adaptive response with exercise. We conclude that the role of carbohydrate availability on the adaptive response with resistance exercise requires more scientific attention (chapter 2). Taking chapter 3 and 4 together, we conclude that carbohydrate availability has only a minor effect on the acute adaptive response to resistance exercise. This conclusion is based on an experimental study where we assessed skeletal muscle gene expression (chapter 3) and plasma cytokine responses (chapter 4). In this study we have shown that a preexercise meal low in carbohydrates did not impair acute gene expression profiles or plasma cytokine responses during the post-resistance exercise period. Next, we hypothesized how protein supplementation may affect the adaptive response to prolonged endurance training from a physiological perspective, and conclude that randomised controlled trials are needed to test this hypothesis (chapter 5). Taking chapter 6 and 7 together, we conclude that dietary protein facilitates the adaptive response to endurance training. We were able to show that protein supplementation further enhances $\mathrm{VO}_{2 \max }$, and stimulates lean mass gain (chapter 6). However, the improved physiological adaptation as a result of protein supplementation was partly explained by changes in the steady-state skeletal muscle transcriptome (chapter 7). 


\section{References}

1. Hawley JA, Burke LM, Phillips SM, Spriet LL. Nutritional modulation of training-induced skeletal muscle adaptations. Journal of applied physiology 2011;110(3):834-45. doi: 10.1152/japplphysiol.00949.2010.

2. Hawley JA, Lundby C, Cotter JD, Burke LM. Maximizing Cellular Adaptation to Endurance Exercise in Skeletal Muscle. Cell metabolism 2018;27(5):962-76. doi: 10.1016/j.cmet.2018.04.014.

3. Knuiman P, Hopman MT, Mensink M. Glycogen availability and skeletal muscle adaptations with endurance and resistance exercise. Nutrition \& metabolism 2015;12:59. doi: 10.1186/s12986-015-0055-9.

4. Bartlett JD, Hawley JA, Morton JP. Carbohydrate availability and exercise training adaptation: Too much of a good thing? European journal of sport science 2015;15(1):312. doi: 10.1080/17461391.2014.920926.

5. Bergstrom J, Hermansen L, Hultman E, Saltin B. Diet, muscle glycogen and physical performance. Acta physiologica Scandinavica 1967;71(2):140-50. doi: 10.1111/j.17481716.1967.tb03720.x.

6. Achten J, Halson SL, Moseley L, Rayson MP, Casey A, Jeukendrup AE. Higher dietary carbohydrate content during intensified running training results in better maintenance of performance and mood state. Journal of applied physiology 2004;96(4):1331-40. doi: 10.1152/japplphysiol.00973.2003.

7. Egan B, Zierath JR. Exercise metabolism and the molecular regulation of skeletal muscle adaptation. Cell metabolism 2013;17(2):162-84. doi: 10.1016/j.cmet.2012.12.012.

8. Watson K, Baar K. mTOR and the health benefits of exercise. Seminars in cell \& developmental biology 2014;36:130-9. doi: 10.1016/j.semcdb.2014.08.013.

9. Marcotte GR, West DW, Baar K. The molecular basis for load-induced skeletal muscle hypertrophy. Calcified tissue international 2015;96(3):196-210. doi: 10.1007/s00223014-9925-9.

10. Hawley JA, Hargreaves M, Joyner MJ, Zierath JR. Integrative biology of exercise. Cell 2014;159(4):738-49. doi: 10.1016/j.cell.2014.10.029.

11. Thomas DT, Erdman KA, Burke LM. Position of the Academy of Nutrition and Dietetics, Dietitians of Canada, and the American College of Sports Medicine: Nutrition and Athletic Performance. Journal of the Academy of Nutrition and Dietetics 2016;116(3):501-28. doi: 10.1016/j.jand.2015.12.006.

12. Kerksick CM, Wilborn CD, Roberts MD, Smith-Ryan A, Kleiner SM, Jager R, Collins R, Cooke M, Davis JN, Galvan E, et al. ISSN exercise \& sports nutrition review update: research \& recommendations. Journal of the International Society of Sports Nutrition 2018;15(1):38. doi: 10.1186/s12970-018-0242-y.

13. Slater G, Phillips SM. Nutrition guidelines for strength sports: sprinting, weightlifting, throwing events, and bodybuilding. Journal of sports sciences 2011;29 Suppl 1:S67-77. doi: 10.1080/02640414.2011.574722.

14. Lambert CP, Frank LL, Evans WJ. Macronutrient considerations for the sport of bodybuilding. Sports medicine 2004;34(5):317-27.

15. Mitchell JB, DiLauro PC, Pizza FX, Cavender DL. The effect of preexercise carbohydrate status on resistance exercise performance. International journal of sport nutrition 1997;7(3):185-96.

16. Sawyer JC, Wood RJ, Davidson PW, Collins SM, Matthews TD, Gregory SM, Paolone VJ. Effects of a short-term carbohydrate-restricted diet on strength and power performance. Journal of strength and conditioning research / National Strength \& Conditioning Association 2013;27(8):2255-62. doi: 10.1519/JSC.0b013e31827da314. 
17. Dipla K, Makri M, Zafeiridis A, Soulas D, Tsalouhidou S, Mougios V, Kellis S. An isoenergetic high-protein, moderate-fat diet does not compromise strength and fatigue during resistance exercise in women. The British journal of nutrition 2008;100(2):2836.

18. Hatfield DL, Kraemer WJ, Volek JS, Rubin MR, Grebien B, Gomez AL, French DN, Scheett TP, Ratamess NA, Sharman MJ, et al. The effects of carbohydrate loading on repetitive jump squat power performance. Journal of strength and conditioning research / National Strength \& Conditioning Association 2006;20(1):167-71. doi: 10.1519/r18300.1 .

19. Leveritt M, Abernethy PJ. Effects of carbohydrate restriction on strength performance. Journal of Strength and Conditioning Research 1999;13(1):52-7.

20. Paoli A, Grimaldi K, D’Agostino D, Cenci L, Moro T, Bianco A, Palma A. Ketogenic diet does not affect strength performance in elite artistic gymnasts. Journal of the International Society of Sports Nutrition 2012;9(1):34.

21. Van Zant R, Conway J, Seale J. A moderate carbohydrate and fat diet does not impair strength performance in moderately trained males. Journal of sports medicine and physical fitness 2002;42(1):31.

22. Camera DM, West DW, Burd NA, Phillips SM, Garnham AP, Hawley JA, Coffey VG. Low muscle glycogen concentration does not suppress the anabolic response to resistance exercise. Journal of applied physiology 2012;113(2):206-14. doi: 10.1152/japplphysiol.00395.2012.

23. Creer A, Gallagher P, Slivka D, Jemiolo B, Fink W, Trappe S. Influence of muscle glycogen availability on ERK1/2 and Akt signaling after resistance exercise in human skeletal muscle. Journal of applied physiology 2005;99(3):950-6. doi: 10.1152/japplphysiol.00110.2005.

24. Churchley EG, Coffey VG, Pedersen DJ, Shield A, Carey KA, Cameron-Smith D, Hawley JA. Influence of preexercise muscle glycogen content on transcriptional activity of metabolic and myogenic genes in well-trained humans. Journal of applied physiology 2007;102(4):1604-11. doi: 10.1152/japplphysiol.01260.2006.

25. Camera DM, Hawley JA, Coffey VG. Resistance exercise with low glycogen increases p53 phosphorylation and PGC-1alpha mRNA in skeletal muscle. European journal of applied physiology 2015. doi: 10.1007/s00421-015-3116-х.

26. Knuiman P, Hopman MTE, Wouters JA, Mensink M. Select Skeletal Muscle mRNAs Related to Exercise Adaptation Are Minimally Affected by Different Pre-exercise Meals that Differ in Macronutrient Profile. Frontiers in physiology 2018;9:28. doi: 10.3389/fphys.2018.00028.

27. Knuiman P, Hopman MTE, Hangelbroek R, Mensink M. Plasma cytokine responses to resistance exercise with different nutrient availability on a concurrent exercise day in trained healthy males. Physiological reports 2018;6(11):e13708. doi: 10.14814/phy2.13708.

28. Abdulla H, Smith K, Atherton PJ, Idris I. Role of insulin in the regulation of human skeletal muscle protein synthesis and breakdown: a systematic review and metaanalysis. Diabetologia 2016;59(1):44-55. doi: 10.1007/s00125-015-3751-0.

29. Morton RW, McGlory C, Phillips SM. Nutritional interventions to augment resistance training-induced skeletal muscle hypertrophy. Frontiers in physiology 2015;6:245. doi: 10.3389/fphys.2015.00245.

30. Staples AW, Burd NA, West DW, Currie KD, Atherton PJ, Moore DR, Rennie MJ, Macdonald MJ, Baker SK, Phillips SM. Carbohydrate does not augment exercise-induced protein accretion versus protein alone. Medicine and science in sports and exercise 2011;43(7):1154-61. doi: 10.1249/MSS.0b013e31820751cb. 
31. Febbraio MA, Steensberg A, Keller C, Starkie RL, Nielsen HB, Krustrup P, Ott P, Secher $\mathrm{NH}$, Pedersen BK. Glucose ingestion attenuates interleukin-6 release from contracting skeletal muscle in humans. The Journal of physiology 2003;549(Pt 2):607-12. doi: 10.1113/jphysiol.2003.042374.

32. Steensberg A, Febbraio MA, Osada T, Schjerling P, van Hall G, Saltin B, Pedersen BK. Interleukin-6 production in contracting human skeletal muscle is influenced by preexercise muscle glycogen content. The Journal of physiology 2001;537(Pt 2):633-9.

33. Holloszy JO. Biochemical adaptations in muscle. Effects of exercise on mitochondrial oxygen uptake and respiratory enzyme activity in skeletal muscle. The Journal of biological chemistry 1967;242(9):2278-82.

34. Holloszy JO, Booth FW. Biochemical adaptations to endurance exercise in muscle. Annual review of physiology 1976;38:273-91. doi: 10.1146/annurev.ph.38.030176.001421.

35. Holloszy JO, Coyle EF. Adaptations of skeletal muscle to endurance exercise and their metabolic consequences. Journal of applied physiology: respiratory, environmental and exercise physiology 1984;56(4):831-8.

36. Holloszy JO, Oscai LB, Don IJ, Mole PA. Mitochondrial citric acid cycle and related enzymes: adaptive response to exercise. Biochemical and biophysical research communications 1970;40(6):1368-73.

37. Hoppeler H. The different relationship of VO2max to muscle mitochondria in humans and quadrupedal animals. Respiration physiology 1990;80(2-3):137-45.

38. Hoppeler H, Baum O, Lurman G, Mueller M. Molecular mechanisms of muscle plasticity with exercise. Comprehensive Physiology 2011;1(3):1383-412. doi: 10.1002/cphy.c100042.

39. Hoppeler H, Howald H, Conley K, Lindstedt SL, Claassen H, Vock P, Weibel ER. Endurance training in humans: aerobic capacity and structure of skeletal muscle. Journal of applied physiology 1985;59(2):320-7.

40. Hoppeler H, Klossner S, Fluck M. Gene expression in working skeletal muscle. Advances in experimental medicine and biology 2007;618:245-54.

41. Hoppeler H, Luthi P, Claassen H, Weibel ER, Howald H. The ultrastructure of the normal human skeletal muscle. A morphometric analysis on untrained men, women and welltrained orienteers. Pflugers Archiv : European journal of physiology 1973;344(3):21732.

42. Ekblom B, Astrand PO, Saltin B, Stenberg J, Wallstrom B. Effect of training on circulatory response to exercise. J Appl Physiol 1968;24(4):518-28. doi: 10.1152/jappl.1968.24.4.518.

43. Saltin B, Blomqvist G, Mitchell JH, Johnson RL, Wildenthal K, Chapman CB, Frenkel E, Norton W, Siperstein M, Suki W. A longitudinal study of adaptive changes in oxygen transport and body composition. Circulation 1968;38(5S7):VII-1-VII-78.

44. Sawka MN, Convertino VA, Eichner ER, Schnieder SM, Young AJ. Blood volume: importance and adaptations to exercise training, environmental stresses, and trauma/sickness. Medicine and science in sports and exercise 2000;32(2):332-48.

45. Bonne TC, Doucende G, Fluck D, Jacobs RA, Nordsborg NB, Robach P, Walther G, Lundby C. Phlebotomy eliminates the maximal cardiac output response to six weeks of exercise training. American journal of physiology Regulatory, integrative and comparative physiology 2014;306(10):R752-60. doi: 10.1152/ajpregu.00028.2014.

46. Klausen K, Secher NH, Clausen JP, Hartling O, Trap-Jensen J. Central and regional circulatory adaptations to one-leg training. Journal of applied physiology: respiratory, environmental and exercise physiology 1982;52(4):976-83. doi: 10.1152/jappl.1982.52.4.976. 
47. Weng TP, Huang SC, Chuang YF, Wang JS. Effects of interval and continuous exercise training on CD4 lymphocyte apoptotic and autophagic responses to hypoxic stress in sedentary men. PloS one 2013;8(11):e80248. doi: 10.1371/journal.pone.0080248.

48. Murias JM, Kowalchuk JM, Ritchie D, Hepple RT, Doherty TJ, Paterson DH. Adaptations in capillarization and citrate synthase activity in response to endurance training in older and young men. The journals of gerontology Series A, Biological sciences and medical sciences 2011;66(9):957-64. doi: 10.1093/gerona/glr096.

49. Jacobs RA, Lundby C. Mitochondria express enhanced quality as well as quantity in association with aerobic fitness across recreationally active individuals up to elite athletes. Journal of applied physiology 2013;114(3):344-50. doi: 10.1152/japplphysiol.01081.2012.

50. Nishida Y, Tanaka H, Tobina T, Murakami K, Shono N, Shindo M, Ogawa W, Yoshioka M, St-Amand J. Regulation of muscle genes by moderate exercise. International journal of sports medicine 2010;31(9):656-70. doi: 10.1055/s-0030-1255065.

51. Radom-Aizik S, Hayek S, Shahar I, Rechavi G, Kaminski N, Ben-Dov I. Effects of aerobic training on gene expression in skeletal muscle of elderly men. Medicine and science in sports and exercise 2005;37(10):1680-96.

52. Atherton PJ, Babraj J, Smith K, Singh J, Rennie MJ, Wackerhage H. Selective activation of AMPK-PGC-1alpha or PKB-TSC2-mTOR signaling can explain specific adaptive responses to endurance or resistance training-like electrical muscle stimulation. FASEB journal : official publication of the Federation of American Societies for Experimental Biology 2005;19(7):786-8. doi: 10.1096/fj.04-2179fje.

53. Goodman CA, Miu MH, Frey JW, Mabrey DM, Lincoln HC, Ge Y, Chen J, Hornberger TA. A phosphatidylinositol 3-kinase/protein kinase B-independent activation of mammalian target of rapamycin signaling is sufficient to induce skeletal muscle hypertrophy. Molecular biology of the cell 2010;21(18):3258-68. doi: 10.1091/mbc.E1005-0454.

54. Sartori R, Schirwis E, Blaauw B, Bortolanza S, Zhao J, Enzo E, Stantzou A, Mouisel E, Toniolo L, Ferry A, et al. BMP signaling controls muscle mass. Nature genetics 2013;45(11):1309-18. doi: 10.1038/ng.2772.

55. von Maltzahn J, Chang NC, Bentzinger CF, Rudnicki MA. Wnt signaling in myogenesis. Trends in cell biology 2012;22(11):602-9. doi: 10.1016/j.tcb.2012.07.008.

56. Leger B, Cartoni R, Praz M, Lamon S, Deriaz O, Crettenand A, Gobelet C, Rohmer P, Konzelmann M, Luthi F, et al. Akt signalling through GSK-3beta, mTOR and Foxol is involved in human skeletal muscle hypertrophy and atrophy. The Journal of physiology 2006;576(Pt 3):923-33. doi: 10.1113/jphysiol.2006.116715.

57. Wu H, Naya FJ, McKinsey TA, Mercer B, Shelton JM, Chin ER, Simard AR, Michel RN, Bassel-Duby R, Olson EN, et al. MEF2 responds to multiple calcium-regulated signals in the control of skeletal muscle fiber type. The EMBO journal 2000;19(9):1963-73. doi: 10.1093/emboj/19.9.1963.

58. Chin ER, Olson EN, Richardson JA, Yang Q, Humphries C, Shelton JM, Wu H, Zhu W, Bassel-Duby R, Williams RS. A calcineurin-dependent transcriptional pathway controls skeletal muscle fiber type. Genes \& development 1998;12(16):2499-509.

59. Vissing K, Schjerling P. Simplified data access on human skeletal muscle transcriptome responses to differentiated exercise. Scientific data 2014;1:140041. doi: 10.1038/sdata.2014.41.

60. Perry CG, Lally J, Holloway GP, Heigenhauser GJ, Bonen A, Spriet LL. Repeated transient mRNA bursts precede increases in transcriptional and mitochondrial proteins during training in human skeletal muscle. The Journal of physiology 2010;588(Pt 23):4795810. doi: 10.1113/jphysiol.2010.199448. 
61. Eming SA, Hubbell JA. Extracellular matrix in angiogenesis: dynamic structures with translational potential. Experimental dermatology 2011;20(7):605-13. doi: 10.1111/j.1600-0625.2011.01309.x.

62. Mackey AL, Brandstetter S, Schjerling P, Bojsen-Moller J, Qvortrup K, Pedersen MM, Doessing S, Kjaer M, Magnusson SP, Langberg H. Sequenced response of extracellular matrix deadhesion and fibrotic regulators after muscle damage is involved in protection against future injury in human skeletal muscle. FASEB journal : official publication of the Federation of American Societies for Experimental Biology 2011;25(6):1943-59. doi: 10.1096/fj.10-176487.

63. Timmons JA, Jansson E, Fischer H, Gustafsson T, Greenhaff PL, Ridden J, Rachman J, Sundberg CJJBB. Modulation of extracellular matrix genes reflects the magnitude of physiological adaptation to aerobic exercise training in humans. 2005;3(1):19. doi: 10.1186/1741-7007-3-19.

64. Akimoto T, Ribar TJ, Williams RS, Yan Z. Skeletal muscle adaptation in response to voluntary running in $\mathrm{Ca} 2+$ /calmodulin-dependent protein kinase IV-deficient mice. American journal of physiology Cell physiology 2004;287(5):C1311-9. doi: 10.1152/ajpcell.00248.2004.

65. Handschin C, Spiegelman BM. The role of exercise and PGC1alpha in inflammation and chronic disease. Nature 2008;454(7203):463-9. doi: 10.1038/nature07206.

66. Jorgensen SB, Jensen TE, Richter EA. Role of AMPK in skeletal muscle gene adaptation in relation to exercise. Applied physiology, nutrition, and metabolism = Physiologie appliquee, nutrition et metabolisme 2007;32(5):904-11. doi: 10.1139/h07-079.

67. Leick L, Wojtaszewski JF, Johansen ST, Kiilerich K, Comes G, Hellsten Y, Hidalgo J, Pilegaard H. PGC-1alpha is not mandatory for exercise- and training-induced adaptive gene responses in mouse skeletal muscle. American journal of physiology Endocrinology and metabolism 2008;294(2):E463-74. doi: 10.1152/ajpendo.00666.2007.

68. Mahoney DJ, Parise G, Melov S, Safdar A, Tarnopolsky MA. Analysis of global mRNA expression in human skeletal muscle during recovery from endurance exercise. FASEB journal : official publication of the Federation of American Societies for Experimental Biology 2005;19(11):1498-500. doi: 10.1096/fj.04-3149fje.

69. Timmons JA, Jansson E, Fischer H, Gustafsson T, Greenhaff PL, Ridden J, Rachman J, Sundberg CJ. Modulation of extracellular matrix genes reflects the magnitude of physiological adaptation to aerobic exercise training in humans. BMC biology 2005;3:19. doi: 10.1186/1741-7007-3-19.

70. Joyner MJ, Coyle EF. Endurance exercise performance: the physiology of champions. The Journal of physiology 2008;586(1):35-44. doi: 10.1113/jphysiol.2007.143834.

71. Kodama S, Saito K, Tanaka S, Maki M, Yachi Y, Asumi M, Sugawara A, Totsuka K, Shimano H, Ohashi Y, et al. Cardiorespiratory fitness as a quantitative predictor of allcause mortality and cardiovascular events in healthy men and women: a meta-analysis. Jama 2009;301(19):2024-35. doi: 10.1001/jama.2009.681.

72. Shephard RJ. Aging, physical activity, and health: Human Kinetics Publishers, 1997.

73. Strasser B, Burtscher M. Survival of the fittest: VO2max, a key predictor of longevity? Frontiers in bioscience (Landmark edition) 2018;23:1505-16.

74. Richardson K, Levett DZH, Jack S, Grocott MPW. Fit for surgery? Perspectives on preoperative exercise testing and training. British journal of anaesthesia 2017;119(suppl_1):i34-i43. doi: 10.1093/bja/aex393.

75. Barberan-Garcia A, Ubre M, Roca J, Lacy AM, Burgos F, Risco R, Momblan D, Balust J, Blanco I, Martinez-Palli G. Personalised Prehabilitation in High-risk Patients Undergoing Elective Major Abdominal Surgery: A Randomized Blinded Controlled Trial. Annals of surgery 2018;267(1):50-6. doi: 10.1097/sla.0000000000002293. 


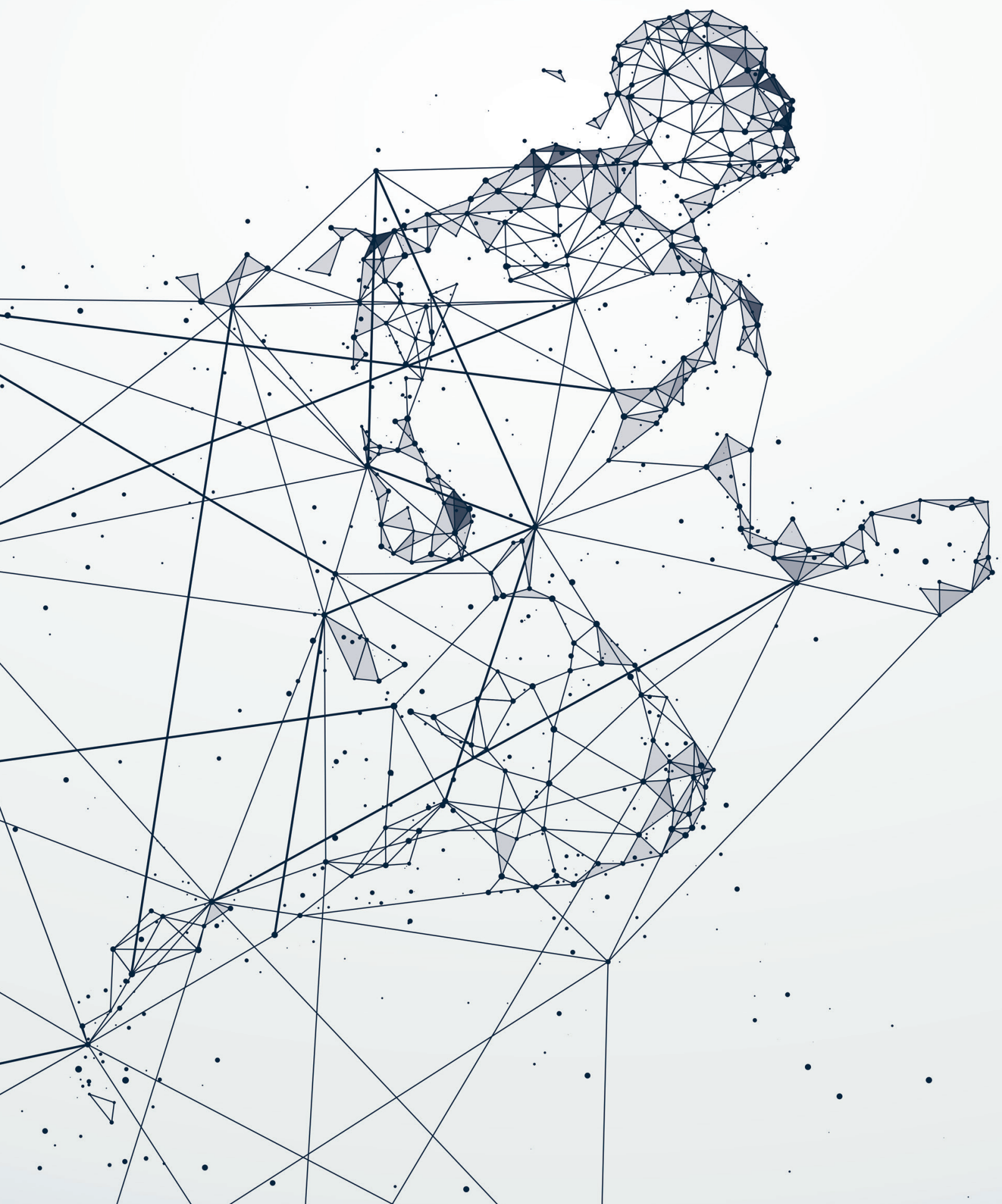




\section{Chapter 9}

Summary

Acknowledgements

List of publications

About the author

Training activities 


\section{Summary}

Skeletal muscle responds to exercise by a diversity of processes that collectively contribute to short-term and structural adaptations to the demanded performance capacities. There is common consensus that, in general, adequate nutrient availability during and after exercise is important to maximise skeletal muscle adaptation and ultimately performance. At the same time, several knowledge gaps remain regarding the precise mechanisms underlying these effects on adaptation, the most optimal nutrient composition in relation to type of exercise, optimal timing etc.

This dissertation addresses some of these unsolved issues by studying the role of carbohydrates and proteins during adaptation following different forms of exercise. The first part (chapters $2-4$ ) focusses on carbohydrate availability with resistance exercise, whereas the second part (chapters $5-7$ ) specifically addresses the effects and potential of protein supplementation with endurance training. In chapter 2 we reviewed the existing literature regarding the role of skeletal muscle glycogen with endurance and resistance exercise. Based on this review we concluded that the role of muscle glycogen levels and/or carbohydrate availability on the skeletal muscle adaptive response to resistance exercise requires further scientific attention. To experimentally explore this, we assessed the impact of a pre-exercise meal that differed in macronutrient content on skeletal muscle glycogen levels and acute transcriptional level analysing specific mRNAs in the post-resistance exercise period in chapter 3. Specifically, after a glycogen depleting endurance exercise session in the morning, subjects received an isocaloric mixed meal containing different amounts of carbohydrates and fat 2 hours before a resistance exercise session in the afternoon, while ample protein was provided throughout the day. We hypothesized that some of the selected mRNAs associated with substrate metabolism and mitochondrial biogenesis would differ between the nutritional conditions, without any changes in proteolytic genes. The findings described in chapter 3 demonstrated that muscle mRNA responses related to exercise adaptation were minimally affected by the preexercise meals that differed in macronutrient composition. In chapter 4, derived from the same study, we describe the analysis of a number of plasma cytokine patterns during the day to investigate whether these mediators were affected by carbohydrate availability. We hypothesized that some selected cytokines would differ between nutritional conditions, whereas other circulating cytokines suggested to be involved in skeletal muscle adaptation would not respond differently. Our main finding was that a pre-exercise meal in general did not influence plasma cytokine responses in the post-resistance exercise period. Findings of chapter 3 and 4 contribute to the view that carbohydrate availability during resistance exercise is of minor importance 
when aiming for an acute positive skeletal muscle adaptive response. In addition, our data question the importance of carbohydrates as both substrate for resistance exercise and as modulator of the skeletal muscle response that underlies adaptation. Yet, at present it might be premature to change carbohydrate recommendations for individuals performing resistance exercise. Shifting our focus to proteins, we first reviewed the effects and possible underlying physiological mechanisms of protein supplementation on the adaptive response to endurance training in Chapter 5. To further explore these insights, we performed a double-blind randomised controlled trial with repeated measures to determine whether protein supplementation impacts the adaptive response to endurance training. In chapter 6 we provide proof-ofconcept that protein supplementation elicited greater increases in $\mathrm{VO}_{2 \max }$ and stimulated lean mass gain in response to prolonged endurance training. To our knowledge, this was the first double-blind randomised controlled trial with repeated measures showing that protein supplementation enhances the adaptive response to endurance training. These remarkable effects of protein on $\mathrm{VO}_{2 \max }$ that were observed give rise to questions regarding their underlying mechanisms. To this end, we analysed the muscle transcriptome to gain insight into changes in the steady-state gene expression. In chapter 7 , we demonstrated that prolonged endurance training changed expression of genes involved in extracellular matrix organisation, energy metabolism and oxidative phosphorylation. Changes in extracellular matrix organisation tended to be greater in the protein group than in the control group and these greater transcriptional changes may reflect the enhanced physiological adaptation as a result of protein supplementation. 


\section{Thank you}

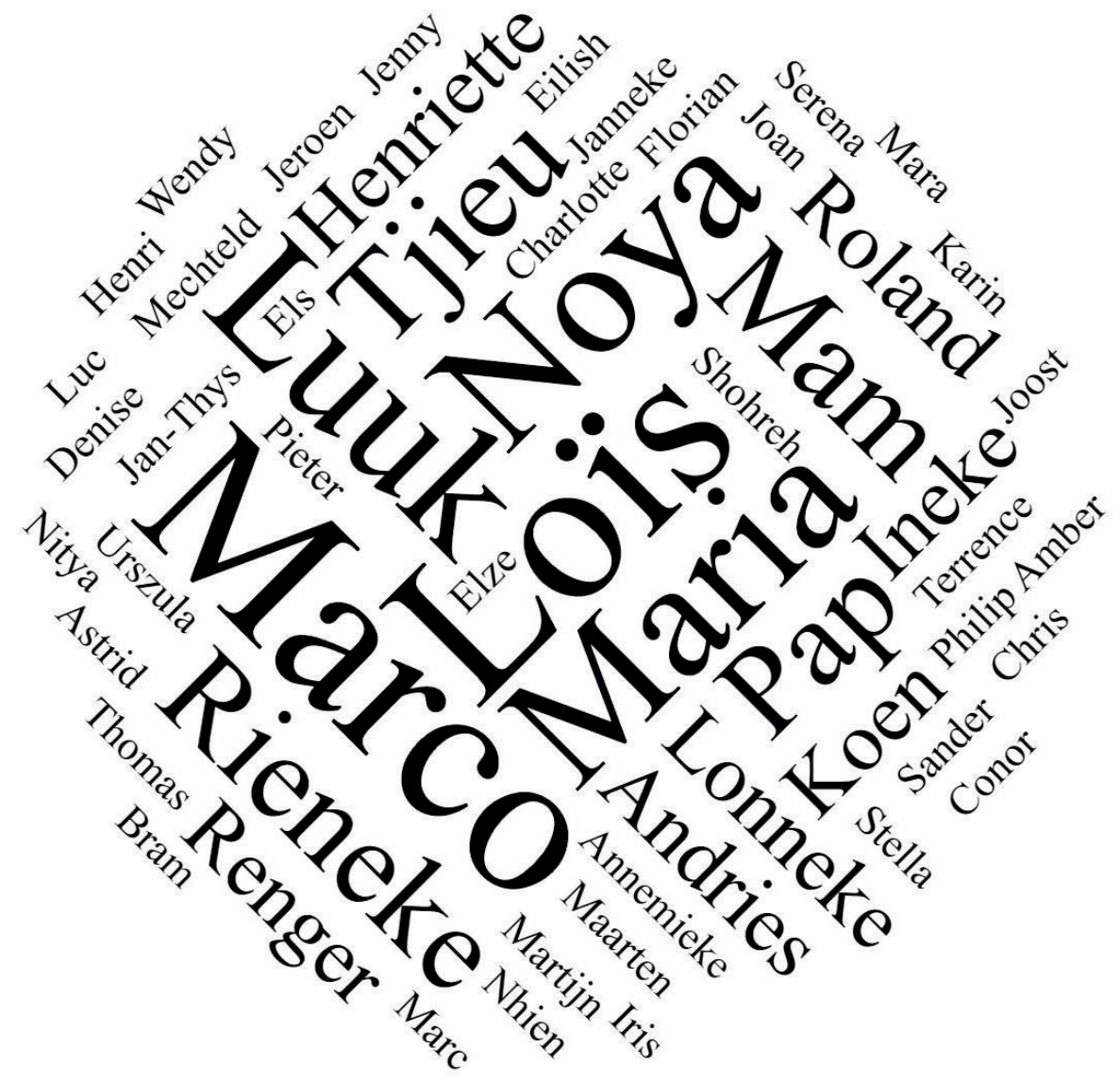




\section{Acknowledgements}

Allereerst bedank ik mijn dagelijkse begeleider dr. Mensink. Marco, bedankt voor het vertrouwen om samen met mij het fysiologisch wetenschappelijk avontuur aan te gaan naar voeding en adaptatie aan training. Als ik nu zo terugkijk op de afgelopen vier jaar ben ik blij dat jij mijn begeleider bent geweest. Je kritische houding, kennis van fysiologie en manier van feedback geven hebben bijgedragen aan mijn ontwikkeling als wetenschapper. Je liet mij over het algemeen aardig mijn gang gaan, maar stelde kritische vragen waar nodig, en hebt mij vaak aan het denken gezet. Op de momenten dat ik je nodig had stond je er altijd, daar ben ik je erg dankbaar voor. Jouw neutrale en nieuwsgierige houding maken je een echte wetenschapper. Enorm bedankt voor al jouw hulp en vertrouwen en ik hoop dat we in de toekomst kunnen blijven samenwerken.

Maria, ook jij hebt een belangrijke rol vervuld binnen mijn promotietraject. De eerste twee jaar hebben wij geregeld overleg gehad. Net als Marco heb je mij veel vrijheid gegeven. Je stelt kritische vragen waar nodig, maar jouw vertrouwen in mijn zelfredzaamheid binnen wetenschappelijk onderzoek was er overduidelijk. Je hebt een brede kennis van fysiologie en bent tevens geïnteresseerd in praktische vraagstukken, wat zo nu en dan voor leuke discussies heeft gezorgd. Je hebt mij geleerd hoe belangrijk het is dat je een verhaal zo opschrijft dat het interessant is voor een editor van een gerenommeerd wetenschappelijk tijdschrift. Je hebt veel charisma, verliest nooit het doel uit het oog en ziet erop toe dat er geleverd wordt. Daarnaast ben je creatief, enthousiast en direct, eigenschappen die ik waardeer aan je. Als ik jouw hulp nodig had, stond je altijd voor mij klaar. Ontzettend bedankt voor alles, Maria.

Luuk, over iconen gesproken......een maat in voor- en tegenspoed. Een PhDtraject is veel meer dan onderzoek alleen. Je kent het wereldje, je prikt er doorheen. Je hoeft bij jou maar een paar woorden te noemen en je begrijpt waar het omgaat. Onze soms filosofische gesprekken, borrels in de stad, uurtjes op de racefiets waren fantastisch. Luuk, ik ga je missen als ik in Leeds woon. Bedankt jongen.

Andries, je begrijpt als geen ander hoe de wetenschappelijke wereld in elkaar steekt. Onze gesprekken waren lachwekkend en relativerend. Als we in de stad zaten te borrelen hadden we altijd de grootste lol, afgewisseld met discussies over de nieuwste wetenschappelijke inzichten op het gebied van voeding, training en gezondheid. Ondanks dat je de laatste jaartjes hebt doorgebracht in Antwerpen heb ik veel aan je gehad tijdens mijn PhD. 
Jan Thys, fantastisch dat je naar Nederland komt voor mijn verdediging. We gaan er een onvergetelijk weekend van maken. Tegen de tijd dat jij weer in Nederland komt wonen, woon ik in Engeland, gelukkig is de afstand dan wat makkelijker te overbruggen.

Chris, altijd goed om met jou te lachen onder het genot van een Indiaas etentje.

Rieneke, iets meer dan 4 jaartjes terug begonnen we beide als PhD-student binnen Eat2Move. We hebben een gedeelte van die tijd samen op kantoor doorgebracht. Het was heerlijk om allerlei werk en niet-werk gerelateerde zaken met je te bespreken. We hebben ook veel gelachen en ergernissen geuit. Je relativeringsvermogen is groot en je was voor mij echt een perfect maatje op het werk. Heel veel succes met de laatste loodjes Rieneke, ik hoop je nog vaak te spreken.

Henriette, bedankt voor alle begeleiding bij de praktische uitvoering paramedische ondersteuning van mijn onderzoek. Wat ben jij een heldin. Je kent alle regeltjes, hebt voor alles een oplossing en bent een heerlijk mens om mee samen te werken. Jouw empathische vermogen is buitengewoon en je bent nauw bij alles betrokken geweest gedurende mijn tijd als PhD student. Ik wens je heel veel succes de laatste jaartjes bij de WUR.

Ineke, we hebben samen heel wat ochtendjes doorgebracht in de bioptruimte. Ondanks jouw oneindige klaagzang heb ik altijd ontzettend met je gelachen. Je sociale betrokkenheid bij proefpersonen is enorm. Je stond altijd voor mij klaar en ik heb ontzettend fijn met je samengewerkt.

Els, heel erg bedankt voor de diëtistische ondersteuning van mijn trials. Jouw creativiteit kwam goed van pas bij het bedenken van de juiste "wetenschappelijke maaltijden". Je hebt jouw zaakjes altijd goed voor elkaar en ik heb goed met je kunnen samenwerken.

Lonneke, wat ben ik jou dankbaar. In eerste instantie kwam je bij mij voor het doen van een afstudeeronderzoek. Onze samenwerking beviel zo goed dat je daarna nog lange tijd als onderzoeksassistent verbonden bleef. Er komt veel kijken bij een humaan interventieonderzoek. Je hebt jouw taken altijd nauwkeurig uitgevoerd, waar ik erg blij mee was. Inmiddels werk je bij de GGD in Haarlem, waar je onlangs een vast contract aangeboden hebt gekregen. Ik wens je heel veel succes met alles en wil je bedanken voor de goede samenwerking.

Koen, ook jou wil ik bedanken voor al je hulp, enthousiasme en gezelligheid. Je denkt altijd mee, voelt je verantwoordelijk en neemt veel initiatief met alles. 
Ook met jou heb ik ontzettend goed kunnen samenwerken. Ik hoop je nog vaak te spreken en wens je alle succes.

Tjieu, jij was mijn begeleider tijdens mijn BSc thesis in Nijmegen. Wat heb ik toen veel van je geleerd. Vooral op het gebied van de fysiologie. Je fysiologische kennis is buitengewoon breed en diepgaand. Tevens heb je oog voor detail. Ik heb veel aan jouw feedback gehad bij mijn eerste PhD review artikel. Ook nam je de tijd om mijn proefschrift volledig te lezen en te voorzien van feedback. Tjieu, ontzettend bedankt.

Roland, mister R. Wat was ik blij met jouw hulp. De analyse van de microarray data had ik nooit zo kunnen uitvoeren zonder jouw input. Heel erg bedankt daarvoor. Ik vond het allemaal best complex in eerste instantie, maar met jouw hulp viel het allemaal best mee en heeft het tevens een interessant artikel opgeleverd. Naast werk kunnen we ook lachen, en ik hoop dan ook dat we elkaar nog regelmatig blijven zien in de toekomst.

Charlotte, bedankt voor de gezellige momenten, een kopje koffie drinken of samen lunchen. Altijd leuk om met jou te kletsen over andere dingen dan wetenschap. Heel veel succes met je PhD.

Bram, speciaalbier met filosofische gesprekken, dat we elkaar nog veel mogen zien. Bedankt jongen.

Janneke, bedankt voor de gezellige lunchwandelingen en interessante gesprekken. Succes met de rest van je $\mathrm{PhD}$ als mamma.

Renger, bedankt voor alle hulp, vooral aan het einde van mijn PhD. Jouw enthousiasme voor en interesse in de wetenschap zijn enorm. Ik heb fijn met je samengewerkt en jouw hulp en input gedurende mijn PhD heb ik altijd zeer gewaardeerd.

Sander, bedankt voor je hulp in sommige fases van mijn $\mathrm{PhD}$. Je was altijd bereid te helpen als ik om hulp vroeg. Je hebt veel kennis van zaken en jouw passie voor wetenschap (en bodybuilding) is enorm, dat siert je.

Jeroen, ook jij stond er altijd als ik je nodig had, bedankt daarvoor. Je hebt een enorm netwerk en dat kwam zo nu en dan goed van pas. Ook je inzet voor het Eat2Move project heb ik altijd zeer gewaardeerd.

Luc, bedankt voor jouw hulp bij de glycogeenmetingen en jouw input bij het bedenken van de eiwit-duurtraining studie. Ik heb veel aan jouw tips gehad en 
het heeft uiteindelijk een mooi artikel opgeleverd. Ik wens je heel veel succes met jouw verdere carrière.

Urszula, het regelen van de drankjes voor de eiwit-duurtraining studies was zo makkelijk nog niet. Bedankt voor alle tijd en moeite die je hierin hebt gestoken.

Astrid, jij nam het stokje van Urszula over. Je hebt dit heel goed gedaan, en ik wil je dan ook bedanken voor het regelen van allerlei zaakjes met betrekking tot de interventiedrankjes.

Mark, bedankt voor je hulp met de analyse van de microarray en de interpretatie van de resultaten. Ook bij jou kon ik altijd terecht met allerlei vragen rondom analyses.

Mara, bedankt voor de gezelligheid die jij bracht op de kamer. Ik heb jouw belangstelling altijd gewaardeerd en vond onze gesprekken altijd leuk. Ik wens je heel veel succes met de uitvoering van jouw studies en de rest van je PhD.

Philip, bedankt voor de gezellige lunchwandelingen en kopjes koffie samen. Onze gesprekken waren altijd interessant en relativerend. Ik wens je heel veel succes met de rest van jouw PhD.

Henri, zonder het universitair sportcentrum had de eiwit-duurtraining studie nooit kunnen plaatsvinden. Fantastisch dat jij volledige medewerking hebt verleend voor de uitvoering van de studie, bedankt.

Shohreh, ook jij bedankt voor de gezelligheid en de lekkernijen op kamer. Daarnaast wil ik je ook bedanken voor al jouw hulp met de analyses in het lab. Nhien, ook jou wil ik bedanken voor de gezelligheid en belangstelling die je altijd had. Daarnaast wil ik je ook bedanken voor al jouw hulp met de analyses in het lab. Jenny, heel erg bedankt voor het uitvoeren van de microarray. Mechteld, hartstikke bedankt voor alle hulp in het lab en ik kon altijd bij je terecht met lab gerelateerde vragen. Karin, bedankt voor jouw hulp met de glycogeenmetingen.

Mam en Pap, ontzettend bedankt voor alle steun tijdens mijn PhD. Koffiedrinken op maandag was altijd gezellig en we hebben veel gesprekken gehad over wetenschap en andere zaken. Mam, je bent altijd een luisterend oor voor mij geweest, als het even tegenzat tijdens mijn $\mathrm{PhD}$ was het na een gesprekje met jou zo weer verholpen. Je hebt me altijd bijgestaan in alles wat ik doe, daar ben ik je ontzettend dankbaar voor. Pap, jou wil ik in het bijzonder bedanken voor jouw kritische blik op mijn wetenschappelijke stukken. Jouw 
kritische vragen zetten mij keer op keer aan het denken en dat heeft de afgelopen jaren bijgedragen aan mijn ontwikkeling als wetenschapper.

Loïs, wat een geweldig avontuur hebben wij samen doorgemaakt met heel wat ups en downs, en dat maakt het juist zo mooi. Ik kies nu eenmaal niet voor de makkelijke weg op mijn werk, en dat ging geregeld samen met de nodige onrust. Maar kletsen en leuke dingen doen met jou hielp altijd ontzettend goed. Een betere afleiding van werk dan jij, bestaat er voor mij niet. Elke seconde ben je er voor mij geweest de afgelopen jaren. Inmiddels hebben we een ontzettend leuk gezinnetje samen met Noya. Ik heb heel veel zin om Leeds en de rest van het Verenigd Koninkrijk en de wereld met jou en Noya te ontdekken. 


\section{List of publications}

Knuiman P, Hangelbroek R, Hopman MTE, Mensink M. Regulation of skeletal muscle transcriptome is increased by protein supplementation and reflects the extent of physiological adaptation to endurance training (under review)

Knuiman P, van Loon L, Wouters JA, Hopman MTE, Mensink M. Protein supplementation elicits greater gains in maximal oxygen uptake capacity and stimulates lean mass accretion during prolonged endurance training in healthy young men. The American Journal of Clinical Nutrition (2019)

Knuiman P, Hopman MTE, Verbruggen C, Mensink M. Protein and the Adaptive Response With Endurance Training: Wishful Thinking or a Competitive Edge? Front Physiol. (2018)

Knuiman P, Hopman MTE, Hangelbroek R, Mensink M. Plasma cytokine responses to resistance exercise with different nutrient availability on a concurrent exercise day in trained healthy males. Physiol Rep. (2018)

Hangelbroek RWJ*, Knuiman P*, Tieland M, de Groot LCPGM. Attenuated strength gains during prolonged resistance exercise training in older adults with high inflammatory status. Exp Gerontol. (2018)

Knuiman P, Hopman MTE, Wouters JA, Mensink M. Select Skeletal Muscle mRNAs Related to Exercise Adaptation Are Minimally Affected by Different Pre-exercise Meals that Differ in Macronutrient Profile. Front Physiol. (2018)

Knuiman P, Hopman MT, Mensink M. Glycogen availability and skeletal muscle adaptations with endurance and resistance exercise. Nutr Metab (Lond). (2015)

Knuiman P, Kramer IF. Contributions to the understanding of the anabolic properties of different dietary proteins. J Physiol. (2012)

*equal contribution 


\section{About the author}

Pim Knuiman was born on March 27, 1984 in Wageningen, the Netherlands. He started his academic career at HAN University of Applied Sciences where he received his bachelor's degree (cum laude) in Exercise and Health in 2010. During his bachelor he performed an internship at the Netherlands Institute for Sports and Physical Activity, where he studied the impact of playgrounds on physical activity behaviour in young children. He then performed his thesis at HAN University lectorate of Sport \& Nutrition where he determined the impact of different exercise modalities on lactate metabolism. His thesis was awarded for best thesis of HAN University of Applied Sciences. He continued with the master program Human Movement Sciences with the specialisation Biology of Human Performance and Health at Maastricht University where he received his master's degree in 2012. During this master he performed an internship at the Muscle Metabolism research group at Maastricht University, assessing the impact of protein intake on immobilization induced skeletal muscle loss. Also, during this internship he contributed two several other human metabolic trials and wrote his first peer-reviewed article. Following completion of his master's degree, he worked three years as a lecturer in exercise physiology and nutrition \& metabolism at two different universities. In March 2015, Pim started his PhD trajectory entitled "Nutritional Impact on Molecular and Physiological Adaptations to Exercise" under the supervision of Dr Marco Mensink and Professor Maria Hopman within the Division of Human Nutrition at Wageningen University \& Research. Pim completed his $\mathrm{PhD}$ in October 2019. From September 2019 Pim is appointed as postdoctoral research fellow at the University of Leeds in England where he will work with Dr. Carrie Ferguson. During this project Pim will focus on the physiological mechanisms of exercise intolerance in patients with chronic heart failure. 


\section{Completed training activities}

\section{Discipline specific activities}

$\begin{array}{lll}\text { Name } & \text { Organiser } & \text { Year } \\ \text { Eat2Move meetings } & \text { Eat2Move } & 2015-2019 \\ \text { Invited presentations } & \text { Universities } & 2015-2019 \\ \text { Nutritional science days } & \text { NWO } & 2015-2019 \\ \text { Live session sport \& nutrition } & \text { Eat2Move } & 2015 \\ \text { Annual ECSS congress } & \text { ECSS } & 2015 \\ \text { NZO symposia } & \text { Dairy association } & 2016 \\ \text { Annual BASES conference } & \text { BASES } & 2016 \\ \text { Annual ECSS congress } & \text { ECSS } & 2018 \\ \text { Annual BASES conference } & \text { BASES } & 2019\end{array}$

\section{General courses}

Name

$\mathrm{PhD}$ week

Nutriscience week

Scientific writing

Essentials of scientific writing

Writing grant proposals
Organiser

VLAG

VLAG

VLAG

VLAG

VLAG
Year

2015

2015

2016

2017

2018

\section{Optional}

Name

Adjusting $\mathrm{PhD}$ proposal

Research group meetings

Muscle meetings
Organiser

Year

WUR

2015

WUR

2015-2019

WUR 
The research described in this thesis was financially supported by a grant from the Province of Gelderland, project EAT2MOVE.

Financial support for printing this thesis from Wageningen University is gratefully acknowledged.

Cover design by: Pim Knuiman \& Dennis Hendriks

Printed by: proefschriftmaken.nl 

